\title{
Winds of change: expanding renewable energies in developing countries
}

Citation for published version (APA):

Edsand, H-E. (2017). Winds of change: expanding renewable energies in developing countries: towards a better understanding of the determinants of technological transitions. [Doctoral Thesis, Maastricht University]. Boekenplan. https://doi.org/10.26481/dis.20171219hee

Document status and date:

Published: 01/01/2017

DOI:

10.26481/dis.20171219hee

Document Version:

Publisher's PDF, also known as Version of record

\section{Please check the document version of this publication:}

- A submitted manuscript is the version of the article upon submission and before peer-review. There can be important differences between the submitted version and the official published version of record.

People interested in the research are advised to contact the author for the final version of the publication, or visit the DOI to the publisher's website.

- The final author version and the galley proof are versions of the publication after peer review.

- The final published version features the final layout of the paper including the volume, issue and page numbers.

Link to publication

\footnotetext{
General rights rights.

- You may freely distribute the URL identifying the publication in the public portal. please follow below link for the End User Agreement:

www.umlib.nl/taverne-license

Take down policy

If you believe that this document breaches copyright please contact us at:

repository@maastrichtuniversity.nl

providing details and we will investigate your claim.
}

Copyright and moral rights for the publications made accessible in the public portal are retained by the authors and/or other copyright owners and it is a condition of accessing publications that users recognise and abide by the legal requirements associated with these

- Users may download and print one copy of any publication from the public portal for the purpose of private study or research.

- You may not further distribute the material or use it for any profit-making activity or commercial gain

If the publication is distributed under the terms of Article $25 \mathrm{fa}$ of the Dutch Copyright Act, indicated by the "Taverne" license above, 


\section{Winds of Change}

Expanding renewable energies in developing countries:

Towards a better understanding of the determinants of technological transitions 
(C) 2017 Hans-Erik Edsand

Front Cover Design: Global Solution: (C) Flynt $\mid$ www.dreamstime.com (Royalty Free License): Preparatory work done by Sandra Valencia and Pia Edsand.

ISBN: 9789086664429

Publisher: Boekenplan, Maastricht

www.boekenplan.nl

All rights reserved. No part of this publication may be reproduced, stored in a retrieval system, or transmitted in any form or by any means, electronic, mechanical, photocopying, recording or otherwise, without the permsission from the author. 


\section{Winds of Change}

\section{Expanding renewable energies in developing countries:}

Towards a better understanding of the determinants of technological transitions

\section{DISSERTATION}

to obtain the degree of Doctor at Maastricht University, on the authority of the Rector Magnificus, Prof. Dr. Rianne M. Letschert in accordance with the decision of the Board of Deans, to be defended in public on Tuesday 19 December 2017, at 13.30 hours by

\section{Hans-Erik Edsand}




\section{Supervisor:}

Prof. Dr. Fred Gault, Tshwane University of Technology

\section{Co-Supervisor:}

Dr. Michiko Iizuka, UNU-MERIT

\section{Assessment Committee:}

Prof. Dr. Luc Soete (chair)

Prof. Dr. René Kemp

Prof. Dr. Rainer Walz, Fraunhofer ISI

Dr. Rasmus Lema, Aalborg University 
Denna bok tillägnas mina underbara föräldrar som genom sitt outtröttliga stöd givit mig tryggheten och självförtroendet att fortsätta anta nya utmaningar. En boll i taget! 


\section{Acknowledgements}

A PhD can be described as a dichotomy. On the one hand, writing a $\mathrm{PhD}$ thesis is a very solitary process, with many long hours alone in front of the computer. No one else is going to write this $200+$ page document but you. On the other hand, you cannot write a thesis and complete a $\mathrm{PhD}$ without the help of a vast number of amazing people that many times go well beyond the job description to give you the support and guidance needed to successfully travel the long $\mathrm{PhD}$ road. These supporting groups of people include technical, administrative and academic staff at UNU-MERIT/MGSoG, supervisors, a great PhD cohort (2012!), friends, and family. I will start from the beginning and try not to forget anyone who made this not only possible but also a fun and enjoyable experience.

There would not be a $\mathrm{PhD}$ program at UNU-MERIT/MGSoG without the incredible set of technical, administrative and academic staff that make the whole machinery run. A big thanks goes out to Eveline in de Braek, Danny Beckers, Susan Roggen, Marc Vleugels, Herman Pijpers, Sueli Brodin, Ingeborg Eijssen-de Beer, Marlies Haak, Howard Hudson, Janneke Knaapen to name a few, for making the institute to what it is! A special thanks and gratitude is expressed to Eveline, the "mother" of the institute. Eveline always goes well beyond her administrative duties, providing an emotional support and warmth to her students that no course could have taught her. Her emotional commitment to all of her PhD studies (and there are many) is truly commendable and the experience at UNUMERIT/MGSoG would not have been the same without her! Beyond the administrative and technical staff, I would like to extend a thank you to Mindel van de Laar, Robin Cowan, Tatiana Skripka, Luc Soete and Bart Verspagen for their management and leadership of the $\mathrm{PhD}$ program.

The first year in Maastricht is very different than the rest of the $\mathrm{PhD}$; fully packed with coursework completed together with your cohort. This is combined with a continuous pressure to produce a research proposal that must pass the scrutiny of a number of experienced academic staff. Despite the hectic coursework and the "what if I don't pass to the second year" question hanging in the air, I am certain that when I look back at the $\mathrm{PhD}$ experience many years from now, the fondest memories will come back from this first year. The reason for this is of course the amazing groups of 17 other people from 15 different countries that make up the 2012 cohort. A big thanks to Ayokuno (Ayo) Adedokun, Saba Afeworki, Eva Bartekova, Tobias Broich, Carla Buil, Juan Carlos Castillo, Stefania Innocenti, Eriko Katashiro, Martin Kügemann, Gintare Mazekaite, Biljana Meshkovska, Tigist Mekonnen Melesse, Thuy Nguyen, Raquel Tsukada, Ralf-Martin Soe, Caroline Wehner, and Sheng Zhong for making the first year of the $\mathrm{PhD}$ a special and fun experience! A special thanks to the governance group for creating a relaxed and supportive environment with a good balance between fun and work! Of course, the experience with the 2012 cohort in Maastricht is not limited to the 
office or classroom but some great friendships have been formed during the many b-day celebrations in Edd's, football road trips and "last-ones" in the Cologne, Nigerian culinary experiences and pre-Mulu pool-games! Thanks for these great memories! I wish you all good health and success in future endeavors and I hope we keep in touch even if geography says otherwise!

Many other great people deserve gratitude for making the Maastricht experience for what it has been, and I apologies in advance for surely forgetting someone. I want to give a special thanks to Carlos Cadena, Sachin Badkas, Paula Nagler, Ibrahima Kaba, Iman Rajabzadeh, and Omar Rodriguez. Thanks Carlos for making the move to Maastricht so much easier through your Brusselsestraat flat and initial info about the lay of the land! Many thanks to Sachin, Ibrahima and Paula for their generosity and kindness of providing a place to crash during my short-term postfirst year visits to Maastricht! Thanks also to Paula for managing her mentoring role in a splendid fashion! To Iman and Omar, I much enjoyed the well-needed badminton, squash and Ping-Pong sessions, after way too much time in front of the computer screen! A special thanks to Omar for providing me with key contacts in Colombia, facilitating a successful fieldwork for my thesis!

Of course a huge thanks and gratitude is extended to my supervisory team, made up by Michiko Iizuka and Fred Gault for their time and dedication! Their great advice, comments and encouragement during this journey have been the key determinants for making this thesis possible. Their different background and experience on working with innovation and system's approaches provided an ideal supervisory team for the topic and direction taken for this thesis. It has been a true pleasure to work with you both throughout this process and I am forever grateful! Thank you also Michiko for bringing me along on the interesting project on India, allowing me to see the fruits of the last years work on TIS, even before the PhD had been concluded. Beyond my supervisory team, I would like to give a big thanks to Adam Eddy Shirmai and René Kemp for taking their time to discuss research ideas and sharing their valuable views from early on in the PhD and through subsequent years.

When I was not busy with writing the thesis, I had the opportunity to work with Mindel van de Laar on initiating a "new" short-course, namely the EPRM program. I really want to express a big thanks to Mindel for the time we worked on this program together. I very much enjoyed the experience and opportunity to meet many new ambitious professionals from all around the World, two of them (Atsuko Okuda and Fatai Adegboye) ending up joining the UNU-MERIT/MGSoG family. From the planning of the program, to lecturing and Walkshops to Sint Pieter, the time working on EPRM (which also financed my scholarship during the $\mathrm{PhD}$ ) will be a fond memory from the $\mathrm{PhD}$ experience. 
Last but not least, I would like to thank my family for their support during my time as a PhD student. To my parents, who no doubt wonder when their son is going to get a real job ; ), have still always given their full support to every new challenge I take on. They have worked hard all their lives to give my sister and I all of the freedom of choice that we could have asked for, and they will always be an inspiration and source of strength for me. To my aunt Gittan (Gotten) and her husband (Anders), for always showing interest in my $\mathrm{PhD}$ and being a constant source of support. And finally, to Sandy: my constant in a World of unknowns. Your own ambition and success have always been a great source of inspiration and it has taught me that no task is too great! It goes without saying, so I will write it instead....Mil gracias for all your support during, before and after this PhD journey! As this book closes, I can't wait to begin a new Chapter in a brand new book with you in our new Casita! 


\section{Abstract}

A fossil fuel dominated consumption of energy has contributed to a $35 \%$ increase of global net greenhouse gas emissions in just two decades (1990-2010) (46 billion metric tons of $\mathrm{CO} 2 \mathrm{e}$ ). The increasing concentration of greenhouse gases has led to warming between $0.5{ }^{\circ} \mathrm{C}$ and $1.3{ }^{\circ} \mathrm{C}$ of the global mean surface temperature over the period 1951 and 2010.

This thesis addresses one of the major challenges to combat climate change, namely that of reducing greenhouse gases in the energy sector. It does so through an analysis of the blocking and driving mechanisms of technological transitions towards renewable sources of energy. The thesis places a specific focus on the adoption of renewable energy technologies in developing countries, using Colombia as an example. In order to analyze the barriers and drivers of technological change, the thesis uses the Technological Innovation System (TIS) approach, and complements it by explicitly assessing the influence of socioeconomic and political factors in technological transitions.

The empirical analysis of barriers and drivers for wind energy in Colombia shows that the country has a high potential for wind energy development, but the reliance on hydropower, backed-up by thermoelectric power has created a sense of a stable and clean energy mix, which is becoming a barrier to transitioning towards other alternative sources of energy. Additional factors obstructing the transition include corruption, unequal access to education and the armed conflict. On the other hand, increasing climate variability is putting pressure on actors within the incumbent energy system to break out of the current hydro-thermoelectric lock-in and to diversify to other RETs.

The thesis shows that by explicitly and systematically including additional socioeconomic and political factors to complement the TIS analysis, comprehensiveness improves, while revealing additional avenues for medium and long-term polices to expand RETs adoption in developing countries. In addition, the evidence suggests that a reconsideration of the boundary of the technological innovation system approach is necessary in developing countries, as an additional set of socioeconomic and political factor appear to influence technological transitions more than in high-income countries.

In addition, the research examined in more detail if one of the factors with potential to facilitate RETs transitions, namely environmental and RETs awareness, can be strengthened through environmental education. The results demonstrated that environmental education is a necessary but not sufficient condition to raise awareness in the case of Colombia. 


\section{Contents}

List of Figures and Tables..................................................................................... 13

List of Acronyms ............................................................................................................. 15

Glossary of Key Terms..................................................................................... 17

Chapter 1. Introducing the Rationale and the Focus of the Research............. 19

1.1 Recognizing the wider Sustainability Challenge .................................... 19

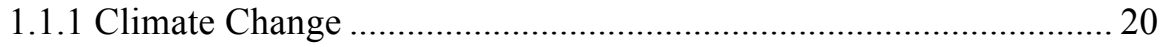

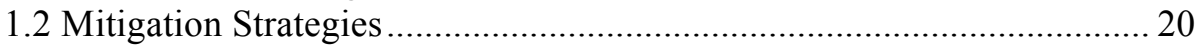

1.2.1 The Role and State of Renewable Energy Technologies ................. 21

1.3 Identifying Blocking Mechanisms to Energy Transition..........................22

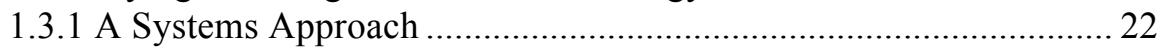

1.3.2 Delimiting a Complex System......................................................... 23

1.3.3 Social and Political Factors - Endogenous or Exogenous to the

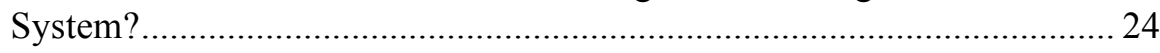

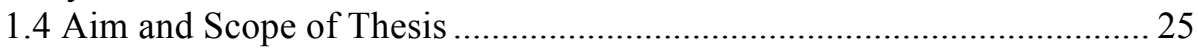

1.4.1 TIS and the Wider Context: A framework for developing countries 26

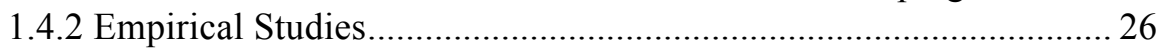

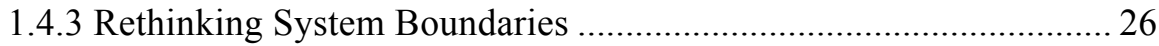

1.4.4 Lessons Learned and Next Steps .................................................. 27

Chapter 2. Background Literature \& Research Gaps ............................................. 29

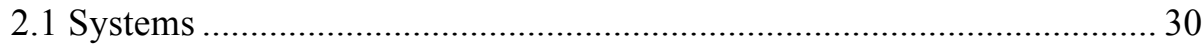

2.1.1 Early Developments and Use of Systems....................................... 30

2.1.2 Key Components of Systems............................................................ 31

2.2 Using Systems Thinking for Studying Innovation................................... 31

2.2.1 Systems of Innovation (SI) Approaches ............................................ 34

2.2.2 Technological Innovation System (TIS) ……………...................... 35

2.3 System Boundaries............................................................................ 37

2.3.1 Categories of Determinants for a Systems of Innovation.................. 38

2.4 Strengthening Positive Framework Conditions ...................................... 40

\section{Chapter 3. Technological Innovation System and the Wider Context: $A$} framework for developing countries ................................................................................43

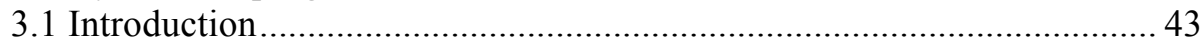

3.2 Technological Innovation System (TIS) ................................................ 44

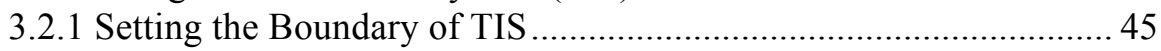

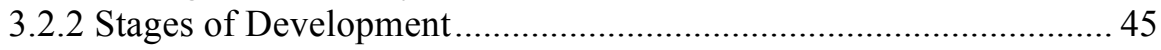

3.2.3 TIS Function Approach .................................................................. 46

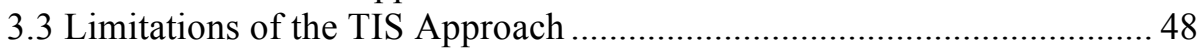

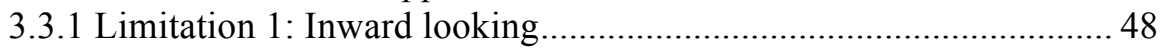

3.3.2 Limitation 2: TIS Function Approach is Based Primarily on

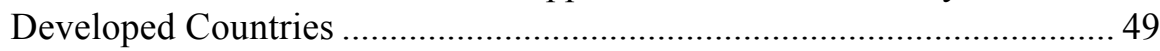

3.4 Energy Transitions in Developing Countries .......................................... 50 
3.5 Suggestions for the Function Framework

3.5.1 Suggestion 1: Function 2 - Knowledge Development and Creating

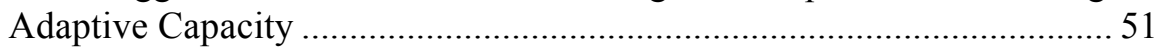

3.5.2 Suggestion 2: Function 6 - Resource Mobilization ......................... 53

3.5.3 Suggestion 3: Function 7 - Creation of Legitimacy/Advocacy

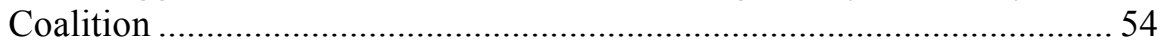

3.5.4 Suggestion 4: Incorporating the External Landscape ........................ 56

3.6 Interactions between Landscape Factors and Functions ............................ 70

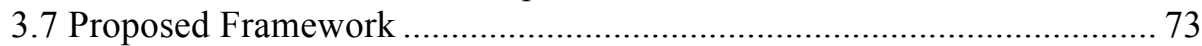

3.8 Conclusions and Suggestions for Future Research............................... 75

Chapter 4. Identifying Barriers to Wind Energy Diffusion in Colombia: A

Function Analysis of the Technological Innovation System and the Wider

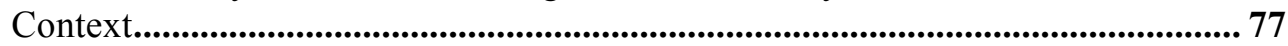

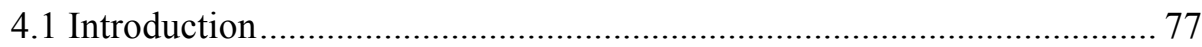

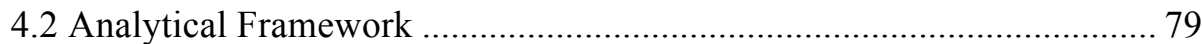

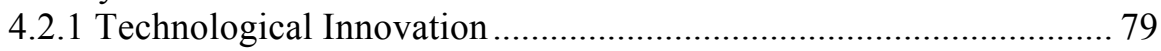

4.2.2 Functions of a Technological Innovation System ............................. 79

4.2.3 Extended TIS function Approach and the Wider Context................. 80

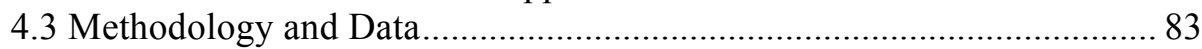

4.3.1 Expert Evaluations: Sampling and Analysis ................................... 83

4.3.2 History Event Analysis .................................................................. 83

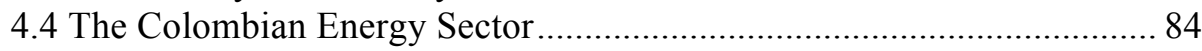

4.4.1 Structure and Actors in the Energy Sector ....................................... 84

4.4.2 Energy Demand and Supply in Colombia ........................................ 85

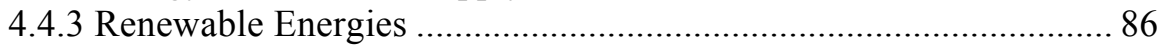

4.4.4 High Technical Potential for Wind Energy ...................................... 86

4.5 Analysis of the Technical Innovation System and Landscape Factors in

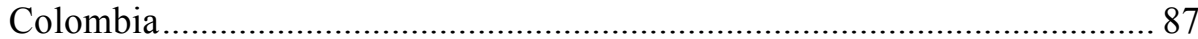

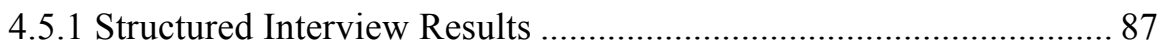

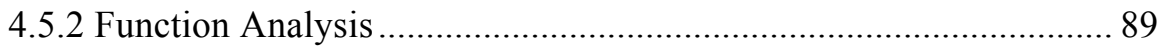

4.5.3 Landscape Factor Analysis .............................................................. 99

4.6 Summary of Findings and Policy Recommendations........................... 104

4.6.1 Landscape Factor Influence on Functions of the Wind Energy

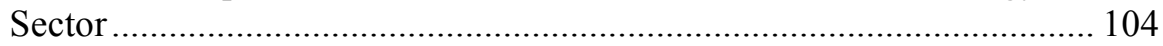

4.6.2 Barriers to wind energy adoption - Functions weaknesses and policy

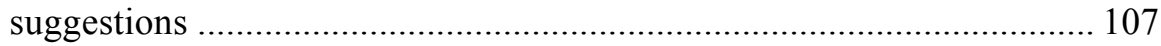

4.7 Concluding Remarks.................................................................. 110

Chapter 5. The Impact of Environmental Education on Environmental and Renewable Energy Technology Awareness: Empirical Evidence from

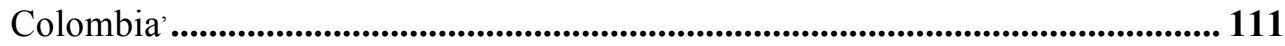

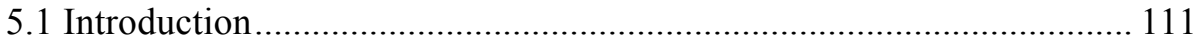

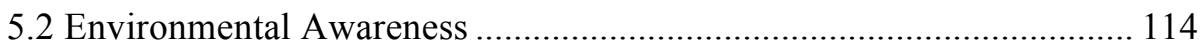

5.2.1 Environmental Awareness and Renewable Energy Technologies . 114

5.2.2 Explaining Different Levels of Environmental Awareness............ 115 
5.2.3 The Concept of Environmental Education .................................... 117

5.3 Country Background - Colombia ....................................................... 120

5.3.1 Economy of Colombia............................................................ 120

5.3.2 Education System in Colombia ………….................................... 120

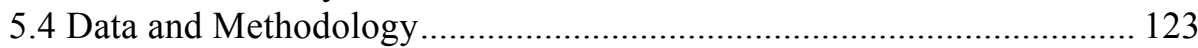

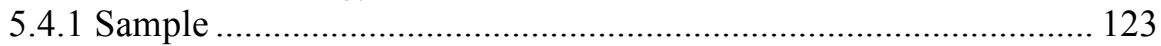

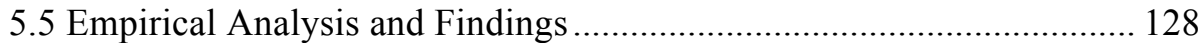

5.6 Discussion and Concluding Remarks ................................................... 139

Chapter 6. Framework Conditions of Technological Transition: Re-thinking the Boundary for a Technological Innovation System ........................................... 143

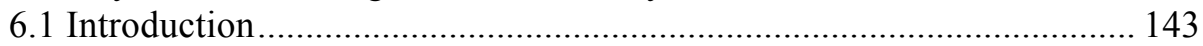

6.2 Using Systems Thinking for Studying Innovation................................ 144

6.3 Where to Draw the Line? ..................................................................... 145

6.3.1 Categories of Determinants for a Systems of Innovation

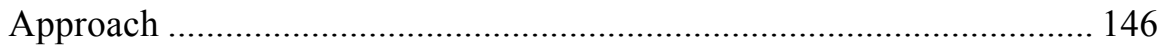

6.4 Reviewing the Evidence - A Comparative View of Framework

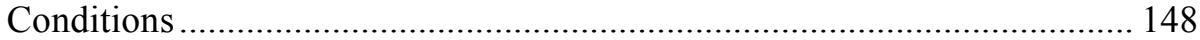

6.4.1 Overview of Framework Conditions ............................................. 148

6.4.2 Framework Condition Influence on RETs Adoption ..................... 150

6.5 Implications for the Boundary of the SI Approach................................. 156

6.5.1 Framework Conditions and Policy ................................................ 157

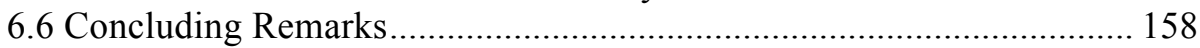

Chapter 7: Conclusions ................................................................................................. 159

7.1 Integral Activities and Processes in Developing Countries .................... 159

7.2 A Closer Look at 'Exogenous' Factors................................................... 161

7.2.1 Systematic Inclusion of Framework Conditions ............................ 161

7.2.2 Strengthening 'Positive' Framework Conditions ............................. 163

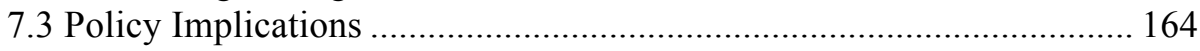

7.3.1 Long, Medium and Short-Term Policies for Innovation Systems.. 165

7.3.2 Remaining Challenges and Suggestions for Future Research ........ 166

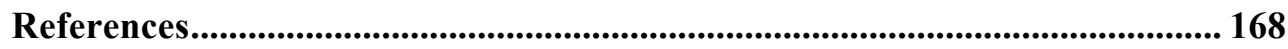

Appendix I: Interview Guide, Forms and List of Key Actors .......................... 192

Appendix II: Scales Constructed by PISA (OECD 2009) ................................ 201

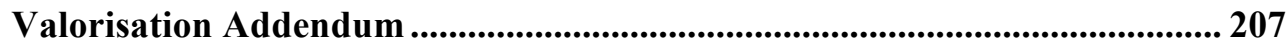

About the Author .............................................................................................................. 212 


\section{List of Figures and Tables}

\section{Figures}

Figure 3.1 Internet Users in Developing and High Income Countries (per 100

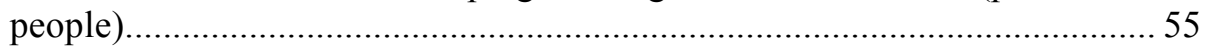

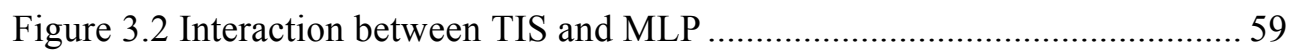

Figure 3.3 Change in GDP per capita (PPP) in developing countries (1990-2014)64

Figure 3.4 Change in Primary and Secondary Enrollment Rates in Developing

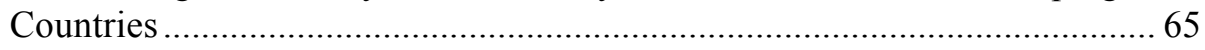

Figure 3.5 Examples of Influence from the Landscape Level.............................. 71

Figure 3.6 Reinforcing or Weakening Influence between Landscape Factors....... 73

Figure 4.1 Planning of the Energy Sector - Responsible Organizations................ 85

Figure 4.2 Differences between Actors' Responses Regarding Landscape Factors Influence on Adoption and Diffusion of Wind Power in Colombia.............. 89

Figure 4.3 Planned Entrepreneurial Activities by Energy Companies to Invest in

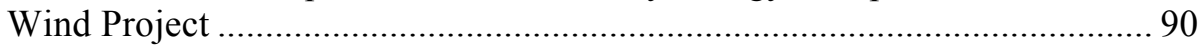

Figure 4.4 Landscape Factor Influence on TIS Functions.................................. 105

Figure 4.5 Landscape - Landscape Factor Influence .......................................... 107

Figure 5.1 Public and Private School Enrollment in Colombia, 1994-2004 ........ 122

Figure 5.2 Relationship between Environmental Education and Environmental

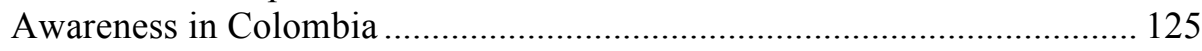

Figure 6.1 Framework Condition (FC) Interaction with Institutions ................... 155

Figure 6.2 System Boundaries for Developing and Developed Countries........... 156

\section{Tables}

Table 3.1 Innovation System Functions ............................................................ 47

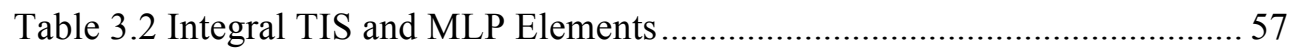

Table 3.3 Possible Landscape Factor Influence on Specific System Functions..... 72 
Table 3.4 Suggested Framework and Possible Indicators

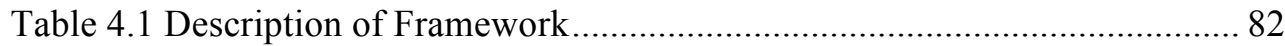

Table 4.2 Structured Interview Outcome - Functions and Landscape Factors....... 88

Table 4.3 Summary of Findings and Policy Suggestions ..................................... 108

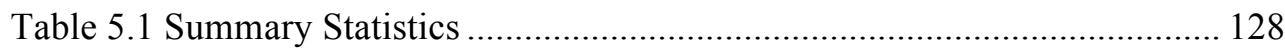

Table 5.2 Environmental Education and Environmental Output Measures, Base

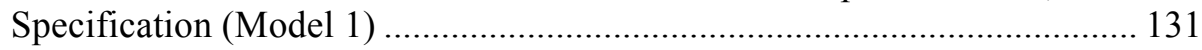

Table 5.3 Environmental Education and Environmental Output Measures,

Controlling for Personal Characteristics at Individual Level (Model 2) ..... 132

Table 5.4 Environmental Education and Environmental Output Measures, Controlling for Science Characteristics at Individual Level (Model 3)....... 134

Table 5.5 Environmental Education and Environmental Output Measures, Controlling for Parents Characteristics at Individual Level (Model 4) ....... 136

Table 5.6 Environmental Education and Environmental Output Measures, Controlling for School Characteristics at School Level (Model 5) ............. 138

Table 6.1 Definitions of Systems of Innovation................................................. 145

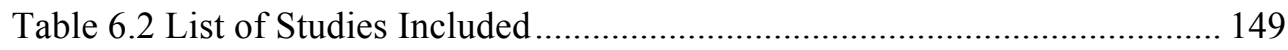

Table 6.3 Authors and List of Framework Conditions ...................................... 149

Table 6.4 Framework Conditions Influence on Adoption of RETs ..................... 151 


\section{List of Acronyms}

\begin{tabular}{|c|c|}
\hline ACOLGEN & 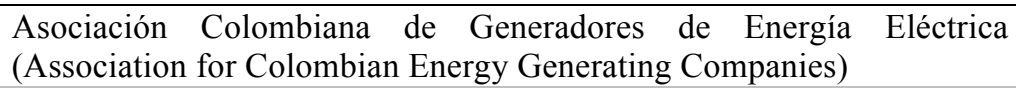 \\
\hline AIC & Akaike Information Criteria \\
\hline ANDEG & $\begin{array}{l}\text { Asociación Nacional de Empresas Generadoras (National Association } \\
\text { for Generating Companies) }\end{array}$ \\
\hline $\mathrm{BIC}$ & Bayesian Information Criteria \\
\hline CCS & Carbon Capture and Storage \\
\hline CDM & Clean Development Mechanism \\
\hline CND & Consejo Nacional de Discapacidad (National Dispatch Center) \\
\hline $\mathrm{CNO}$ & Consejo Nacional de Operación (National Council of Operation) \\
\hline $\mathrm{CO} 2 \mathrm{e}$ & Carbon Dioxide Equivalent \\
\hline $\begin{array}{l}\text { COLCIENCI } \\
\text { AS }\end{array}$ & $\begin{array}{l}\text { Departamento Administrativo en Colombia de Ciencia, Tecnología e } \\
\text { Innovación (Colombian Association for Science, Technology and } \\
\text { Innovation) }\end{array}$ \\
\hline CREG & $\begin{array}{l}\text { Comisión de Regulación de Energía y Gas (Regulatory Commission } \\
\text { for Energy and Gas) }\end{array}$ \\
\hline DNP & $\begin{array}{l}\text { Departamento Nacional de Planeación (Department for National } \\
\text { Planning) }\end{array}$ \\
\hline EA & Environmental Awareness \\
\hline EE & Environmental Education \\
\hline EGC & Energy Generating Companies \\
\hline EIA & U.S. Energy Information Administration \\
\hline ENSO & El Niño Southern Oscillation \\
\hline EPA & Economic Partnership Agreement \\
\hline ESCS & Economic, Social and Cultural Status \\
\hline FDI & Foreign Direct Investment \\
\hline GDP & Gross Domestic Product \\
\hline GEF & Global Environment Facility \\
\hline GEM & Global Entrepreneurship Monitor \\
\hline GHG & Greenhouse gases \\
\hline GMO & Genetically Modified Organisms \\
\hline GNI & Gross National Income \\
\hline GWEC & Global Wind Energy Council \\
\hline IDB & Inter-American Development Bank \\
\hline IEA & International Energy Agency \\
\hline ILO & International Labour Organization \\
\hline IPCC & Intergovernmental Panel on Climate Change \\
\hline IRENA & International Renewable Energy Agency \\
\hline ISCED & International Standard Classification of Education \\
\hline MLP & Multiple-Level Perspective \\
\hline MME & Ministerio de Minas y Energía (Ministry of Mines and Energy) \\
\hline
\end{tabular}




\begin{tabular}{|c|c|}
\hline NAMA & Nationally Appropriate Mitigation Actions \\
\hline NGO & Non-Governmental Organization \\
\hline NIS & National Innovation System \\
\hline OECD & Organisation for Economic Co-operation and Development \\
\hline Oxfam & Oxford Committee for Famine Relief \\
\hline PACES & Programa de Ampliacion de Cobertura de la Educacion Secundaria \\
\hline PISA & Programme for International Student Assessment \\
\hline PPP & Purchasing Power Parity \\
\hline $\mathrm{R} \& \mathrm{D}$ & Research \& Development \\
\hline REN21 & Renewable Energy Policy Network for the 21st Century \\
\hline RET & Renewable Energy Technology \\
\hline RIS & Regional Innovation System \\
\hline SES & Socio-Ecological System \\
\hline SI & Systems of Innovation \\
\hline SIN & Sistema Interconectado Nacional (National Interconnected System) \\
\hline SIPRI & Stockholm International Peace Research Institute \\
\hline SIS & Sectoral Innovation System \\
\hline SSPD & $\begin{array}{l}\text { Superintendencia de Servicios Públicos (Superintendent of Public } \\
\text { Services) }\end{array}$ \\
\hline TIS & Technological Innovation System \\
\hline UNDP & United Nations Development Programme \\
\hline UNEP & United Nations Environment Programme \\
\hline UNESCO & United Nations Educational, Scientific and Cultural Organization \\
\hline UNFCCC & United Nations Framework Convention on Climate Change \\
\hline UPME & $\begin{array}{l}\text { Unidad de Planeación Minero Energética (Planning Office for Mining } \\
\text { and Energy) }\end{array}$ \\
\hline VAT & Value Added Tax \\
\hline WLE & Weighted Likelihood Estimation \\
\hline $\mathrm{XM}$ & Compañía de Expertos en Mercados (Public Service Company) \\
\hline ZNI & Zonas No Interconectadas (Non-Interconnected Zones) \\
\hline
\end{tabular}




\section{Glossary of Key Terms}

\begin{tabular}{ll}
\hline $\begin{array}{l}\text { Activities (of the } \\
\text { innovation system) }\end{array}$ & $\begin{array}{l}\text { Activities refers to the same aspects as functions, namely the } \\
\text { integral processes an innovation system. }\end{array}$ \\
$\begin{array}{l}\text { Carbon Dioxide } \\
\text { Equivalent }\end{array}$ & $\begin{array}{l}\text { Term used to describe different greenhouse gases with a } \\
\text { common unit. Any quantity of a greenhouse gas is calculated } \\
\text { using its individual Global Warming Potential (GWP) and } \\
\text { expressed in CO2 (e.g., since methane has a 25 times higher } \\
\text { GWP than CO2, } 1 \text { kg of methane would be equal 25 kg CO2e). }\end{array}$ \\
& $\begin{array}{l}\text { The warm phase of El Niño Southern Oscillation (ENSO) } \\
\text { phenomenon produces less than average precipitation and }\end{array}$ \\
prolonged dry seasons, leading to droughts. \\
\hline Endogenous & $\begin{array}{l}\text { Factors referred to as being 'inside' or part of the system. } \\
\text { Exogenous }\end{array}$ \\
\hline Fxternal Factors & $\begin{array}{l}\text { Refer to aspects that are not considered to be integral internal } \\
\text { factors to the formation of a specific technical innovation } \\
\text { process (e.g. organizations and individuals directly } \\
\text { contributing with specific knowledge, technical skills and } \\
\text { resources), but that may assert influence on the TIS. }\end{array}$
\end{tabular}

Feedback Loops $\quad$ Feedback loops result from linkages between the actors. They (Positive or Negative) may have positive or negative effects in response to interventions, such as change of policy, and they are the reason the response to an intervention is non-linear.

Focal System/Focal Refers to the collection of the most central elements, activities TIS system and linkages (systematic interdependencies) necessary for the system to achieve its purpose.

Framework Refers to factors that make up the wider context in which firms Conditions innovate.

Functions $\quad$ Refers to processes integral to the creation and development of a technical innovation system and supports a systemic analysis that can help to identify characteristics of the system, such as weaknesses and strengths.

Jepírachi Name of the first Colombian Wind Energy Park.

La Niña The cold phase of ENSO in turn is manifested through higher than average precipitation and prolonged wet seasons, often leading to floods.

Landscape Factors Landscape factors or Socio-Technical Landscape Factors originates from the Multiple-Level Perspective framework and refers to macro-level factors with the potential of influencing existing actors involved in the technology in questions and provide opportunities for new technologies to emerge.

Multiple-Level The MLP framework includes three levels, where the socio- 

other levels are the niche (micro - protected spaces for emerging innovations) and socio-technical regime (meso incumbent technical systems).

Non-linear This refers to the response of a system to an intervention. A linear intervention may not result in a linear outcome.

System Boundary Where the system ends and the remaining world continues.

Technological These terms refer to how technological innovations develop Transition/Socioand become part of the society, i.e., not restricted to

Technical Transition technological aspects of transition. In this thesis the two terms are used interchangeably.

Wider Context Refers to a collection of factors considered to be outside of the focal system (see focal system). 


\section{Chapter 1. Introducing the Rationale and the Focus of the Research}

Sustainable development is development that meets the needs of the present without compromising the ability of future generations to meet their own needs (World Commission on Environment and Development 1987).

\subsection{Recognizing the wider Sustainability Challenge}

There is scientific evidence that human influence on the resources necessary to support life on Earth has reached unparalleled levels (IPCC 2014; Jerneck et al. 2011; Millennium Ecosystem Assessment 2005; Steffen et al. 2015). Since the mid-1980s, human consumption of natural resources has resulted in an 'ecological debt' of borrowing from Earth's biological capacity from future generations. Roughly 1.5 planets are required to provide the resources for the current human consumption (Global Footprint Network 2015). An increasing world population combined with a rapidly rising material and per capita energy consumption is exacerbating the ecological deficit.

Human influence on the planet includes pollution of oceans, reduced freshwater availability, and loss of biological diversity. In a 2009 study by Rockström et al., a framework was introduced that identified nine 'Earth System processes' (or planetary boundaries) argued to be essential for sustained human development on the planet. The planetary boundary processes include climate change, depletion of stratospheric ozone, land use change, freshwater use, rate of loss of biological diversity, ocean acidification, nitrogen and phosphorus inputs to the biosphere and oceans, air pollution from aerosol loading and chemical pollution. In the most recent update of the framework by Steffen et al. (2015), four out of nine of the Earth processes have surpassed their sustainable boundaries. The four processes are loss of biosphere integrity, land-system change, altered biogeochemical cycles (phosphorus and nitrogen) and climate change (Steffen et al. 2015). Oxfam extended the planetary boundary idea by incorporating social aspects, emphasizing the interdependence between environmental sustainability and social and economic development (Raworth 2012).

This thesis addresses one of the major sustainability challenges; that of climate change, through an analysis of blocking and driving determinants of technological transition, including the influence of socio-economic and political factors. The thesis places a specific focus on the adoption of renewable energy technologies in developing countries, using Colombia as an example. 


\subsubsection{Climate Change}

Emissions of anthropogenic greenhouse gases (GHG) have increased significantly since the industrial revolution. About $40 \%$ of the emissions between 1750 and 2011 have remained in the atmosphere, increasing the concentrations of carbon dioxide, methane and nitrous oxide. Land and oceans have absorbed the rest of the emissions (IPCC 2013). It has been estimated that global net greenhouse gas emissions ${ }^{1}$ in 2010 amounted to almost 46 billion metric tons of $\mathrm{CO} 2$ equivalent (CO2e), a 35\% increase from 1990. Energy production and use (including emissions from fuels from vehicles) represented about $71 \%$ of the global greenhouse gas emissions for that year (EPA 2016). The increasing concentrations of greenhouse gases have led to warming between $0.5^{\circ} \mathrm{C}$ and $1.3{ }^{\circ} \mathrm{C}$ of the global mean surface temperature over the period between 1951 and 2010 (IPCC 2013).

These changes to the Earth's energy balance and the resulting change in climate have led to an intensification of flooding in some parts of the worlds and extreme heat waves and drought in other parts, all of which have a significant impact on human development (IPCC 2012). Moreover, according to leading scientists, with the current commitments as outlined in the United Nations Framework Convention on Climate Change (UNFCCC), global temperature is still expected to increase between 3.5-4.0 degree Celsius during the $21^{\text {st }}$ century, with detrimental human and planetary effects (The World Bank 2012a). In an effort to avoid this, in December of 2015, 195 countries agreed to a global action plan with the objective to keep the global warming below 2.0 degrees Celsius (European Commission 2016).

The Paris agreement (United Nations 2015) represents an equally positive and pressing ambition for tackling climate change. Projections made up to 2040 show that energy use is expected to grow substantially, however predominately in nonOECD countries ( $>85 \%$ of the increase), as a result of population increase, economic growth and, higher standard of living (EIA 2013). Meeting the goals of reduced emissions will require a rapid and successful expansion of a wide range of mitigation alternatives.

\subsection{Mitigation Strategies}

The reduction of green house gas emission would require a multifaceted approach involving a wide spectrum of strategies, such as alternative energies, negative emissions (e.g., carbon capture), or demand side management (e.g., energy efficiency and behavioral change). From the demand side management, addressing

\footnotetext{
${ }^{1}$ Net emissions include the effects of land use and forestry.
} 
human consumption and behavior, alongside the transitions towards alternative energy sources has been emphasized as an essential aspect of mitigation strategies (Victor et al. 2014). In fact, the risk of loosing important energy efficiency gains to increased human consumption has long been emphasized by the work on the rebound effect (Binswanger 2001; Greening and Greene 1998). ${ }^{2}$

\subsubsection{The Role and State of Renewable Energy Technologies}

Renewable energies technologies (RETs) are widely acknowledged as one of the most important aspects of climate change mitigation (IPCC 2012). ${ }^{3}$ Beyond the positive environmental implications, given the low operation and maintenance costs, RETs could also be considered a principal instrument in alleviating energy poverty in developing countries (Bhide and Monroy 2011). ${ }^{4}$ RETs have also been attributed with the potential to improve energy security for the future (ADB 2009). Moreover, by diversifying its energy mix, countries can avoid increasing costs and price volatility of fossil fuels, which can hamper economic growth and result in exacerbating effects on poverty alleviation in many regions (IEA 2011; Victor et al. 2014). ${ }^{5}$

Despite the apparent recognition for the importance of transitioning to renewable energy sources, the total share of global electricity generated from renewable sources has decreased. In fact, in 1990, renewable sources represented $19.5 \%$ of the global electricity generation, and in 2009 , this share fell to $19.3 \%$, largely due to that growth in demand has been predominately supplied by conventional technologies (EIA 2013). ${ }^{6}$ Moreover, after three decades of encouraging the transition to RETs, it is estimated that only $20-25 \%$ of their full potential has been

\footnotetext{
${ }^{2}$ A broad definition of the rebound effect can be described as when the growth of an economy overcompensates the increases in efficiency gained by technological innovation (Radermacher 1997).

${ }^{3}$ It should be noted that RETs are not problem free, e.g., food security and high GHG emission during the lifecycle of certain biofuels (Delucchi 2010).

${ }^{4}$ Approximately 1.2 billion people are without access to any form of electricity and without successful policy interventions, 1 billion people are still expected to be without electricity in 2030 (IEA 2015). Worst off is Sub-Saharan Africa, with data from 2014 demonstrating that only $35 \%$ of the population has access to electricity, with as little as $19 \%$ in rural areas (IEA 2016b).

${ }^{5}$ See also e.g., The Economics of Climate Change: The Stern Review, written by Nicholas Stern (2007).

${ }^{6}$ It should be noted that from the sustainability perspective renewable sources vary significantly in terms of impact on the environment. An example of this is the Niagara Falls (US) vs. the Three Gorges project (China), both being examples of hydropower, but the latter having a considerable negative human and ecological impact.
} 
achieved (Rao and Kishore 2010). According to the International Energy Agency, by 2020 a doubling of today's level of energy generated by renewable sources is necessary, in order to achieve the objective to cut global GHG emissions by half by 2050 (IEA 2011). Motivated by the pertinence of increasing the share of RETs in the energy supply of countries, understanding the mechanisms that hinder a more rapid transition towards RETs represent a key aspect of sustainability research.

\subsection{Identifying Blocking Mechanisms to Energy Transition}

To enable policy makers to take the appropriate actions that facilitate the transition towards new technologies, such as renewable energies, an improved understanding of the mechanisms that hinder or drive a rapid diffusion is needed. Such research includes identifying determinants that may exist in a number of actors such as firms, government organizations, knowledge generating organizations such as universities, the general public through norms and attitudes, or in the quality of institutions. Moreover, the barriers to transition towards RETs may exist between rather then simply within, in the form of insufficient links or communication between the various actor groups (Edquist 2001). This complexity is further exacerbated when considering that the 'right' or adequate set-up for technical transitions differs between nation states.

Identifying determinants of technological transitions should be based on two fundamental principles. The first is an interdisciplinary approach that encompasses the potential determinants across different actors groups, and considers social, economic, political and environmental factors, and thus transcends academic disciplines. Limiting the analysis of technological transitions to economic and technological aspects would significantly reduce comprehensiveness, and the possibility for designing well-targeted policies. The second is a clear structure that allows for a systematic analysis of potential determinants, due to the complexity of factors and actors that influence technological transitions. A combination of a holistic and reductionist reasoning would be required to allow for potential determinants from a wider perspective to be considered, while keeping the analysis to manageable scale that permit for well-measured policy suggestions to be devised and implemented.

\subsubsection{A Systems Approach}

One framework where an interdisciplinary and systematic analysis of multiple factors is possible is through a systems approach. Early protagonists argued for a holistic approach, in order to encompass the complex and evolutionary 
characteristics of living beings or society (Weckowicz 2000). ${ }^{7}$ The systems approach is usually required to "break down the boundaries between academic disciplines" (Forrester 2009, 9), fulfilling the interdisciplinary requirement of utilizing a systems approach for studying technological transition. A holistic approach of system thinking can also be found in the systems of innovation literature, where Charles Edquist $(1997,14)$ defines a system as being "all important economic, social, political, organizational, institutional, and other factors that influence the development, and use of innovation".

\subsubsection{Delimiting a Complex System}

In order to empirically analyze a system it is imperative to know what factors are part of the system and what factors should be left out. In other words, a system under study must be delimited from the rest of world in order for a boundary to be established.

A manner of delimiting the boundary of the system under study, other than spatially (e.g., borders of nation) or by sector (e.g., specific technological field) is to 'simply' identify the activities or determinants that influence the development and utilization of an innovation (Edquist 2005). Delimiting a system of innovation by identifying all of its determinants may not be possible. However, identifying as many relevant determinants as possible can serve as a guiding objective, which in turn can incrementally improve the accuracy of delimiting the system while enhancing the comprehensiveness of the systems of innovation approach.

One example of an attempt to delimit a system, both by sectoral delimitation and by determinants is through the Technological Innovation System (TIS) approach and its lists of functions. ${ }^{8}$ These lists of functions, developed by several authors in the TIS literature, specify the integral processes believed to be necessary to create, develop and utilize a 'new' technology. They provide a concrete set of functions that can be utilized as a framework for empirical analysis can help translate empirical findings into usable policy suggestions.

The potential risk when delimiting the system is that important determinants of the innovation system under study are left out of the analysis. In fact, several authors have criticized the TIS approach for being too inward looking and ignoring the

\footnotetext{
${ }^{7}$ Ludwig von Bertalanffy, an Austrian biologist, argued for an open 'holistic' systems approach already in the $1930 \mathrm{~s}$. While beginning his work in the areas of physics and biology, he would broaden his approach to create a General Systems Theory with application in social sciences (Weckowicz 2000).

${ }^{8}$ See for example Johnson and Jacobsson (2001) and Bergek et al. (2008).
} 
aspects that would be described as exogenous to the TIS system (Coenen and Díaz López 2010; Markard and Truffer 2008). The other limitation arises when the TIS approach is applied in a developing country context. The approach has been developed for and mainly tested in high-income countries, such as the Netherlands, Germany and Sweden (S. Jacobsson and Bergek 2004; Negro, Hekkert, and Smits 2007; Negro, Suurs, and Hekkert 2008). However, the application of the TIS approach in a developing country context is emerging. ${ }^{9}$ As shown throughout the chapters of this thesis, understanding technological transitions in developing countries requires complementing the list of endogenous and 'exogenous' factors of the system.

\subsubsection{Social and Political Factors - Endogenous or Exogenous to the System?}

Addressing the criticism of the TIS approach for not sufficiently taking into consideration its wider context ${ }^{10}$, and adjusting the framework to developing country contexts, may require a re-thinking of the boundaries for the technological system. Aspects that have previously been overlooked and considered external to the focal TIS system could instead be considered endogenous to the system, if regarded as determinants (positive or negative) for innovation. While the objective is not to include all socio-economic factors as part of the Systems of Innovation several questions remain. Which factors do exercise an influence on the integral elements of the systems of innovation that should not be ignored? How does this potential influence differ in countries of different income-level ${ }^{11}$, e.g., developing (low, low-middle, upper-middle) and developed (high-income) countries?

Another framework that has developed parallel to the systems of innovation approaches is the Multiple-Level Perspective (MLP). The MLP framework has emphasized wider socio-economic and political factors as part of their socio-

${ }^{9}$ Some examples are Jacobsson and Bergek (2006) (RET specific); Iizuka and Gebreeyesus (2012; 2016) (Agriculture Sector).

${ }^{10}$ Throughout the chapters of this thesis, the terminology wider context and framework conditions are both used to describe factors that are generally not considered part of the inner workings of the technological innovation system, but that may still exercise influence on technological transitions.

${ }^{11}$ This thesis uses the income classification (GNI per capita) by the World Bank. For the fiscal year of 2017 , low-income economies are those of $\$ 1,025$ or less; lower middleincome economies $(\$ 1,026$ to $\$ 4,035)$; upper middle-income economies $(\$ 4,036$ to $\$ 12,475$ ); and high-income economies have a GNI per capita of $\$ 12,476$ or more. Low, lower middle and upper middle-income are characterized as developing countries (The World Bank 2016b). 
technical landscape analysis. ${ }^{12}$ Leading authors have raised factors such as "oil prices, economic growth, wars, emigration, broad political coalitions, cultural and normative values, environmental problems" (Geels 2002, 1260). Other authors refer to the importance of environmental awareness in socio-technical transitions. They declare that "growing environmental awareness is a socio-cultural development that can be considered a landscape process, and which is questioning the performance of multiple regimes, whilst generating opportunities for niches" (Smith, Voß, and Grin 2010, 441). Other disciplines, e.g., psychology research, have also demonstrated a link between environmental awareness and a higher preference for energy produced from RETs (see e.g., De Groot et al. 2012; Steg, Dreijerink, and Abrahamse 2005; Van der Werff, Steg, and Keizer 2013). Moreover, in developing countries, studies that specifically analyzed the awareness about RETs found a lack of awareness concerning the new technologies to constitute a significant barrier for its adoption (Reddy and Painuly 2004; Kennedy and Basu 2013; Luthra et al. 2015). Other frameworks and previous interdisciplinary research can assist in identifying sociopolitical factors that should be considered when assessing the determinants and consequently the boundaries for systems of innovation.

Again, identifying all the determinants that drive or block technological innovation may not be possible, especially since the evolutionary nature of socio-technical systems signify that the systems change over time. In this thesis, the preferred approach to systems of innovation and technological transition is that of Lundvall (1992) who argues for a flexible approach to deciding what processes to consider in a system.

\subsection{Aim and Scope of Thesis}

This introductory chapter has identified the need to expand the adoption of RETs, predominately motivated by climate change, but to reduce energy insecurity and energy poverty. Several conceptual weaknesses and remaining challenges in current approaches to systematically analyze the barriers and drivers to RETs adoption have been raised along with the need for additional empirical analyses, particularly in developing countries.

Inspired by these challenges and research gaps, the thesis aims to contribute to the understanding of the mechanisms that hinder or drive adoption of RETs, with a special focus on developing countries. This compilation thesis is made up of four

12 The MLP framework includes three levels, where the socio-technical landscape level refers to macro level factors. The other levels are the niche (micro - protected spaces for emerging innovations) and socio-technical regime (meso - incumbent technical systems). 
substantive Chapters (Ch. 3-6), which address related research questions and a wide range of possible determinants of energy transition, through an interdisciplinary lens. The chapters vary in their level of analysis, from a wide approach where multiple possible determinants are included in the analysis (Chapters 3, 4 and 6), to zooming into a specific determinant (Chapter 5).

The substantive Chapters (Ch. 3-6) are preceded by a literature review in Chapter 2. The literature review brings together the background literature and identifies gaps that need to be addressed to advance the subject. These research gaps presented in Chapter 2 have motivated the work described in the subsequent chapters. In Chapters 3-6, there is some repetition of what is found in Chapter 2. This is deliberate as it allows each of the Chapters (Ch. 3-6) to stand alone. Finally, Chapter 7 concludes the thesis by revisiting key findings and discussing how these can translate into feasible policy suggestions. Chapter 7 finishes by elaborating on remaining challenges not addressed in this thesis. They lead to recommendations for future research.

\subsubsection{TIS and the Wider Context: A framework for developing countries}

The first substantive Chapter (Ch. 3) begins by addressing limitations raised by previous scholars concerning the TIS function approach. In order to conceptually map integral elements and activities along with wider contextual factors of technological transitions in a developing country context, Chapter 3 undertakes a thorough review of previous approaches (TIS and MLP), along with additional cross-disciplinary research. The chapter proposes an analytical framework that includes additions to the list of integral processes or functions of the TIS, along with wider contextual factors that may influence the system. This framework sets the stage for two empirical studies (Chapters 4 and 5), and one conceptual chapter (Chapter 6).

\subsubsection{Empirical Studies}

While Chapter 3 theoretically justifies the inclusion of the factors that make up the framework used in this thesis, Chapter 4 empirically tests the framework in a case study analyzing barriers and drivers to wind energy adoption in Colombia. Next, Chapter 5 zooms into one of the contextual factors discussed in Chapter 3 and 4 , namely environmental awareness, by performing an empirical study on the effectiveness of environmental education in creating environmental awareness in 15-year old adolescents in Colombia.

\subsubsection{Rethinking System Boundaries}

Chapter 6 builds on the knowledge acquired in the first three related Chapters $(3,4$ and 5), dedicated to advancing the knowledge on the contextual factors/framework 
conditions. The chapter elaborates on the contextual factors deemed exogenous by the TIS literature, through theoretical discussion, combined with empirical evidence from previous case studies of countries from different income-levels. By using a wider Systems of Innovation (SI) approach to map framework conditions, Chapter 6 addresses the issue of systems boundaries, i.e., should these framework conditions be considered endogenous or exogenous of the system. Moreover, by including countries of different income-levels, Chapter 6 attempts to differentiate the role of framework conditions between developing and developed countries, and the conceptual consequence this may have for delimiting the system.

\subsubsection{Lessons Learned and Next Steps}

In the last Chapter (Ch. 7), the conceptual and empirical findings from Chapters 36 are revisited and reflected upon. The final Chapter collates the findings presented in this thesis in an effort to emphasize specific contributions from the individual chapters, but also how they relate and reinforce each other. Moreover, Chapter 7 dedicates a session for discussing how the findings, including driving and obstructing framework conditions, found in this thesis could be translated into short/medium-term and long-term policy suggestions. Finally, this chapter concludes by highlighting remaining challenges and suggests possible avenues for future research. 


\section{Chapter 2. Background Literature \& Research Gaps}

In this thesis, a specific focus is placed on attempting to understand and improve strategies for accelerating the transition towards sustainable energy alternatives, namely Renewable Energy Technologies (RETs). As discussed in the previous chapter, increasing the share of RETs in a country's energy mix can contribute to energy security and climate change mitigation. As highlighted in Chapter 1, enhancing the understanding concerning the mechanisms that hinder or drive a rapid diffusion of RETs requires an interdisciplinary approach capable of identifying potential determinants across different actor groups in a systematic and structured manner.

Over the past decades, a multitude of theoretical approaches to analyze sustainable technological transitions have emerged, such as social construction of technology (Bijker, Hughes, and Pinch 2012), sociology of expectations (Van Lente and Rip 1998; Borup et al. 2006), constructive technology assessment (Rip, Schot, and Misa 1995), technology future studies (Porter et al. 2004; Truffer, Voß, and Konrad 2008), reflexive governance (Kuhlmann, Shapira, and Smits 2010; Voß, Bauknecht, and Kemp 2006), long waves (Freeman and Louçã 2001; Perez 2002), Transition Management (Kern and Smith 2008; Loorbach 2010; Rotmans, Kemp, and Van Asselt 2001), Strategic Niche Management (Kemp, Schot, and Hoogma 1998; Raven and Geels 2010; Smith 2007), Multiple-Level Perspective (Geels 2002; Geels and Schot 2007; Smith, Voß, and Grin 2010), Technological Innovation System approach (Bergek et al. 2008; S. Jacobsson and Johnson 2000; Hekkert et al. 2007), and Systems of Innovation approach (Edquist 1997).

A theoretical discussion about all the possible approaches for studying sustainable transitions is beyond the scope of this thesis. The literature review will therefore be restricted to the approaches used in this thesis, namely Technological Innovation System (TIS), Multiple-Level Perspective (MLP) and Systems of Innovation (SI). The TIS, MLP and SI have been selected as theoretical framework because they stand out from other approaches in that they support a comprehensive analysis of a wide array of socio-technical aspects in a systematic manner. Given the focus of this thesis on identifying barriers and driving mechanisms for expanding RETs adoption, these wide-ranging frameworks provide a good conceptual starting point.

This chapter will review essential background literature of the theoretical frameworks used in this thesis. The chapter will also highlight the existing limitations of these frameworks, motivating the focus and theoretical contributions, which will be made in Chapters 3-6. As the literature reviewed in this chapter will show, questions remain about what factors should be considered when applying a systems approach, especially in a developing country context. This thesis aims to 
shed light to these questions through the conceptual and empirical analyses done in Chapters 3-6.

Since both the TIS and SI framework are grounded on systems approaches, the literature review will begin by providing a review of the systems literature. Following, the systems of innovation approaches will be presented, including the TIS, its advantages and limitations. This leads to a discussion about defining the boundary of the system in question, in the case of this thesis, renewable energy technological innovation systems. Next, the MLP approach will be introduced. In this thesis, the MLP serves as a complement to the TIS, in order to consider potentially influential factors not explicitly encapsulated by previous TIS studies and to make the framework better suited for analyses in developing countries. Due to discrepancies regarding the use of various terms in previous literature, this chapter will also provide definitions of key concepts used throughout this thesis such as innovation, institutions, and organizations.

\subsection{Systems}

\subsubsection{Early Developments and Use of Systems}

A systems approach for analyzing complex phenomena has for long been used in natural science, where in certain conditions, i.e., when the exact number of particles or elements in the system is known, a closed system analysis can be applied. However, the complexity and possibility of external influences in sociotechnical transitions does not allow for a closed system. The rationale for an open systems approach was argued for already in the 1930s by the Austrian biologist Ludwig von Bertalanffy. ${ }^{13}$ While von Bertalanffy began his open system discussion in the area of physics and biology (Bertalanffy 1950b), he would extend his theory to create a General Systems Theory (Bertalanffy 1950a), which would transcend natural sciences to also prove applicable in social science (Weckowicz 2000). The central argument by von Bertalanffy, sprang from a description of living things as an evolutionary, dynamic and complex system, a complexity ${ }^{14}$ that could not be justified by the previously held mechanistic perspective, which explained life by the laws of physics and chemistry (Weckowicz 2000). Just as in the case of a biological organism, he contended that a reductionist view was

\footnotetext{
${ }^{13}$ His original publications on the open systems theory were written in German in 1932 and 1942. A publication followed in English in 1950, titled: The Theory of open systems in physics and biology.

14 The word complex has its origin in the latin word plectere, meaning entwine or to weave. Complexity of a system can be described as immensely entwined simple parts. For a detailed discussion about complexity or complex systems, see Mitchell (2009).
} 
inadequate to explain complex intricacies of societies, but instead argued for a holistic systems approach.

An elaboration about the dynamic and complex nature of systems was initiated by Jay Forrester in the 1950s, which would culminate in several important publications in the 1960s and onwards. ${ }^{15}$ This approach, which became known as system dynamics, placed a special emphasis on the relationship or links between different components of the system. These links between the elements of the system provided positive or negative feedback loops. A consequence of the feedback loops was that interventions to change the behavior of the system resulted in non-linear outcomes. These dynamic and non-linear characteristics contribute to a higher degree of complexity of the system. While systems dynamics began with a focus on industrial dynamics, the breadth of the approach has been expanded and used in areas such as, urban system (Forrester 1969), social-ecological systems (Ostrom 2009) and even global systems. ${ }^{16}$

\subsubsection{Key Components of Systems}

A system can in general terms be described as "any group of interacting, interrelated, or interdependent parts that form a complex and unified whole that has a specific purpose" (Kim 1999, 2). The links or interdependencies between parts or components, in the form of positive or negative feedback loops is what makes it a system, rather than a collection of different parts. In fact, in Forrester's system dynamics, the relationships between the different elements are considered as vital to the configuration and behavior of any system as the actual elements (Meadows et al. 1972). In addition, understanding the boundary of the system under study, i.e., where the system ends and where the remaining world continues, is essential for empirical studies to be undertaken (Edquist 2005).

\subsection{Using Systems Thinking for Studying Innovation}

The study of innovations has increasingly seen the use of systems approaches as such approaches allow analyzing the complexity, nonlinearity and feedback loops of different types of innovations, such as technological, organizational and marketing. This section will begin by defining innovation, followed by an introduction of different Systems of Innovation Approaches before discussing in detail the Technology Innovation Systems Approach (TIS).

\footnotetext{
${ }^{15}$ See for example, Forrester $(1961 ; 1968)$

${ }^{16}$ System Dynamics modeling was used for The Limits to Growth publication (Meadows et al. 1972).
} 


\section{The Meaning of Innovation}

The term innovation is used extensively, but with varying meanings (Edison, bin Ali, and Torkar 2013). While discussing all the different definitions of innovation is beyond the scope of this chapter, it is important to review a few distinctions in order to establish the concept of innovation and how it relates to the Systems of Innovation framework that is used in this thesis.

One of the most ambitious efforts of defining innovation has been undertaken by the OECD and Eurostat, in the form of the Oslo Manual, which was first published in 1992 (OECD 1992). An important ambition of the Oslo Manual was to improve the measurement of firms' propensity to innovate and track it over time. Following the first edition of the Oslo Manual, which focused on manufacturing, while including technological product and process innovation, the definition of innovation has evolved, resulting in second and third editions of the manual. In paragraphs 146 and 150 of the third edition the definition of innovation is described as follows:

146. An innovation is the implementation of a new or significantly improved product (good or service), or process, a new marketing method, or a new organisational method in business practices, workplace organisation or external relations.

150. A common feature of an innovation is that it must have been implemented. A new or improved product is implemented when it is introduced on the market. New processes, marketing methods or organisational methods are implemented when they are brought into actual use in the firm's operations (OECD/Eurostat 2005, 46-47).

As can be inferred from paragraph 146 and 150, in order for e.g., a product to be considered an innovation, it must be new or significantly improved and introduced to the market. If it is not introduced on the market it is not considered an innovation but rather an invention (Gault 2016). With regard to the concept of novelty, the manual includes several degrees of novelty, including "new to the firm, new to the market, and new to the world" (OECD/Eurostat 2005, 57). "The minimum entry level for an innovation is that it must be new to the firm" (OECD/Eurostat 2005, 57). In other words, "an innovation does not need to be developed by the firm itself but can be acquired from other firms or institutions 
through the process of diffusion ${ }^{17}$ " $(\mathrm{OECD} /$ Eurostat 2005,17$)$. By including this minimum degree of novelty, the Oslo Manual allows for the concept of adoption of e.g., a technology, between firms or even between countries, through the process of diffusion.

This broad degree of novelty provided by the Oslo Manual has strong similarity to certain definitions by early system of innovation thinkers. For example, Nelson and Rosenberg (1993, 4-5), define innovation "rather broadly, to encompass the processes by which firms master and get into practice product design and manufacturing process that are new to them, whether or not they are new to the universe, or even to the nation". As stated by Edquist (1997), their concept of innovation is not limited to its first introduction but also include its diffusion, e.g., the adoption of a technology that is new to the firm or the country.

As discussed in Chapter 1 as well as in the introduction of this chapter, a main focus of this thesis is the diffusion of sustainable energy alternatives, namely Renewable Energy Technologies (RETs). In Chapter 4, an empirical study is undertaken in Colombia to understand the slow adoption of wind energy. Wind energy in Colombia was first implemented (introduced on the market) in 2003 but has since been stagnant. The technology is relatively new to the country as well as most firms in Colombia. These two conditions, i.e., that wind energy is new to most firms and has been introduced to the market satisfies the required definition of innovation as stipulated by the Oslo Manual. That said, since the thesis is concerned with RETs and with special focus on wind energy in Colombia, the definition of innovation would be imposed with a restriction (Gault 2016). The restriction of focusing on a specific technology will have implications for measuring and ultimately for policies (Gault 2016), as data gathering and analysis would focus on the technologies in question. Details about how data is gathered for the restricted innovation, including the structured and semi-structured interviews conducted for the qualitative data collection and analysis will be discussed in Chapter 4 and shown in Appendix I (final interview guide).

Furthermore, the research conducted in this thesis is not solely interested in the propensity of firms to innovate but rather to explain what hinders and drives adoption of RETs. In other words, this thesis is interested in the processes that block or enable the adoption of technological innovations, which requires a wider perspective beyond firms. In the words of Jan Fagerberg $(2005,20)$, "a firm does not innovate in isolation, but depends on extensive interaction with its

${ }^{17}$ The Oslo Manual describes diffusion as "the way in which innovations spread, through market or non-market channels, from their very first implementation to different consumers, countries, regions, sectors, markets and firms" (OECD/Eurostat 2005, 17). 
environment". This environment is made up by a wide array of "other firms (suppliers, costumers, competitors etc.) or non-firm entities such as universities, schools, and government ministries", whose behaviors are "shaped by institutionssuch as laws, rules, norms and routines" (Edquist 2005, 183), all of which may influence innovation. Put differently, "innovation is constrained or advanced by the cultural, geographical, and legislative and regulatory environment in which it happens" (Gault 2010, 104). Consequently, understanding a slow adoption of RETs thus requires a framework that encapsulates the myriad of potential determinants that may have a positive or negative influence on diffusion. By taking a systems approach to study innovation, this thesis aims to contribute to the understanding of the multiple processes influencing innovation, beyond, but not excluding, firms. The next section will review the systems of innovation approaches, including their advantages, remaining limitations and research gaps. Chapter 3 discusses in greater detail the framework that is used to measure key processes of the innovation system, again with restrictions imposed by its focus on RETs.

\subsubsection{Systems of Innovation (SI) Approaches}

Various Systems of Innovation (SI) approaches have been developed since the mid-1980s as analytical frameworks and policy tools. There are some approaches with a geographical focus such as the National Innovation System (NIS) (Freeman 1987; Lundvall 1992; Nelson 1993), and the Regional Innovation System (RIS) (Cooke, Uranga, and Etxebarria 1997; Saxenian 1994); the Sectoral Innovation System (SIS) (Breschi and Malerba 1997) focuses on an industrial sector; the Technological Innovation System (TIS) (Carlsson and Stankiewicz 1991), in turn, focuses the analysis on a technology. While they are distinct approaches, they are also interrelated as a specific technology innovation system, for example, can operate at the national, regional and/or sectoral level (Markard and Truffer 2008).

The National Innovation Systems (NIS) approach is the most common SI approach. NIS was first used by Freeman (1987) in an analysis of Japan's economic and technological policy and development. He defined the NIS as "the network of institutions in the public and private sectors whose activities and interactions initiate, import, modify and diffuse new technologies" (Freeman 1987, 1). Lundvall (1992, 13), who has also developed and used the NIS approach, defines it as "all parts and aspects of the economic structure and the institutional set up affecting learning as well as searching and exploring". Different authors diverge somewhat in the definition of an NIS, however the central elements remain the same.

The Technological Innovation System (TIS) approach has been defined as "a network of agents interacting in the economic/industrial area under a particular institutional infrastructure and involved in the generation, diffusion and utilization 
of technology" (Carlsson and Stankiewicz 1991, 94). The NIS and TIS share the focus on technology and the importance of institutions. The TIS approach is, however, different from NIS in that a technology is often not limited to the national border or geographical boundary (Carlsson 1995). Given that a technological sector often transcends national boundaries, strictly using NIS may make technological analyses fall short in analytical scope. That said, focusing too strictly on the technological sector in question also carries risks, i.e., that the analysis becomes too narrow and misses relevant processes that would be captured at the national level. This relates to one of the limitations of the TIS approach that will be discussed in more detail in section 2.3.

\subsubsection{Technological Innovation System (TIS)}

Actors, Networks, and Institutions make up the fundamental components of the TIS (Carlsson and Stankiewicz 1991). Actors are made up by organizations and individuals who work towards the development of the technology in question (Hellsmark and Jacobsson 2009). Examples of these organizations include research institutes, firms, financial institutions, governmental agencies or policy makers each with specific competences, resources and strategies (Carlsson and Stankiewicz 1991). These actors may be organized in networks where interactive learning (e.g. university-industry networks or user-supplier) and formation of policy networks may occur (S. Jacobsson and Lauber 2006; Bergek, Jacobsson, and Sandén 2008). These actors and networks share a given "sets of common habits, routines, established practices, rules, or laws that regulate the relations and interactions between individuals and groups" (Edquist and Johnson 1997, 46), known as institutions (North 1991).

Technological innovation systems go through two main stages of development, a formative stage and a growth stage. At the formative stage various components necessary for development, diffusion and utilization of the TIS take place, such as knowledge accumulation and configuration of necessary infrastructure and institutional arrangements (Bergek, Jacobsson, and Sandén 2008). During this stage, the system is particularly vulnerable to exogenous influence (Raven 2005). TIS analyses of RETs in developing countries are likely to focus on this stage, and therefore exogenous factors may be particularly important to consider (as will be discussed in Chapters 3, 4 and 6) The length of this stage, which can be decades, depends on the technology in question, market conditions and the actions of industry and policy-making actors (Van de Ven and Garud 1989).

The next stage, the growth stage, starts taking place once essential structural components of the TIS have been developed. During this stage, positive feedback loops may occur between components of the system, which can contribute to an acceleration of its development. Negative feedback loops may similarly occur during the growth stage, which may limit or prevent growth. If sufficient positive 
feedback loops occurs, the system can then become increasingly self-sustaining, reaching a stable and mature structure capable of withstanding external pressures (Bergek, Jacobsson, and Sandén 2008, 577-78).

\section{TIS Function Approach}

To facilitate the analysis of the main processes related to the creation and development of a technological innovation system, system functions were introduced by Johnson and Jacobsson (2001). Functions can be understood as the integral components and activities of the TIS. ${ }^{18}$ System functions enable the characterization of the innovation system, its strengths and weaknesses by separately studying its underlying processes (Lundvall et al. 2002; Hekkert et al. 2007). The function approach can also serve to assess the performance of different functions, which can reveal significant information about its drivers and barriers. Furthermore, an ample examination of the functions of the TIS can contribute to a better understanding of the dynamics within the systems, which is a result of the interaction between functions (Johnson and Jacobsson 2001). The lessons drawn from the function analysis can contribute to devising policies for developing, diffusing and adopting a new technology as well as monitoring and evaluating innovation policies.

The TIS function approach has been tested and adjusted by several scholars. As a result, several 'lists of TIS functions' exist. ${ }^{19}$ Examples of functions that can be included in a TIS analysis include: Entrepreneurial Activities, Knowledge Development, Knowledge Diffusion, Guidance of the Search (expectations set by the government for new technologies), Market Formation, Resource Mobilization, and Creation of Legitimacy (Hekkert et al. 2007). The many sets of system functions that have emerged over the past decade suggest that the TIS function approach is still in a developmental stage and continued improvements will be needed as the understanding of technological innovations advances (Edquist 2005).

Most sets of functions have been developed predominantly in high-income country contexts (Johnson and Jacobsson 2001; Edquist 2005; S. Jacobsson and Bergek 2006; Hekkert et al. 2007), and empirically tested in countries where a technology has achieved a later growth stage (Negro, Hekkert, and Smits 2007; Negro, Suurs, and Hekkert 2008; Negro and Hekkert 2008; Hillman et al. 2008). In fact, several

${ }^{18}$ A parallel from TIS functions can be made to the statistical measurement literature, which refers to the key processes for the development of innovations as innovation activities (OECD/Eurostat 2005).

${ }^{19}$ See for example: Bergek et al. (2008); Edquist (2005); Hekkert et al. (2007); Hillman et al. (2008); Jacobsson and Bergek (2006); Johnson and Jacobsson (2001); Suurs and Hekkert (2009). 
authors have questioned the applicability of the innovation system approach to developing countries. ${ }^{20}$ Schott and Wickstrom Jensen (2008), for instance, argue that without considering the specific context, the innovation system approach cannot be applied to developing countries. This represents a research gap, which will be addressed in Chapter 3. As will be shown in that Chapter, the function analysis in a developing country context is relevant, with an adequate adjustment to the set of functions together with the inclusion of relevant exogenous factors.

\subsection{System Boundaries}

In the context of technological transitions, the boundary of the system may be regional, national or even global, making the delimiting of the innovation system a persisting challenge. In other words, identifying what should be included in the system and what should be left out remains an important avenue for research, and strategies for defining the boundary of systems differ amongst various authors. Authors such as Lundvall (1992) argue that a flexible approach is to be preferred when deciding what processes to consider in a system.

The system can be delimited by the sector of a technology (e.g., geothermal or wind sector) (Carlsson and Stankiewicz 1991) or in term of its activities (Edquist 2005) or functions. The concept of focal TIS has been used to refer to a delimited system, which is made up by the functions and their linkages. The focal TIS has also been defined as "the realm where systematic interdependencies in a specific technological field play out" (Bergek et al. 2015, 52). Delimiting the system, however, requires determining which are the relevant innovation activities and the interdependencies that would be encapsulated in the focal TIS (see an example of a list of functions in the previous section). If a narrow boundary is set, there is a risk that relevant interdependencies that fall outside the delimited focal TIS are missed. Edquist $(2005,15)$ argues that understanding the various activities and their relative importance for any innovation system changes as our knowledge increases.

Furthermore, Charles Edquist $(1997,14)$ contributes to the delimitation of the system by broadly defining it as "all important economic, social, political, organizational, institutional, and other factors that influence the development, and use of innovation". Edquist $(1997,15)$ motivates this broad and comprehensive definition by stating, "an advantage of this definition is that it is open in the sense that it does not a priori exclude any determinants. An obvious disadvantage is that it is unspecific at the present state of the art". Edquist $(1997,15)$ recognizes the monumental task of identifying all the determinants that make up the innovation

${ }^{20}$ See for example: Arocena and Sutz (2000); Schott and Wickström Jensen (2008); van Alphen, Hekkert and van Sark (2008). 
system adding that "at the present state of the art, defining the limits of a system of innovation in this way (as all determinants) is a 'catch 22' problem"; he further clarifies "we simply do not know in detail what all the determinants of innovation are, particularly not for all types of innovations" (Edquist 1997, 15).

\subsubsection{Categories of Determinants for a Systems of Innovation}

Following Edquist's (1997) suggestion of specifying the boundary of a system based on its determinants (i.e., what helps the system achieve its purpose), a systematic analysis of potential candidates is necessary. Categorizing determinants in a structured manner can also serve as an important tool in the process of identifying what makes up the system, and what is irrelevant for the system to realize its objective. A first step to categorizing the determinants of innovation is differentiating integral components and activities from framework conditions of the system.

\section{Integral Components and Activities}

As previously mentioned, in the TIS literature, integral components and activities are referred to as processes or functions of a technological system. Integral components of the system are the ones that shape its formal structures. They include a variety of actors involved in the innovation activities, particularly those related to learning, and include firms, private and public organizations, and universities (e.g. organizations and individuals directly contributing with specific knowledge, technical skills and resources).

The collection of these integral processes or functions is referred to as the focal system of technological innovation (or focal TIS). Functions within the focal systems are regarded as endogenous to the system. Factors or activities that fall outside the focal system are considered exogenous (Bergek et al. 2015).

\section{Criticisms of TIS}

The TIS focus on integral functions has contributed to criticisms of the approach not sufficiently taking into account the influence of external factors to understand technological transitions (Coenen and Díaz López 2010; Markard and Truffer 2008; Geels, Hekkert, and Jacobsson 2008; Hekkert and Negro 2009). External factors here refer to aspects that are not considered to be integral factors to the formation of a specific technological innovation, but that may still influence the development and diffusion of the TIS.

This criticism of the TIS function approach highlights a research gap pertaining to the system boundary debate. Should the focal system alone delimit the system or are there are additional determinants of the system that are not part of the integral 
functions? And if they are influential system determinants, should these factors be considered endogenous to the system? An attempt to address these questions is undertaken in Ch. 3, 4 and 6.

\section{Framework Conditions - Institutions}

Other system determinants, and one of the main focuses of this thesis, are framework conditions that can be described as factors that make up the environment or contextual setting in which firms innovate. Framework conditions can be supportive or interruptive of innovation activities (Gault 2010). Institutions have traditionally been a key framework condition to system of innovation approaches. In this thesis, the Edquist and Johnson's definition of institutions will be used. Institutions are defined as the formal and informal rules, habits, established practices, and routines underlying the relations and interactions between individuals, groups and organizations (Edquist and Johnson 1997, 46; Edquist 2005; North 1991). The type, quality and effectiveness of institutions can contribute or hinder a technological transition.

Institutions can be formal or informal. Formal institutions include laws, regulations and rights. Informal institutions includes societal codes of conduct, customs, traditions, and taboos (North 1991, 97). Institutions have been considered in the SI literature conceptually and implicitly, but a systematic and explicit consideration of different aspects of institutions, and in particular informal institutions, can still be considered a research gap. A more detailed discussion about the role of institutions in influencing socio-technical transitions will be provided in Chapter 6 .

\section{Other Framework Conditions}

There are other framework conditions that can influence negatively or positively technological transitions (hindering or driving them), and that have not been formally conceptualized as part of the TIS (Hekkert and Negro 2009, 592). These framework conditions include economic and sociopolitical factors. The relevance of considering additional sociopolitical and economic framework conditions has been emphasized to a larger degree in another approach, the Multiple-Level Perspective (MLP).

\section{Multi- Level Perspective (MLP)}

The Multiple-Level Perspective (MLP), which was built on previous work by Kemp, Rip and Schot (Kemp, Rip, and Schot 2001; Rip and Kemp 1998), explains socio-technical transitions by the dynamic interaction of three different levels, namely niche, regime and landscape (Geels 2002). Niches can be described as “"protected spaces' such as R\&D laboratories, subsidized demonstration projects, or small market niches where users have special demands and are willing to support emerging innovations" (Geels 2011, 27). The regime level "account[s] for 
the stability of existing socio-technical systems", and "include[s] scientists, users, policy makers and societal groups besides engineers and firms" (Geels and Kemp 2007, 443). The landscape level can be described as an "external structure or context for interactions of actors" (Geels 2002, 1260), which in turn can destabilize existing regimes and provide opportunities for new niche-innovations (Schot and Geels 2008).

By including the landscape level in this heuristic approach authors have more consistently raised the potential influence of factors such as economic growth, changes in oil prices, cultural values, armed conflicts, political coalitions, environmental problems and changing environmental awareness (Geels 2002, 1260; Smith, Voß, and Grin 2010, 441) in socio-technical transitions.

The MLP can be an approach that can complement the TIS approach with the identification and systematical incorporation of important framework conditions that may constrain or drive technological transitions. A more thorough literature review of the MLP framework, including its similarities, advantages, and disadvantages against the TIS approach is provided in Chapter 3.

Beyond the need of enhancing the understanding concerning which framework conditions could and should be complementing to the integral components and activities of the TIS, learning how potentially positive framework conditions, i.e., framework conditions that drive sustainable transitions, can be strengthened, or how potentially negative framework conditions, i.e. conditions that hinder sustainable transitions, can be reduced, are important endeavors.

\subsection{Strengthening Positive Framework Conditions}

As was mentioned in the introductory Chapter 1, environmental awareness can contribute with shifting towards a more sustainable energy mix, and this can also be considered a framework condition. Environmental psychology research has shown a correlation between environmental awareness and a higher user preference for renewable sources of energy (De Groot et al. 2012; Steg, Dreijerink, and Abrahamse 2005; Van der Werff, Steg, and Keizer 2013). Population with increased environmental awareness may impose additional pressure on government and energy providers to diversify their energy supplies towards cleaner technologies ${ }^{21}$. Informal lobbying can open opportunities for new technologies, such as RETs, to enter the market through organized environmental groups pressuring for environmental policies or through increasing demand from

${ }^{21}$ The potential impact that public environmental awareness can have on environmental policies and regulation has been documented by Ramachandra Guha (1999) in his book 'Environmentalism: A Global History'. 
individual citizens for clean energy alternatives (Smith, Voß, and Grin 2010). ${ }^{22}$ In contrast, a lack of awareness for RETs can act as a barrier, in the form of lowered social acceptance for new technologies (Wüstenhagen, Wolsink, and Bürer 2007). In developing countries, the lack of environmental awareness and concerns for the costs and benefits of RETs have been found to have a significant negative influence on the adoption of renewable energies (Kennedy and Basu 2013; Luthra et al. 2015).

Moreover, in environmental psychology research, problem awareness, in this thesis denoted environmental awareness, has been found to be one of the most influencial proximal determinants on behavior (Bamberg and Möser 2007). However, despite the importance of environmental awarness in explaining behavior, it should be regarded as a necessary but not sufficient condition. In other words, when positioned within two major frameworks for environmental psychology, namely the Norm-Activation Model (Schwartz 1977) and the Theory of Planned Behavior (Ajzen 1991), environmental awareness should be regarded as one out of several factors influencing behavior. For example, Bamberg and Möser (2007), who combine both frameworks, lists environmental awareness (problem awareness) together with seven other determinanst of behavior, i.e., Internal Attribution, Social Norm, Feeling of Guilt, Perceived Behavioral Control (PBC), Attitude, Moral Norm, Intention. The result of their meta-analysis, which is based on 46 independent studies, however confirm that the total effect of awareness/knowledge of the problem "on behavior as well as intention is higher than the total effect of the more proximal determinants moral norm, attitude and PBC" (Bamberg and Möser 2007, 22). The importance of environmental awareness can be explained through its abiliy to influence both internal attributions, social norms and feelings of guilt, but also by directly impacting attitudes and and PBC (Bamberg and Möser 2007). That said, while the inclusion of environmental awareness as part of this thesis is futher motivatied by the literature from environmental psychology, it should be understood as one possible factor, often indirectly influencing behaviour by affecting other factors, such as moral norm or feeling of guilt.

Given the potential influence that environmental awareness can have on behavior and consequently technological transitions, one of the Chapters of this thesis (Chapter 5) is dedicated to improving the understanding how this framework condition in particular can be strengthened. By analyzing the effect of environmental education in generating environmental awareness, this thesis will

${ }^{22}$ See for example, P.C. Stern et al. (1999) or P.C. Stern (2000), for a detailed discussion about the Value-Belief-Norm (VBN) theory and possible avenues of influence derived from environmental awareness: i.e., Environmental Activism, Non-Activism, PrivateSphere environmentalism and Organizational actions. 
also advance the knowledge of one possible strategy for strengthening environmental awareness. In addition, a deeper understanding will be gained regarding the relationship between environmental education and environmental literacy in a developing country context, namely Colombia.

\section{Concluding Remarks}

The purpose of this chapter has been to provide a review of the key background literature that has served as theoretical background of the upcoming chapters in this thesis. This chapter has also served to highlight existing limitations and research gaps. This chapter has shown the relevance of applying a systems approach for this thesis, as it gives the ability to analyze, in a structured and comprehensive manner, the complex multildimentional nature of technological transitions. The chapter has also demonstrated the advantage of the TIS function approach for identifying the potential weaknesses within technological systems. Identifying such weakenesses can facilitate the identification of appropriate policy measures to drive the expansion of technological innovations, such as RETs, which are the focus of this thesis. Furthermore, the limitations of the TIS approach have been emphasized, such as the concern of being 'inward looking' or predominately developed for and applied in high-income countries. It has been noted that potential lessons can be learned from other frameworks such as the MLP, which includes the socio-technical landscape, or framework conditions, in the analysis of transitions. More accurately delimiting the system to be analyzed (e.g., an RET in a particular country) based on its determinants has been raised as challenging and ongoing effort (this will be further discussed in Chapters 3, 4 and 6). Finally, improving the understanding of how potentially 'postive' framework conditions, e.g., environmental awareness, can be strenghened, has been stressed as another important avenue for research. Two conceptual chapters (Ch. 3 and 6) and two empirical chapters (Ch. 4 and 5) in this thesis address the questions raised and the research gaps discussed in this chapter. 


\section{Chapter 3. Technological Innovation System and the Wider Context: A framework for developing countries ${ }^{23}$}

\subsection{Introduction}

The evidence concerning the environmental, economic and human risks associated with a changing climate has brought renewable energy technologies (RETs) to the foreground in international debates as one of the most important aspects of climate change mitigation (IPCC 2012). ${ }^{24}$ The necessity to move from fossil fuels to renewable sources of energy in order to curb greenhouse gas (GHG) emissions has resulted in worldwide commitments accompanied by a significant increase in resources targeting new investments in RETs. ${ }^{25}$ Moreover, according to the International Energy Agency (IEA), RETs have made significant gains in costcompetitiveness and many are today considered to have reached a level that is competitive with existing fossil fuel-based alternatives (IEA 2011). RETs are also raising the importance of renewable energy policy and the need to measure and monitor renewable energy activities to support and evaluate policy implementation, especially in developing countries. ${ }^{26}$

To observe the success and failures in adopting and adapting RETs analytical tools and studies are required. In an attempt to study technological innovations (see $\mathrm{Ch}$. 2 ), in the form of RETs, in developed countries, studies have been conducted using the Technological Innovation System (TIS) function approach (Bergek and Jacobsson 2003; S. Jacobsson and Bergek 2004; Negro, Hekkert, and Smits 2007; Negro and Hekkert 2008; Negro, Suurs, and Hekkert 2008). However, the existing TIS function approach for analyzing technological innovation systems has

${ }^{23}$ An earlier version of this chapter has been published as a working paper at the UNUMERIT working paper series (Edsand 2016). The paper was also been presented at the $14^{\text {th }}$ Globelics International Conference (Oct. 12-14, 2016) where it received the best $\mathrm{PhD}$ student paper award.

${ }^{24}$ Renewable Energies, in the form of wind, solar, geothermal, small hydro, and biomass are all examples of energy derived from natural processes, which are replenished at a faster rate than they are consumed (IEA 2011). Examples of other mitigation alternatives include carbon capture and storage and carbon sinks (e.g. through reforestation) (IPCC 2007).

${ }^{25}$ In 2011,118 countries had some form of renewable energy support policy or target for RETs at the national level, compared to 55 countries in early 2005 (REN21 2011). During 2012 fiscal year, the World Bank approved US\$3.6 billion towards financing of renewable energy projects, which represented $44 \%$ of the World Bank's total annual lending (The World Bank 2012b).

${ }^{26}$ Global projections estimate that global emissions in developing or emerging countries will exceed that of the developed world in the next decades (EIA 2013). 
limitations. Firstly, the framework has been constructed from a developed country perspective and cannot be directly applied in developing countries, without first considering their characteristics. Secondly, the TIS function approach has been criticized for being inward looking and not sufficiently incorporating the contextual factors that may influence the success or failure of RETs diffusion.

This chapter addresses these constraints by adding to the number of functions of the TIS. This process is informed by an examination of previous attempts to utilize the TIS function approach in developing countries, and by drawing on lessons from the Multi-Level Perspective (MLP) approach. The result is an extended TIS function approach, with functions that are applicable in developing countries, and with framework conditions that reflect the socio-economic context present in many of these countries. ${ }^{27}$

In this chapter, reflections and suggestions are made that can benefit future studies of technological transitions in a general sense, i.e., regardless of a specific technology. However, as indicated in the introduction, the aim of this chapter is to understand how the TIS framework can be enhanced so it can be used to understand the transition to RETs. Consequently, suggestions provided in this chapter have been developed with renewable energy technologies in mind.

\subsection{Technological Innovation System (TIS)}

Since the emergence in the mid-1980s of Systems of Innovation (SI) as an analytical framework and a policy tool, various IS approaches have been developed and are widely covered in the literature. The IS approaches include the National Innovation System (NIS) (Freeman 1987; Lundvall 1992; Nelson 1993), Regional Innovation System (RIS) (Cooke, Uranga, and Etxebarria 1997; Saxenian 1994), Sectoral Innovation System (SIS) (Breschi and Malerba 1997), and Technological Innovation System (TIS) (Carlsson and Stankiewicz 1991). The NIS and RIS focus on a geographical area and the SIS on an industrial sector (Hekkert et al. 2007). The TIS which focuses on a technology has been defined "as a

${ }^{27}$ No single definition of the term developing country is recognized internationally; however the term includes a multitude of countries, the developmental status of which varies widely. In this chapter (and in the rest of the thesis), the World Bank definition of developing countries, based on categories of income will be followed. Based on fiscal year 2015 , countries with a Gross National Income (GNI) per capita of less than US\$ 1,045 (Low-income), US\$ 1,046-4,125 (Lower-middle-income) and US\$ 4,126-12,735 (Uppermiddle-income) are considered developing (The World Bank 2015b). The suggested function changes and framework conditions proposed in this chapter have been developed with middle-income developing countries in mind. 
network of agents interacting in the economic/industrial area under a particular institutional infrastructure and involved in the generation, diffusion, and utilization of technology" (Carlsson and Stankiewicz 1991, 94). Despite their development as different approaches they are interrelated, i.e., a technology specific IS (TIS) could operate at the National, Regional and/or Sectoral level (Markard and Truffer 2008).

\subsubsection{Setting the Boundary of TIS}

Setting the boundary of a TIS is a complicated undertaking. As suggested by Carlsson and Stankiewicz (1991), the TIS could be delimited by the sector of a technology, e.g. wind or photovoltaic sector. Another suggestion is to delimit the TIS "in terms of activities" (Edquist 2005, 15). TIS literature has referred to the focal TIS as "the realm where systematic interdependencies in a specific technological field play out" (Bergek et al. 2015, 52). But what would be considered a relevant innovation activity or what systematic interdependencies would be encapsulated in the focal TIS? If a narrow boundary is set, are there relevant dependencies outside the delimited TIS that are being missed? Edquist $(2005,15)$ argues that understanding the various activities and their relative importance for any innovation system is "subject to change as our knowledge increases". This chapter contributes to the above TIS framework boundary debate through the development of an extended TIS framework that explicitly considers additional factors critical for the development and adoption of a technology in a developing country context. A more elaborate discussion concerning the system boundary is provided in Chapter 6 , including considerations for delimitating TIS systems in countries with different socio-economic levels.

\subsubsection{Stages of Development}

In order for a new technology to reach the final phases of development, diffusion and utilization, it must first undergo a formative stage. At this stage, various components necessary for the formation of the TIS are taking shape, e.g. knowledge accumulation, necessary infrastructure and institutional configurations (Bergek, Jacobsson, and Sandén 2008). Depending on the technology in question, market conditions as well as on actions taken by policy makers and industry actors this cumulative change of the different components of the TIS may last for decades (Van de Ven and Garud 1989).

After the development of essential structural components, the TIS enters a growth stage where positive feedback is established between components, contributing to an accelerated development of the system. It should be noted that negative feedback loops are also possible, which may hamper growth. However, if a momentum is created by positive feedback loops, this can make the system "increasingly self-sustained" and eventually becomes a stable and mature structure, "resilient to external pushes and pulls" (Bergek, Jacobsson, and Sandén 2008, 577- 
78). This can be contrasted to the earlier formative stage where exogenous factors may assert more influence on the system (Raven 2005).

In short, the TIS framework can be used to analyze both the formation and growth of technological innovation systems (T. Jacobsson and Jacobsson 2014). A TIS analysis in developing countries would, in most cases, be focused on the formative stage, rather than on a later growth stage. Consequently, the exogenous factors could be of greater importance when mapping and analyzing TIS systems in developing countries.

\subsubsection{TIS Function Approach}

In 2001, Johnson and Jacobsson introduced system functions to the TIS approach in order to analyze the processes integral to the creation and development of a technical innovation system. Separately studying the underlying processes that make up the innovation system supports a systemic analysis that can help to identify characteristics of the system, such as weaknesses and strengths (Lundvall et al. 2002; Hekkert et al. 2007).

The dynamics of a technical system are considered a consequence of the interaction between different functions (Johnson and Jacobsson 2001). Thus, a comprehensive analysis of the functions of the TIS may also allow for a better understanding of the dynamics within the system. Moreover, the function approach can reveal important lessons concerning the drivers and barriers within a system, by identifying the performance of different functions. These lessons in turn can assist in devising policies for generating, diffusing and utilizing a new technology.

Over the last decade several authors have tested, adopted and further developed the TIS function approach, resulting in different versions of system functions lists. ${ }^{28}$ The many sets of system functions suggest that the TIS function approach is still in a developmental stage and continued changes will be needed as the understanding of the system function advances (Edquist 2005). This chapter uses the list of system functions presented by Hekkert et al. (2007) (see Table 3.1). This list has been chosen as the preferred baseline for this chapter, as it has been used in several empirical studies and the relevance of the functions has been demonstrated. ${ }^{29} \mathrm{In}$ addition, all of the functions by Hekkert et al., (2007) fit into the OECD Oslo manual definition of innovation activities (OECD/Eurostat 2005).

${ }^{28}$ See for example: Bergek et al. (2008); Edquist (2005); Hekkert et al. (2007); Hillman et al. (2008); Jacobsson and Bergek (2006); Johnson and Jacobsson (2001); Suurs and Hekkert (2009).

${ }^{29}$ See for example: Negro et al. $(2007 ; 2008)$. 


\begin{tabular}{|c|c|c|}
\hline \multicolumn{2}{|c|}{ System Functions } & \multirow{2}{*}{$\begin{array}{l}\text { Description } \\
\text { Activities concerning the new technology (projects started, } \\
\text { planned etc.) }\end{array}$} \\
\hline F1 & $\begin{array}{l}\text { Entrepreneurial } \\
\text { Activities }\end{array}$ & \\
\hline F2 & $\begin{array}{l}\text { Knowledge } \\
\text { Development }\end{array}$ & $\begin{array}{l}\text { Existing and new knowledge created regarding the technology } \\
\text { (R\&D, experimentation etc.) }\end{array}$ \\
\hline F3 & Knowledge Diffusion & $\begin{array}{l}\text { How and to what extent knowledge regarding new tech. is } \\
\text { shared among actors (number of workshops, conferences etc.) }\end{array}$ \\
\hline F4 & Guidance of the Search & $\begin{array}{l}\text { Expectations set by government for new technology in terms } \\
\text { of regulations and specific targets }\end{array}$ \\
\hline F5 & Market Formation & $\begin{array}{l}\text { Market entry assistance for new tech. (protected space } \\
\text { ('nursing') for niche market, new environmental standards, } \\
\text { tax exemptions, feed-in tariffs etc.) }\end{array}$ \\
\hline F6 & Resource Mobilization & $\begin{array}{l}\text { Funds allocated by government or industry towards R\&D } \\
\text { (Human Capacity) or Subsidies (Financial Capacity) for the } \\
\text { tech. }\end{array}$ \\
\hline F7 & Creation of Legitimacy & $\begin{array}{l}\text { Advocacy for new tech. (Lobbying to increase legitimacy and } \\
\text { support for new tech.) }\end{array}$ \\
\hline
\end{tabular}

Source: Hekkert et al. (2007).

Note: The description of the functions is provided in a concise format. For a more elaborate discussion of the functions see Hekkert et al. (2007).

Most lists of functions, including Hekkert et al. (2007), have been primarily developed for, and applied in, a developed country context, where a technology has achieved a later growth stage. However, with an appropriate adjustment to the list of functions along with the inclusion of relevant exogenous factors in the analysis, the function analysis in a developing country context is relevant. It should be noted that even though the adjustments and additions to the TIS function approach proposed in this chapter have been made with a middle-income developing country in mind (see footnote 11), possible relevance of some of the proposed changes in high-income (developed) countries cannot be excluded. Mapping the functioning of the innovation system at an early formative stage will provide important information regarding the status and trends of processes considered essential for achieving the later growth stage of generating, diffusing and utilizing the technology in question. The following section will discuss some limitations raised in previous literature concerning the TIS and specifically the function approach. Next, suggestions for general improvements to the function approach, along with specific aspects relevant for its application in a developing country context will be provided. 


\subsection{Limitations of the TIS Approach}

\subsubsection{Limitation 1: Inward looking}

While the TIS function approach has been credited with being a useful tool for analyzing dynamic processes, the approach has been criticized for not sufficiently taking into account the influence of external factors on the technological innovation system (Coenen and Díaz López 2010; Markard and Truffer 2008; Geels, Hekkert, and Jacobsson 2008). ${ }^{30}$

Markard and Truffer $(2008,610)$ refer to the TIS approach as "myopic with regards to the explanation of technological transitions". They elaborate by describing the system perspective as being "inward oriented and does not pay much attention to the system's environment" (Markard and Truffer 2008, 610). The recognition of the potential influence of the external landscape is not a new notion but was already emphasized my Gunnar Myrdal in 1957, when he argued that a principal scientific task is "to analyze the causal inter-relations within the system itself as it moves under the influence of outside pushes and pulls and the momentum of its own internal processes" (Myrdal 1957, 18). In other words, what the authors emphasize is that beyond the boundary of the focal technological innovation system, there is an external context that may influence the system in a positive or negative manner. Over the years, the "structures and processes inside a focal TIS are generally well conceptualized in the literature" (Bergek et al. 2015, 53). However, given that a technological sector would need to be geographically delimited, i.e., nationally or perhaps even internationally, accurately defining a boundary for a TIS is not an easy task (Edquist 2005). A focus on the focal TIS has meant that "what happens outside and across the system boundary has been less systematically worked out" (Bergek et al. 2015, 53).

To clarify, the criticism of the myopic nature of the TIS approach is partly justified but not entirely. Some of the early TIS literature does mention the relevance of a wider context, referring to the potential influence of other external systems and national system-level factors. ${ }^{31}$ However in a recent paper by T. Jacobsson and S. Jacobsson $(2014,820)$, they acknowledge a lack of explicit reference to this wider context in subsequent analyses, which can partly be explained by "taking for granted certain features in the disciplines from which TIS emerged".

\footnotetext{
${ }^{30}$ In this context external factors refer to aspects that are not considered to be integral internal factors to the formation of a specific technical innovation process (e.g. organizations and individuals directly contributing with specific knowledge, technical skills and resources), but that may equally assert influence on the TIS.

${ }^{31}$ See for example: Ehrnberg and Jacobsson (1997); Jacobsson and Johnson (2000); and Johnson and Jacobsson (2001).
} 
More importantly, the wider context has not sufficiently been systematically integrated to complement the existing focal TIS function analysis. ${ }^{32}$ Given that one of the purposes for adding functions to the TIS analysis was to be able to produce concrete policy suggestions for enabling development and diffusion of new technologies, the lack of systematically incorporating the wider context into the analysis constitutes a limitation to the approach.

Consequently, by neglecting the wider context in the analysis, the comprehensiveness of the TIS function approach may be reduced, which could result in incomplete policy recommendations that leave out essential aspects concerning existing drivers and barriers for the system. Given that exogenous factors may potentially have a stronger influence at the formative stage (Raven 2005), the lack of explicit recognition and analysis of the wider context can be of greater concern when applying the TIS function approach in a developing country.

\subsubsection{Limitation 2: TIS Function Approach is Based Primarily on Developed Countries}

The TIS function approach has been developed for, and primarily applied in, developed industrialized nations such as the Netherlands, Sweden and Germany (see e.g., S. Jacobsson and Bergek 2004; Negro, Hekkert, and Smits 2007; Negro, Suurs, and Hekkert 2008; Negro and Hekkert 2008; Suurs and Hekkert 2009), but its application in developing countries has been limited.

In fact, several authors have even questioned the applicability of the innovation system approach to developing countries (see e.g., Arocena and Sutz 2000; Schott and Wickstrom Jensen 2008; van Alphen, Hekkert, and van Sark 2008). Schott and Wickstrom Jensen (2008) argue that without considering the specific context, the innovation system approach cannot be applied to developing countries. The context may involve institutions, the socio-economic environment of the country, and existing dynamics within the country (Arocena and Sutz 2000).

Other studies, on the other hand, while recognizing that the TIS framework was developed mostly for developed countries, they have tested it in emerging economies such as China and India. In Gosens and Lu (2013)'s study of wind power development in China, the authors highlight the importance of not only considering the domestic technological system but also looking at the relation between the domestic and the global technological system. The authors caution that the large domestic market in China and India might be a unique contributing factor to the development of the TIS in these countries, and thus the process may

\footnotetext{
${ }^{32}$ An exception being the inclusion of the function "development of positive externalities", referring to positive external economies (see e.g., Bergek, Jacobsson, and Sandén 2008).
} 
not be applicable to smaller developing economies. Klagge et al. (2012) also raised a similar point in their analysis of the Chinese wind energy sector.

Radhika Perrot applied the TIS function approach to analyze the transition of renewable energies in South Africa and India (2012). The paper provides some interesting insights into the case of the South African and Indian technical innovation systems. The article points out that existing frameworks do not sufficiently take into account the context of developing countries and that "there is a pressing need to develop new analytical frameworks when analyzing renewable energy industries in developing countries" (Perrot 2012, 8).

\subsection{Energy Transitions in Developing Countries}

According to the World Bank, 135 countries are considered developing countries, $63 \%$ of the world's countries (The World Bank 2016b). The vast variety of characteristics encapsulated in this category of countries emphasizes the complexity in designing a generic framework for developing countries. Not withstanding, the suggestions proposed in the following section have been made while considering commonalities found in developing countries.

Global projections have estimated that GHG emissions in developing or emerging countries will exceed those of developed countries over the next decades (EIA 2013). These projections emphasize the need for developing countries to divert from the carbon intensive development path that characterized today's developed countries. By 'leapfrogging' over the carbon intensive stage, developing countries can therefore avoid the 'carbon lock-in' experienced in many developed countries (Watson and Sauter 2011). Leapfrogging in terms of technology refers to "the implementation of a new and up-to-date technology in an application area in which at least the previous version of that technology has not been deployed" (Davison et al. 2000, 2).

Given that most technologies have been created in developed countries, a transfer of technology from developed to developing countries must occur to enable leapfrogging (Gallagher 2006). Beyond the transfer of the technology, a successful technology leapfrogging is dependent on appropriate organizational structure changes and appropriate policy reforms (Steinmueller 2001; Perkins 2003). With the list of functions provided by Hekkert et al. (2007) as a starting point, the following section will provide suggestions for how this framework can be adjusted to improve its applicability in developing countries. 


\subsection{Suggestions for the Function Framework}

\subsubsection{Suggestion 1: Function 2 - Knowledge Development and Creating Adaptive Capacity}

Since most technologies were created in developed countries, several authors have stressed the need for placing attention on technology transfer and technological absorptive capacity (Cohen and Levinthal 1990; Arocena and Sutz 2001; IPCC 2001). Most of the absorptive capacity research has focused on the firm level (Criscuolo and Narula 2008). Absorptive capacity at the firm level has been described as the capability of firms to digest and utilize external knowledge (Cohen and Levinthal 1989). A recent study by Peuckert, Bodenheimer and Gandenberger (2016), specially looked at the role of international trade for domestic development of the wind energy sector in developing countries. ${ }^{33}$ Several studies have used various forms of research and development (R\&D) as a proxy to measure absorptive capacity of firms (Flatten et al. 2011). ${ }^{34}$ In the TIS function list chosen for this chapter (Hekkert et al. 2007), however, R\&D is referred to as a proxy for knowledge development for a particular technology (see Table 3.1: function 2). ${ }^{35}$ In this chapter, R\&D will be associated with the development of new technological knowledge domestically, rather than the absorptive capacity of external knowledge. ${ }^{36}$

This does not imply that absorptive capacity should be ignored in the TIS function approach. On the contrary, the ability of countries to assimilate and utilize external knowledge is highly relevant, especially in a developing country context, where transfer of technology is common practice. The focus however, when discussing the transfer of technology, should be on the capability of countries to successfully receive the technology in question. Therefore, a better proxy than $R \& D$ for assessing the absorptive capacity of countries at the receiving end of a technological transfer is their level of technical and higher education (Mowery and Oxley 1995). Beyond formal technical and higher education, learning by Doing,

${ }^{33}$ Their study identified e.g., an increase in domestic patent applications after imports occurred for the specific sector.

${ }^{34}$ See Oltra and Flor (2003) for an example of R\&D input (intensity), and Ahuja and Katila (2001) for an example of R\&D output (patents). See Flatten et al. (2011) for a more extensive list of studies using R\&D as a proxy.

${ }^{35}$ Hekkert et al. (2007) refer to this function as including learning by searching and learning by doing.

${ }^{36}$ The use of R\&D (input and output) to measure the knowledge creation/development function of the TIS is widely used. See Bergek et al. (2008) for an extensive comparative list of TIS functions. 
Using and Interacting (DUI), is another potential mode of learning (Lundvall 1992).

In addition, in the developing country context, attention should also be directed towards the institutional and organizational capacity to receive a new technology. This necessitates a wider focus on the national absorptive capacity, rather than the sole attention of the absorptive capacity of firms. A country's national absorptive capacity can be defined as "the ability to learn and implement the technologies and associated practices of already developed countries" (Dahlman and Nelson 1995, $88)$.

An example where this has been tested is in the study by van Alphen, Hekkert and van Sark $(2008,166)$, which analyzed the diffusion of RETs in the Maldives. They refer to "the development and strengthening of human, organizational, and institutional capacity" as creating adaptive capacity. They chose to replace the knowledge development function with creating adaptive capacity, which was motivated by arguing that the Maldives is not "capable of developing the appropriate technology domestically" (van Alphen, Hekkert, and van Sark 2008, $166)^{37}$

While replacing the knowledge creation function with an adaptive capacity function may have been motivated in the case of the Maldives, there are reasons for caution when discussing a general framework for developing countries. When considering a framework to be used in developing countries, replacing knowledge development with creating adaptive capacity may lead to missing important information concerning knowledge development trends or learning curves. In other words, even though the country under study may not be capable of domestically developing the technology, there may still be on-going knowledge development in the form of research projects or experimentation for a specific technology.

In that respect, it is important to recognize the wide discrepancies between developing countries in terms of their ability to develop new knowledge. For example, expenditure on $\mathrm{R} \& \mathrm{D}$ differs widely among developing countries (low, lower-middle, upper-middle income). In 2012, El Salvador spent $0.03 \%$ of GDP on R\&D, compared to $1.92 \%$ of GDP spent by China (The World Bank $2015 \mathrm{a}$ ). ${ }^{38}$ The varying levels of R\&D expenditure would suggest different capabilities for domestic knowledge development amongst developing countries. Moreover, the capability for knowledge development of a developing country is not static but

\footnotetext{
${ }^{37}$ Van Alphen et al. (2008) began with Hekkert et al. (2007) as a baseline (function) list.

${ }^{38}$ The data include both private and public R\&D expenditure for basic research, applied research, and experimental development.
} 
changes over time, along with its ability to shift from purchasing technologies to adapting or developing technologies domestically.

India and China represent two examples that demonstrate developing countries' ambition to rapidly move from buying technology from industrialized countries to manufacturing and developing it. Within a span of about 10 years, China and India went from importing all wind turbines from foreign companies to having a large domestic manufacturing industry and prominent RET companies (Lewis 2007). Put differently, India and China transitioned from an early formative stage to a growth stage with widespread generation, diffusion and utilization of a new technology within a decade. Incrementally improving their knowledge creation played an essential part in moving China and India from the formative to the growth stage. Earlier literature has also emphasized the importance of recognizing the potential of developing countries of improving technologies or adapting them to the local context (Fransman 1982; Voss 1988).

The examples of the China and India represent an extraordinary rapid transition from an early formative stage to growth stage. This transition may take much longer, or perhaps never fully occur, in other developing countries. However, given the dynamic quality of knowledge development in developing countries, the inclusion of the knowledge development function in future TIS studies should be considered. Moreover, recognizing the influence of knowledge development in cases that have successfully moved from purchasing technology to domestic innovation further motivates this approach.

To conclude, the first suggestion of this chapter is that new knowledge development in a TIS function analysis could be mapped by reviewing R\&D (input and output), but should be analyzed separately from creating adaptive capacity. The former will strictly assess new knowledge being created, which can be analyzed by mapping the number of research projects, R\&D expenditure, and patents relating to the technology in question. Considering including knowledge development in a developing country study may alleviate the risk of missing valuable information concerning knowledge trends. The latter (i.e., adaptive capacity) will evaluate the readiness of a particular country to receive a new technology, which can be done by mapping the existing level of human, institutional and organizational capacity. A proxy for human capacity can be the level of technical and higher education in a country.

\subsubsection{Suggestion 2: Function 6 - Resource Mobilization}

The second suggestion to better adapt the function approach to a developing country context is to split the resource mobilization function (F6) (see Table 3.1) into two categories of resources. Most developing countries receive grants and loans for technical assistance (e.g. for human capacity building) and financing of projects for renewable energies and other mitigation efforts from bilateral and 
multilateral organizations. International financing also involves Foreign Direct Investment (FDI) and other sources such as carbon offsets or specific climate change funds or through the Clean Development Mechanism (CDM).

International investments in clean energy in South America, Middle East and Africa, and Asia and Oceania, grew by more than 400\% between 2005-2009 (Limaye and Zhu 2012). Therefore international resource mobilization towards renewable energies and other mitigation efforts play an important role for developing countries and regions. For example, in May 2014, the Global Environment Facility (GEF) had 25 projects (out of 53 executed by the InterAmerican Development Bank) dedicated to energy efficiency, renewable energy and carbon markets, totaling US\$301 million (IDB 2015a). Previous research has emphasized the potential for CDM to go beyond the financial aspect to also contribute to technology transfer (Popp 2011; Murphy et al. 2015). The issue is however divided, with other studies demonstrating a less pronounced effect on technology transfers from CDM (Das 2011; Spalding-Fecher et al. 2012).

Including an analysis of international resource mobilization towards RET in developing countries would most likely provide a more accurate assessment of function 6. The suggestion is therefore to split function 6 into two categories, (F6a: resource mobilization (government)) and (F6b: resource mobilization (international loans and grants)), in order to analyze domestic resources and international resources separately. The international resource function could be analyzed by examining the availability, size and type (human and/or financial) of international resource mobilization for the technology in question.

\subsubsection{Suggestion 3: Function 7 - Creation of Legitimacy/Advocacy Coalition}

Enhanced legitimacy for a new technology can potentially influence several other functions, such as increased resource mobilization (F6) or improved tax regimes (F5) (Hekkert et al. 2007). Hekkert et al. (2007) have mapped the advocacy coalition/creation of legitimacy function through changes in interest groups and their lobbying activities, as well as public support and acceptance. The lobbying groups in these studies are generally organized, well financed and often with political and economic interests and influence, such as firms, government, knowledge institutions, NGOs or environmental groups. Industries can for example utilize their existing financial strength to form specialized divisions responsible for lobbying upon their behalf (Unruh 2000).

However, lobbying can also occur from groups of people that lack initial organization, financial strength or economic and political influence. This form of lobbying may involve engaged individuals and smaller environmental or university research groups, advocating for clean technologies. Negative lobbying, i.e., resistance to new technologies may also be present in the form lack of social 
acceptance, e.g. resistance to the visual impact of wind energy (Wüstenhagen, Wolsink, and Bürer 2007).

The emergence of the Internet, and subsequently the information age, has revolutionized the way information is shared and accessed. Social media in the form of blogs, twitter, Facebook and YouTube allow for public opinion to be shaped at a speed that was not possible a few decades ago. In recent years, the forming of public opinion on social media has been accredited as an important force for political change, such as the Presidential election of Barack Obama, the 2011 demonstrations in Spain and the 'Arab Spring' (Qualman 2009). Internet access in developing countries has steadily risen in the last decade (see Fig. 3.1), which facilitates expression of public opinion. Clearly a wide discrepancy exists in Internet users across developing countries, e.g. 1/100 people in Burundi to 68/100 people in Malaysia, and the usefulness of this suggestion will need to be decided based on the country under study (The World Bank 2016e).

Figure 3.1 Internet Users in Developing and High Income Countries (per 100 people)

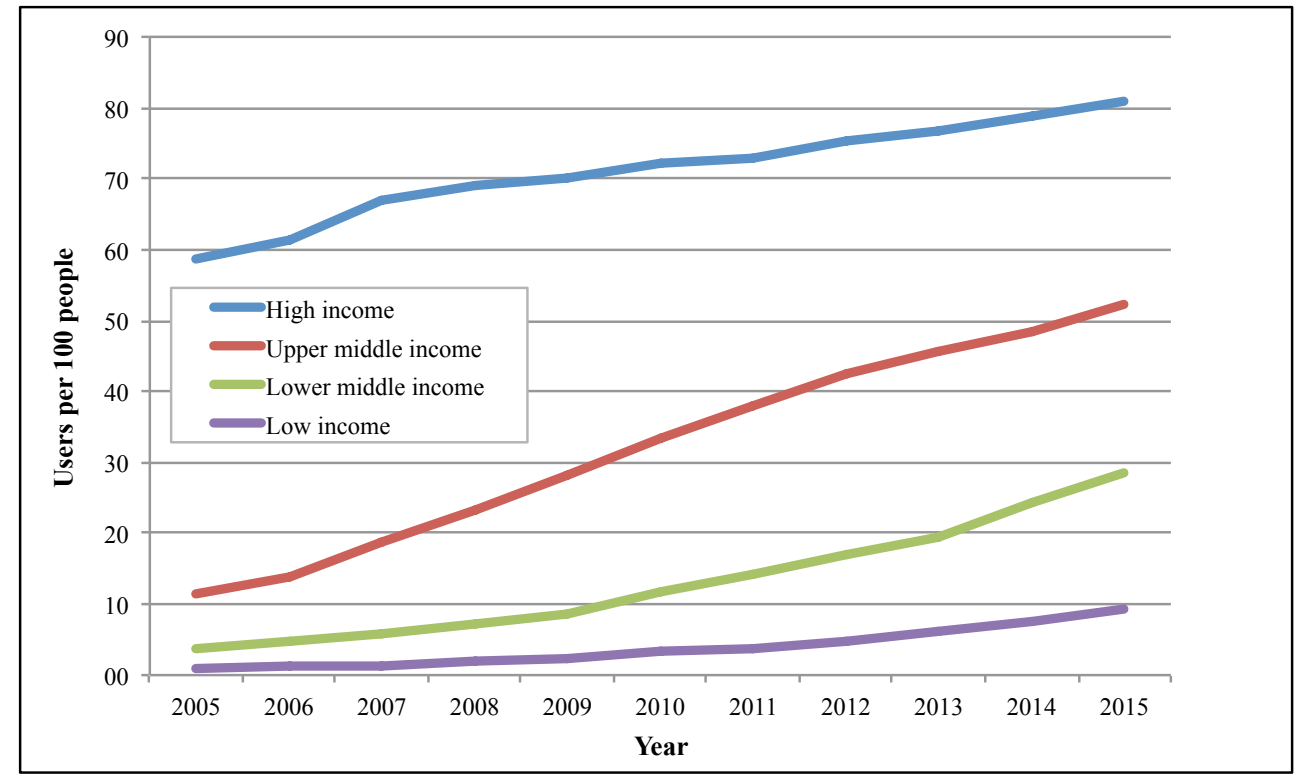

Source: The World Bank, 2016.

However, for the purpose of a general framework, the rise of Internet users in developing countries enable, particularly in upper-middle income countries, for a new form of lobbying (e.g., through social media), which may influence other TIS functions e.g., guidance of the search or resource mobilization. The argument is therefore made that it would be beneficial to separately analyze this relatively new form of lobbying when mapping activities for function 7 (legitimacy and advocacy coalition). The suggestion is therefore to split function 7 into two categories, namely formal (F7a) and informal lobbying (F7b). Formal lobbying refers to 
legitimacy and advocacy coalition exercised by well-established lobbying groups with economic and political weight, while informal lobbying includes advocacy by smaller groups (e.g., environmental groups), associations or individuals. One way to examine informal lobbying can be through changes in public opinion, support and acceptance expressed in social media for the technology in question. This split also holds relevance for future TIS function analyses in high-income countries. A limitation of Suggestion 3 is in developing countries where access to Internet is very low, e.g., low-income countries; the suggested split of function 7 may lose its relevance.

\subsubsection{Suggestion 4: Incorporating the External Landscape}

The fourth and last suggestion relates to the concern that the TIS approach does not sufficiently account for factors beyond the activities of the actors in the focal technological innovation system, i.e., concern of being too inward looking. While it is possible to find a theoretical discussion in the TIS literature concerning the relevance of the wider context, the TIS function approach has not sufficiently included explicit contextual factors as part of the framework that would enable a systematic empirical analysis of the wider context. Therefore, the following section will discuss how the TIS function approach could incorporate lessons from the Multiple-Level Perspective (MLP) about the wider context, as a systematic manner to complement the existing TIS function approach. This section will begin with a general discussion about the TIS and MLP by reviewing the existing literature. This will be followed by a set of explicit contextual factors based on MLP literature along with conditions found in many developing countries that may have an influence on the Focal TIS.

\section{Learning from MLP}

While the MLP and the TIS are both rooted in evolutionary economics and share the same conceptual basis such as path dependency, lock-in and nonlinearity, the two analytical frameworks have formed separately from one another over the last two decades. While the TIS is concerned with institutions, actors and networks to help explain the performance, growth and decline of a technology, the MLP refers to niche, regime and landscape levels when analyzing technological transitions (see Table 3.2). More specifically, the principal postulate of the MLP is that transitions occur from an interaction between the three levels, where landscape levels creates pressure on the regime, which in turn can destabilize existing regimes and provide opportunities for new niche-innovations (Schot and Geels 2008). 
Table 3.2 Integral TIS and MLP Elements

\begin{tabular}{|l||l}
\hline \multicolumn{1}{|c||}{ Technological Innovation System } \\
(TIS)
\end{tabular}

Source: Author tabulation.

\section{Complementary Characteristics}

Despite their disconnected development path, several authors have recognized the various overlapping and complementary characteristics between the TIS and MLP (Coenen and Lopez 2010; Weber and Rohracher 2012). For example, Coenen and Lopez (2010) highlighted that the concepts from one framework include aspects that are considered a weakness in the other framework. For example, while one of the strengths of the TIS is its capacity to analyze dynamic processes (Hekkert et al. 
2007), the analysis of the interaction between actors, institutions and networks is considered a weakness of the MLP (Farla et al. 2012; Smith, Stirling, and Berkhout 2005). In contrast, the lack of analysis of the socio-technical regime and sociotechnical landscape in the TIS framework is considered one of the strengths of the MLP (Markard and Truffer 2008; Weber and Rohracher 2012). Geels et al. (2008, 530) make a similar point by stating that, even though both TIS and MLP utilize levels in their analysis, "it seems fair to say that the MLP has progressed further in conceptualizing interactions between internal and external processes".

The complementing aspects of the two frameworks have resulted in two recent attempts to combine the MLP and TIS (Markard and Truffer 2008; Meelen and Farla 2013). The paper by Markard and Truffer (2008) explains the interaction between the elements of the multi-level framework and the TIS, where it is apparent that the TIS primarily concerns the niche level, while partly analyzing existing regimes but leaving out the potential effects generated by the landscape level (Fig. 3.2). As was briefly discussed in section 3.3.1, fully leaving out the landscape level or wider context is not an accurate description of the TIS approach, but rather a lack of explicitly and systematically analyzing socio-economic landscape factors. While the purpose of this chapter is not to integrate the two frameworks, but rather to propose complementary additions that could benefit the empirical application of the existing TIS framework, the model by Markard and Truffer (2008) emphasizes an important point, namely that the TIS approach can learn from the MLP to explicitly analyze the influence of the landscape level.

As stated before, while the landscape factors have been emphasized to be influencing both existing regimes and the TIS, these factors have been mostly left out of empirical analyses. Two studies that have attempted to incorporate the wider context as shown in Figure 3.2, are Markard, Stadelmann and Truffer (2009) and Wirth and Markard (2011). The former, which empirically analyzed biogas development in Switzerland, emphasized the role of landscape factors, such as changes in environmental laws and climate change; but they do not engage in a deeper analysis concerning the influence of other landscape factors. The latter empirical study solely focuses on the impact of other competitive or supporting TIS, along with a deeper analysis of existing socio-technical regimes. Bergek et al. (2015) highlight the need for conceptualizing the interaction between the focal TIS and its context, while also suggesting four context structures. ${ }^{39}$ Moreover, they emphasize the existing research gap, and one of the main contributions of this chapter, namely the need for understanding contextual structures in developing or emerging countries.

${ }^{39}$ The four context structures suggested are: industrial sectors, geographical territories, other TISs and political structures. 


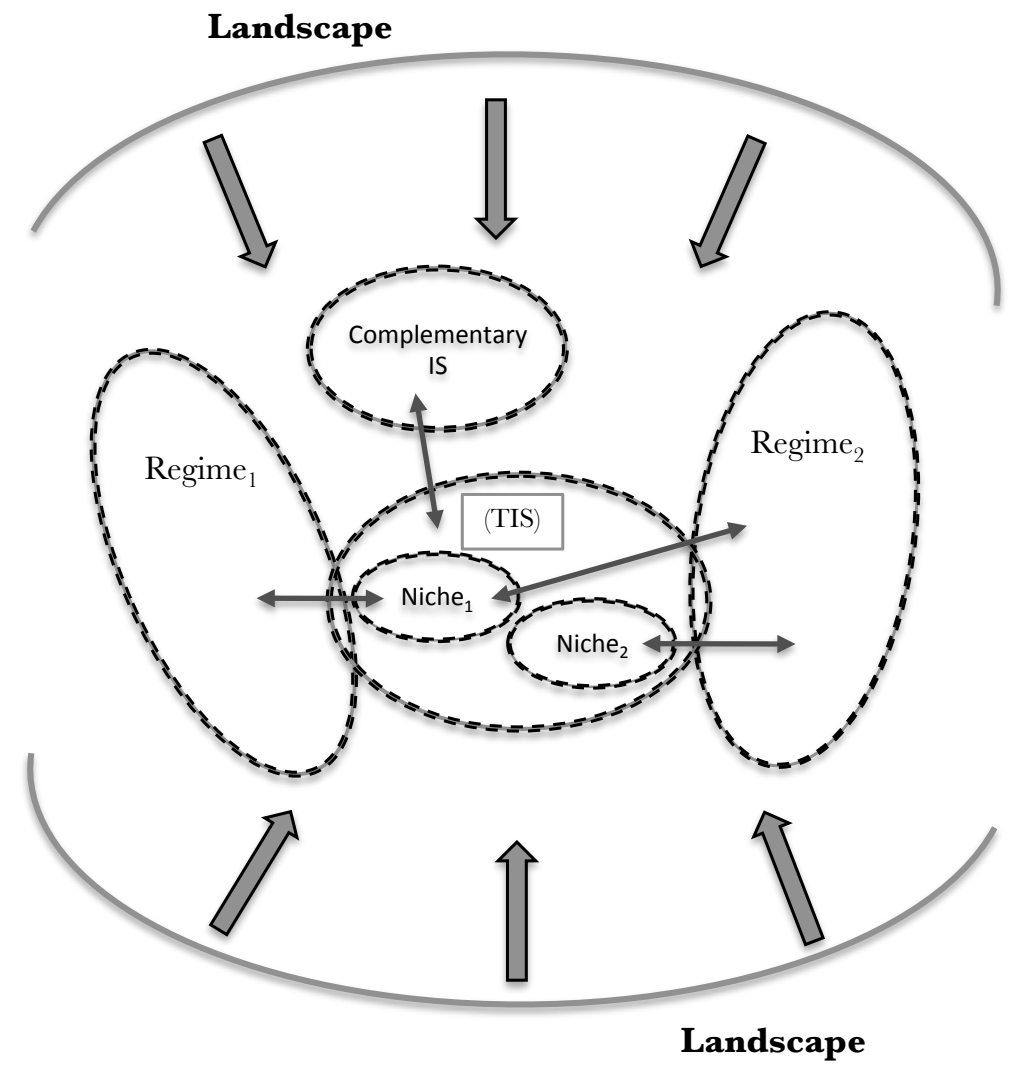

Source: Adapted from Markard and Truffer $(2008,612)$

This study has chosen to use the terminology 'landscape factors', rather than context structures, given that the suggested landscape factors in this chapter will be to a large extent based on a review of the MLP literature. ${ }^{40}$ Using the MLP literature to assist in selecting relevant landscape factors is justified by the more extensive conceptualization made by MLP approach of the wider context (Markard and Truffer 2008).

The next section will discuss landscape factors relevant for developing countries, and which could be systematically integrated as a part of the existing TIS function approach. This will contribute to addressing an existing gap in the literature, while also improving the comprehensiveness of future empirical TIS studies. As

${ }^{40}$ It should be noted that the socio-technical landscape factors is the complete denotation used in the MLP approach. For simplicity, the term landscape factors will be used throughout this chapter. 
previously mentioned, in this chapter, a specific focus is placed on the transition of technologies that could advance sustainable development. Consequently, RETs are central in the discussion and selection of the following landscape factors.

\section{Landscape Factors Influence on TIS in Developing Countries}

Changes in external landscape factors can contribute to positive change (towards sustainable transition) by providing pressure on existing regimes and create possibilities for niche development (Schot and Geels 2008). Smith et al. (2010) argue that while landscape factors can generate opportunities for niche developments they can also negatively influence transition to more sustainable technologies by reinforcing the existing trajectory of a regime. The notion that factors exogenous to the focal TIS influence the "strengths of the functions" is widely accepted and emphasized in the TIS and MLP literature (Bergek, Jacobsson, and Sandén 2008, 579). As depicted in Table 3.2, the landscape or socio-technical landscape has been defined by Geels $(2002,1260)$ as a "set of heterogeneous factors, such as oil prices, economic growth, wars, emigration, broad political coalitions, cultural and normative values, environmental problems". Growing awareness concerning environmental sustainability and the role of renewable energy has also been identified as a landscape process, which by questioning existing regimes can create opportunities for niche development (Smith, Voß, and Grin 2010).

Given the vast complexity and multitude of factors existing in the landscape level it will not be possible to incorporate all aspects. Based on the factors of the sociotechnical landscape raised by Geels (2002), Smith et al. (2010), and others, along with the justifications provided below, six Landscape Factors (LF) are selected to complement the existing TIS function approach in a developing country context. The proposed landscape factors are: Economic Growth, Environmental Awareness, Climate Change, Armed Conflicts, Corruption and Inequality (Unequal Access to Higher Education). The proposed list of landscape factors consists of nationally bound factors along with those transcending the national level.

Certain landscape factors will also be relevant in developed countries. However, as previously mentioned, including a more comprehensive landscape factor analysis is particularly relevant when performing a TIS analysis in developing countries. This position is based primarily on two specific aspects found in many developing countries. The first aspect relates to the reasoning made by Rob Raven (2005, 2010), that system components (functions) are not fully developed in the early formative stage of a system, which results in a larger influence from exogenous factors. Since TIS in many developing countries can be described to be in an early formative stage, an emphasis on exogenous factors (landscape factors) is justified. This does not suggest to imply that exogenous factors will necessarily discontinue their influence on the TIS after a technology has left the formative stage and entered the growth stage. The second aspect is that some of the landscape factors 
that are being proposed are generally stronger and more dominant in many developing counties, e.g., corruption, unequal access to education and armed conflicts. This higher prevalence of landscape factors and how they may influence the TIS functions in developing countries will be discussed in greater length below.

\section{Landscape Factor 1: Economic Growth}

A tight coupling between increased economic activities and energy demand has been demonstrated (D. I. Stern 2004). With four countries (Saudi Arabia, Iran, Iraq and Kuwait) responsible for about half for the World's oil reserves, price volatility for oil has contributed to increased long-term energy insecurity (Sadorsky 2009). In the interest of tackling energy insecurity and sustaining economic growth, energy production from renewable energy sources offers an alternative to these concerns (Dincer 2000; Sadorsky 2009). Given that the majority of the increase in energy demand in the future will come from developing or emerging countries, it is relevant to better understand the influence of economic growth on a developing country focal TIS system. ${ }^{41}$

Economic growth is also correlated with an increased availability of government resources as a result of higher tax revenues. Increased availability of government resources does not necessarily result in more subsidies, tax reductions, or $R \& D$ investments beneficial for RETs, as this also depends on aspects such as political will, government policies, strength of advocacy groups, etc. However, it is fair to assume that the likelihood for more resources being mobilized towards RETs will be improved with additional public and private resources available.

While increased economic growth contributes to government revenues, a decline in economic growth due to domestic and/or international events may also prove conducive to technological change. Economic growth may in fact generate inaction from dominant actors with the preference of preserving the existing regime, while an economic decline or recession may create pressure on government and existing regimes for change (Geels 2013). The 2008 financial crisis, for example, arguably provided a 'window of opportunity' for transitioning towards more sustainable energy sources during the early years of the crisis (Geels 2013, 93). In other words, a financial crisis may enhance the demand for change from the incumbent system, which could contribute to legitimizing (function 7) new technologies such as RETs. The opposite may also occur, where a financial crisis may redirect attention away from sustainability issues towards shorter-term concerns such as employment opportunities and securing personal income.

${ }^{41}$ China and India alone are expected to drive $45 \%$ of the World's increased energy demand between 2005-2030 (IEA 2007). 
Whatever the impact of economic growth, i.e., positive or negative, its potential influence as a landscape factor on technological transition justifies its inclusion in the landscape analysis. The changes in economic growth can be mapped by tracking changes in the Gross Domestic Product (GDP) and domestic and international economic events, along with their influence on TIS functions such as resource mobilization (F6) and legitimacy creation (F7).

\section{Landscape Factor 2: Environmental Awareness}

"Growing environmental awareness is a socio-cultural development that can be considered a landscape process, and which is questioning the performance of multiple regimes, whilst generating opportunities for niches" (Smith, Voß, and Grin 2010, 441). The United Nations Environmental Programme (UNEP) describes environmental awareness as:

the ability to emotionally understand the surrounding world, including the laws of the natural environment, sensitivity to all the changes occurring in the environment, understanding of cause-and-effect relationships between the quality of the environment and human behaviour, an understanding of how the environment works as a system, and a sense of responsibility for the common heritage of the Earth, such as natural resources - with the aim of preserving them for future generations (UNEP 2016, chap. 4.2).

In this chapter, the inclusion of environmental awareness as a landscape factor for transition of RETs considers this definition of environmental awareness to be a state of mind, which facilitates an understanding of the mitigating role that RETs play, e.g. on climate change and air pollution. The inclusion of environmental awareness as a landscape factor is motivated through the assumption that an increase environmental awareness amongst actors such as civil society and government may lead to increased pressure on existing energy producing regimes to diversify towards cleaner technologies. Even though environmental awareness can be seen as a 'softer' 'behind the stage' factor, when compared to concrete policies or financial incentives directed at RETs development and diffusion, convincing arguments exist for not omitting the potential influence of environmental awareness in the context of socio-technical transitions, as will be shown in the text below. Environmental awareness is discussed further in Chapter 5 .

An increase in environmental awareness in civil society may give rise to influence on both government and actors in the energy sector to invest more in clean technologies. For example, Guha (1999) has documented the potential impact that public environmental awareness can have on environmental policies and regulations. The influence can be consumer-driven (i.e., demand for energy produced from RETs) and/or through pressure, support or acceptance of 
environmental policies exercised by organized environmental groups or individual citizens (informal lobbying). ${ }^{42}$

Evidence from environmental psychology research has shown a link between environmental awareness and a higher preference for utilizing energy produced from renewable energy technologies (see e.g., De Groot et al. 2012; Steg, Dreijerink, and Abrahamse 2005; Van der Werff, Steg, and Keizer 2013). While, the just mentioned empirical studies were performed with data from Hungary and the Netherlands, there are several reasons for including the environmental awareness influences in developing country contexts as well. Firstly, large crossnational studies have shown that concern for the environment is equally important for developed and developing countries, including minor differences in the willingness to pay to protect the environment (Riley E. Dunlap and Mertig 1995). ${ }^{43}$ Secondly, the theory of post-materialist values (Inglehart 1977; Inglehart 1990; Inglehart 1997), which has as a central argument that people of affluence and education are who primarily exercise environmental concern, does no longer exclusively apply to high-income industrialized countries. As shown in Figure 3.3, the GDP per capita income level has significantly risen in many developing countries. As a comparison, GDP per capita in upper-middle income countries, based on purchasing power parity (PPP), is almost at the same level as it was for high-income countries in the early 1990s (The World Bank 2016d).

In a similar fashion, primary and secondary enrollment rates in developing countries have increased across developing countries, with primary enrollment above $80 \%$ in all income categories (Fig. 3.4). This is not to say that the arguments made by Inglehart about post-materialist values are irrelevant, but rather to stress that affluence and education levels in many developing countries have improved significantly over the last decades.

Following the logic of post-materialist value theory, the rise in GDP per capita and education levels in developing countries suggests that the relevance for including environmental awareness in a developing country study is steadily rising. Moreover, the falling prices of RETs, such as wind and solar power, further enhance their competitiveness against conventional energy alternatives (IRENA 2015). In the context of assessing the potential influence of environmental

${ }^{42}$ See for example, P.C. Stern et al. (1999) or P.C. Stern (2000), for a detailed discussion about the Value-Belief-Norm (VBN) theory and possible avenues of influence derived from environmental awareness: i.e., Environmental Activism, Non-Activism, PrivateSphere environmentalism and Organizational actions.

${ }^{43}$ The data used in Dunlap and Mertig (1995) are based on the Health of the Planet Survey (1993), which included 22 developing and developed countries. 
awareness on the focal TIS, it helps to reduce a barrier, namely costs, from the equation.

Figure 3.3 Change in GDP per capita (PPP) in developing countries (1990-2014)

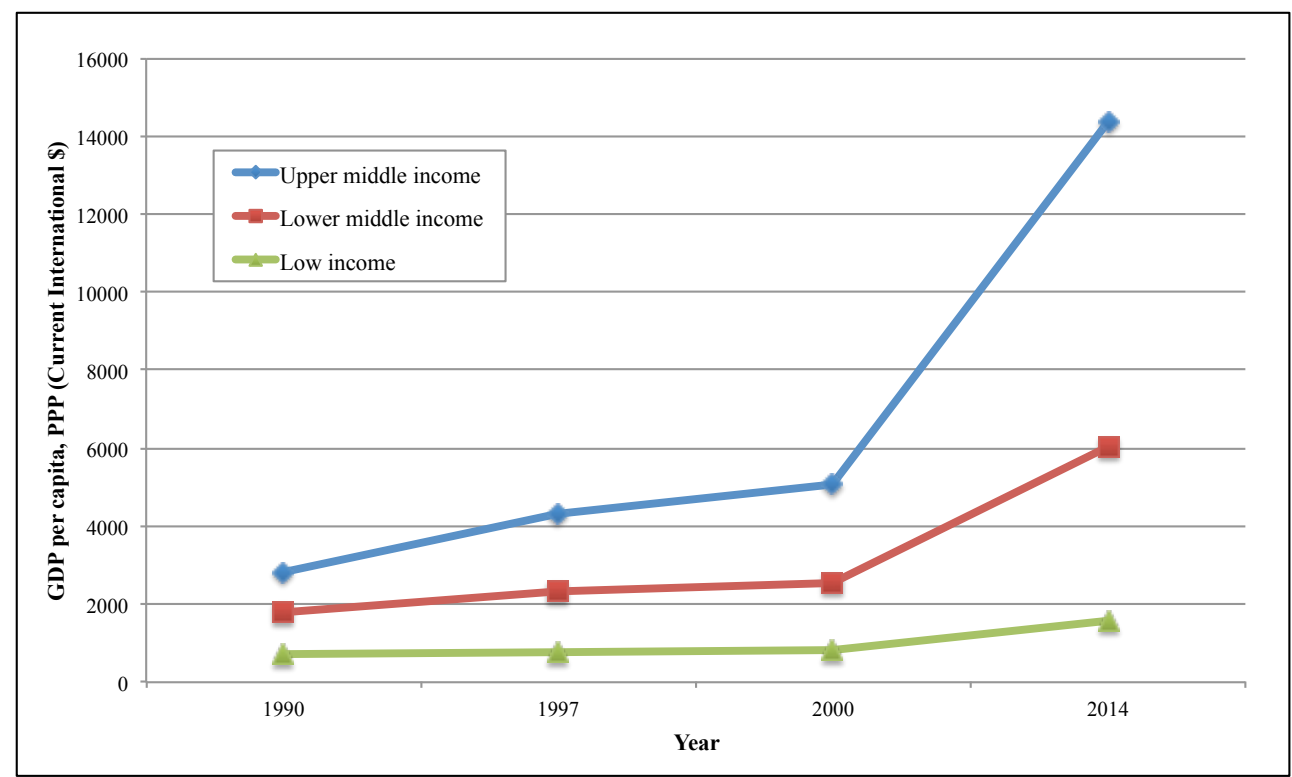

Source: The World Bank, 2016.

Finally, while an increasing environmental awareness can have a positive influence on emerging RETs, the absence of awareness in a population can slow down the diffusion of RETs. Specifically, the lack of awareness for new energy technologies, e.g. awareness about the benefits and costs of RETs, has been stressed as a significant barrier in developing countries (Reddy and Painuly 2004; Kennedy and Basu 2013; Luthra et al. 2015). For example, in an Indian study of barriers to RET adoption, "lack of consumer awareness to technology" together with "lack of sufficient market base" were found to be the most important market barriers, in front of aspects such as "lack of paying capacity" (Luthra et al. 2015, 770).

Awareness of the benefits and actual costs of RETs is an essential first step for both informal lobbying (F7b) carried out by individual citizens or organized environmental groups, and for consumer-driven demand to occur. Therefore, tracking changes in environmental awareness can reveal barriers or drivers at the landscape level and can contribute to making the TIS function approach more comprehensive. Environmental awareness can be analyzed by mapping changes in societal trends, which can include frequency in online discussion forums regarding sustainability and the role of RETs, changes in participation in environmental programs (higher education), changes in overall environmental awareness among 
actors from existing national surveys, as well as the perceived influence of environmental awareness on system functions.

Figure 3.4 Change in Primary and Secondary Enrollment Rates in Developing Countries

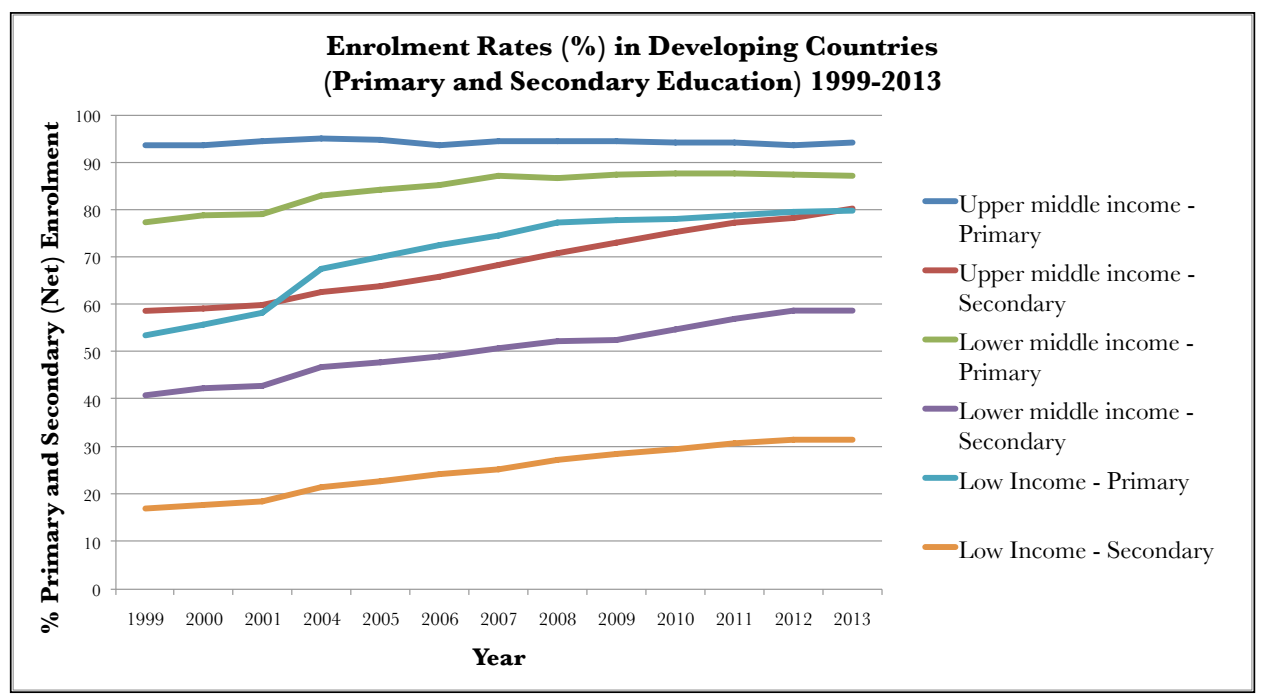

Source: The World Bank, 2016.

\section{Landscape Factor 3: Climate Change}

Climate change is impacting nations in different ways, from the intensification of precipitation events leading to flooding in some parts of the world, to increased heat waves and droughts in other parts, for example (IPCC 2012). The impacts of climate variability and change may influence technological transitions in several ways, affecting other landscape factors as well as TIS functions. Climate change may influence a technological transition by creating a need for mitigation (reduction of GHG emissions) and/or adaptation (reduction of the vulnerability of the system to the impacts of climate change) efforts.

First, the economic costs of environmental disasters caused by an intensification of extreme weather events are placing a strain on businesses (LF1: Economic growth) and government resources (F6a: Resource Mobilization), in both developing and developed countries. According to the Stern review of 2006, extreme weather could, by the middle of this century, amount to losses of $0.5-1.0 \%$ of global GDP per year. The 2003 heat wave in Europe alone contributed to approximately 35,000 deaths and a loss of approximately US\$ 15 billion from reduced agricultural yields (N. H. Stern 2007). Conversely, bilateral and multilateral aid grants and loans for climate change mitigation and adaptation will positively influence available government resources (Resource Mobilization: F6b). 
Second, the human and economic costs of climate change can induce awareness (LF2), which can contribute to mobilizing support and creating legitimacy (F7) for a need to modify and diversify the energy matrix. Increased awareness about climate change, however, can take different forms and lead to different transitions. In some areas, the impacts of climate variability and change on the hydrological cycle, for example, may highlight the vulnerability of current energy systems, particularly those energy systems highly dependent on hydropower. As it will be shown in Chapter 4, in the case of Colombia, a country whose energy matrix is composed mostly of hydropower, droughts induced by El Niño phenomenon have put a strain on the hydropower generation opening the space for discussions on the need to diversify the energy matrix. The diversification, however, will not necessarily be towards cleaner sources of energy, but could instead increase fossil fuel-based energy production through thermoelectric power plants. The increased awareness can also be about the risks of inaction and thus a space may be opened towards finding alternative cleaner sources of energy, such as RETs.

Thirdly, the increased attention towards the severity of a changing climate has resulted in several international agreements and commitments to curb GHG emissions, partly by increasing the share of RETs in the energy mix. 43 These international agreements, such as the Paris Climate Agreement in 2015, may influence the targets set by governments (F4: Guidance of the Search) and if covered in mainstream media raise public awareness (LF2) concerning the importance of climate change mitigation and adaptation. This third point is particularly important to reduce the risk of taking measures that may increase the resilience of the system to climate variability and change, but that may diversify the energy system towards dirtier sources of energy, instead of RETs. Even in countries with limited GHG emissions, and where their mitigation efforts may not significantly influence global emissions, international agreements, including the mobilization of international funds, may serve as incentives to invest in mitigation efforts, such as investing in RETs.

In short, climate change as a landscape factor has the potential to support RETs diffusion in various ways. Mostly, the impacts of climate change can weaken the existing regime, opening the space for niche growth. As mentioned above, attention needs to be given, and the appropriate policies need to be put in place, to ensure that the impacts of climate change do not lead to short-term decisions of moving towards dirtier but climate resilient sources of energy (e.g., coal and oilbased electricity production). International climate agreements and international funding options, such as the Green Climate Fund and the Clean Development Mechanism (CDM), can encourage countries to invest in alternative sources of energy that contribute both to mitigation and adaptation. This landscape factor can be analyzed by mapping climate change related events and corresponding costs along with international and domestic commitments to alter the energy mix towards sustainable sources of energy. 


\section{Landscape Factor 4: Armed Conflicts}

Any form of violent conflict, whether state-based or non-state based is defined as conflict when at least 25 battle-related deaths have occurred in one conflict. Under that condition, a state-based armed conflict can be further defined as a "contested incompatibility that concerns government and/or territory where the use of armed force between two parties, of which at least one is the government of a state" (UCDP 2014). ${ }^{44} \mathrm{~A}$ more detailed discussion regarding the different forms of conflicts and the varying impacts they pose on populations is beyond the scope of this chapter. ${ }^{45}$ In this chapter, armed or violent conflicts will be used when discussing their possible influence on the success or failure of technological transitions.

In 2013, about 1.5 billion people across the world were impacted by violent conflicts (The World Bank 2013). A total of 38 armed conflicts, with the majority taking place in Africa (13), followed by Asia (12), Middle East (7), Europe (5) and Latin America (1) were reported during 2012 (Armengol et al. 2013). Larger macro-economic effects from armed conflicts have been widely studied and generally demonstrate a reduced income per capita, increased military expenditure, technological degeneration, damaged infrastructure as well as reduced human capital, innovation and economic growth (Abadie and Gardeazabal 2003; Collier and Duponchel 2013; Brück, Naudé, and Verwimp 2013). For example, one study (Collier 1999) estimated an annual reduction of 2.2\% GDP in countries affected by conflict.

The direct impact that armed conflicts have on entrepreneurial activities has been less studied, and has so far yielded contradictory results. Ongoing conflicts have been found to provide a worsened business environment in the form of higher uncertainty and transaction, reduced markets and lucrative investment prospects, which can contribute to reduced entrepreneurial activities (Naudé 2007). However, a study by the International Labour Organization (ILO) and the Global Entrepreneurship Monitor (GEM) found an increase in new firms start-ups during the crises (Brück, Naudé, and Verwimp 2013). Moreover, there are examples throughout history for how technological innovations have occurred during armed conflicts, e.g. the development of the Internet or the invention of firearms (Humphreys 2003). Whether an armed conflict will obstruct or provide opportunities for entrepreneurial activities within renewable energy sectors, e.g. in the form of directed military R\&D spending towards RETs would have to be

\footnotetext{
${ }^{44}$ Non-state based conflict is defined as "the use of armed force between two organized armed groups, neither of which is the government of a state" (UCDP 2014).

${ }^{45}$ For more details on types, cases and trends of armed conflicts, see for example: Scherrer, 2003.
} 
scrutinized on a case by case basis. The possible influence (positive or negative) of armed conflicts on entrepreneurial activities, human capital, economic growth and technological innovation, however, justifies its inclusion as a landscape factor to complement the TIS function analysis.

By including armed conflicts in conjunction with the TIS function analysis, the aim is to better understand their influence on technological transitions by shedding light on the following type of questions: Does the cost of the conflict influence the government expenditure to the extent of hampering resource mobilization towards RETs (F6a: Resource mobilization)? Does the conflict contribute to levels of insecurity that have obstructed potential new developments of renewable energy infrastructure (F1: Entrepreneurial activity)? Does the conflict contribute to an increase in technological innovation and development? This landscape factor can be analyzed by mapping the cost of the armed conflict (as percentage of government expenditure), mentioned number of entrepreneurial activities canceled or never initiated, or new technological innovations initiated, as a consequence of the conflict.

\section{Landscape Factor 5: National Corruption}

Transparency International (2015) defines corruption "as the abuse of entrusted power for private gain", and can involve various forms such as embezzlement, state capture, bribery, rent seeking, and nepotism. Corruption exists to some extent in all nations around the world, however, it is often more prevalent in developing countries. The presence of corruption has been argued to negatively affect democratic systems and rule of law, social trust among citizens, public resources, economic growth, and inequality (Transparency International 2014).

For the purpose of analyzing corruption as a landscape factor for the TIS, this chapter proposes to concentrate on the influence that corruption may have on entrepreneurial activities (F1), resource mobilization (F6), economic growth (LF1), and unequal access to quality education (LF6). Globally, it has been estimated that $5 \%$ of the world's GDP is lost to corruption each year, with bribes comprising approximately US\$ 1 trillion. According to the African Union, in 2002 about US\$ 148 billion constituting approximately $25 \%$ of GDP of African States was lost to corruption (OECD 2014). The loss of public revenues due to corruption in turn influences the amount of funds that can be dedicated towards $R \& D$, subsidies, investment and infrastructure that are essential for an emerging technology. Moreover, by distorting market mechanisms such as free competition, corrupt countries receive about $5 \%$ less investments, and the cost of doing business is on average 10\% higher (OECD 2014).

This landscape factor can be analyzed by reviewing the estimated loss in public resources (percentage of GDP), mentioned canceled/never initiated entrepreneurial activity, and estimated impact on economic growth, as a result of corruption. 
The inclusion of unequal access to education as a landscape factor, is motivated by the central role of knowledge creation in relation to TIS system development. As put by Lundvall $(1992,1)$, "it is assumed that the most fundamental resource in the modern economy is knowledge and, accordingly, that the most important process is learning". Lundvall $(1992,1)$ further emphasizes the "historical establishment" as well as the "institutional and cultural context", in order to understand learning as a "socially embedded process". In many developing countries, institutions have developed in a direction to primarily benefit the elite, which has contributed towards less inclusive economic and political institutions (Acemoglu and Robinson 2012). In wider system analyses (e.g. national innovation systems), unequal access to education in developing countries has been credited as one of the central aspects for explaining their "lack of technological congruence" (Soete, Verspagen, and Weel 2010, 1172). ${ }^{46}$ In the systems of innovation literature, the national education system is commonly discussed in the wider NIS, which can be considered exogenous to the focal TIS and its functions. With the inequality component embedded in the national education systems in developing countries, it would be reasonable to treat it as landscape factor, rather than as an actor within the focal TIS. By including this landscape factor the aim is to bring clarity to the relationship between the national education system and technical innovation system in a developing country context.

As shown in the environmental awareness discussion (LF2), in the last decades, access to primary and secondary education has significantly improved in most of the developing world (see Fig. 3.4). Access to higher education, however, remains limited and restricted to a privileged elite in many developing countries, leaving a large portion of the population without access to higher education. The latest available data (2013) show that in low, lower middle and upper middle-income countries the total gross enrollment rates at the tertiary level are $8 \%, 22 \%$ and $35 \%$, respectively (The World Bank 2016a). These tertiary enrollment rates can be compared to $74 \%$ in high-income countries (The World Bank 2016a).

The dual role of the education system, namely generating human capital (individual learning) while contributing to new knowledge, gives it a central role in the knowledge and learning environment (Edquist 2001). If a large part of the population is excluded from higher education, it may contribute to shortages in human capital and reduced learning to an extent that obstructs the focal TIS in

\footnotetext{
${ }^{46}$ Abramovitz introduced technological congruence in 1986 when discussing catching-up countries and absorptive capacity (Soete, Verspagen, and Weel 2010).
} 
question. ${ }^{47} \mathrm{~A}$ reduced possibility for generating awareness for the environment (LF2) and sustainable development is another potential consequence of low access to higher education (Lambrechts et al. 2013). Accordingly, the aim of including this landscape factor is to reveal its influence on knowledge development (F2a), adaptive capacity (F2b), entrepreneurial activities (F1) and other landscape factors. This landscape factor addresses questions such as how does unequal access to vocational and higher education influence human capacity and learning? And how does it influence the focal TIS? More specifically, in what way does unequal access to education influence the availability of researchers, engineers, project managers, and technical personnel? This landscape factor can be evaluated by mapping changes in access to higher education (post-secondary, vocational and tertiary education (including research), along with expressed mismatch (lack of trained personnel) by the industry of the technology in question, as a result of lack of access to quality education.

\subsection{Interactions between Landscape Factors and Functions}

A rationale for including the above mentioned landscape factors into the analysis is to understand the different pressure that they assert on the focal TIS in question. The suggested landscape factors can be nationally bound or transcend the national level. Economic growth and climate change are clearly landscape factors that operate across the national boundary. The performance of the national education system and the level of national corruption are nationally bound landscape factors. Armed conflicts or environmental awareness are relevant to analyze from a nationally bound perspective, i.e., how they influence the country under study, but may be transnational in nature. For example, the long lasting armed conflict in Colombia is predominately a domestic conflict, but it has involved neighboring countries, such as Venezuela and Ecuador, when armed groups have crossed the borders or displaced population has moved to these neighboring countries, for example. With the emergence of Internet and access to information across the national boundary, it can be debated whether domestic environmental awareness is linked with a changing global awareness, resulting from international environmental campaigns and movements.

Widening the analytical lens by systematically incorporating landscape factors to complement the TIS functional approach could assist in explaining the slow

\footnotetext{
${ }^{47}$ Note that in addition to universities, new knowledge is also created in research institutes and research oriented firms (Edquist 2001). R\&D can be carried out within firms or academia, this has been classified as search and exploration, respectively (Soete, Verspagen, and Weel 2010). Lundvall (1992) has also emphasized learning through Doing, Using and Interacting (DUI) as opposed to the scientific approach.
} 
diffusion of RETs in many developing countries. In addition, the objective is to determine if the landscape level influence is having a reinforcing or weakening effect on the incumbent system outcomes. In the MLP literature, landscape factors can create opportunities for change, while reinforcing factors do not contribute to innovation (Geels and Schot 2007).

The different landscape factors can induce reactions (disruptive or reinforcing) amongst different actors, e.g. incumbent regimes and/or policy makers. These reactions can influence the conditions for the focal TIS, or concrete changes in the TIS functions. Figure 3.5 provides examples of potential reactions induced by the selected landscape factors.

Figure 3.5 Examples of Influence from the Landscape Level

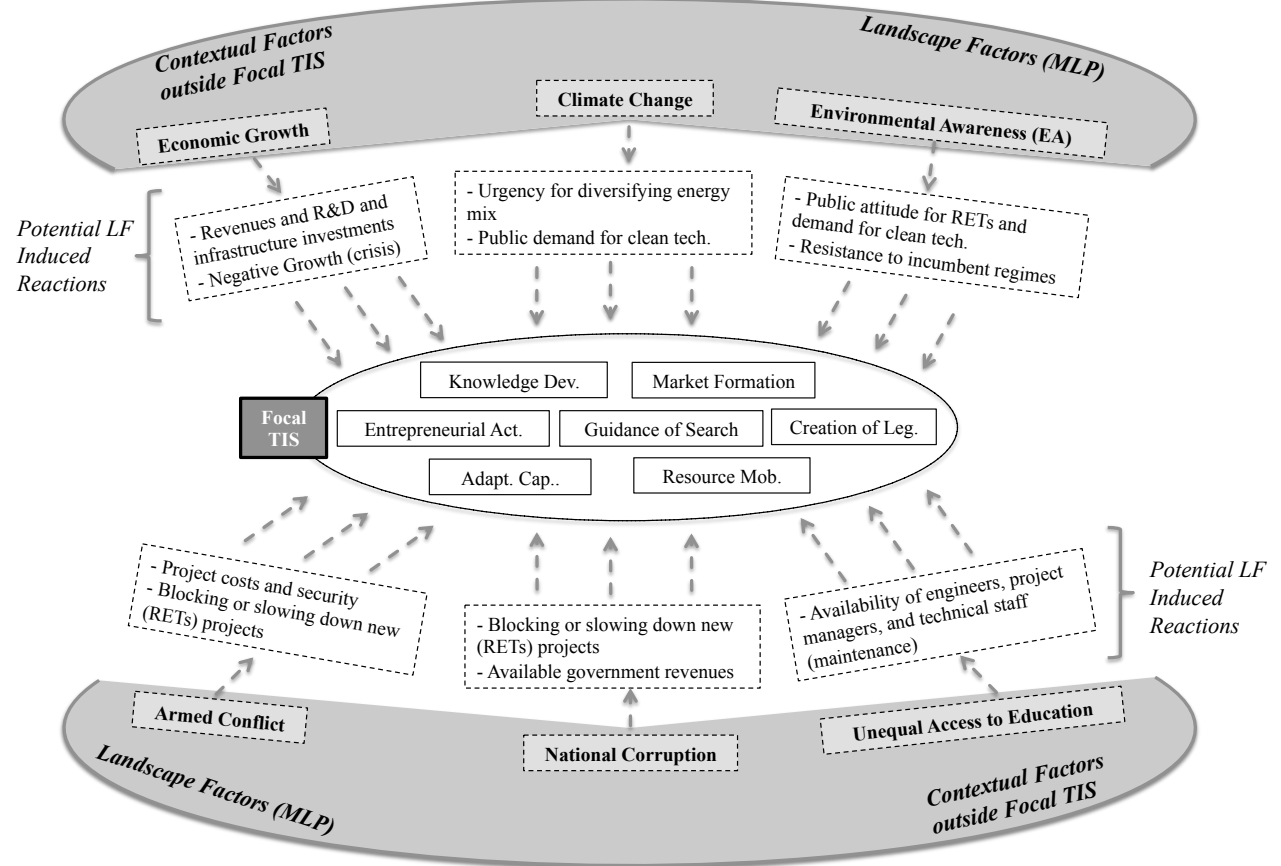

Source: Author

Note: This figure draws upon the compilation of interdisciplinary literature discussed in this chapter.

It is important to note that the landscape factors are macro-level factors operating outside the focal TIS, and do not exclusively influence specific technology sectors. Instead, the landscape level influence should be seen as an overarching umbrella, which can produce potential spillover effects that can prove conducive or impeding for a specific technology. The previous section, discussed the potential influence that the proposed landscape factors can have on TIS functions from a theoretical perspective. Based on these arguments, Table 3.3 provides a summary of the 
potential influence that different landscape factors may pose on specific TIS functions. Table 3.3 is not suggested to be an exhaustive list of potential influence, but rather an initial guide for future empirical studies that opt to include the landscape factor influence into the analysis.

The landscape factor-induced influence on TIS functions, could then initiate reinforcing actions between different functions, providing positive feedback loops. These feedback loops between the functions can lead to a positive momentum that ultimately improves the performance of the system as a whole. ${ }^{48}$ The feedback loops between functions have been covered in previous literature and will not be discussed further in this chapter (S. Jacobsson and Bergek 2004; S. Jacobsson and Bergek 2006; e.g., Hekkert et al. 2007). Instead, examples of possible reinforced influence between landscape factors will be discussed below (see Fig. 3.6).

Table 3.3 Possible Landscape Factor Influence on Specific System Functions

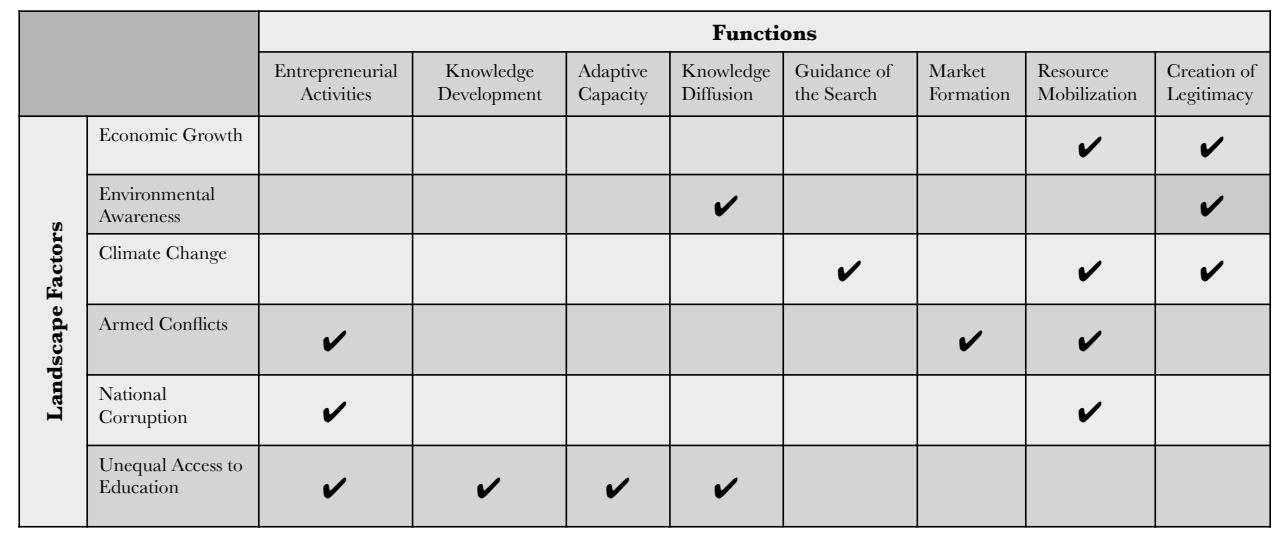

Source: Author (based on findings discussed in this chapter)

Note: Black check marks indicate possible interaction

\section{Landscape Factors Reinforcing Effects}

While the main focus of this chapter is on the influence that landscape factors may have on a focal TIS and its functions, evidence from existing literature suggests that reinforcing and weakening influence is occurring between landscape factors. The reactions or activities generated by one landscape factor may have reinforcing or weakening influence on another landscape factor. A non-exhaustive summary of possible influence between landscape factors is displayed in Figure 3.6.

${ }^{48}$ Note that negative feedback loops are also possible, which could instead limit growth. 
In this chapter, the potential influence of the individual landscape factors on TIS functions has been emphasized. As it follows, the landscape factor to landscape factor (LF- LF) influence can contribute to shaping a more or less beneficial external landscape for technological innovation. Again, the selected landscape factors should be seen as a first step to systematically mapping out the wider context, and its weakening or reinforcing influence for a given focal TIS at an early formative stage. The focus of this chapter on environmental sustainability is reflected in the suggested framework. While landscape factors such as climate change or environmental awareness have been included with RETs in mind, other mitigating technologies, such as carbon capture and storage (CCS) or energy efficient technologies could also benefit from the suggestions made in this chapter. It is also the aspiration that the reflections made concerning the processes and landscape factors of the Technological Innovation System in developing countries will also benefit future empirical studies focused on technologies beyond the sustainability niche.

Figure 3.6 Reinforcing or Weakening Influence between Landscape Factors

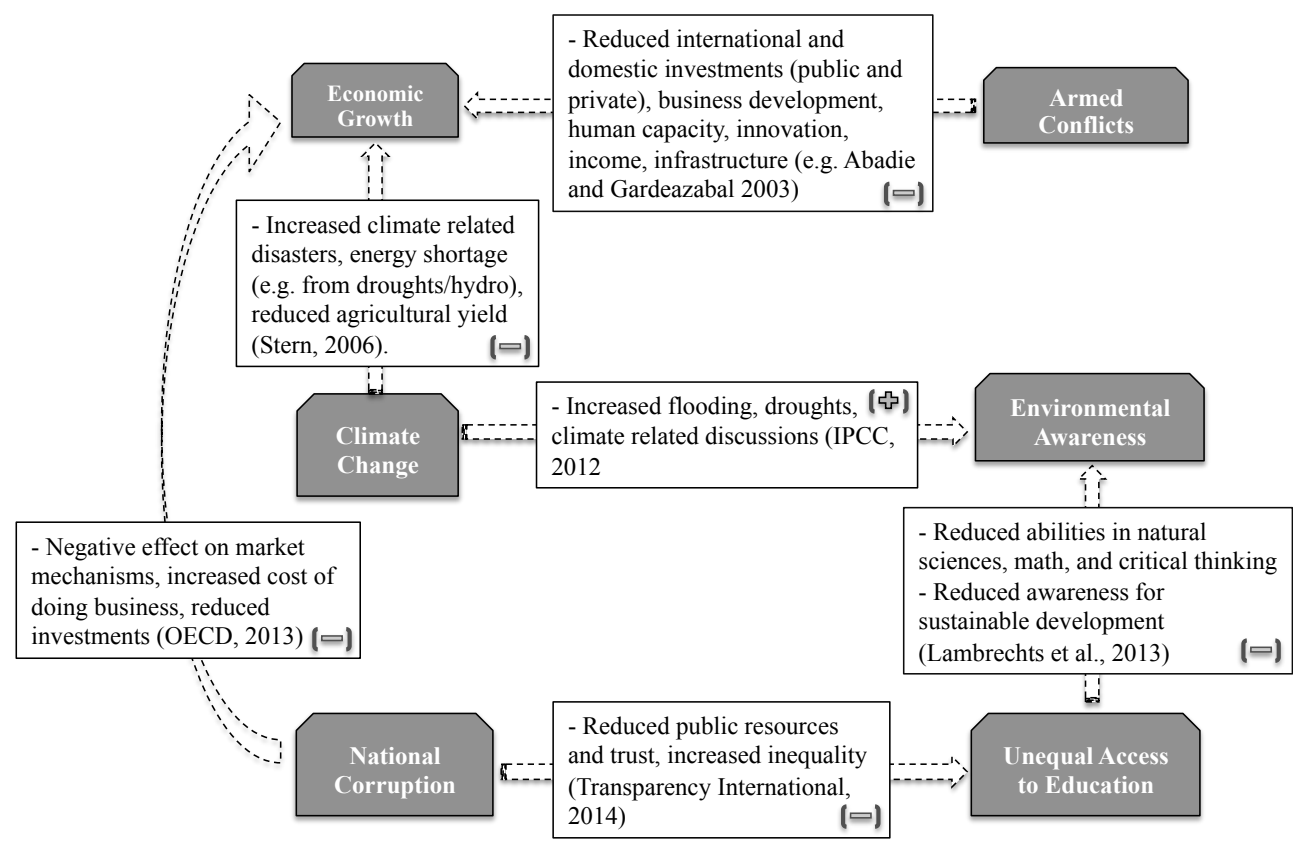

Source: Author

Note: Generated reactions are displayed in the white box. Reinforcing influence is denoted by $(+)$ and the weakening influence by $(-)$.

\subsection{Proposed Framework}

The following section offers a summary of the suggestions provided in this chapter in the form of a proposed framework. Based on previous literature on the TIS approach, empirical studies in developing countries and lessons from the MLP, 
four suggestions have been made. These suggestions show how the existing TIS framework can be elaborated upon to enhance its comprehensiveness and broaden the applicability of the framework to developing countries.

Table 3.4 Suggested Framework and Possible Indicators

\begin{tabular}{|c|c|c|}
\hline \multicolumn{2}{|c|}{ System Function } & \multirow{2}{*}{$\begin{array}{l}\text { Possible Indicators } \\
\text { Started and planned projects, experimentations and } \\
\text { activities from incumbent actors for new technology }\end{array}$} \\
\hline F1. & Entrepreneurial Activities & \\
\hline F2.a & Knowledge Development & $\begin{array}{l}\text { Planned and ongoing research projects and patents } \\
\text { filed; trends in publications relevant to the technology }\end{array}$ \\
\hline F2.b & Creating Adaptive Capacity & $\begin{array}{l}\text { Human (level of technical and higher education), } \\
\text { organizational, and institutional capacity to receive } \\
\text { new technology }\end{array}$ \\
\hline F3. & Knowledge Diffusion & $\begin{array}{l}\text { Number of workshops, conferences, or other forums } \\
\text { (social media) organized about the new technology }\end{array}$ \\
\hline F4. & Guidance of the Search & $\begin{array}{l}\text { Expectations set by government or industry for new } \\
\text { technology in terms of regulations and specific targets }\end{array}$ \\
\hline F5. & Market Formation & $\begin{array}{l}\text { Market entry assistance for new technologies } \\
\text { (protected space ('nursing'), new environmental } \\
\text { standards, tax exemptions, feed-in tariffs, etc.) }\end{array}$ \\
\hline F6.a & $\begin{array}{l}\text { Resource Mobilization } \\
\text { (Government) }\end{array}$ & $\begin{array}{l}\text { Resources allocated by government or industry } \\
\text { towards R\&D (Human Capacity) or subsidies for the } \\
\text { new technology (financial). }\end{array}$ \\
\hline F6.b & $\begin{array}{l}\text { Resource Mobilization } \\
\text { (International loans and grants) }\end{array}$ & $\begin{array}{l}\text { Availability, size and type (human and/or financial) of } \\
\text { international resource mobilization for new tech. }\end{array}$ \\
\hline F7.a & $\begin{array}{l}\text { Creation of } \\
\text { Legitimacy/Advocacy } \\
\text { coalition (formal lobbying) }\end{array}$ & $\begin{array}{l}\text { Change in lobbying activities by formal and } \\
\text { established lobbying groups with economic and } \\
\text { political weight }\end{array}$ \\
\hline F7.b & $\begin{array}{l}\text { Creation of Legitimacy } \\
\text { (informal lobbying) }\end{array}$ & $\begin{array}{l}\text { Changes in public opinion, support and acceptance for } \\
\text { new technology in social media }\end{array}$ \\
\hline \multicolumn{2}{|c|}{ Landscape Factors (LF) } & Possible Indicators ${ }^{1}$ \\
\hline LF1. & Economic Growth & $\begin{array}{l}\text { Changes in Gross Domestic Product (GDP), Global } \\
\text { Economic Events }\end{array}$ \\
\hline LF 2. & Environmental Awareness & $\begin{array}{l}\text { Changes in frequency of online discussion forums, } \\
\text { enrollment in environmental programs (higher } \\
\text { education), changes in public awareness for RETs (e.g. } \\
\text { national polls). }\end{array}$ \\
\hline LF 3. & Climate Change & $\begin{array}{l}\text { Changes in international and domestic commitment to } \\
\text { RETs adoption; economic costs as a result of climate } \\
\text { change }\end{array}$ \\
\hline LF 4. & Armed Conflict & $\begin{array}{l}\text { Cost of Conflict (\% of Gov. Expenditure), number of } \\
\text { canceled (or not initiated) entrepreneurial activities }\end{array}$ \\
\hline LF 5. & National Corruption & $\begin{array}{l}\text { Loss in public resources (\% of GDP), canceled } / \text { not } \\
\text { initiated entrepreneurial activity }\end{array}$ \\
\hline LF 6. & $\begin{array}{l}\text { National Education System: } \\
\text { Unequal Access to Education }\end{array}$ & $\begin{array}{l}\text { Access to upper secondary, vocational or higher } \\
\text { education (including research), expressed mismatch } \\
\text { from industry on available human capacity for new } \\
\text { technology }\end{array}$ \\
\hline
\end{tabular}

Source: Expanded by author

Note: Indicators for unchanged functions reflect suggestions provided in the baseline function list by Hekkert et al. (2007). F2.b draws on van Alphen et al. (2008).

${ }^{1}$ All indicators include the perceived influence on functions and other landscape factors 
Table 3.4 displays the added suggestions to complement the original list of functions by Hekkert et al. (2007), namely including creating adaptive capacity, a split of the resource mobilization function and a split in the creation of legitimacy/advocacy of coalition function. The landscape factors are added at the end of the list of functions and possible indicators to measure these factors are provided.

The fulfillment of system functions and the influence of landscape factors on system functions can be analyzed by a combination of a history event analysis, literature review and expert evaluations, i.e., structured and/or semi-structured interviews with experts in the field from the country under evaluation. In order to enhance the analytical comprehensiveness of the TIS framework, the findings of the external landscape assessment would be analyzed together with the findings from the Innovation System Function analysis.

\subsection{Conclusions and Suggestions for Future Research}

This chapter has discussed limitations of the TIS function approach and proposed a framework that both takes into consideration the wider context in which the focal TIS operates, while making adjustments to better account for the context found in many developing countries. While the changes to the previous function list were made with the consideration of developing countries, there are suggestions that also hold relevance for future studies in developed countries. For example, the split of the creation of legitimacy function that was made to better reflect changes in public support for renewable energy is also relevant in developed countries.

The landscape factors proposed in this chapter have been selected to hold special relevance in a developing country context, given the higher prevalence of corruption, inequality and unequal access to quality education often found in developing countries. This is not to say that certain landscape factors would not benefit future studies in developed countries. Landscape factors such as climate change, economic growth and the role of the national education system to reduce mismatch are aspects that could have an influence on incumbent regimes and focal TIS in developed countries as well. More generally, given the increased connectedness in the form of globalization and information technologies, countries may experience more rapid changes in landscape factors such as economic growth or environmental awareness today than a few decades ago. Thus, as a consequence, the inclusion of the potential effect of landscape factors on the TIS may be of even greater relevance.

The inclusion of the socio-technical landscape in the analysis of TIS proposed in this chapter should be seen as a first step to improve the analytical comprehensiveness of the TIS framework. The list of landscape factors proposed in this chapter must be empirically tested in developing countries (see Chapter 4 
and 6) to determine its relevance for the formation of the focal TIS. Thus, a pragmatic approach to potential reductions and additions of the landscape analysis is to be preferred. Moreover, differentiating between what factors exclusively influence RETs and the TIS and what factors also apply to other technologies or the entire NIS, could add value to the approach and should be subject for future research.

Moreover, while a systematic landscape analysis arguably improves the comprehensiveness in explaining barriers and drivers of technological transitions, there are other aspects that are considered external to the focal TIS. For example, during the attempt to combine the TIS and MLP framework by Markard and Truffer (2008), they stress the influence of one niche-level technological innovation on another niche innovation. The potential effect of a complementary innovation system is a topic for future research. Overall, more work is needed to map the role that the wider context has on the development, diffusion and utilization of a new technology.

Finally, given the multitude of factors that can serve as a driver or barrier to RETs adoption, additional empirical studies determining the relative pertinence amongst factors is needed, in order for the TIS function approach not to become excessively complex and lose its practical applicability. It is important to find a balance between a comprehensive framework that takes into account the intricacy of the system and the factors that influence it, and a practical framework that can contribute to the decision making process. In Chapter 4, the framework is applied to a renewable energy technology in a developing country context, namely wind energy in Colombia. 


\section{Chapter 4. Identifying Barriers to Wind Energy Diffusion in Colombia: A Function Analysis of the Technological Innovation System and the Wider Context ${ }^{49}$}

\subsection{Introduction}

The need for diversifying the energy mix towards Renewable Energy Technologies (RETs) in developing countries is motivated by the pressure of reducing greenhouse gas emissions and supporting future energy security. By one estimate carbon dioxide emissions alone in developing countries will be roughly twice that of developed countries by 2040 (EIA 2013). Despite a large technical potential for renewable energies in many developing countries, the progress in adopting RETs and moving towards a diversified energy mix remains slow. In this chapter, Colombia's wind energy sector, which represents a largely unexploited energy source for the country, will be analyzed.

Colombia's energy mix is composed mostly of hydropower and thermoelectric plants that run with coal, diesel and natural gas. Given the ecological and human impact of large hydropower dams and of using non-renewable sources of energy, such as oil and coal, combined with diminishing reserves (oil is estimated to run out in 8 years and coal in 23), Colombia is in great need of diversifying its energy mix and transitioning towards renewable energy sources such as wind power (Vergara et al. 2010).

By utilizing only half of its technical wind energy potential, Colombia would be able to supply the entire country's demand for electricity (Pérez Bedoya and Osorio Osorio 2002). With a consistent presence of class seven winds (i.e. winds of $9 \mathrm{~m} / \mathrm{s}$ at a height of 50 meters), Colombia is rated as one of the best countries in South America for generating electricity from wind energy. Moreover, wind in particular has been shown to serve as a good complementary energy source to existing hydro generation. In fact, higher average wind speeds have been found to coincide with droughts caused by El Niño ${ }^{50}$, which highlights the role that wind

\footnotetext{
${ }^{49}$ An earlier version of this chapter has been published in the journal Technology in Society (Edsand 2017).

${ }^{50}$ In most of Colombia, El Niño, the warm phase of El Niño Southern Oscillation (ENSO) phenomenon, produces less than average precipitation and prolonged dry seasons, leading to droughts. La Niña, the cold phase of ENSO in turn is manifested through higher than
} 
energy could play in assuring a reliable energy supply in Colombia (Vergara et al. 2010). However, after the first installed wind farm in 2003 (the Jepírachi project), the diffusion of wind energy has been at a standstill. Currently, Colombia has an installed capacity of wind power of only $19.5 \mathrm{MW}$, representing about 0.4 percent of the total technical potential. This chapter will focus on large-scale electricity generation, involving large wind power turbines. ${ }^{51}$

In order to conduct a comprehensive analysis of the barriers and drivers of wind energy in Colombia, this chapter applies an extended Technology Innovation System (TIS) function approach adapted for a developing country context in Chapter 3, while taking into account the influence of the wider context on the wind energy sector. By applying the proposed framework and methodology this chapter aims to answer the following research question.

\section{What can explain the slow adoption of wind energy in Colombia?}

In trying to answer the main research question, two sub-research questions are also posed:

1. What are the barriers within the functions of the technical innovation system in Colombia?

2. In what way does the wider context in Colombia influence the transition to wind energy and other Renewable Energy Technologies (RETs)?

The aim of this empirical chapter is also to contribute to the overall knowledge of applying the extended TIS function approach in a developing country context proposed in Chapter 3. Moreover, by including the wider contextual factors into the analysis, the aim is to contribute to the existing boundary debate ${ }^{52}$, i.e., what factors that should be considered exogenous vs. endogenous to the technological innovation system. ${ }^{53}$

average precipitation and prolonged wet seasons, often leading to floods (Poveda, Álvarez, and Rueda 2011).

${ }^{51}$ Large wind turbines normally range between $660 \mathrm{~kW}-1.8 \mathrm{MW}$ capacity and are designed for large-scale electricity generation, which feeds into the electrical grid. Small wind turbines are designed for agricultural, residential or small businesses, and have a capacity between $50 \mathrm{~kW}-250 \mathrm{~kW}$.

${ }^{52}$ An elaborate discussion about the issue of delimiting the system is found in Chapter 6 , comparing data from multitude studies, including the data and findings presented in this chapter.

${ }^{53}$ For a discussion concerning the difficulties of setting system boundaries see for example, Edquist, 2006. 


\subsection{Analytical Framework}

\subsubsection{Technological Innovation}

The Technological Innovation System framework used in this chapter is based on the idea that existing technologies can be 'locked-in' in a current system and, by default, 'locking out' or blocking new technologies from entering the established market (Unruh 2000). A technology system should be seen as a complex compilation of actors, or put differently "as a network of agents interacting in the economic/industrial area under a particular institutional infrastructure and involved in the generation, diffusion, and utilization of technology" (Carlsson and Stankiewicz 1991, 94).

As its name implies, the Technological Innovation System (TIS) approach centers around a technology, instead of a geographical area as in the National Innovation System (NSI) approach (Freeman 1987; Lundvall 1992; Nelson 1993); an industrial sector, as is the case in the Sectoral Innovation System (SIS) approach (Breschi and Malerba 1997); or a specific region as in Regional Innovation Systems (RIS) (Cooke, Uranga, and Etxebarria 1997; Saxenian 1994). The TIS approach, which was introduced by Carlsson and Stankiewicz (1991), has been extensively adopted by scholars, as this approach is not limited to the study of technological aspects, but instead it captures the socio-technical processes which can influence the diffusion of technologies of socio-technical variation and their influence on the diffusion of technologies. ${ }^{54}$

\subsubsection{Functions of a Technological Innovation System}

To understand the innovation system in detail it is important to analyze the activities of the different actors in the system. Studying the underlying processes that make up the innovation system improves the chances of identifying key characteristics of the system, including weaknesses and strengths (Lundvall et al. 2002; Hekkert et al. 2007). In the TIS literature these activities or processes are identified as 'functions'. The function approach has been found to be effective in analyzing the essential elements of a technical system (Johnson and Jacobsson 2001). Numerous lists of system functions have been developed over the last decade, which indicates the fluidity of the TIS function approach and the need to adapt it to the particular system under study (Edquist 2005). ${ }^{55}$

${ }^{54}$ See e.g., Hekkert et al. (2007); Jacobsson and Bergek (2004); Jacobsson and Johnson (2000); Suurs and Hekkert (2009).

${ }^{55}$ See e.g., Edquist (2005); Hekkert et al. (2007); Hillman et al. (2008); Johnson (2001); Suurs and Hekkert (2009). 


\subsubsection{Extended TIS function Approach and the Wider Context}

The extended TIS function analysis used in this chapter was developed to address limitations of previous TIS frameworks. ${ }^{56}$ The first concern with previous TIS frameworks expressed in the literature was that they have primarily been developed and tested empirically in developed countries (van Alphen, Hekkert, and van Sark 2008).

Secondly, previous TIS analyses have received criticism for not adequately considering the influence of the wider context, i.e. the context in which the TIS is embedded but that is not considered part of the focal TIS $^{57}$ (Coenen and Díaz López 2010; Markard and Truffer 2008; Geels, Hekkert, and Jacobsson 2008). The second limitation relates to the boundary debate, namely what factors outside the focal TIS may influence the performance of the TIS functions, i.e., acting as a driver or barrier for the new technology in question. Earlier literature has suggested that exogenous factors may have an even greater influence in a developing country context, due to the low level of development of the various functions of the innovation system found in many developing countries (Raven 2005). ${ }^{58}$

The extended TIS framework used as baseline the functions list developed by Hekkert et al. (2007), ${ }^{59}$ namely 1) entrepreneurial activities, 2) knowledge development, 3) knowledge diffusion, 4) guidance of the search, 5) market formation, 6) resource mobilization, and 7) creation of legitimacy. In order to better incorporate the developing country context, three changes were made to this list. The changes were: adding creating adaptive capacity ${ }^{60}$, i.e. a country's ability to receive a new technology; splitting the resource mobilization and creation of

${ }^{56}$ See Chapter 3 for an extensive theoretical justification of the framework used for this chapter.

${ }^{57}$ One definition describes the focal TIS as "the realm where systematic interdependencies in a specific technological field play out" (Bergek et al. 2015, 52).

${ }^{58}$ Before the development, diffusion and utilization of a new technology is reached the TIS and its functions go through a formative (early) and growth stage (late) (Bergek, Jacobsson, and Sandén 2008).

${ }^{59}$ Hekkert et al. (2007) was chosen as a baseline functions' list, since it has been tested in various empirical studies and, thus, certain validity has been established (Negro, Hekkert, and Smits 2007; Negro and Hekkert 2008). See Hekkert et al. (2007) for a theoretical justification of the functions.

${ }^{60}$ Including adaptive capacity as a function is not novelty in the literature; it has been used in previous empirical studies in developing countries (see e.g. van Alphen, Hekkert, and van Sark 2008). 
legitimacy functions to include a specific analysis of international resource mobilization and informal lobbying, i.e. public support and opinion.

The wider context factors of the extended TIS framework draw on the MultipleLevel Perspective (MLP) framework. The MLP framework, which can be used in the analysis of technological transitions, places more emphasis on the wider context than the TIS (Geels 2002). The ability of the MLP to take into account the incumbent actors (the 'socio-technical regime') and the wider context (the 'sociotechnical landscape') has been considered an asset of the framework; while lacking in the TIS framework, according to Markard and Truffer (2008). Thus, this chapter addresses this criticism by systematically including the landscape analysis. Throughout the chapter, factors operating in the external context, i.e., outside the focal TIS system, will be referred to as landscape factors.

The following six Landscape Factors (LF) are included in the framework used for this study: Economic Growth, Environmental Awareness, Climate Change, Armed Conflicts, Corruption and National Education System (Unequal Access to Education). The landscape factors included in this study were carefully selected with a developing country context in mind and based on MLP and other crossdisciplinary literature, where they were suggested as potentially having reinforcing or disruptive influence on incumbent regimes or niche developments. ${ }^{61}$ Table 4.1 presents and describes the resulting functions and landscape factors of the extended TIS framework.

The extended TIS function approach used in this empirical should seen as an attempt to improve the comprehensiveness of the analysis of barriers and drivers of technological change, but is not claimed to be a conclusive list of possible determinants. Rather an open and flexible approach is preferred (Lundvall 1992).

${ }^{61}$ See for example Economic Growth (Geels 2013), Environmental Awareness (Smith, Voß, and Grin 2010), Climate Change (N. H. Stern 2007), Armed Conflict (Naudé 2007; Brück, Naudé, and Verwimp 2013), National Corruption (OECD 2014), National Education System (Edquist 2001). 
Table 4.1 Description of Framework

System Functions (F) Description

1. Entrepreneurial Activities Activities/Interest shown by companies for new technology, e.g., started and planned projects

2a. Knowledge

Development Existing and new knowledge regarding the technology,

2b. Creating Adaptive Capacity e.g., research projects

3. Knowledge Diffusion Human, organizational and institutional capacity of a country to receive new technology

$\begin{array}{ll}\text { s. Guidance of the Search } & \text { Actions by government or companies that affect }\end{array}$ expectations of new tech. (e.g., regulations and specific targets)

5. Market Formation Specific mechanisms that facilitate entry of the new tech. to the energy market (e.g., tax exemptions, pricing policies)

\begin{tabular}{|c|c|}
\hline $\begin{array}{l}\text { 6a. Resource Mobilization } \\
\text { (Domestic) }\end{array}$ & $\begin{array}{l}\text { Financial resources allocated by government or } \\
\text { companies for new tech. }\end{array}$ \\
\hline $\begin{array}{l}\text { 6b. Resource Mobilization } \\
\text { (International) }\end{array}$ & $\begin{array}{l}\text { Financial and technical assistance by international actors } \\
\text { for new tech. }\end{array}$ \\
\hline $\begin{array}{l}\text { 7a. Creation of Legitimacy } \\
\text { (formal lobbying) }\end{array}$ & $\begin{array}{l}\text { Lobbying activities affecting legitimacy and support for } \\
\text { new tech. by established groups with economic and } \\
\text { political weight }\end{array}$ \\
\hline $\begin{array}{l}\text { 7b. Creation of Legitimacy } \\
\text { (informal lobbying) }\end{array}$ & $\begin{array}{l}\text { Activities affecting legitimacy and support for new tech. } \\
\text { by the general public }\end{array}$ \\
\hline Landscape Factors (LF) & Description \\
\hline 1. Economic Growth & $\begin{array}{l}\text { How the strength or weakness of the country's economy } \\
\text { may influence the adoption of new tech. }\end{array}$ \\
\hline $\begin{array}{l}\text { 2. Environmental } \\
\text { Awareness }\end{array}$ & $\begin{array}{l}\text { How environmental awareness may create actions that } \\
\text { influence transition towards new tech. (e.g., through } \\
\text { pressure on incumbent actors to diversify) }\end{array}$ \\
\hline 3. Climate Change & $\begin{array}{l}\text { How climate change may influence the transition to the } \\
\text { new tech. }\end{array}$ \\
\hline 4. Armed Conflict & $\begin{array}{l}\text { How armed conflicts may influence the adoption of the } \\
\text { new tech. (e.g., through the impact on govt. expenditure, } \\
\text { and/or canceled/ never initiated entrepreneurial activities } \\
\text { in conflict areas) }\end{array}$ \\
\hline 5. Corruption & $\begin{array}{l}\text { How corruption may affect transition of a new tech. (e.g., } \\
\text { loss of financial resources) }\end{array}$ \\
\hline $\begin{array}{l}\text { 6. Inequality: Unequal } \\
\text { Access to Quality Education }\end{array}$ & $\begin{array}{l}\text { How unequal access to quality education may influence } \\
\text { adoption of new tech. (e.g., through limited human } \\
\text { resources in areas with high technical potential for wind) }\end{array}$ \\
\hline
\end{tabular}

Source: Author, based on analysis and suggestions made in Chapter 3.

Note: Baseline function list before changes is based on Hekkert et al. (2007). 


\subsection{Methodology and Data}

In order to answer the research questions, interviews and a history event analysis were carried out. The primary data to analyze the barriers and drivers (within functions and landscape factors) of the wind energy sector is gathered from structured and semi-structured interviews. The history event analysis aimed at providing a broader picture of changes related to the functions and landscape factors, as well as corroborating and complementing the interviews.

\subsubsection{Expert Evaluations: Sampling and Analysis}

Interviews were conducted in Colombia between April and June of 2014. The sampling targeted experts with extensive experience within wind energy and RETs in Colombia. A total of 16 leading experts were interviewed. The early formative stage of the wind sector in Colombia limits the amount of specialists that actively work within the sector, constraining the possibility for a larger sample size. This limitation was compensated by conducting a maximum variation sampling of a wide representation of experts that actively work within the field of wind energy and other renewable energy technologies in Colombia from a variety of groups including government agencies, energy generating companies (EGCs), research institutions (universities), and international development organizations.

For the structured part of the interviews, experts were asked to rate the performance of each function using the following Likert scale: very bad (1 point), bad (2), acceptable (3), good (4), very good (5 points), and not applicable (N/A). Experts were also asked to rate the perceived influence of each landscape factor on the TIS functions as: not important (1 point), little importance (2), important (3), very important (4), extremely important (5 points), and not applicable (N/A).

To allow experts to elaborate on their answers, the interviews also included a semistructured part (Somekh and Lewin 2005). The semi-structured interviews followed a prepared topic guide with a list of open-ended questions relating to all TIS functions and landscape factors included in the framework (Table 4.1). ${ }^{62}$ See Appendix I for detailed information concerning the forms used and questions posed during the interviews.

\subsubsection{History Event Analysis}

The history event analysis was conducted through a combination of media content analysis, existing databases and literature review. The data for the media content

${ }^{62}$ All quotes in this chapter are translated from Spanish by author. 
analysis was collected using the Lexis Nexis $\odot$ database in 2014, including major Colombian and Latin American mainstream and business newspapers. ${ }^{63}$ The search words used were wind energy, Colombia and Projects. The history event analysis was constrained by unavailability of data.

\subsection{The Colombian Energy Sector}

This section provides an overview of the Colombian energy sector, including current energy supply, existing actors and structure of the energy sector.

\subsubsection{Structure and Actors in the Energy Sector}

In 1994, a new law was passed that initiated the restructuring of the Colombian energy sector. The restructuring involved allowing participation of private companies in the energy sector and dividing the electricity production chain into four activities: generation, transmission, commercialization, and distribution (Coviello, Gollán, and Pérez 2012). Regulated natural monopolies control transmission and distribution, while private companies and public enterprises are responsible for generation and commercialization. ${ }^{64}$ While a multitude of energy companies exist in Colombia, three large companies, are responsible for $72 \%$ of all electricity generation: Empresas Públicas de Medellín (EPM), EMGESA and ISAGEN, (ACOLGEN 2015). Several public institutions are responsible for planning of the energy sector that serves the National Interconnected System (SIN, for its acronym in Spanish) and Non-Interconnected Zones (ZNI, for its acronym in Spanish) (see Fig. 4.1). ${ }^{65}$

${ }^{63}$ Newspapers used in analysis include: El Espectador, El Colombiano, La República, Portafolio, Dinero, Esmerk Colombia News, News Bites - Latin America: Colombia, Noticias Financieras, Noticias Financieras Premium Publications, Troubled Company Reporter - Latin America, Webnews-Spanish, ABC, Reforma.

${ }^{64}$ Ownership of energy companies are classified as private, public or mixed. At the end of 2015 there were 56 electricity generators, 12 transmission companies, 31 grid operators and 93 commercialization companies registered in the SIN (National Interconnected System) (XM 2015). Examples of distribution companies include Codensa S.A. E.S.P., Empresa de Energía de Boyacá S.A. E.S.P., Empresas Públicas de Medellín S.A. E.S.P.

${ }^{65}$ The National Interconnected System (SIN) is the nationally integrated power grid and supplies $96 \%$ of the Colombian population with electricity but only spreads over one third of the country. The remaining two thirds making up $4 \%$ of the population are known as remote Non-Interconnected Zones (ZNI) (The World Bank 2004). 
Figure 4.1 Planning of the Energy Sector - Responsible Organizations

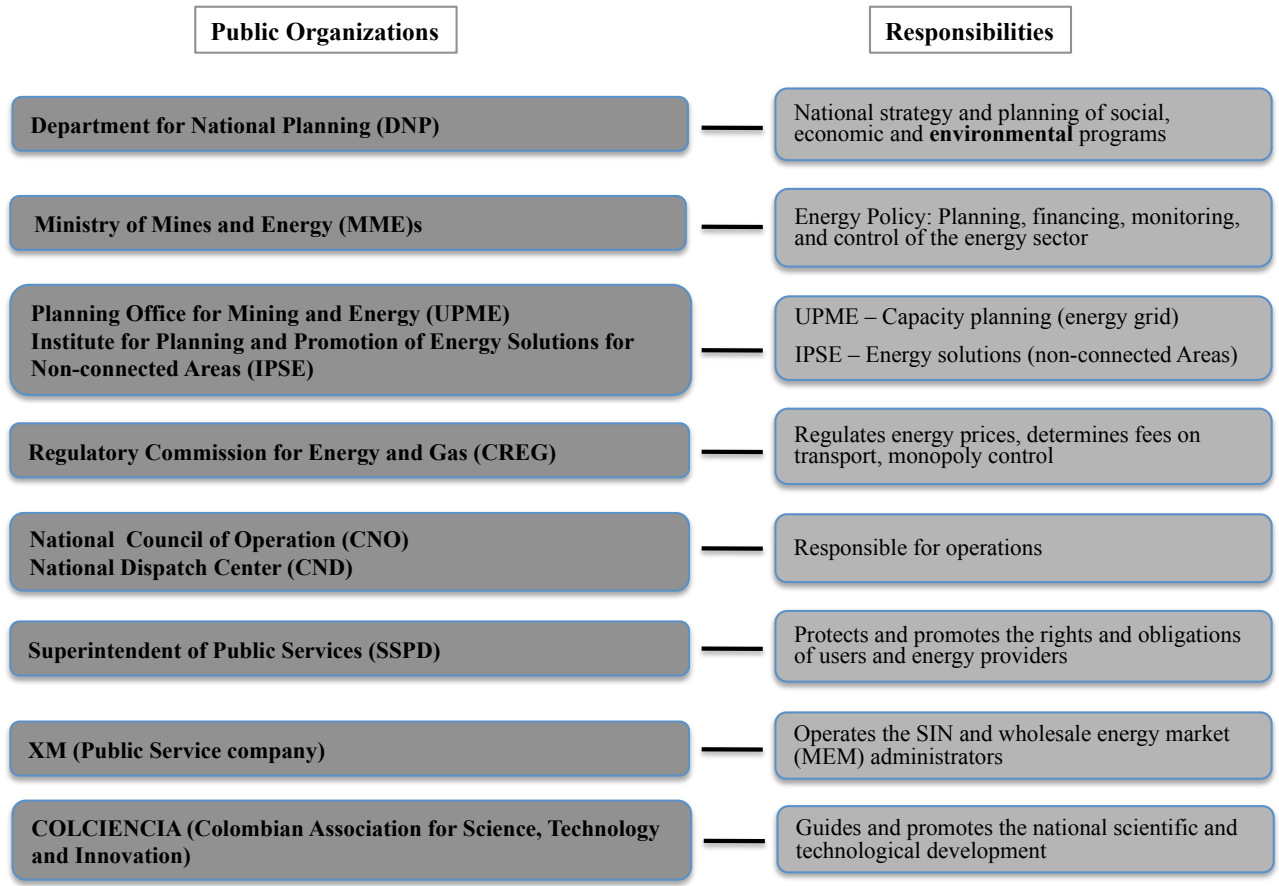

Source: MME and IDB (2010) (Modifications made by author: DNP and COLCIENCIA added).

\subsubsection{Energy Demand and Supply in Colombia}

Energy demand in Colombia has risen steadily in the past decades. Between 1990 and 2013 the total demand for electricity alone nearly doubled, increasing from 28.85 to 55.73 Twh per year (IEA 2016a). The energy mix in Colombia has maintained a similar composition for the past 30 years with almost $80 \%$ of its electricity generation produced by hydropower and almost $20 \%$ by thermoelectric (García et al. 2013). The participation of non-conventional renewable sources of energy is less than $1 \%$ produced by biomass and wind power, and $4.3 \%$ by small hydropower $(<20 \mathrm{MW})$. In $2005,81.26 \%$ of the electricity was generated by hydropower, $18.64 \%$ by thermoelectric and $0.10 \%$ by wind (XM 2005). In 2012, $67 \%$ of electricity was generated by hydropower (of which $65 \%$ was large hydro, and $2 \%$ small hydro), and $32.7 \%$ by thermoelectric, $0.14 \%$ was co-generation and $0.13 \%$ wind power (García et al. 2013). In 2014, hydropower accounted for $65.5 \%$ of energy generation, thermoelectric for $28.6 \%$. In 2015, the share of thermoelectric generation increased to $31 \%$, while hydropower reduced to $63.8 \%$ (XM 2015). In short, a trend of increasing share of thermoelectric generation has been seen in the past decade, intensified in years of water scarcity where deficiencies in hydropower generation are normally compensated with increased thermoelectric generation (García et al. 2013; XM 2015). 
The consequence of augmented electricity demand being largely covered by increased thermoelectric generation has resulted in a continuous rise in Colombia's greenhouse gas emissions from fuel combustion, from an annual $45.78 \mathrm{Mt}$ of CO2 in 1990 to $72.50 \mathrm{Mt} \mathrm{CO} 2$ in 2014 (IEA 2016a). Based on the country's generation and transmission expansion plan for 2011-2025, it is projected that in the period of 2011-2025 Carbon Dioxide Equivalent (CO2e) emissions from energy production will double ${ }^{66}$ (García et al. 2013). Meanwhile, the diffusion of renewable energies, including wind, geo-thermal and small hydro has been slow or stagnant. The augmented demand for electricity, generated by economic growth as well as urban migration will, unless a diversification of the energy mix occurs, further increase energy sector-related greenhouse gas emissions.

\subsubsection{Renewable Energies}

Together, renewable energies such as wind, geo-thermal and small hydroelectric generation make up about 5 percent of the total energy generation in Colombia, 0.4 percent of which is derived from wind energy (MRI, UNC, and NUMARK 2010). The majority of renewable energy originates from small hydro, which by Colombian law is only fully considered as a renewable source when below $10 \mathrm{MW}$ in size. Based on this law, Colombia generates about 169MW from renewable small hydro. Slightly larger hydroelectric generation (size 10-20 MW) contributes with $296 \mathrm{MW}$ to the national grid. Biomass and wind energy generate a very small amount of renewable electricity, approximately $32 \mathrm{MW}$ and $20 \mathrm{MW}$ respectively (MRI, UNC, and NUMARK 2010).

\subsubsection{High Technical Potential for Wind Energy}

Several areas of Colombia hold great technical potential for wind energy generation. La Guajira in the north of Colombia has some of the best wind potentials in South America. The trade winds in this part of the country blow nearly all throughout the year, with an average wind speed of $9.8 \mathrm{~m} / \mathrm{s}$. In addition to La Guajira, other regions, including the island groups of San Andrés and Providencia, along with the departments of Santander, Norte de Santander, Boyacá, Valle del Cauca, Risaralda and Huila also hold potential for wind power.

In 2002, Colombia, in collaboration with the World Bank and Empresas Públicas de Medellín (EPM) installed its first wind park in La Guajira, located on the northeastern Caribbean coast. The wind park, which was named Jepírachi, meaning northeast winds in the local indigenous language Wayuunaiki, consists of fifteen 1.3 MW wind turbines, totaling 19.5 MW for the entire park. The park, which

${ }^{66}$ This estimate includes projected energy generation from biomass, natural gas, liquid combustion and mineral coal. 
became fully commercially operational in 2004, was instigated under the Clean Development Mechanism (CDM) ${ }^{67}$, and was considered a first step in reducing the GHG emissions in Colombia. However, since the development of Jepírachi, there have been no new wind parks installed in the country.

\subsection{Analysis of the Technical Innovation System and Landscape Factors in Colombia}

The following section uses the extended TIS framework to examine the status of functions and the perceived importance of landscape factors in influencing wind energy adoption in Colombia. The analysis will reveal the current relative strength and discrepancies in the innovation system. The section begins by depicting the results from the structured interviews, which will provide an initial indication of the perceived strength and weakness of functions, along with the perceived importance of the landscape factors. This is followed by a more in-depth analysis is of each function and landscape factor (including the direction of the influence, i.e., positive or negative), based on the semi-structured interviews and history event analysis.

\subsubsection{Structured Interview Results}

Table 4.2 provides a computed average of the function fulfillment and perceived importance of landscape factors in Colombia based on the structured interviews. The results reveal an overall low fulfillment of the functions, with scores ranging between 1.7 and 2.6, out of a maximum of 5 ('very good'). The small difference between function average scores limits the inference of clear indications of significantly better and worse performing functions. Looking at the outcome from an individual basis, no functions received the rating 'very good' (5 points) from any expert. The only functions receiving the rating 'good' (4 points) were entrepreneurial activities, international resource mobilization, adaptive capacity and knowledge diffusion; the former two receiving 'good' by only one expert from the government and the latter two receiving the rate of 'good' by two different experts from EGCs.

Government resource mobilization in Colombia was considered the lowest performing function, with an average score between 'very bad' (1) and 'bad' (2), while entrepreneurial activities and adaptive capacity demonstrate a slight advantage against the other functions. The explanations behind these results will be further elaborated in following sections.

${ }^{67}$ The Clean Development Mechanism (CDM) is specified under Article 12 of the Kyoto Protocol to support projects aiming at reducing carbon emissions (UNFCCC 2014). 


\begin{tabular}{|c|c|}
\hline Technological Functions & Mean Score \\
\hline F1. Entrepreneurial Activities & 2.6 \\
\hline F2.a. Knowledge Development & 2.3 \\
\hline F2.b. Adaptive Capacity & 2.6 \\
\hline F3. Knowledge Diffusion & 2.3 \\
\hline F4. Guidance of the Search & 2.0 \\
\hline F5. Market Formation & 2.2 \\
\hline F6.a. Resource Mobilization (Government) & 1.7 \\
\hline F6.b. Resource Mobilization (International loans and grants) & 2.1 \\
\hline F7.a. Creation of Legitimacy/Advocacy coalition (formal & 1.8 \\
\hline F7.b. Creation of Legitimacy (informal lobbying) & 1.8 \\
\hline Landscape Factors & Mean Score \\
\hline LF1. Economic Growth & 3.7 \\
\hline LF2. Environmental Awareness & 3.3 \\
\hline LF3. Climate Change & 3.8 \\
\hline LF4. Violence and Conflict & 3.1 \\
\hline LF5. Corruption & 3.8 \\
\hline LF6. Inequality: Unequal Access to Quality Education & 3.6 \\
\hline
\end{tabular}

Note: Based on Likert Scale (1-5), where the score 1 indicate the weakest performance of a function and 5 the highest. For the landscape factors, 1 indicates the lowest importance in terms of their influence on the functions and 5 represents the highest perceived influence. The results depicted for both functions and landscape factors are the combined averages based on all actors (government departments, EGCs, and research institutions (universities) and international organizations) in Colombia.

Similarly to the functions, small differences resulted in the mean scores between the six landscape factors. Corruption and climate change showed a slightly higher level of importance than the other landscape factors, with a mean closer to "very important'. Violence and conflict received the lowest average score in comparison, however they were also considered 'important' (3.1). An interesting contrast in how the different actors perceive the influence of the landscape factors can be observed in the data, as shown in Figure 4.2. For example, interviewees from EGCs gave low average scores across several landscape factors. In particular, the lower perceived importance of climate change amongst EGCs stands out, as compared to other actors. Another notable variation is the consistently higher emphasis of landscape factor influence on functions expressed by experts from research institutes. One plausible explanation for this variation could be that the often-slower change and influence generated by the landscape level is revealed in wider longitudinal studies, which may be considered to a lesser degree by EGCs. Regardless of the cause for the discrepancy, the variation suggests that information 
regarding landscape factors influence is not sufficiently shared amongst actors. A limited knowledge sharing and the consequential mismatch in describing the barriers and drivers of wind energy and other RETs could contribute to the slow diffusion in Colombia.

Figure 4.2 Differences between Actors' Responses Regarding Landscape Factors Influence on Adoption and Diffusion of Wind Power in Colombia

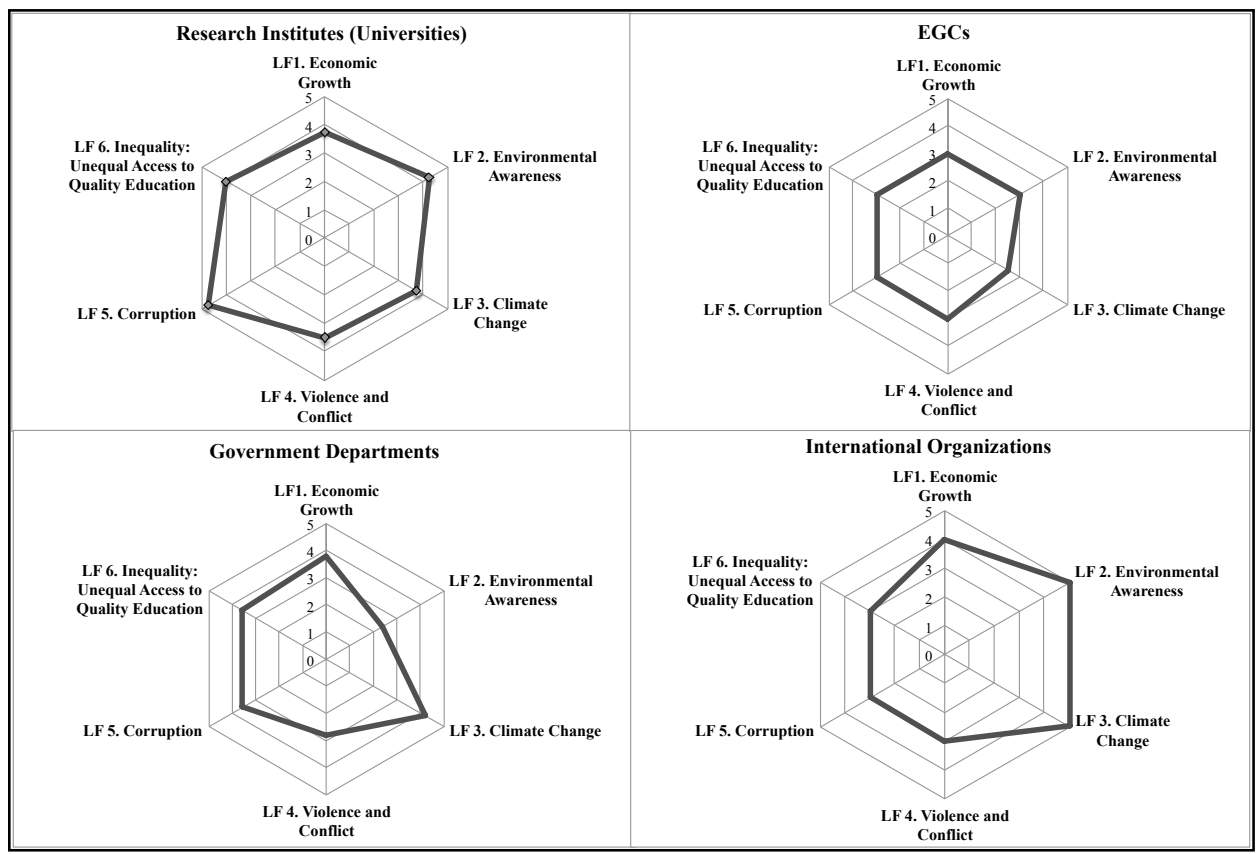

Note: Scores are accumulated averages of all experts within each actor category.

\subsubsection{Function Analysis}

\section{Function 1: Entrepreneurial Activities}

As noted earlier, despite the large technical potential for wind, Colombia has not built any additional wind farms since installing Jepírachi in 2003. Initiatives for additional wind parks first began to be frequently mentioned again as an alternative power source in 2009 (see Fig. 4.3). The media content analysis showed that 2009 was the year with the highest number of companies mentioning their interest to invest in wind energy projects.

In August of 2009, EPM made investment plans of US\$ 2.5 billion over the next four years, and mentioned new wind farms as part of the investment. Moreover, due to Colombia's large technical capacity for wind energy, international companies from Argentina (Impsa) and Spain (Grupo Endesa) declared in 2009 
their interest for investing in wind energy in Colombia. Collaboration between Ecopetrol, the Colombian state-owned oil company, and the Institute for the Development of Science and Technology (Colciencias) has committed investments of US\$ 3.68 million for the development of ten energy projects, one of which involves plans for a small scale wind power project (Portafolio 2010a).

Figure 4.3 Planned Entrepreneurial Activities by Energy Companies to Invest in Wind Project

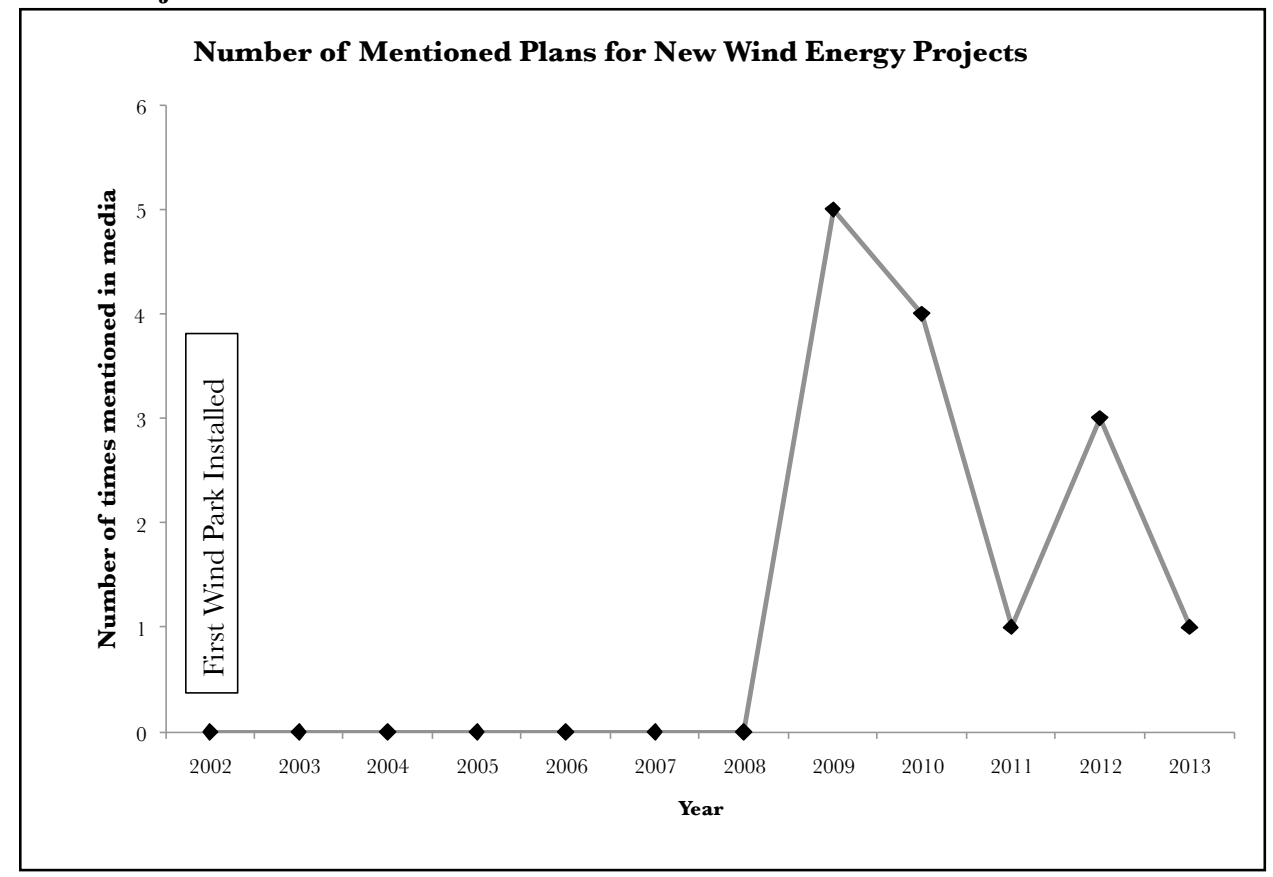

Source: Media content analysis through Lexis Nexis.

The most concrete and promising initiative is a wind farm in Uribia, La Guajira, currently being developed by ISAGEN and the local indigenous population Wayuu. The project, which received initial approval by the regional authorities in early 2010 will involve twenty $1.5 \mathrm{MW}$ turbines. The wind farm will be divided into plants, where ISAGEN will be in charge of $20 \mathrm{MW}$ of generation and Wayuu communities of $12 \mathrm{MW}$ (Portafolio 2010b). Overall, despite the stalemate of wind energy projects in Colombia since 2003, the increase of mentioned plans in media by Colombian and international energy companies still provides a positive indication of the future of wind energy in the country.

However, among the incumbent energy generator companies, which are still today heavily invested in hydroelectric generation, the realization of finalized wind parks in Colombia is moving at a very slow pace. The interviews revealed that there is a persisting lack of knowledge for the potential benefits of wind energy, along with a concern for how wind energy may impact the existing energy system, which can 
explain the slow pace (Chapter 5). Experts explained that knowledge diffusion (F3) is hampered by the limited partnerships between the EGCs and academia. Also, guidance from the government (F4) encouraging collaboration between various actors around wind energy is expressed as largely absent.

The interviews also revealed another possible explanation for the limited entrepreneurial activities around wind energy, namely the operational difficulties experienced with Colombia's first wind park. Jepírachi was not primarily designed as a learning project, which resulted in that as soon as it experienced problems, it did not receive sufficient funding or maintenance, which in turn provided bad publicity for wind energy as an alternative energy source (negatively affecting legitimacy - F7). The current energy market (F5) in Colombia rewards reliability, and given the lack of knowledge about wind, combined with the negative experiences from Jepírachi (see also functions $2 \mathrm{a}$ and $6 \mathrm{~b}$ ), wind energy is being undermined as a viable energy alternative when compared to well tested technologies such as hydro and thermoelectric.

Finally, insufficient infrastructure, in terms of energy grids was expressed in the interviews as another aspect that slows down the implementation of new wind energy projects. The installation of energy grids, which is the responsibility of the government agency Mining and Energy Planning Unit (Unidad de Planeación Minero Energética - UPME), has left the regions with high potential for wind energy, such as La Guajira, unconnected or poorly connected to the national grid (SIN). Without an electric grid in place, the cost would fall on the energy companies, which could serve as a deterrent for entrepreneurial activities.

\section{Function 2a: Knowledge Development}

As noted by experts from research institutes, while Jepírachi experienced many complications for the first 3 years of operation, EPM hired wind energy experts to study the wind park where lessons for future projects could be extracted. However, when it comes to the technology, Colombia has not made the necessary investments to develop its own large wind turbines and would have to adopt such technology from other countries. The knowledge base and the political support to create the industrial base for developing large turbines for wind parks does not currently exist in Colombia. Interviews with experts from several research institutes, however, confirmed ongoing innovative research and projects, where small-size wind turbines are being developed. In recent years, collaboration between several universities has emerged where different applications of both solar and wind energy are being tested and analyzed. This collaborative research between universities has contributed to developing new knowledge about wind, including the technical potential for wind power across Colombia. Moreover, as will be discussed under landscape factor 4 (armed conflicts), military funding has been granted to universities to develop small sized RETs solutions for military personnel, which has influenced the directionality of knowledge creation for 
technological innovation. Consequently, as experts have highlighted, technological innovations are limited to smaller sized solutions for wind energy and do not involve large wind turbines suitable for wind parks, which is the focus of this study.

Additional knowledge development activities include ongoing efforts to analyze the complementarity of resources in Colombia, and how to diversify from a hydrodominated energy mix drawing on studies from other countries with similar energy supply conditions, such as Norway. Also, initial studies mapping wind resources in Colombia have already been completed, although EGCs are asking government for more detailed maps that would facilitate the planning for future investments, including wind energy cost-benefit analyses. Since previous wind mapping studies have been conducted by private entities, the government loses much of this information, which contributes to the knowledge gap among policy makers concerning the potential of wind generation.

Experts from EGCs stress that one essential knowledge gap that exists in the government is the lack of recognition of the complementary potential of wind for hydropower, i.e. when there is little water there are usually significant levels of wind, and vice versa. An important step to realizing this potential is to change the existing method for calculating how energy can be provided to the system by wind power, as the current system of calculating reliability is based on incumbent regimes, i.e., hydro and thermoelectric.

\section{Function 2b: Creating Adaptive Capacity}

Adaptive capacity, or the ability of a country to receive a new technology, can be explored by looking at the human, organizational and institutional capacity of the country. In Colombia in terms of human capacity, the country has a high degree of qualified engineers, although engineers specialized in wind energy are few. Interviews with universities revealed a concern for the lack of specialized higher programs in RETs, which forces many researchers to pursue their Master's and Doctoral degrees in other countries, primarily Europe and the USA, where they often remain after completion of their studies. At the same time, research institutes confirm a slight increase in the return of Colombian researchers and a positive trend for new research and knowledge concerning wind and other RETs. A specific concern in terms of human capacity, revealed in the interviews, is the limited technical personnel with the skills necessary for installing and maintaining a wind park, especially in remote rural areas where wind parks could be installed. The lack of technical personnel in rural areas also relates to the high level of urban-rural inequality in Colombia, which will be further discussed under landscape factor 6 (unequal access to quality education).

The capacity of the government to make decisions and take action for new initiatives (i.e., organization capacity) is unanimously described amongst EGCs, 
research institutes, governmental agencies and international organizations as slow and inefficient. This is being manifested in the limited capacity of the central government to provide a clear direction for regional actors. In addition, there are seven different entities within the central government involved in the energy sector, and thus the actions (or inaction) of one may affect the diffusion of wind energy. For example, the Ministry of Finance may not provide sufficient funds for wind energy or the Ministry of Environment may block its progress due to protection of birds or natural protected areas. This slow decision making and implementation of new initiatives can be described as coordination failure amongst central government entities as well as between central government entities and regional actors. The latter can be seen as consequence of decentralization policies in Colombia, which demands good coordination between central and regional government entities, while relying on regional government's ability to implement policies.

The organizational capacity is further influenced by short-term contracts and rotation of personnel in government agencies, which is a result of the existing contracting scheme where people remain in their roles for 6-8 months. This turnover of people that work in a specific area such as RETs creates a strain on institutional effectiveness, in the form of low productivity during the training period of new personnel, periods of absence of personnel in-between contracts, and a lack of institutional memory.

Moreover, the Colombian institutional culture was described by study participants as reactive, i.e. the country does not usually plan ahead and preparing to receive a new technology by, for example training technicians, specialized engineers and projects managers; instead once a new technology arrives the country reacts to the needs that come with the technology. This in turn creates a 'chicken and egg' situation where the government will not make the necessary investments in preparing the country for the technology until it has arrived, and where investors may hesitate to invest due to apparent deficiencies in adaptive capacity. An explanation for the institutional inadequacy has been described as a general lack of awareness (LF 2) in the government for the role of wind energy. As a Colombian researcher puts it, "I do not think that the awareness of the Government for the importance of wind energy is enough to be able to say, '[this is important], let's bet on this and let's go for it', and thus, there is no pressure for action from the institutions that have the power to make it happen".

\section{Function 3: Knowledge Diffusion}

The level of knowledge dissemination concerning wind energy is perceived differently amongst different actors. While staff from EGCs describes limited to non-existent knowledge diffusion, research institutions and government agencies referred to a variety of existing dissemination activities for wind energy and other RETs. That is, while certain knowledge exchange is occurring amongst 
government departments, international organizations and research institutes, the information appears not to be reaching some of the EGCs. The lack of clear policy directives creates limited incentives to bring the knowledge diffusion from a theoretical discussion to practical implementation with EGCs. The new RETs energy law passed by Congress in May 2014, which will be further discussed under function 4 (Guidance of the Search), may contribute to an increased interaction between different actors.

Despite the low knowledge diffusion found in EGC, one company described how they are actively trying to break existing misconceptions regarding wind energy, and sharing the findings from internal research projects with other energy companies and government agencies. Representatives from the government declare that while some knowledge diffusion exists in government, the exchange of knowledge does not reach all the essential departments of the government. An overall expansion of knowledge exchange between different actors is needed in Colombia, which could turn into important feedback loops for the functions. For example, an enhanced knowledge exchange about the benefits of wind energy, such as reducing the risk of energy shortages during El Niño, could contribute to the legitimacy of wind energy, and this in turn could improve resource mobilization and/or guidance of the search.

Another reiterated aspect of knowledge diffusion by experts was the need of introducing knowledge generation for wind energy and other RETs in education, as early as early childhood education, in order to increase overall environmental awareness. This would include education about sustainability, in which RETs is an integral part of, among the population at large, and in turn enable for a higher legitimacy for wind energy and other RETs.

\section{Function 4: Guidance of the Search}

All interviewees agreed with the need for the government to provide clear longterm targets, which specify the desired percentage of wind in the energy mix, including a date for when to reach this objective. The government has increasingly paid attention to environmental issues, including the need for a diversified energy mix, but specific guidance on targets remains vague. Environmental sustainability was first mentioned in the National Development Plan, which is prepared by each president, in 2006 during the presidency of Álvaro Uribe. Since then environmental sustainability has received increased priority in national objectives. The 2014 Renewable Energy (RE) law can be considered a positive step towards mainstreaming RETs into the existing energy mix. However, even in the law, the objectives remain vague. For instance, as explained by a representative of the planning department (DNP), there is a national target that by $202510 \%$ of the energy mix should come from renewable energy. Yet, targets do not specify how much generation should originate from which renewable energy source, e.g., wind, solar or geothermal. The lack of clear targets and specific incentives for wind 
energy could hamper investments in this source of energy.

Representatives from EGCs confirm, for example, that while there are few subsidies for importing equipment, there are no subsidies for wind energy generators. Representatives from EGCs also emphasized the need for government support to construct the required infrastructure that would connect zones with high potential for wind to the national grid. Finally, government support that would mediate in the negotiations in areas with large indigenous communities would greatly facilitate wind energy projects. According to one EGC, the installment of one tower for measuring wind resources in La Guajira took 3 years, due to negotiations with the indigenous populations. The government thus may have to take a more active role in supporting wind energy in its initial stage.

Since the current energy system is designed to benefit hydro and thermoelectric generation, even with the new RE law in place, further reforms are needed to allow for the new law to take effect. Colombia takes pride in regulatory stability and the new law provides responsibilities to seven different institutions to implement a new policy. With this institutional rigidness and bureaucracy a slow implementation of the new regulation is most likely to be expected. However, the recent intention of the Colombian government to join the Organization for Economic Co-operation and Development (OECD) would commit the country to sustainable growth and to setting clear goals and targets for how to achieve this, which may speed up the process for change in Colombia (OECD 2013).

\section{Function 5: Market Formation}

Market incentives for environmentally friendly products have increased over the last decade. The new RE law proposes tax exemptions for import of RETs equipment, along with an exemption of the added value tax (VAT), and potentially other subsidies for initial investments. A fifteen-year tax exemption for energy sales from wind energy was already introduced in 2002. The tax exemption can be acquired through Clean Development Mechanism certificates, which provide supplementary income for the generating company (Dyner, Olaya, and Franco 2011). However, this tax exemption, which includes the conditionality to reinvest $50 \%$ of the obtained subsidy into social programs, has proven insufficient to incentivize new investments in wind power.

Actors express a culture in Colombia that holds reluctance towards supporting direct market incentives, which deems it unlikely that tools such as feed-in tariffs will be introduced for wind energy. This attitude is particularly of concern due to the dominating hydropower sector where the cost of a $\mathrm{kWh}$ of energy in Colombia is very low. Thus, without direct market incentives, wind energy would have to compete freely on the market with the dominant hydro and thermoelectric competitors, which could negatively affect market entry for wind. 
The comparative advantage for wind, compared to large hydro and thermoelectric power generation, is its lower environmental and social impact. The larger generating companies have recognized the increased resistance by communities to new hydro projects, and they are as a result increasingly considering wind energy as a viable investment. Thus, including the social and environmental costs in the cost-benefit calculations would enhance the chances for wind energy to enter the market.

\section{Function 6a: Resource Mobilization (Government)}

There is an expressed need for additional resources for Research and Development (R\&D) to bridge the persisting knowledge gaps in regards to wind. The R\&D spending (\% of GDP) has remained low, with only a minor increase from 0.110.18 percentage of GDP between 2000-2011. This can be compared with the OECD average of 2.39 percentage of GDP (The World Bank 2016c). Moreover, from the government resources allocated, a large part (about 70\%) is lost to paying salaries at COLCIENCIAS, which is the organization responsible for distributing money for research in Colombia. Also, about half of the budget available for research is allocated to scholarships for $\mathrm{PhD}$ students abroad. As previously discussed, many Colombian doctoral students choose to stay in Europe or the USA, which contributes to a brain drain in Colombia. However, a new proposal by the government to utilize $10 \%$ of profits from oil towards research in Colombia could significantly strengthen the countries' R\&D capabilities. The usefulness of this initiative is however still to be seen, which will depend on existing actors and the institutional and organizational capacity of Colombia (see function 2B) to make effective use of these additional resources.

There are already research groups in several universities that are working with wind energy and other RETs that would greatly benefit from additional resources. Lack of resources for specific research activities such as mapping the costs and benefits for wind energy, including energy demand and social and environmental aspects, was raised as an issue in the interviews. Another suggested government sponsored activity was to improve the connection or research collaboration between government, EGCs and universities (F3) to improve the transfer of knowledge between the different actors.

Building of transmission lines, i.e. extending the national grid that today only covers about half of the country's territory is a priority that requires government resources and engagement. The current process to receive approval to build transmissions involves rigid requirements where projects must prove the demand and reliability for wind energy. The benefits of emerging technologies are often harder to ensure, and thus many new transmission line projects that would connect to RETs receive a negative verdict, resulting in transmission lines never being built. 


\section{Function 6b: International Resource Mobilization}

There is a large global interest in wind energy, e.g. China just reached $7 \%$ of its total generation from wind energy, earning it first place in the world before Germany and the Unites States (GWEC 2014). The role of wind energy in reducing dependence on fossil fuels has engaged corporations, multilateral organizations and other international groups to promote investments in wind. Multilateral organizations such as the World Bank and the Inter-American Development Bank (IDB) have provided the Colombian government with both capacity building, through empirical studies on wind energy, and with financial support for energy projects. ${ }^{68}$ Colombia is the second largest recipient In Latin America and the Caribbean of financing for energy projects from IDB, with US\$ 3.029 billion disbursed for energy projects since the early 1960s (IDB 2015a).

However, in part due to previous low level of interest by the government and lack of a central entity that can drive these efforts through, the investments do not reach the market in the form of wind projects, which have resulted in lost opportunities. Thus, capital for investments is available but sufficient government guidance (F4) is missing. The hope, expressed by several interviewees, is that the new RE law will not only provide improved incentives for wind energy but also promote financing of future projects. In fact, the new law contemplates the creation of a fund that can receive resources from private and public entities and multilateral organizations to develop infrastructure and promote wind energy and other RETs. This fund would be supervised by the Mines and Energy Ministry and managed by a leasing company.

Some hesitance in regard to international financing was expressed in the expert evaluations, which is a result of previous poor experiences and fear of debt. For example, the financing of Jepírachi, which was financed by a loan from the World Bank, experienced several simultaneous problems. The project's cost was estimated at US\$ 21 million but ended up being much more expensive because there was a sharp rise in the value of the US dollar, which went from about 1,900 Colombian pesos to 2,500 pesos per dollar shortly after the project had begun. In addition, bonds to the Clean Development Mechanism (CDM) were sold for US\$ 4/ton of CO2e by the Colombian government; the next day the price for bonds rose to US\$ $21 /$ ton of CO2e. The poor financing experience both raised the hesitance for international financing, while also painted a dim picture for wind energy in terms of price as compared with hydro. That said, Colombia is dependent on receiving international financing for future projects and EGCs do not see much difficulty in obtaining the necessary capital once the right incentives for investment are in place.

${ }^{68}$ (See e.g. Vergara et al. 2010; IDB 2015b) 


\section{Function 7a: Creation of Legitimacy (Formal lobbying)}

As mentioned above about the Colombian energy sector, three very large companies, all of which are heavily invested in hydropower, dominate the energy generation in Colombia (EMGESA, EPM and ISAGEN). These three companies, which together with 14 other companies make up $100 \%$ of hydro-generation in Colombia and $52 \%$ of thermoelectric generation in the country, have formed a lobbying association called ACOLGEN.

An association of thermoelectric companies (ANDEG), created in 2010, lobbies for improved conditions for thermoelectric energy generation. According to actors from within the hydro dominating generators, thermoelectric companies generally resist new technologies such as wind energy, given that it would deem thermoelectric energy production both environmentally and price-wise inferior to the new technology.

Support for wind energy is interestingly found amongst the large hydro generating companies, which can be largely explained by the environmental and social constraints of hydro, combined with complementary qualities of wind for hydro generation. The dominant actors within ACOLGEN, that is, EPM, EMGESA and ISAGEN, for which hydro generation makes up $85 \%, 86 \%$ and $91 \%$ respectively of their total generation, are a group with regulatory weight, i.e., with the power to influence government decisions (ACOLGEN 2015). The semi-structured interviews conducted with representatives from these companies revealed that they have begun to lobby for improved conditions for wind energy. They mentioned having recently raised the possibility to open a sub-association to ACOLGEN that would solely focus on the promotion of wind energy.

However, cautionary voices from both government agencies and research institutes emphasize the heavy investment of ACOLGEN members in hydropower, and their probable reluctance to rapid changes in energy generation. In other words, Colombia is experiencing a significant hydro lock-in. Due to the existing knowledge gap in essential government agencies with regards to the potential of wind energy in Colombia, formal and/or informal lobbying activities (F7A and B) will be important to unlock the current path and allow for wind energy to be diffused.

\section{Function 7b: Creation of Legitimacy (Informal lobbying)}

Government agencies recognized that there is limited public focus on RETs, and thus limited informal lobbying for the issue, but there is a trend of increased attention to environmental issues. In addition, some scattered informal lobbying is also taking place in the form of individual journal and news articles where wind and other RETs are being promoted. Government representatives explain that the 
limited public focus on RETs is in part due to larger concerns such as poverty, violence, as well as other environmental issues such as that of mining. One EGC confirms that a more active informal lobbying has emerged, although with less regulatory strength than the formal lobbying. As described by an ISAGEN representative, "there are a series of people on the environmental side, and a series of people and companies promoting and selling RETs but they do not have the strength or market power to carry it through." Accounts from smaller energy companies confirm this picture, that RETs and especially wind energy is being promoted in news articles and research documents but in an unorganized manner.

Perhaps the most positive trend in informal lobbying for wind energy and other RETs can be found in universities. There is a general change in mindset and increasing attention given to RETs in universities. As a professor leading a RETs research group at a major Colombian university explains, "If you would have come [to a university like this one] 5 years ago, we did not talk about RETs, but today we have a research group that focuses specifically on this topic". Research groups and interdisciplinary teams working on RETs are growing in size and focus, including engineers and social scientists, many of whom are generating and disseminating knowledge to the public and government officials concerning wind and other RETs, and thereby increasing the critical mass necessary for informal lobbying.

\subsubsection{Landscape Factor Analysis}

\section{Landscape Factor 1 - Economic Growth}

Colombia has experienced an average Gross Domestic Product (GDP) growth of 3.6\% between 1998 and 2014 (The World Bank 2016c). Energy demand and economic growth have been traditionally correlated in Colombia with reduced energy demand during economic downturns, such as during the economic recession of 1999 and the economic deceleration of 2009; and increasing energy demand during economic upturns (Macías Parra 2013). The most reiterated aspect of how economic growth influences the adoption of wind energy is the augmented demand for electricity that is generated by the growth. As put by a representative of EMGESA, "economic growth has led to increased demand for energy that must be met by a more diversified energy mix, thus leaving the country's dependence on hydro, and instead investing in new technologies such as wind energy, which is one of the most developed renewable energies today in the world". As mentioned earlier, the increasing energy demand has been so far met mostly by thermoelectric. The new RE law will be crucial for insuring that the increased public and private capital that economic growth (LF1) generates positively contributes to wind energy development. 
Representatives from EGCs also emphasized the combination of economic growth and climate change (LF3) as a driver for change towards alternative sources of energy. The increased demand for energy as a result of increased economic growth, together with increased concern for intensified climate related events, such as El Niño, is increasingly making wind energy a viable alternative. Research institutes also report an increase in research funding (F6a) for wind energy as a consequence of economic growth. An interesting remark from both research institutes and government officials is that since much of the economic growth is derived by exploitation of natural endowments such as oil and coal, a realization of finite nature of these resources could contribute to political decisions to preserve them, by investing in more alternative energies. Thus, paradoxically an economic growth based on fossil fuels could create the opportunity to better manage natural resources in the country.

\section{Landscape Factor 2: Environmental Awareness}

Environmental awareness is currently considered by the experts to have a small effect on TIS functions and the transition towards wind energy. At the same time, several study participants described it as an important factor for RETs diffusion and the overall sustainability of Colombia's future. Study participants expressed that there is a general lack of knowledge concerning environmental issues among citizens, which is largely explained by low level of education. As a representative of one of the research institutes put it, "it should start with our children, through early childhood education to make environmental awareness part of every child". Over the last decade, however, Colombia has experienced an overall rise in awareness for environmental issues. Climate change is now present in the minds of Colombians, in part due to the harsh consequences of El Niño/La Niña events the country has experienced. As a result, there has been an increase in the awareness concerning the role of wind energy and other RETs to combat global climate change. However, the perception of the government and EGCs, in particular, of the energy system in Colombia is that since it is a hydro-dominated system, it is already basically carbon neutral. While Colombia's energy system is relatively 'clean' as compared to many other countries, as previously mentioned the existing hydro-dependent energy system has been forced to increase investments in thermoelectric generation, in order to offset the risks from climate variability, which decreases the reliability and availability of hydro-power, especially during El Niño drought periods. Increased awareness amongst key actors in Colombia concerning the impacts of climate change on hydropower and the local and global environmental impacts from increased GHG emissions could facilitate the transition towards wind energy and other RETs. 


\section{Landscape Factor 3: Climate Change}

Climate change was shown to have a large influence in Colombia and makes its presence in policy discussions. Climate variability impacts the heavily dominant hydro sector dependent on a steady flow of water. Going forward, the two real alternatives for Colombia are to either increase thermoelectric generation, which adds to greenhouse gas emissions, or to diversify its energy mix with wind and other RETs. The vulnerability to climate change is "an aspect that puts certain pressure for change in Colombia" (Representative of UPME).

"The pressure that climate change is putting on the decisions for renewable energy is fundamental" and "it forces Colombia to stop and reflect on its resources and what steps to take, and ultimately consider other forms of energy such as wind power" (Representative from DNP - National Planning Department). To illustrate, climate change concerns have resulted in a concrete implication, a strategy to reduce GHG emissions through the 'Low Carbon Development Strategy'. In addition, several interviewees described the concern of climate change as a central factor in passing the 2014 RE law.

Furthermore, the decisions of EGCs are influenced by climate change not only by reducing the reliability of hydropower generation, but also affected energy prices. The price of energy is also influenced by climate variability, which creates insecurity for businesses. EGCs are forced to mitigate the risks posed by climate change by diversifying their portfolio. This insecurity has increased lobbying activities (F7a) by influential EGCs to expand resource mobilization (F6) for wind energy and other RETs.

\section{Landscape Factor 4: Armed Conflicts}

While the situation of the armed conflict has significantly improved in Colombia ${ }^{69}$ over the last decades, armed groups and criminal gangs are still present and controlling the drug trade. The share of government expenditure for the military amounts to an average $12.1 \%$ over the last 15 years (2000-2014), more than twice that of most South American countries and even higher than the United States (SIPRI 2015).

${ }^{69}$ A peace agreement was signed between the Colombian Government and the largest guerilla group, FARC (Fuerzas Armadas Revolucionarias de Colombia) in 2016. Demobilization and disarmament of guerrilla combatants started early in 2017. Peace talks started in February 2017 with the second largest guerrilla group, ELN (Ejército de Liberación Nacional) in Ecuador. 
Study participants confirmed a negative influence on investments and entrepreneurial activities by the persisting armed conflict in Colombia. From a business perspective, the primary consequence of the persisting armed conflict is higher interest rates for investments in Colombia. In the region with the highest wind capacity, La Guajira, the presence of armed groups has implied higher risks for new investor, leading to higher interests rates from financial institutions. Along with higher interest rates, a new technology such as wind power, which takes time to construct, is especially vulnerable to these insecurities, and implies higher project costs for assuring the security of personnel.

A noteworthy finding concerning the influence of armed conflicts on wind energy in Colombia is that was found to have a dual effect, namely positive and negative. Beyond the negative influence on large-scale wind projects discussed above, the armed conflict fueled innovations of smaller size (i.e., not large wind turbines suitable for wind parks) for wind energy and solar PV. More specifically, the conflict motivated the need for portable RETs solutions for soldiers that are stationed in remote areas of Colombia for longer durations. Consequently, the government directed military funding for the innovation of suitable RETs solutions. Thus, as a consequence of the armed conflict, innovative portable wind turbines and solar panels that could charge cell-phone or be used for other electronic devises are being developed at universities in Colombia.

To counteract the negative influence for large-scale wind projects, an interesting observation was made by university research groups who have been in contact with armed groups during wind energy studies. The claim that as long as a consultation is made with the local community and that they can prove that they are there for sole educational purposes, i.e. no political interest, the armed groups are less inclined to oppose their presence. Based on this observation, a community-based project that is successful in formulating and communicating the social benefits of the project may be able to reduce the risks imposed by armed groups.

\section{Landscape Factor 5: Corruption}

Reliable data concerning the level of corruption and its impacts on societies and entrepreneurial activities is difficult to obtain due to its informal and taboo nature. However, one study has estimated that between 1989 and 1999 corruption in Colombia was responsible for an annual loss of $1 \%$ of GDP, which in monetary terms equals approximately US\$ 750-800 million (Gallón Gómez and Gómez Portilla 2000). Despite several efforts from the Colombian government to curb 
corruption, the country went from $57^{\text {th }}$ to $94^{\text {th }}$ place in the Corruption Perception Index ranking ${ }^{70}$ between 2002-2012 (Gutierrez 2013).

Interviewees considered that corruption is not a significant issue at the central government level, but rather a problem once the resources have been allocated to local/regional governments. The perspective of several EGCs representatives is that corruption within the energy sector is not widespread, and has been much reduced as a consequence of the 1993/94 privatization of the energy sector. They, however, reiterated the concern of corruption in government, and recognize it as factor that influences society at large.

From the EGCs, there are no mentioned cases of dry-out of funds due to corruption, leading to the cancellation of an ongoing project. However, there is a clear consensus among experts that corruption has blocked the initiation of wind energy projects. Numerous interviewees expressed concerned regarding politicians requiring an informal payment in order to approve a permit for a project, or in other ways facilitate the initiation of a project. The informal payments contribute to making projects more expensive, which can result in the projects becoming financially unfeasible. Also, it is worth highlighting that some of the interviewees noted that they had been unwilling to pay the bribes and had opted for canceling projects in areas where bribes were required. Thus, corruption is deemed a very important landscape factor since even with the right economic and regulatory incentives in place, the expropriation of funds allocated for wind farms or the expectance of informal payments could reduce the positive progress made.

\section{Landscape Factor 6: Inequality: Unequal Access to Quality Education}

Unequal access to quality education in Colombia is manifested in two distinct ways. The first aspect is the difference in quality education between urban and rural areas, where the urban counterpart significantly outmatches rural areas. There are also discrepancies in quality between urban schools, but the contrast is particularly stark between urban and rural areas. Secondly, private schools are generally of higher quality than public schools. This is particularly true for primary and secondary levels, as Colombia has several high quality public institutes at the tertiary level. Unequal access to quality education at primary and secondary level perpetuates existing inequalities, whereas a graduate from an urban private school will have much greater opportunity to pursue higher education. As a result, many young people in Colombia are blocked from entering higher-level studies, either by unaffordable tuition fees or inability to qualify for universities enrollment due to poor quality at the primary and secondary level (The World Bank 2008).

${ }^{70} 175$ countries participated in the 2012 study. A higher number in the ranking implies higher corruption in the country. 
Existing discrepancies in education quality potentially influence the wind energy sector from through lower awareness of population in regard to environmental issues and the role of RETs, as well as a mismatch of personnel, or lack of sufficient qualified personnel, required to plan, design and maintain future wind parks. Experts in the government and research institutes stress that part of this mismatch can be attributed to the limited amount of eligible people for tertiary education. Another reason is the limited availability of specialized programs for wind energy. As mentioned during the analysis of function 2, the base for engineers in Colombia is good, which is reiterated by experts in the EGCs. However, EGCs and government agencies raised the lack of specialized university programs for Wind Energy and other RETs as an area of concern that will create a mismatch for future wind energy projects and other RETs investments.

The effect of unequal access to quality education on specialized human capital is of particular concern in rural areas. Even with qualified engineers in urban areas, the low technical capacity in rural areas to operate and maintain the energy system risks delaying repairs and the system coming to a halt when issues occur. The lack of human capacity in rural areas is not only associated with the low quality basic education but also the limited access to technical education in these areas. To conclude, mismatch can be explained by a lack of specialized programs on wind energy available in Colombian universities, which is exacerbated by the lower amount of tertiary graduates caused by unequal access to quality education, which is especially of concern in rural areas. In turn, this mismatch could prove to become a deterrent for wind energy investments, especially in rural areas.

\subsection{Summary of Findings and Policy Recommendations}

This chapter has aimed to explain the slow diffusion of wind energy in Colombia by analyzing the underlying processes that make up the innovation system in the form of functions, along with the influence of the wider context, in the form of landscape factors operating outside the focal wind energy sector. This section provides a summary of the findings explaining the slow diffusion of wind energy in Colombia, the influence of the selected landscape factors, along with policy suggestions for how to remedy existing barriers.

\subsubsection{Landscape Factor Influence on Functions of the Wind Energy Sector}

The study found several insights regarding the pressure that the landscape factors place directly on the TIS functions but also indirectly by influencing the existing regime. Figure 4.4 summarizes these findings, while indicating the relative strength of the influence of the different landscape factors on the TIS. Climate change proved to have a strong positive influence on several functions. For example, climate change was described to have been fundamental in the formation of the new RE law and the 'Low Carbon Development Strategy' (which falls under the 
guidance of the search function), as well as having positive effect on legitimizing wind energy and contributing to an increase in government resource mobilization towards research on wind energy and other RETs.

Climate change also proved to indirectly influence functions by first putting pressure on the existing socio-technical regime, which in turn influences the wind energy sector. For example, climate variability and change and the accompanying unreliability of water availability has contributed to a realization amongst the largest hydro generating companies regarding the risk of not diversifying their energy portfolio. Moreover, wind energy was expressed as the primary alternative amongst RETs. As a consequence, formal lobbying (F7a) has been taking place by existing hydro companies to improve the conditions for wind energy diffusion has been taking place in the past couple of years.

Figure 4.4 Landscape Factor Influence on TIS Functions

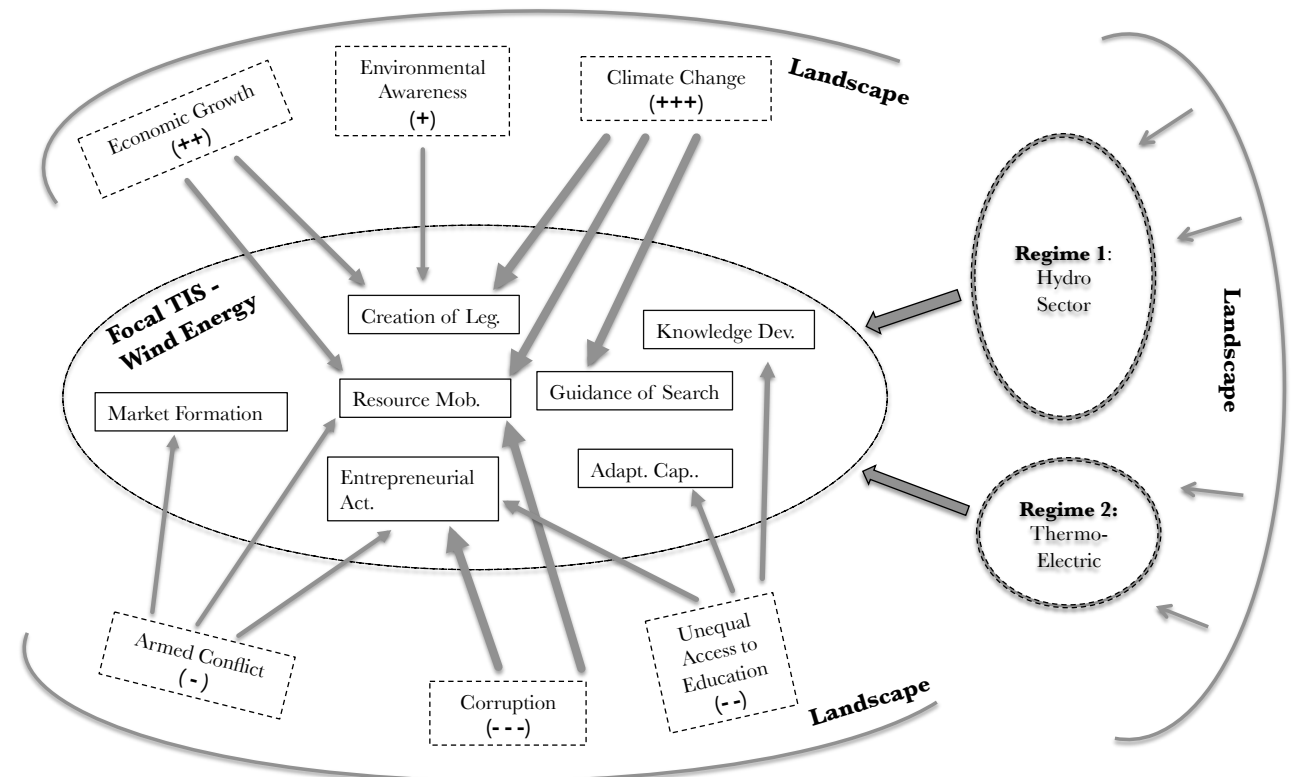

Source: Author, based on analysis of interview data.

Note: (+++/- - -) signifies strongest positive/negative influence, (++/- -) medium influence and $(+/-)$ least influence.

The environmental awareness landscape factor was not considered to put significant influence on the creation of legitimacy for wind energy, and the contribution of environmental awareness on knowledge diffusion proved absent all together. The weak influence of environmental awareness can largely be explained by a widespread belief that the Colombian energy system is already clean, due to the large generation from hydro. While this is partly true in the short-term, measured only by greenhouse gas emissions, a misconception exists, both in the general public and amongst government officials concerning the medium and long- 
term perspectives of hydropower. Building new hydro projects is becoming increasingly difficult due to the environmental and human effects of new dams. As a consequence, thermoelectric generation is increasing in order to cover an increasing demand for electricity and to mitigate the risks associated with more frequent and extreme 'El Niño' events. Thus, the energy mix in Colombia has shown an increasingly dirtier trend (i.e., higher greenhouse gas emissions) and environmental awareness in the country is not attuned to these existing realities. Therefore, additional knowledge diffusion (F3) amongst all actors concerning Colombia's current and future greenhouse gas emissions and the role of RETs is needed. The need for including topics of environmental awareness, including alternative energy generation in early childhood education was reiterated by experts as not only essential for increasing legitimacy for wind and other RETs but also for changing behavior in the Colombian population that would allow for consideration of sustainability concerns beyond energy supply (e.g., curving energy demand).

Corruption was described as a strong blocking mechanism for entrepreneurial activities and government resource mobilization, with inefficiencies at the regional and local government level being emphasized as the main area of concern, while corruption in the central government and energy sector was described as less of an issue. The armed conflict in Colombia has contributed to elevated costs, in terms of higher interests rates and extra security to assure the safety of personnel, which has deterred entrepreneurial activities. However, the EGCs did not express a great concern over the impact of the armed conflict for future wind energy, and by drafting an inclusive community based project plan, this risk could be further reduced. A landscape factor that was not part of the initial framework but relates to the inclusiveness of new projects, involves the indigenous population in Colombia. Experts from EGCs expressed the approval of new projects to be significantly slowed down due to negotiations with indigenous populations. Clearer guidelines from the central government that would speed up the process from planning to implementation, while taking into consideration the demands and rights of indigenous populations and their culture, would facilitate the emergence of future wind energy projects.

Finally, the study also analyzed the influence that landscape factors exercise on each other (either positively or negatively) (see Fig. 4.5). For example, climate change related events, such as intensified El Niño, were found to positively affect environmental awareness. Corruption proved to have a negative effect on access to quality education. This reinforcing landscape-landscape interaction is of importance in the medium to long-term as it may strengthen other landscape factors that in turn could influence TIS functions in a positive (or negative) direction. 


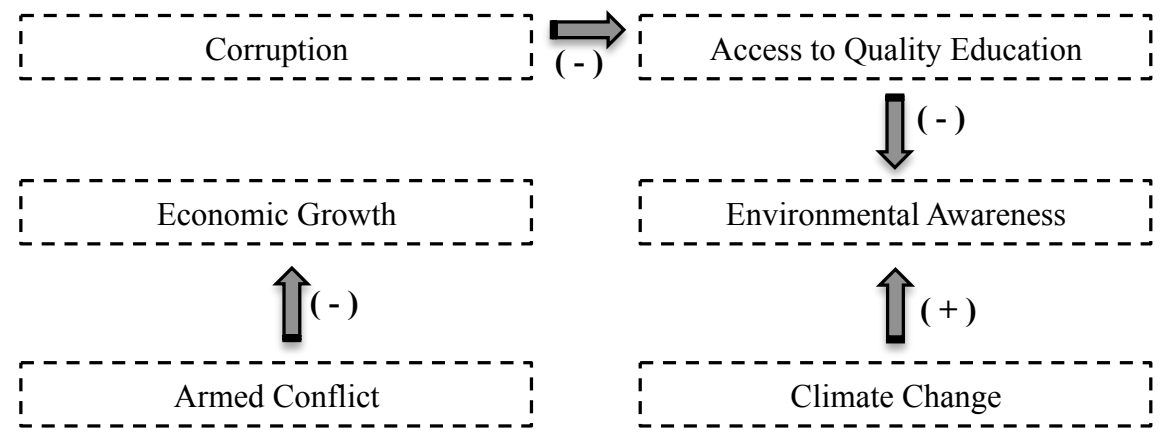

Source: Author, based on analysis of interview data.

Note: The $(-)$ and $(+)$ reflect negative and positive influence found in the study. Relative strength of influence between landscape factors is beyond this study.

\subsubsection{Barriers to wind energy adoption - Functions weaknesses and policy suggestions}

For the last 6 years, interest in wind energy amongst energy companies in Colombia, especially the hydroelectric generating companies, has risen. Entrepreneurial activities, in the form of planned projects and activities from incumbent actors for wind energy was found to be one of the strongest functions in the innovation system. However, despite the increased entrepreneurial activities for wind energy, several functions are acting as barriers for further progress and help explain the slow diffusion of wind parks in Colombia. Based on the data from the interviews and history event analysis, Table 4.3 provides a description of the specific barriers within each function, along with policy strategies that could reduce existing barriers and induce diffusion of wind energy in Colombia. The final compilation of the findings presented in Table 4.3 stresses the importance of a comprehensive approach to analyzing slow diffusion of a new technology. A diffusion of wind energy in Colombia will be best achieved by addressing weaknesses across the technological innovation system, while taking into account the barriers and drivers acting beyond the integral actors and activities (focal innovation system), as was done in the landscape analysis in this chapter.

The policy suggestions displayed in Table 4.3 are restricted to policies that could be implemented in the short or medium term. More structural barriers were also revealed in the analysis. These structural barriers are more complicated to implement and can in most cases only be addressed in the long-term. An example of this was the rigidness and low institutional and organizational capacity in Colombia, which would require significant and lengthy institutional and organizational reforms. Another structural barrier that was raised by the experts was the need to redesign the curriculum in Colombian schools to introduce environmental sustainability and the role of RETs from an early age. This too 
would require longer time to implement, although less complicated than institutional and organizational reforms.

Despite the existing barriers to wind energy diffusion in Colombia, there is cause for optimism. The study has identified positive trends across a majority of functions. The new RE law places a focus on renewable energy technologies that if aptly nurtured could result in improved conditions for several functions, e.g., through a special fund to channel international financing, additional targets, and subsidies for wind energy. The increased activities in universities over the past years, in terms of research groups specialized in wind and other RETs, are also contributing to reducing the existing knowledge gap, and are likely to result in more discussions and diffusion of knowledge. The existence of high quality universities, wide availability of engineers and the positive trend of increased research focus on wind energy technologies, provide a good base for a stronger knowledge development function. R\&D on RETs has already resulted in small-size innovations for wind and solar energy. For large turbines, however, Colombia will have to, for the time being, continue to rely on purchasing the technology from abroad.

Table 4.3 Summary of Findings and Policy Suggestions

\begin{tabular}{lll}
\hline Functions & Barriers within Functions & Policy Suggestions \\
\hline Adaptive & - Lack of programs in tertiary & - Increase number of Master and Doctoral \\
Capacity & $\begin{array}{l}\text { education with specialized } \\
\text { focus on Wind and other RETs } \\
\text { - Low to no human capacity in } \\
\text { rural remote areas }\end{array}$ & $\begin{array}{l}\text { - Vocational programs to develop technical } \\
\text { skills for installation and maintenance } \\
\text { (especially in remote rural areas) }\end{array}$ \\
& - Low institutional and & - Limit shorter term government contracts \\
organizational capacity & to retain knowledge
\end{tabular}




\begin{tabular}{|c|c|c|}
\hline $\begin{array}{l}\text { Market } \\
\text { Formation }\end{array}$ & $\begin{array}{l}\text { - Low KWh price from hydro } \\
\text { combined with lack of pricing } \\
\text { policies for wind } \\
\text { - Lack of targeted subsidies in } \\
\text { place for import of wind } \\
\text { energy material (turbines, etc.) }\end{array}$ & $\begin{array}{l}\text { - Introduce pricing policies (feed-in tariffs, } \\
\text { etc.) } \\
\text { - Provide specific tax benefits for wind } \\
\text { - Incorporate social and environmental } \\
\text { costs in energy price generated by large } \\
\text { hydro and thermo-electrics }\end{array}$ \\
\hline $\begin{array}{l}\text { Resource } \\
\text { Mobilization } \\
\text { (Government) }\end{array}$ & $\begin{array}{l}\text { - Insufficient resources for } \\
\text { R\&D } \\
\text { - Insufficient resources to } \\
\text { extend grid in non- } \\
\text { interconnected areas }\end{array}$ & $\begin{array}{l}\text { - Additional resources for research groups } \\
\text { at universities, and to improve } \\
\text { collaboration between government, EGCs } \\
\text { and universities } \\
\text { - Targeted funds to map cost-benefit for } \\
\text { wind and its complementary qualities to } \\
\text { existing hydro generation (as requested by } \\
\text { EGCs.) } \\
\text { - Increased funding for extending national } \\
\text { grid (SIN) }\end{array}$ \\
\hline $\begin{array}{l}\text { Resource } \\
\text { Mobilization } \\
\text { (International } \\
\text { loans and } \\
\text { grants) }\end{array}$ & $\begin{array}{l}\text { - Availability (from the lender } \\
\text { side) of funding is not } \\
\text { considered a barrier } \\
\text { - Skepticism of international } \\
\text { loans for wind } \\
\text { - Low government interest and } \\
\text { lack of specific entity to } \\
\text { effectively disburse funds for } \\
\text { WE projects }\end{array}$ & $\begin{array}{l}\text { - Following through on mentioned plans to } \\
\text { create a specific fund for international } \\
\text { financing and assign sufficient qualified } \\
\text { personnel to oversee an effective } \\
\text { distribution of funds towards wind energy } \\
\text { projects }\end{array}$ \\
\hline $\begin{array}{l}\text { Creation of } \\
\text { Legitimacy } \\
\text { (formal } \\
\text { lobbying) }\end{array}$ & $\begin{array}{l}\text { - Formal lobbying for wind is } \\
\text { dominated by a few large } \\
\text { hydro companies with risk of } \\
\text { slow action } \\
\text { - Thermoelectric companies } \\
\text { pose opposition to wind energy }\end{array}$ & $\begin{array}{l}\text { - Government sponsored workshops and } \\
\text { conferences aimed at reducing knowledge } \\
\text { gap among influential actors (government } \\
\text { departments, incumbent actors and experts } \\
\text { researchers) regarding the cost-benefit of } \\
\text { wind energy }\end{array}$ \\
\hline $\begin{array}{l}\text { Creation of } \\
\text { Legitimacy } \\
\text { (informal } \\
\text { lobbying) }\end{array}$ & $\begin{array}{l}\text { - Insufficient and scattered } \\
\text { informal lobbying } \\
\text { - Limited public engagement } \\
\text { and support }\end{array}$ & $\begin{array}{l}\text { - Workshops and information campaigns } \\
\text { geared towards the general public } \\
\text { - Develop a forum where environmental } \\
\text { groups, research groups and public voices } \\
\text { can be unified and heard }\end{array}$ \\
\hline $\begin{array}{l}\text { Entrepreneurial } \\
\text { Activities }\end{array}$ & $\begin{array}{l}\text { - Knowledge gap among actors } \\
\text { concerning potential of wind } \\
\text { - Insufficient infrastructure i.e. } \\
\text { energy grids connecting areas } \\
\text { with high wind potential } \\
\text { - Lack of pricing policies and } \\
\text { targeted subsidies }\end{array}$ & $\begin{array}{l}\text { - Improvements across several functions } \\
\text { will help remove barriers for this function. } \\
\text { A special emphasis on knowledge } \\
\text { diffusion (e.g., more conferences with } \\
\text { private and public sector involvement); } \\
\text { Guidance of the search (clear targets for } \\
\text { wind); and Market Formation (e.g., tax } \\
\text { exemption for wind, feed-in tariffs). }\end{array}$ \\
\hline
\end{tabular}




\subsection{Concluding Remarks}

In this chapter, a multitude of barriers that are obstructing the takeoff of wind energy projects in Colombia have been identified and analyzed by utilizing a comprehensive framework of system functions and landscape factors. By including landscape factors to complement the TIS function analysis in Colombia, the analysis took into consideration 'pushes and pulls' from the wider context on the diffusion of new technologies in a developing country context. The results of this extended TIS function approach, and the indicated influence from the landscape factors suggests that delimiting the system by the integral actors and activities (focal system) alone is insufficient, and that the landscape factors should instead be treated as endogenous to the system. Using an extended TIS function approach in future studies in developing countries can help shed light on additional barriers and drivers to RETs adoption, and widen the alternatives of both short and long-term policies to address them.

That said, while this chapter has confirmed the value of including the landscape analysis to complement the TIS function approach in the case of Colombia, certain flexibility is to be preferred when selecting landscape factors for future studies. For example, the study revealed the influence of indigenous communities on the implementation of wind energy projects in their territories, which was not included in the original list of landscape factors. Additional case studies that combine the TIS function analysis with the wider context in developing countries are needed to further develop the extended TIS function approach utilized in this chapter. 


\section{Chapter 5. The Impact of Environmental Education on Environmental and Renewable Energy Technology Awareness: Empirical Evidence from Colombia $^{71,72}$}

\subsection{Introduction}

Already in 1998, the Human Development Report stressed the significant pressure on the environment that was being generated by human consumption (UNDP). Since then, human consumption of natural resources has steadily increased and according to the 'Planetary Boundary' framework, four out of nine Earth system processes have passed the sustainable boundaries (Steffen et al. 2015). ${ }^{73}$

Energy efficient and cleaner technologies are considered an essential aspect in reducing the human impact on the environment, while assuring a high quality of life (Dell and Rand 2001). The pressing concern of climate change has placed an increased focus on Renewable Energy Technologies (RETs) (IPCC 2012). In the other chapters, environmental awareness and specific awareness for RETs have, in the context of technical innovation systems, been highlighted as a framework condition/landscape factor that may positively influence technological transitions towards RETs. Therefore, improving the understanding of how a positive framework condition can be strenghtened is an important avenue of research.

From a wider sustainability perspective, learning how to augment environmental awareness is also of importance, as relying solely on technological solutions to meet the challenges of sustainability will likely not be effective. Parallel to technological advances, human attitudes and behavior towards energy use and overall consumption ought to be addressed for sustainability goals to be viable. Without simultaneously tackling an augmented human consumption, much of the

${ }^{71}$ An earlier version of this chapter has been submitted to a peer-reviewed journal (currently under review). This chapter has been co-written by Hans-Erik Edsand and Tobias Broich (UNU-MERIT/Maastricht Graduate School of Governance, University of Maastricht). Data collection, selection of variables, preparation of data and analysis of the results was a joint effort. Hans-Erik Edsand was the lead author with the main responsible for designing the study and carrying out the literature review. Tobias Broich ran the econometric modeling in Stata and performed initial interpretation of results.

${ }^{72}$ The authors are very thankful to Professor Dr. Pierre Mohnen (UNU-MERIT) for his contributions to this chapter.

${ }^{73}$ For more information concerning the Planetary Boundary framework see (Rockström et al. 2009). 
advancements and efficieny gained by new technologies risk being lost, as emphasized by the rebound effect. ${ }^{74}$ Thus, devising strategies to more effectively generate environmental awareness and awareness for RETs specifically should be considered an essential aspect of sustainability efforts and support for policy development.

Over the past few decades, the international governmental and non-governmental organizations, policymakers, and education ministers have continually argued to enhance the environmental literacy of their citizens. Environmental education (EE) is considered one of the silver bullets in developing environmental knowledge, awareness and attitudes at the student age already in order to encourage civic participation for sustainable development (Hungerford and Volk 1990). Whether environmental education can be considered a major determinant of improved environmental literacy is however not yet clear. A vast amount of literature has examined the impact of several individual-related and school-related factors on environmental literacy, mainly in developed countries (Hungerford and Volk 1990; Iozzi 1989; Kollmuss and Agyeman 2002; OECD 2007). The literature that looks at the relationship between environmental literacy and schools as well as individual characteristics in the developing world is surprisingly rare. Understanding how certain student- and school-related factors can (or cannot) influence environmental literacy, both in the developed and developing world, "can help to further improve educational policies, programs, and practices for sustainable development" (Lin and Shi 2014, 74).

Since previous research on the student- and school-level determinants of environmental literacy is (i) surprisingly sparse, (ii) mainly focused on developed countries, and (iii) is mostly of qualitative and philosophical nature, this study uses quantitative estimation techniques to assess several student- and school-level determinants of environmental literacy for a developing country, namely Colombia. The decentralized education system in Colombia, combined with discrepancies in both quality and dedication to environmental education between schools provides for an interesting developing country case study. By using Colombian PISA (Programme for International Student Assessment) 2006 data on environmental awareness and other environmental output measures, our study addresses the following main research questions:

1. To what extent can environmental education (EE) at school explain variation in environmental awareness of 15 -year olds?

2. To what extent can environmental education (EE) at school explain variation in awareness for RETs of 15 -year olds?

\footnotetext{
${ }^{74}$ See Chapter 1 for additional discussion about the rebound effect.
} 
Besides the two main research questions, this chapter also addresses two subresearch questions:

3. Do other individual-level characteristics matter? That is, do personal, demographic characteristics, student science abilities, or parental values and characteristics have a differential effect on varying levels of environmental awareness and awareness for RETs?

4. Do specific school characteristics matter? That is, to what extent does the school 'infrastructure' (public versus private, school size, teacher-student ratio, teacher shortage, proportion of qualified/certified teachers, quality of educational resources, etc.) promote environmental awareness and awareness for RETs?

We use a multilevel mixed-effects linear regression model, where the individual observations are nested within schools. Based on the maximum likelihood estimation method, we estimate a linear mixed model which contains both fixed effects and random effects. Our empirical results only provide weak evidence that environmental education can promote a higher level of environmental awareness. The relationship between environmental education and awareness of RETs is even weaker. Our findings therefore suggest that environmental education should not be considered a silver bullet in promoting environmental literacy among students. Additionally, we find more reliable predictors for environmental awareness than for awareness of RETs. Overall, the socio-economic status, stronger student science abilities, parent characteristics and a few school-level characteristics such as quality of education resources and school ownership (public versus private) seem to be decisive factors for varying levels of environmental literacy among students in Colombia.

This chapter fits into the literature that explores individual and school-related determinants of environmental literacy (Coertjens et al. 2010; Lin and Shi 2014). Coertjens et al. (2010) empirically test whether schools can make a difference in promoting environmental awareness and attitudes among students using crosssectional data of the OECD PISA 2006 for the Flemish part of Belgium. (Lin and Shi 2014) investigate the relationship between individual and school-related factors and environmental literacy for the US and Canada using OECD PISA 2006 data. Compared to the two aforementioned studies, our analysis differs in four major ways. First, our study addresses a much more specific research question compared to the studies by Coertjens et al. (2010) and Lin and Shi (2014). Second, the focus of this chapter is on a developing country, rather than a developed country. Third, we introduce a novel dependent variable as proxy for environmental literacy, namely the level of awareness for renewable technologies. Fourth, we use potential confounding factors at the school level as control variables that have not been used in previous studies.

The rest of the chapter is structured as follows. First the existing literature on environmental awareness and environmental education is briefly summarized. The 
following section provides country information on Colombia, followed by a description of the data used in this chapter. Next, the methodology is described and the empirical findings presented. The last section concludes.

\subsection{Environmental Awareness}

Environmental awareness has been defined as "the ability to emotionally understand the surrounding world, including the laws of the natural environment, sensitivity to all the changes occurring in the environment, understanding of causeand-effect relationships between the quality of the environment and human behaviour" (UNEP 2016, chap. 4.2). This awareness for the environement has been identified as a facilitating factor for achieving overall pro-environmental behavior ${ }^{75}$ in human societies (Vlek and Steg 2007).

\subsubsection{Environmental Awareness and Renewable Energy Technologies}

Environmental awareness in the broader sense has been raised as a facilitating factor to move societies towards a more sustainable energy mix. An increased environmental awareness has been described as putting pressure on incumbent energy providers to diversify its energy supply, which provides opportunity for new technologies, such as RETs, to enter the market (Smith, Voß, and Grin 2010). On the demand side, higher environmental awareness has been shown to increase the preference for consuming energy from RETs (De Groot et al. 2012; Van der Werff, Steg, and Keizer 2013). Moreover, the driving influence on policy makers and environmental regulations by an environmentally aware public has been well documented (Guha 1999). ${ }^{76}$

Reversibly, a lack of awareness for RETs can act as a barrier, in the form of lowered social acceptance for new technologies (Wüstenhagen, Wolsink, and Bürer 2007). In developing countries, the lack of environmental awareness and awareness for the costs and benefits of RETs has been found to have a significant negative influence on RETs adoption (Kennedy and Basu 2013; Luthra et al. 2015).

\footnotetext{
${ }^{75}$ Note that the data used for this chapter allows for analyzing the link between environmental education and awareness (attitudes), which can provide insights for future studies of changed behavior (actions taken). Analyzing changed behavior requires additional data collection over time, and therefore beyond the scope of this chapter.

${ }^{76}$ See also the work by Stern et al. (1999) and P. C. Stern (2000) on the value-belief-norm theory, which discusses social movements and environmentalism.
} 


\subsubsection{Explaining Different Levels of Environmental Awareness}

\section{Three Broad Competing Hypotheses}

Inglehart's $(1997 ; 1977 ; 1990)$ post-materialism hypothesis argues that as societies advance economically they tend to pursue more post-materialistic goals such as self-expression, political freedom, environmental protection and quality of life more general. Put differently, the post-materialism hypothesis claims that a certain level of material standard must be achieved before other aspects such as environmental concern can be given focus. Seminal contributions by Dunlap et al. (1993; 1995; 1997) challenge Inglehart's post-materialism hypothesis arguing that environmental concern must be considered a global phenomenon that is not restricted to a few wealthy countries, but also concern countries with lower per capita material status. Based on earlier work on the development of a new 'ecological paradigm' (R.E. Dunlap and Van Liere 1978), Dunlap and Mertig's (1995) empirical work suggests that environmental concern is in fact predomiately negatively correlated with per capita GNP. ${ }^{77}$

The third hypothesis is deeply rooted in classical economic theory (Baumol, Oates, and Blackman 1979; B. C. Field 1994). This approach stresses the importance of prosperity and economic affluence. It argues that the quality of environment should not only be regarded as a public good but also a private good: as the economic income of the population rises, the demand for a better quality of environment increases. This line of reasoning suggests a positive relationship between wealth and environmental concern. The quantitative evidence, however, remains ambiguous (Diekmann and Franzen 1999; Israel and Levinson 2004). While the study by Diekmann and Franzen (1999) suggests that the relationship between wealth and environmental quality is linear, Israel and Levinson (2004) argue that the relation is concave (i.e. the marginal willingness to pay for environmental quality increases at a decreasing rate and might eventually decline again).

\section{Commonly Used Indicators to Explain Environmental Awareness}

Much of the previous research that aimed to explain different levels of environmental awareness across individuals has focused on demographic factors. These demographic indicators include age and/or birth cohort (Dietz, Stern, and Guagnano 1998), personal values (Karp 1996; de Groot and Steg 2007), ethnicity (Howenstine 1993), religion (Biel and Nilsson 2005; Hand and Van Liere 1984), gender (Blocker and Eckberg 1997; Zelezny, Chua, and Aldrich 2000) and level of

\footnotetext{
${ }^{77}$ Note that GNP (Gross National Product) was used in these articles, rather than GDP (Gross Domestic Product) that is used in contemporary research.
} 
education (Gelissen 2007). Age, and education level were found to be good predictors of environmental awareness, while gender and income have yielded mixed results (Ahern 2012). ${ }^{78}$

Beyond the individual factors, the wider socio-economic context also helps explain people's level of environmental awareness (P. C. Stern 2000). Based on the mentioned sociological theory of post-materialism (Inglehart 1977; Inglehart 1990; Inglehart 1997), several studies have focused on the impact of a country's economic affluence - measured by GDP (GNP) per capita - on environmental awareness and attitudes (Brechin 1999; Franzen 2003; Kidd and Lee 1997; Panayotou 1993; Panayotou 1997). The overwhelming majority of these studies suggests that stronger environmental awareness and attitudes are positively associated with a higher level of economic development.

Examples of other factors that have been identified as potential determinants for environmental awareness include the openness of the political system (Scruggs 2003; Zahran et al. 2007), political preferences (Fransson and Garling 1999), the level of democracy (Neumayer 2002), the length of the country's existence (Hershfield, Bang, and Weber 2014), economic inequality (Magnani 2000), rural versus urban living environment (Arcury and Christianson 1993; Berenguer, Corraliza, and Martin 2005), the degree of urbanization (Wilson 1984), population density (Brechin and Kempton 1994), enrollment ration in tertiary education (Goetz, Debertin, and Pagoulatos 1998), happiness (Frey and Stutzer 2002; Welsch 2002), choice of environmentally-friendly technology (Acemoglu, Aghion, and Hémous 2014; Acemoglu et al. 2012; Bovenberg and Smulders 1995; Yakita 2009), forest conservation (Pawar and Rothkar 2015), environmental degradation (Givens and Jorgenson 2011) and cultural conditions (Oreg and Katz-Gerro 2006).

Another contextual factor that can influence environmental awareness are schools and specifically the type of information given at schools concerning the environment and sustainability. The influence of environmental education at schools as an indicator has not received as much attention in previous empirical studies. Given that the total instruction time in formal schooling alone can range between 4,500-8,500 hours between the ages of 7-14, schools have a unique position in influencing childrens' and adolescents' norms and values. ${ }^{79}$

\footnotetext{
${ }^{78}$ Older birth cohorts (higher age) showed to have a lower environmental concern than newer (younger) cohorts. Higher education attainment was associated with a higher degree of environmental concern. People with conservative political preferences were associated with a lower concern for the environment (Ahern 2012).

${ }^{79}$ Data example is based on OECD countries (Poland: Low-end; Italy: High-end) from OECD's Education at a Glance (2011).
} 


\subsubsection{The Concept of Environmental Education}

Broadly speaking, environmental knowledge includes both knowledge of and knowledge about the environment (Lucas 1979). According to the OECD (2007), knowledge of can be defined as the student's ability to recall and understand a range of various environmental concepts, problems, and issues. Knowledge about can be described as the means (scientific inquiry) and goals (scientific explanations) of environmental education.

The concept of environmental education is not new; it has been discussed for several decades. While no universally accepted definition of environmental education exists, the objectives and categories set out by United Nations Educational, Scientific and Cultural Organization (UNESCO) in the late 1970s are commonly referred to in the literature (Marcinkowski 2003). The 1978 final report of the Tbisili conference describe the role of environmental education as to "enable individuals of all ages and from all backgrounds, to assimilate the values, the basic concepts and the practical knowledge which will help them to an awareness of environmental problems, help them to adapt their everyday behaviour accordingly and thus make a useful contribution to the joint effort to safeguard the environment" (UNESCO 1978, 67).

The ultimate objective of environmental education is to promote environmental literacy among citizens. Environmental education "resonates with the model which refers to the environment in a holistic, human-oriented approach as interacting biophysical (organisms and life-support systems), social (people living together), economic (livelihood, money and services) and political (power, policy and decisions) dimensions" (Goldman, Assaraf, and Shaharabani 2013, 517). Environmental education also fits well into the socio-ecological system (SES) framework (Ostrom 2009).

In addition to environmental education, various forms of information dissemination can contribute towards raising environmental awareness. Information concerning the environmental impact from human material and energy consumption can and should be addressed on several fronts simultaneously. Government channels of communication, campaigns by environmental organization and the media are examples of other possible conduits for information dissemination (Dincer 2000). 
However, there are good reasons to focus on the role of environmental education in basic education. ${ }^{80}$ First, adolescence constitutes the period when moral awareness, individual philosophies, and belief systems are being formed (Damon and Hart 1988). ${ }^{81}$ Second, there is evidence that suggest that the absorption of new knowledge (fluid intelligence) and concepts is very high at this age (Savage et al. 1973). These findings do not imply that education and awareness building should not also be directed towards adults, but rather to emphasis the opportunity of introducing new concepts such as environmental sustainability during adolescence. Finally, the need to re-connect children with nature has been emphasized in previous research, referring to an existing 'nature-deficit disorder' (Louv 2008). Schools can serve as an important source of information regarding environmental sustainability and amend existing disconnects with nature.

\section{Role of School Education in Generating Environmental Literacy}

Literature that examines the impact of school education on environmental literacy is surprisingly sparse. Previous empirical studies on the effects of schools and environmental education are limited and are largely restricted to developed countries. Bradley, Waliczek and Zajicek (1999) investigate the relationship between environmental knowledge and environmental attitudes of US high school students in Texas. Their study suggests that students with higher knowledge scores have more favorable environmental attitudes compared to students with lower knowledge scores. In contrast, DeChano (2006) does not find a significant relationship between environmental knowledge and environmental attitude using data from high school students in Chile, England, Switzerland and the United States.

Negev et al. (2008) study the effects of environmental education in Israel. The authors do not find a significant correlation between environmental knowledge and environmental behavior. Another contribution that uses Israel as a case study examines the impact of environmental education programs conducted by out-ofschool environmental organizations: while the program increased student's sensitivity to human-environment interrelationships, its impact on the cognitive domain, in developing a more systemic understanding of environmental issues, was limited (Goldman, Assaraf, and Shaharabani 2013).

\footnotetext{
${ }^{80}$ Based on International Standard Classification of Education (ISCED) basic education encompasses primary and lower secondary education (UNESCO-UIS 2012).

${ }^{81}$ This further motivates the use of PISA statistics to analyze environmental awareness, which evaluates 15 years olds, who are in the adolescence range (12-18 years).
} 
A study by Coertjens et al. (2010) provides interesting insights into the role of schools, but is limited to a region within Belgium (Flanders). While several student-related factors like gender, immigrant status and socio-economic status seem to explain differences in student's environmental attitudes and awareness, the authors also show that school policies matter: "schools in which science is taught in a more hands-on manner are associated with higher student environmental awareness whilst environmental learning activities are associated with more proenvironmental attitudes amongst students" (Coertjens et al. 2010, 497). A similar contribution by Lin and Shi (2014) examines individual and school-related determinants for environmental literacy in North America (Canada and USA). The authors find that, in general, increased environmental knowledge is associated with a deeper sense of responsibility toward positive environmental impact. However, the study also provides 'only' mixed results with regard to individual-level factors for both countries related to environmental awareness, attitudes, and behavior.

There exist only a few studies that empirically test the relationship between environmental education and environmental literacy in developing countries. Using Cote d'Ivoire as a case study, Borchers et al. (2014) found that extra-curricular environmental teaching in primary schools has a strongly positive effect on environmental knowledge and attitudes towards the environment. Haryono et al. (2014) find a significant impact of environmental education in school on students' knowledge but not on students' environmental attitudes and awareness in the Indonesian city of Probolinggo. A case study on rural Madagascar shows that children in villages who received environmental education had higher environmental knowledge and more positive environmental attitudes than children in the villages not exposed to the environmental education (Rakotomamonjy et al. 2015).

In this chapter, we aim to strengthen the overall empirical knowledge base concerning the effect of environmental education in generating environmental awareness and awareness for RETs. Moreover, we will address an existing research gap by gaining a deeper understanding of the relationship between environmental education and environmental literacy in a developing country context, namely Colombia. 


\subsection{Country Background - Colombia}

\subsubsection{Economy of Colombia}

Colombia is a highly diverse middle-income ${ }^{82}$ developing country, both in terms of ecology and population. Its population of almost 50 million people consists of a mixture of people with indigenous, Spanish, European, African and MiddleEastern desent. Since the 1999 recession, Colombia has experienced a stable and high economic growth, with an average annual GDP growth of 4.4 percent between 2000 and 2014 (The World Bank 2016c). Despite a positive economic development in the past decades, inequality in Colombia persists, with a Gini coefficient for income distribution of 0.55 in 2011, roughly the same as in 2003 (Moller 2012). The Gini coefficent ranges from 0 (perfect equality) to 1 (perfect inequality) and generally countries range between 0.3-0.5 (Haughton and Khandker 2009).

The strong economic performance has led to sharp increases in demand for energy as well as material and natural resource consumption. The increase in energy demand has primarily been covered by a rapid expansion of thermo-electric energy generation, rather than diversifying its energy mix towards RETs (MRI, UNC, and NUMARK 2010). Raising environmental awareness and awareness concerning the costs and benefits from RETs in the Colombian society serves as one important aspect in moving the country towards a sustainable development path. In this chapter, we focus on one of the strategies for raising awareness in Colombia; namely through the education system.

\subsubsection{Education System in Colombia}

The constitution of 1991 introduced compulsory school for children between 5-15 years of age. At the same time, the Colombian education system became largely decentralized giving autonomy and academic decision making to sub-national governments (Faguet and Sánchez 2014). The decentralization process of the education system in Colombia was part of a wider decentralization process that began in the late $1970 \mathrm{~s} .{ }^{83}$ In contrast to other countries where decentralization was

${ }^{82}$ Based on the World Bank income (GNI per capita of countries) classification (low, lower-middle income, upper-middle income (all considered as developing countries), and high income. In 2006, Colombia was classified a low-middle income country. According to the latest income classification (2015) Colombia was considered an upper-middle income (The World Bank 2016b).

${ }^{83}$ J.-P. and Sánchez (2014) provide an insightful account of Colombia's decentralization process and its impact on access to social services. Colombia's decentralization process 
implemented rapidly, such as Bolivia (Faguet and Sánchez 2008), the Colombian process took around 25 years. In late 1991, the Colombian government established the Programa de Ampliación de Cobertura de la Educación Secundaria (PACES), or Program for Coverage Expansion in Secondary Education, as part of a wider decentralization effort and as an attempt to (i) expand private provision of public services (King et al. 1997), (ii) expand school capacity and (iii) to raise secondary school enrollment rates (King, Orazem, and Wohlgemuth 1999).

Several studies have examined the effects of Colombia's decentralization on education. According to a World Bank study, the decentralization process resulted in a significant increase in funding for public education in Colombia, from 3.3 percent of GDP in 1993 to $4.75 \%$ in 2007 (The World Bank 2008). As a result, access to primary as well as lower and higher secondary education has significantly improved. ${ }^{84}$ Angrist, Bettinger, \& Kremer, (2006) found that the PACES program increased secondary school completion rates by 15-20 percent and improved student test scores. Their study suggests that the PACES program and the decentralization process of the education system in general had a positive effect on Colombia's education performance. Other studies, however, show that this effect was not homogenous (Melo 2005; Sánchez 2006). Melo, (2005) highlights the disparities in performance (technical and allocation efficiency in the provision of public education) between the 32 departments in Colombia, even though all departments were under the same legislature.

Núñez et al. (2002) find a clear private school advantage: their empirical results suggest that the school sector plays a fundamental role in explaining existing gaps in student achievement and attainment in Colombia. While J.- Faguet and Sánchez (2008) find improved enrollment rates in public schools and a shift from infrastructure investment towards primary social services as a result of decentralizing education finance for the period 1994-2004; the result was mainly driven by the behavior of smaller, poorer, more rural municipalities. Their findings are based on a rich database that covers over 95 percent of Colombian municipalities.

Figure 5.1 portrays public, private and total school enrollment data for Colombia over the time period 1994-2004. School enrollment in 1994 is indexed to one. While public and private enrollment trends are similar in the mid-1990s, the slopes diverge from the early 2000 s onwards, leading to a large gap between both

began in the late 1970 s and initially only included fiscal measures aimed at strengthening municipal finances.

${ }^{84}$ The access to schooling was further guaranteed in 2012, by introducing free schooling until the end of upper secondary level (15-16 years of age/grades 10-11) (OECD and IBRC/The World Bank 2012). 
education systems. Overall, the decentralization of Colombia's education system led to a 20 percent increase in total school enrollment but the effect was unequally distributed: public school enrollment rose by 30 percent while private school enrollment dropped by 7 percent.

Figure 5.1 Public and Private School Enrollment in Colombia, 1994-2004

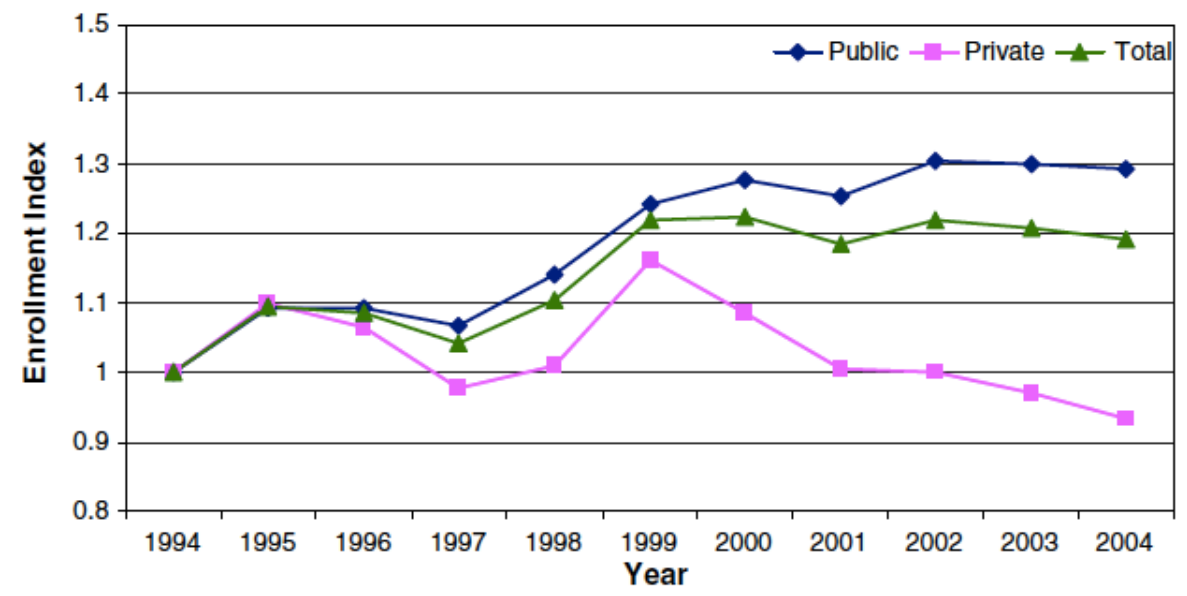

Source: J.- Faguet and Sánchez (2008).

A more recent study by Faguet and Sánchez (2014) suggests that the improved school enrollment rates in public schools due to decentralization were mainly driven by financial contributions of local governments. The authors conclude that "decentralization appears not to improve public schooling at the expense of private schools, but rather to promote the idea of education more generally" (Faguet and Sánchez 2014, 245). At the same time, however, the high inequality in the economy is also reflected in the education system. Wide discrepancies in the quality of education between different parts of the country still persist, especially between rural and urban areas (Rangel and Lleras 2010). Focusing on the Colombian city of Cartagena, Rangel and Lleras (2010, 291), find that even though family socio-economic background influences student achievement, "school [poverty] composition and school resources explain as much as half of the effects of family background on student achievement".

There have been national efforts of introducing specific programs on environmental education with the aim of enabling students to become more responsible citizens (The World Bank 2008). However, the implementation of national educational directives is ultimately carried out by the autonomous schools at the local level, which results in differences between schools in their emphasis of environmental education. Overall, we find Colombia an appropriate case study for this chapter, due to its role as an emerging middle-income country with a need for environmental awareness to coincide with the increased demand for energy and 
overall consumption. The decentralization of academic decisions in Colombia, combined with discrepancies in quality between schools, also provides for an interesting case study, due to varying levels of overall learning and dedication to environmental education between schools.

\subsection{Data and Methodology}

\subsubsection{Sample}

In this section, we will utilize the 2006 PISA dataset for Colombia to analyze the effect of environmental education on awareness. The 2006 PISA dataset provides a rich dataset for OECD and partner countries on the 15-year old students, parents and schools, including a specific survey on environmental education, awareness and attitudes (OECD 2007; OECD 2009). The selection of schools was made by PISA using random selection, making the sample representative for the Colombian school population (OECD 2007). The final sample for Colombia consist of 4478 Students in 165 schools.

\section{Individual- and School-Level Variables}

Certain variables were available on the individual (student or parent) level, while other variables were aggregated on the school level. In order to maximize the number of observations in our analysis, we decided to keep the data on the individual level by harmonizing the school level data with the individual level. This was achieved by assigning the school level data to students with the corresponding school identification number. For most of the variables we used the scales developed by PISA. A detailed description of the construction of theses scales is available in the PISA 2006 technical report (OECD 2009). ${ }^{85}$ Each of the PISA scales are based on different questions, including multiple items and varying response alternatives for each question. The questions that the scales are based on are briefly discussed in the text. The complete questionnaires for the scales are available in Appendix II. The reliability for each scale, based on Cronbach's

${ }^{85}$ For this dataset PISA used scaling models that are based on the Item Response Theory (IRT) methodology, that helps determine the fit for the pooled sample. Unless otherwise noted, the items of the questionnaires were inverted for IRT scaling, so that a positive WLE (Weighted Likelihood Estimation) scores indicate a higher level of the respective scale. For example, a positive WLE score would indicate a higher enjoyment for science (one of the control variables included in this study) (OECD 2009). 
alpha, ${ }^{86}$ is shown in Table 5.1, together with the summary statistics for the variables included in our study.

Dependent Variable

In order to test our main research questions in this chapter, we chose two dependent variables. As proxy for environmental awareness amongst 15-year old students in Colombia, we selected the Envaware variable, constructed by PISA (OECD 2009). Envaware is a scale variable which is based on a questionnaire with five items. The questionnaire asks students about their awareness concerning (i) greenhouse gases, (ii) genetically modified organisms (GMO), (iii) acid rains, (iv) nuclear waste and (v) consequences of clearing forests for other land use. The answers were measured on a four-point Likert scale, with the answer categories ranging from, 'I have never heard of this' ( 1 point) to 'I am familiar with this and I would be able to explain this well' (4 points). The complete questionnaires for Envaware and all subsequent scales that are not fully described in the main text are available in Appendix II.

To address our second research question, we chose a single item from the PISA student questionnaire as proxy for RETs awareness. The single item asks how much students agree with the statement that 'Electricity should be produced from renewable sources as much as possible, even if this increases the cost'. ${ }^{87}$ The answer categories included 'strongly disagree' (1 point); disagree ( 2 points); agree (3 points) and 'strongly agree' (4 point). We created the binary variable Retaware which is equal to one if the student either 'strongly agreed' or 'agreed' to that the question (0 otherwise).

In order to check whether our empirical results from our main explanatory variable varies depending on the measure of our main dependent variables (Envaware and Retaware), we decided to include three additional environmental output measures as dependent variables. The three additional dependent variables are: (i) responsibility for sustainable development (Respdev); (ii) environmental optimism (Envopt) and (iii) perception of environmental issues (Envperc) (OECD 2009). Similar to Envaware, those three variables are also scale variables. Respdev is made up by seven items pertaining to sustainable development; e.g., protection of endangered species, car emissions or waste management. Envopt and Envperc consist of six items concerning student's perception and optimism about aspects

\footnotetext{
${ }^{86}$ Cronbach's alpha is a statistic which is used as a measure of internal consistency or reliability (see Cronbach, 1951).

${ }^{87}$ This question is combined with six other questions to form another environmental output measure, namely responsibility for sustainable development (Respdev).
} 
such as air pollution, energy shortages or nuclear waste (see Appendix II for a detailed description).

\section{Main Explanatory Variable}

Our main explanatory variable, environmental education (Envedu), is also a scale variable and is constructed based on a questionnaire about learning of environmental topics, denoted Envlearn by PISA (OECD 2007; OECD 2009). In the questionnaire, school principals are asked to what extent their respective school organizes activities aimed at learning about environmental topics. The scale consists of five items, namely (i) outdoor education, (ii) trips to museums, (iii) trips to science and/or technology centers, (iv) extracurricular environmental projects (including research) and (v) lectures and/or seminars (e.g. guest speakers). The principals were given the response alternatives 'yes' and 'no' to whether these activities occurred at their school (OECD 2009). Figure 5.2 plots environmental awareness against environmental education. The bivariate correlation between the two variables is 0.0868 and statistically significant at the 1 percent level.

Figure 5.2 Relationship between Environmental Education and Environmental Awareness in Colombia

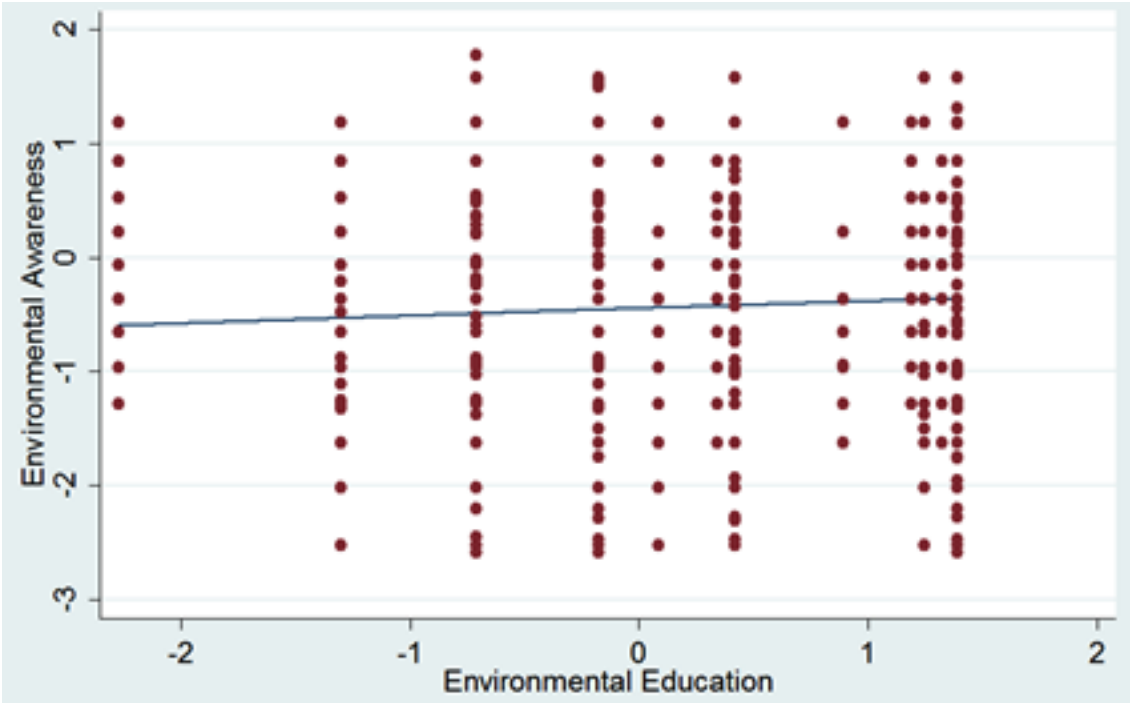

Source: Authors' own calculations based on OECD (OECD 2007; OECD 2009).

\section{Student Level Control Variables}

To account for potential bias we utilize an extensive list of carefully considered control variables at the student, parent and school level. The control variables on the individual student level include gender, immigration status, age and a socio- 
economic index that captures the economic, social and cultural status (ESCS) of the student. The ESCS index is constructed by PISA (OECD 2009). ${ }^{88}$

Previous literature has also emphasized the role of science in shaping environmental awareness and behavior. Littledyke $(2008,1)$ argues that "science education has an important part in developing understanding of concepts that underpin environmental issues, leading potentially to pro-environmental behaviour". Thus, motivated by his and other previous findings, we also control for science ability at the student level. We include six PISA constructed scales: four forms of science teaching styles, enjoyment of science and science activities.

The first four science teaching indices capture student's reports on the frequency of four different forms of teaching, i.e., 'application/models' (Scapply); 'interaction' (Scintact); 'student investigations' (Scinvest) and 'hands-on activities' (Schands). Students were asked 'When learning < school science> topics at school, how often do the following activities occur?'. For all the four different teaching styles, the students were given the response alternatives 'In all lessons', 'In most lessons', 'In some lessons' and 'Never or hardly ever'.

For the enjoyment of science (Joyscie) students were asked whether they 'strongly agree', 'agree', 'disagree' and 'strongly disagree' with five different statements pertaining to their enjoyment in 'reading about', 'doing problems' or 'acquiring new knowledge' in science. Six items make up the science activity scale (Scieact), with information about the frequency with which students, 'watch TV programmes', 'borrow or buy books' or 'visit websites' with focus on science, among others.

\section{Parent Level Control Variables}

For the control variables at the parental level we use five different scales: parents' perception on environmental issues (Pqenperc), parents' environmental optimism (Pqenvopt), parents' view of the importance of science (Pqscimp), parents' personal value of science (Pqpersci), and parents' science activities at age 10 (Pqsciact). The parental variables Pqenvopt and Pqenperc were constructed in the same way as for students (sse above). For Pqgensci parents were asked about their view about the general influence of science on society, covering aspects such as the economy or social benefits. For Pqpersci, parents were asked how science affects them personally in their daily life. In the final parent level index, Pqsciact,

${ }^{88}$ The ESCS index is comprised of five OECD-standardized indices: highest occupational status of parents (HISEI), highest educational level of parents (PARED), family wealth (WEALTH), cultural possessions (CULTPOS), and home educational resources (HEDRES). See OECD (2009) for additional information about the ESCS computation. 
parents had to indicate how often ('very often', 'regularly', 'sometimes' or never') they read books, watched TV programs or visited website related to science at the age of 10, among others (for a full description of Pqgensci, Pqpersci and Pqsciact see Appendix II).

\section{School Level Control Variables}

We chose to include seven control variables at school level: school size (Schlsize), teacher student ratio (Stratio), proportion of certified teachers (Propcert), proportion of teachers with ISCED 5A level qualifications (Propqual), quality of educational resources (Scmatedu), responsibility for curriculum index (Respcurr) and teacher shortage (Tcshort). Having acquired an ISCED 5A level education corresponds to a post-graduate or tertiary degree.$^{89}$ Stratio was computed by PISA, by dividing the size of schools with number of teachers at the corresponding school and by weighting part-time teachers by 0.5 as compared to 1.0 for full-time teachers (OECD 2009). Propcert and Propqual were calculated by dividing the total number of certified and ISCED 5A qualified teachers respectively, with the total number of teachers at the school in question (OECD 2009).

The school variables Scmatedu, Respcurr, and Tcshort are PISA calculated scales and indexes. Scmatedu is computed from answers by school principals on seven items on whether school instruction is hindered by material shortage or school infrastructure inadequacies (see Appendix II). Respcurr is an index calculated on four items pertaining to the responsibilities at schools for 'Establishing student assessment policies', 'Choosing which textbooks are used', 'Determining course content', and 'Deciding which courses are offered' (OECD 2009). The final index is a calculated ratio between 'yes' answers from principals or teachers at schools compared to 'yes' answers from education establishment at the central level, where the higher values signify higher school autonomy in decision making in the item categories. Tcshort is a scale based on four items concerning lack of science, math, language teachers and other subject, to assess the school's capacity to operate. ${ }^{90}$

${ }^{89}$ For Colombia, achieving an ISCED 5A level education was calculated by PISA to equal 15.5 years of schooling (OECD 2009).

${ }^{90}$ The Tcshort items were not inverted for scaling, thus, a higher WLE score reflects a higher degree of teacher shortage. 
Table 5.1 Summary Statistics

\begin{tabular}{|c|c|c|c|c|c|c|}
\hline Variable & Obs. & Mean & $\begin{array}{l}\text { Std. } \\
\text { Dev. }\end{array}$ & Min & Max & $\begin{array}{c}\text { Scale } \\
\text { Reliab. }\end{array}$ \\
\hline Awareness of Environmental Issues (Envaware) & 3956 & -0.43 & 0.87 & -2.58 & 1.77 & 0.74 \\
\hline $\begin{array}{l}\text { Awareness of Renewable Technologies } \\
\text { (Retaware) }\end{array}$ & 3903 & 0.72 & 0.45 & 0.00 & 1.00 & $\mathrm{~N} / \mathrm{A}$ \\
\hline $\begin{array}{l}\text { Responsibility for Sustainable Development } \\
\text { (Respdev) }\end{array}$ & 3956 & 0.08 & 0.70 & -2.01 & 2.19 & 0.64 \\
\hline Environmental Optimism (Envopt) & 3956 & 0.31 & 1.21 & -1.61 & 2.85 & 0.87 \\
\hline Perception of Environmental Issues (Envperc) & 3956 & 0.72 & 0.80 & -1.60 & 1.39 & 0.79 \\
\hline Environmental Education & 3956 & 0.32 & 0.88 & -2.27 & 1.39 & 0.49 \\
\hline Female & 3956 & 0.55 & 0.50 & 0.00 & 1.00 & $\mathrm{~N} / \mathrm{A}$ \\
\hline Age & 3956 & 15.85 & 0.29 & 15.42 & 16.33 & $\mathrm{~N} / \mathrm{A}$ \\
\hline Native & 3855 & 0.997 & 0.06 & 0.00 & 1.00 & N/A \\
\hline Economic, Social and Cultural Status & 3951 & -0.94 & 1.24 & -5.03 & 2.32 & 0.73 \\
\hline Enjoyment of Science & 3951 & 0.76 & 0.76 & -2.15 & 2.06 & 0.85 \\
\hline Science Activities & 3947 & 0.96 & 0.77 & -1.69 & 3.38 & 0.76 \\
\hline Science Teaching - Application/Models & 3879 & 0.56 & 0.97 & -2.46 & 2.63 & 0.71 \\
\hline Science Teaching - Interaction & 3904 & 0.36 & 0.81 & -2.51 & 2.47 & 0.64 \\
\hline Science Teaching - Student Investigations & 3872 & 0.63 & 0.92 & -1.26 & 3.03 & 0.68 \\
\hline Science Teaching - Hands-on Activities & 3885 & 0.28 & 0.90 & -2.10 & 2.91 & 0.68 \\
\hline Parents Perception of Environmental Issues & 3704 & 0.27 & 0.74 & -6.21 & 0.68 & 0.71 \\
\hline Parents Environmental Optimism & 3694 & 0.18 & 1.15 & -1.09 & 2.93 & 0.91 \\
\hline Parents General Value of Science & 3689 & 0.36 & 0.87 & -3.29 & 1.73 & 0.77 \\
\hline Parents Personal Value of Science & 3691 & 0.87 & 0.91 & -3.25 & 2.30 & 0.73 \\
\hline Parents Science Activities at Age 10 & 3695 & 0.38 & 1.08 & -2.27 & 3.33 & 0.67 \\
\hline Log School Size & 3688 & 7.00 & 1.24 & 1.10 & 8.84 & N/A \\
\hline Log Teacher Student Rati & 3468 & 2.95 & 1.06 & -1.02 & 3.74 & $\mathrm{~N} / \mathrm{A}$ \\
\hline Proportion of certified teachers & 3408 & 0.89 & 0.28 & 0.00 & 1.00 & N/A \\
\hline Teacher Shortage & 3912 & 0.10 & 1.11 & -1.06 & 3.62 & 0.87 \\
\hline Proportion of teachers with ISCED 5A & 3403 & 0.75 & 1.29 & -25.19 & 1.00 & N/A \\
\hline Quality of Educational Resources & 3956 & -1.14 & 1.15 & -3.43 & 2.14 & 0.89 \\
\hline Responsibility for curriculum index & 3956 & -0.20 & 0.78 & -1.33 & 1.27 & N/A \\
\hline
\end{tabular}

Source: Authors tabulations, based on PISA 2006 dataset.

Note: The values of Cronbach's alpha can be understood as high reliability $(>0.80)$, moderate reliability $(0.70-0.79)$, low reliability $(0.60-0.69)$ and very low reliability $(<0.60)$ (OECD 2007); N/A = Not applicable.

\subsection{Empirical Analysis and Findings}

In our cross-sectional sample, we are interested in predicting whether environmental education has an impact on environmental output measures using student-level and school-level characteristics. In order to analyze our multilevel data, we cannot use simple OLS regression models as hierarchically structured data violate standard linear regression assumptions. We have a two-level nested model, where the individual observations are nested within schools. Based on the maximum likelihood estimation method, we estimate a linear mixed model which 
contains both fixed effects and random effects. The general matrix notation for our model is:

$$
y=X \beta+Z \mu+\varepsilon
$$

where $y$ is an $\mathrm{n} \times 1$ vector of responses, $X$ is an $\mathrm{n} \times \mathrm{p}$ matrix containing the fixed effects regressors, $\beta$ is a $\mathrm{p} \times 1$ vector of fixed-effects parameters, $Z$ is an $\mathrm{n} \times \mathrm{q}$ matrix of random effects regressors, $\mu$ is a $\mathrm{q} \times 1$ vector of random effects, and $\varepsilon$ is an $n \times 1$ vector of errors.

More specifically, our multilevel mixed-effects linear regression model allows for a random slope on our main explanatory variable, environmental learning (captured by $u_{1 j}$ ) :

$$
\text { envaware }_{i j}=\beta_{0}+\beta_{1} * \text { envlearn }_{i j}+u_{0 j}+u_{1 j} * \text { envlearn }_{i j}+\varepsilon_{i j}
$$

Before the data analysis, we identify outliers on the dependent variables by assessing whether or not they fall within a set of numerical boundaries called 'inner fences' and 'outer fences'. Extreme outliers, i.e., points beyond an outer fence, are dropped from the analysis. We also test the normality of our dependent variables and our main explanatory variable. Values for skewness and kurtosis between -2 and +2 are considered acceptable in order to prove normal univariate distribution (George and Mallery 2010). ${ }^{91}$ Kurtosis and skewness values below -3 and above +3 strongly indicate non-normality. The absolute values of the skewness and kurtosis for Envedu were -0.18 and 2.08 respectively, indicating no concern about the normality of data. Kurtosis and skewness values for our output measures are equal to 2.6 or below, indicating some concern about the normality of data. We also tested multicollinearity between the explanatory variable and the control variables (both individual and school level characteristics) with linear regression on the dependent variable. The variance inflator diagnostics were always below the threshold of 10, suggesting that collinearity does not affect the regression coefficients.

In order to empirically test whether environmental education has a positive impact on the environmental outcome variables (Envaware and Retaware), we run a base estimation controlling for environmental education only (Model 1). We then control for individual demographic control variables to the model (Model 2). In Model 3, we control for individual science abilities. Model 4 controls for parental characteristics and Model 5 controls for school-level variables. In all models, we

${ }^{91}$ Meyers, Gamst and Guarino (2006) use a stricter threshold of \pm 1.00 for both skewness and kurtosis. 
specify the intercept to be random. Moreover, the random effects will be reported as variances rather than as standard deviations in all our models.

\section{Model 1}

In Table 5.2, we report the empirical results for our base specification. In this model we include our main explanatory variable environmental education. Column (1) reports the results for our first main dependent variable, environmental awareness. Column (2) does the same for our second main independent variable, awareness for RETs. Since awareness for RETs is a binary variable, we run a multilevel mixed-effects ordered logistic regression model for this specific dependent variable throughout the analysis. We also provide additional estimation results for three other environmental output measures (e.g. responsibility for sustainable development, environmental optimism, and perception of environmental issues) in columns (3)-(5). In each Table, we also report the number of observations, the Akaike information criteria (AIC) and the Bayesian information criteria (BIC) in smaller-is-better form as well as the deviance of each model, indicating how well the model fits the data.

Looking at the relationship between environmental awareness and environmental education first, we observe a strong positive and highly statistically significant relationship. A higher level of environmental education is associated with a higher level of environmental awareness. The strong and statistically significant relationship disappears, however, when we use awareness for RETs as dependent variable. We would like to remind the reader that Retaware was a sub-component of Respdev. When we use Respdev as dependent variable, the relationship becomes positive and statistically significant again. This suggests that even though environmental education may promote responsibility for sustainable development in general, it may not necessarily encourage awareness for renewable technologies.

Last, our model also predicts that more environmental education goes hand in hand with a decrease in environmental optimism. This finding would suggest that students who learn more about the environment at school acquire a more realistic (less optimistic) picture of our global ecosystem and recent environmental developments. All in all, the results displayed in Table 5.2 provide only some tentative evidence that environmental education promotes environmental literacy as the coefficient on environmental education is statistically significant in only three out of six cases. 
Table 5.2 Environmental Education and Environmental Output Measures, Base Specification (Model 1)

\begin{tabular}{|c|c|c|c|c|c|}
\hline & $\begin{array}{c}\text { (1) } \\
\text { Envaware }\end{array}$ & $\begin{array}{c}(2) \\
\text { Retaware }\end{array}$ & $\begin{array}{c}(3) \\
\text { Respdev }\end{array}$ & $\begin{array}{c}\text { (4) } \\
\text { Envopt }\end{array}$ & $\begin{array}{c}\text { (5) } \\
\text { Envperc }\end{array}$ \\
\hline \multicolumn{6}{|l|}{ Fixed Effects } \\
\hline Envlearn & $\begin{array}{l}0.07^{* * * *} \\
(0.03)\end{array}$ & $\begin{array}{c}0.00 \\
(0.05)\end{array}$ & $\begin{array}{l}0.05^{* * * *} \\
(0.02)\end{array}$ & $\begin{array}{l}-0.08^{*} \\
(0.04)\end{array}$ & $\begin{array}{c}0.00 \\
(0.02)\end{array}$ \\
\hline Intercept & $\begin{array}{c}-0.46^{* * *} \\
(0.03)\end{array}$ & $\begin{array}{l}0.94^{* * *} \\
(0.05)\end{array}$ & $\begin{array}{c}0.07^{* * *} \\
(0.02)\end{array}$ & $\begin{array}{l}0.34^{* * *} \\
(0.04)\end{array}$ & $\begin{array}{c}0.72^{* * * *} \\
(0.02)\end{array}$ \\
\hline \multicolumn{6}{|c|}{ Random Effects } \\
\hline sd (Envlearn) & $\begin{array}{c}0.00 \\
(0.02)\end{array}$ & $\begin{array}{c}0.00 \\
(0.14)\end{array}$ & $\begin{array}{c}0.04 \\
(0.04)\end{array}$ & $\begin{array}{c}0.00 \\
(0.00)\end{array}$ & $\begin{array}{c}0.00 \\
(0.00)\end{array}$ \\
\hline sd (Intercept) & $\begin{array}{c}0.31 \\
(0.02)\end{array}$ & $\begin{array}{c}0.29 \\
(0.06)\end{array}$ & $\begin{array}{c}0.11 \\
(0.02)\end{array}$ & $\begin{array}{c}0.38 \\
(0.03)\end{array}$ & $\begin{array}{c}0.15 \\
(0.02)\end{array}$ \\
\hline sd (Residual) & $\begin{array}{c}0.81 \\
(0.01)\end{array}$ & & $\begin{array}{c}0.69 \\
(0.01)\end{array}$ & $\begin{array}{c}1.14 \\
(0.03)\end{array}$ & $\begin{array}{c}0.78 \\
(0.01)\end{array}$ \\
\hline \multicolumn{6}{|c|}{ Model Fit Statistics } \\
\hline Deviance & 9828.78 & 4650.64 & 8366.15 & 12493.99 & 9410.72 \\
\hline AIC & 9833.52 & 4658.64 & 8376.15 & 12503.99 & 9420.72 \\
\hline $\mathrm{BIC}$ & 9823.52 & 4683.72 & 8407.56 & 12535.40 & 9452.14 \\
\hline Observations & 3956 & 3903 & 3956 & 3956 & 3956 \\
\hline
\end{tabular}

\section{Model 2}

In Table 5.3, we control for student background variables such as gender, age, immigrant status and economic, social and cultural status (ESCS). The gender and immigrant status variables are dummy-coded. With regard to the immigrant status, we distinguish between native students, first-generation students and secondgeneration students. Male and native students serve as reference group for the respective variables.

Compared to the results in Table 5.2, the positive effect of environmental education on environmental awareness has been reduced in magnitude and is no longer statistically significant when controlling for demographic factors at the student-level. Similar to the results presented in Table 5.2, we do not find empirical evidence for a strong relationship between environmental education and awareness of RETs. In this model, we also start addressing our third research question, namely to what extent individual-level characteristics determine environmental literacy. 
Table 5.3 Environmental Education and Environmental Output Measures, Controlling for Personal Characteristics at Individual Level (Model 2)

\begin{tabular}{|c|c|c|c|c|c|}
\hline & $\begin{array}{c}(1) \\
\text { Envaware }\end{array}$ & $\begin{array}{c}(2) \\
\text { Retaware }\end{array}$ & $\begin{array}{c}(3) \\
\text { Respdev }\end{array}$ & $\begin{array}{c}\text { (4) } \\
\text { Envopt }\end{array}$ & $\begin{array}{c}(5) \\
\text { Envperc }\end{array}$ \\
\hline \multicolumn{6}{|l|}{ Fixed Effects } \\
\hline Envlearn & $\begin{array}{c}0.04 \\
(0.03)\end{array}$ & $\begin{array}{l}-0.02 \\
(0.05)\end{array}$ & $\begin{array}{c}0.02 \\
(0.01)\end{array}$ & $\begin{array}{l}-0.04 \\
(0.04)\end{array}$ & $\begin{array}{l}-0.00 \\
(0.02)\end{array}$ \\
\hline Female & $\begin{array}{c}0.00 \\
(0.03)\end{array}$ & $\begin{array}{c}-0.20^{* * *} \\
(0.08)\end{array}$ & $\begin{array}{l}-0.05^{* *} \\
(0.02)\end{array}$ & $\begin{array}{c}-0.03 \\
(0.04)\end{array}$ & $\begin{array}{l}0.20^{* * *} \\
(0.03)\end{array}$ \\
\hline Age & $\begin{array}{c}0.13^{* * *} \\
(0.05)\end{array}$ & $\begin{array}{l}-0.13 \\
(0.13)\end{array}$ & $\begin{array}{l}-0.00 \\
(0.04)\end{array}$ & $\begin{array}{l}-0.06 \\
(0.07)\end{array}$ & $\begin{array}{c}0.07 \\
(0.04)\end{array}$ \\
\hline Generation 1 & $\begin{array}{c}0.50 \\
(0.58)\end{array}$ & $\begin{array}{c}12.45 \\
(505.73)\end{array}$ & $\begin{array}{l}-0.39 \\
(0.49)\end{array}$ & $\begin{array}{c}0.30 \\
(0.82)\end{array}$ & $\begin{array}{c}0.34 \\
(0.55)\end{array}$ \\
\hline Generation2 & $\begin{array}{l}-0.45^{*} \\
(0.25)\end{array}$ & $\begin{array}{l}-0.82 \\
(0.64)\end{array}$ & $\begin{array}{c}-0.17 \\
(0.21)\end{array}$ & $\begin{array}{c}0.51 \\
(0.35)\end{array}$ & $\begin{array}{l}-0.46^{*} \\
(0.24)\end{array}$ \\
\hline ESCS & $\begin{array}{c}0.13^{* * *} \\
(0.01)\end{array}$ & $\begin{array}{l}0.10^{* * *} \\
(0.03)\end{array}$ & $\begin{array}{c}0.06^{* * *} \\
(0.01)\end{array}$ & $\begin{array}{c}-0.10^{* * *} \\
(0.02)\end{array}$ & $\begin{array}{l}-0.00 \\
(0.01)\end{array}$ \\
\hline Intercept & $\begin{array}{c}-2.36^{* * *} \\
(0.73)\end{array}$ & $\begin{array}{c}3.21^{* * *} \\
(2.03)\end{array}$ & $\begin{array}{c}0.19 \\
(0.62)\end{array}$ & $\begin{array}{c}1.19 \\
(1.04)\end{array}$ & $\begin{array}{l}-0.50 \\
(0.70)\end{array}$ \\
\hline \multicolumn{6}{|c|}{ Random Effects } \\
\hline sd (Envlearn) & $\begin{array}{c}0.00 \\
(0.00)\end{array}$ & $\begin{array}{c}0.00 \\
(0.12)\end{array}$ & $\begin{array}{c}0.01 \\
(0.01)\end{array}$ & $\begin{array}{c}0.00 \\
(0.00)\end{array}$ & $\begin{array}{c}0.00 \\
(0.00)\end{array}$ \\
\hline sd (Intercept) & $\begin{array}{c}0.25 \\
(0.02)\end{array}$ & $\begin{array}{c}0.23 \\
(0.07)\end{array}$ & $\begin{array}{c}0.08 \\
(0.02)\end{array}$ & $\begin{array}{c}0.34 \\
(0.03)\end{array}$ & $\begin{array}{c}0.13 \\
(0.02)\end{array}$ \\
\hline sd (Residual) & $\begin{array}{c}0.80 \\
(0.01)\end{array}$ & & $\begin{array}{c}0.68 \\
(0.01)\end{array}$ & $\begin{array}{c}1.14 \\
(0.01)\end{array}$ & $\begin{array}{c}0.77 \\
(0.01)\end{array}$ \\
\hline \multicolumn{6}{|c|}{ Model Fit Statistics } \\
\hline Deviance & 9441.90 & 4478.38 & 8049.06 & 12138.62 & 9040.66 \\
\hline AIC & 9461.90 & 4496.38 & 8069.06 & 12158.62 & 9060.66 \\
\hline $\mathrm{BIC}$ & 9524.46 & 4552.57 & 8131.63 & 12221.18 & 9123.23 \\
\hline Observations & 3852 & 3805 & 3852 & 3852 & 3852 \\
\hline
\end{tabular}

Note: Standard errors are shown in parentheses. ${ }^{* * *}$ denotes significance at the $1 \%$ level, ${ }^{* *}$ at the $5 \%$ level, ${ }^{*}$ at the $10 \%$ level.

Age is positively correlated with environmental awareness. However, we do not want to overemphasize the positive coefficient on age as the analysis only includes 15- and 16-year old students. What is however very interesting is the fact that native Colombian students (e.g. students who have at least one parent born in Colombia), tend to be more aware of environmental issues than second-generation immigrant students. Probably not very surprisingly, a higher socio-economic status coincides with a higher level of environmental awareness. The same is true when we use awareness for RETs as dependent variable. Once again, the coefficient on 
ESCS is positive and highly statistically significant. While we did not find a significant relationship between gender and environmental awareness, we do so for awareness of RETs. The negative coefficient on female suggests that Colombian female students are less aware of renewable energy technologies if compared to Colombian male students.

Overall, the results displayed in Table 5.3 show that when controlling for individual-level demographic characteristics, environmental education is not statistically significant anymore regardless of the environmental output measure used. Gender is not only statistically significant when examining awareness for RETs, but it is also highly statistically significant when examining responsibility for sustainable development and perception of environmental issues. Our data suggests that women tend to feel less responsible for sustainable development than men but tend to have a stronger perception of environmental issues than men, ceteris paribus. The only variable that has sufficient explanatory power in all six specifications is the socio-economic status of the student. The higher the socioeconomic status of a Colombian student the more concerned he/she is with environmental issues than those Colombian students that have low ESCS, ceteris paribus. This result can be interpreted as empirical support for the sociological theory of post-materialism (Inglehart 1977; Inglehart 1990; Inglehart 1997), whereby environmental awareness is strongly influenced by economic development at the country level and a higher socio-economic status at the individual level (see also Brechin 1999; Franzen 2003; Kidd and Lee 1997; Panayotou 1993; Panayotou 1997).

\section{Model 3}

Since "most environmental topics (e.g. photosynthesis, biodiversity etc.) and issues (e.g. biodiversity loss, habitat fragmentation etc.) have underlying scientific principles drawing from different science fields (e.g. chemistry or mathematics)" (Coertjens et al. 2010, 498), we also need to control for students' science abilities (i.e. knowledge and skills). While previous studies aggregated science teaching methods scores (Scintact, Schands, Scinvest, and Scapply) for each school based on the indexes of science teaching methods at student level (Coertjens et al. 2010; Lin and Shi 2014), we do not aggregate the science ability indexes for each school but use those indices at the student level to test whether differences in the science ability of individuals have sufficient explanatory power (Table 5.4). 
Table 5.4 Environmental Education and Environmental Output Measures, Controlling for Science Characteristics at Individual Level (Model 3)

\begin{tabular}{|c|c|c|c|c|c|}
\hline & $\begin{array}{c}(1) \\
\text { Envaware }\end{array}$ & $\begin{array}{c}(2) \\
\text { Retaware }\end{array}$ & $\begin{array}{c}(3) \\
\text { Respdev }\end{array}$ & $\begin{array}{c}\text { (4) } \\
\text { Envopt }\end{array}$ & $\begin{array}{c}(5) \\
\text { Envperc }\end{array}$ \\
\hline \multicolumn{6}{|l|}{ Fixed Effects } \\
\hline Envlearn & $\begin{array}{l}0.07^{\text {** }} \\
(0.03)\end{array}$ & $\begin{array}{c}0.07 \\
(0.05)\end{array}$ & $\begin{array}{l}0.04^{* * *} \\
(0.02)\end{array}$ & $\begin{array}{l}-0.07^{*} \\
(0.04)\end{array}$ & $\begin{array}{l}-0.00 \\
(0.02)\end{array}$ \\
\hline JoyScie & $\begin{array}{c}0.21^{* * *} \\
(0.02)\end{array}$ & $\begin{array}{l}0.15^{* * *} \\
(0.05)\end{array}$ & $\begin{array}{l}0.14^{* * *} \\
(0.01)\end{array}$ & $\begin{array}{c}0.02 \\
(0.03)\end{array}$ & $\begin{array}{l}0.10^{* * *} \\
(0.02)\end{array}$ \\
\hline ScApply & $\begin{array}{c}0.07^{* * *} \\
(0.02)\end{array}$ & $\begin{array}{c}0.07 \\
(0.05)\end{array}$ & $\begin{array}{l}0.08^{* * *} \\
(0.01)\end{array}$ & $\begin{array}{l}-0.02 \\
(0.03)\end{array}$ & $\begin{array}{c}0.07^{* * *} \\
(0.02)\end{array}$ \\
\hline ScIntact & $\begin{array}{c}0.08^{* * *} \\
(0.02)\end{array}$ & $\begin{array}{l}-0.00 \\
(0.05)\end{array}$ & $\begin{array}{l}0.07^{* * *} \\
(0.02)\end{array}$ & $\begin{array}{c}-0.11^{* * *} \\
(0.03)\end{array}$ & $\begin{array}{l}0.03^{*} \\
(0.02)\end{array}$ \\
\hline ScInvest & $\begin{array}{c}-0.07^{* * *} \\
(0.02)\end{array}$ & $\begin{array}{l}-0.01 \\
(0.05)\end{array}$ & $\begin{array}{c}-0.03^{* *} \\
(0.01)\end{array}$ & $\begin{array}{c}0.19^{* * *} \\
(0.03)\end{array}$ & $\begin{array}{c}-0.08^{* * *} \\
(0.02)\end{array}$ \\
\hline ScHands & $\begin{array}{c}-0.66^{* * *} \\
(0.03)\end{array}$ & $\begin{array}{c}0.06 \\
(0.01)\end{array}$ & $\begin{array}{c}-0.08^{* * *} \\
(0.02)\end{array}$ & $\begin{array}{l}0.24^{* * *} \\
(0.04)\end{array}$ & $\begin{array}{c}0.67^{* * *} \\
(0.02)\end{array}$ \\
\hline Intercept & $\begin{array}{c}-0.66^{* * *} \\
(0.03)\end{array}$ & $\begin{array}{l}0.77^{* * *} \\
(0.06)\end{array}$ & $\begin{array}{c}-0.08^{* * *} \\
(0.02)\end{array}$ & $\begin{array}{l}0.24^{* * *} \\
(0.04)\end{array}$ & $\begin{array}{c}0.67^{* * *} \\
(0.02)\end{array}$ \\
\hline \multicolumn{6}{|c|}{ Random Effects } \\
\hline sd (Envlearn) & $\begin{array}{c}0.00 \\
(0.00)\end{array}$ & $\begin{array}{c}0.00 \\
(0.23)\end{array}$ & $\begin{array}{c}0.06 \\
(0.03)\end{array}$ & $\begin{array}{c}0.00 \\
(0.00)\end{array}$ & $\begin{array}{c}0.05 \\
(0.06)\end{array}$ \\
\hline sd (Intercept) & $\begin{array}{c}0.30 \\
(0.02)\end{array}$ & $\begin{array}{c}0.28 \\
(0.06)\end{array}$ & $\begin{array}{c}0.11 \\
(0.02)\end{array}$ & $\begin{array}{c}0.37 \\
(0.30)\end{array}$ & $\begin{array}{c}0.13 \\
(0.03)\end{array}$ \\
\hline sd (Residual) & $\begin{array}{c}0.78 \\
(0.01)\end{array}$ & & $\begin{array}{c}0.66 \\
(0.01)\end{array}$ & $\begin{array}{c}1.14 \\
(0.01)\end{array}$ & $\begin{array}{c}0.77 \\
(0.01)\end{array}$ \\
\hline \multicolumn{6}{|c|}{ Model Fit Statistics } \\
\hline Deviance & 9281.62 & 4544.17 & 7884.39 & 12149.32 & 9059.50 \\
\hline AIC & 9301.62 & 4562.17 & 7904.39 & 12169.32 & 9079.50 \\
\hline $\mathrm{BIC}$ & 9364.21 & 4618.44 & 7966.99 & 12231.91 & 9142.09 \\
\hline Observations & 3863 & 3838 & 3863 & 3863 & 3863 \\
\hline
\end{tabular}

Note: Standard errors are shown in parentheses. ${ }^{* * *}$ denotes significance at the $1 \%$ level, ${ }^{* *}$ at the $5 \%$ level, ${ }^{*}$ at the $10 \%$ level.

When controlling for students' science abilities, environmental education has once again a positive and statistically significant effect on environmental awareness, but also on responsibility for sustainable development in general. Environmental education, however, does not have a significant influence on awareness for RETs. Like in Model 1, environmental education impacts environmental optimism negatively. 
In five out of six cases, the coefficient on enjoyment of science is highly statistically significant and positive. Colombian students that tend to show a greater enjoyment of learning science are found to be more environmentally literate, holding all other factors constant. Our empirical findings are therefore in line with previous results by Littledyke, (2008) who found a positive relationship between enjoyment of science and environmental attitudes.

All science ability variables are important in explaining student's environmental awareness. Students that report (i) a strong focus on model or applications in science teaching and (ii) higher levels of student interaction in their science lessons show higher levels of environmental awareness. Interestingly, higher levels of hands-on activities in science teaching and higher levels of student investigations are negatively correlated with environmental awareness. These results are very surprising and we do not have an intuitive explanation for those two findings at this stage.

With regard to awareness for RETs, we only find enjoyment of science to be (positive) statistically significant predictors. Awareness for RETs among Colombian students do not vary much based on the other student science abilities such as student interaction or student investigations. Another major observation is that several science abilities seem to negatively impact environmental optimism. More use of student investigation, more student interaction science teaching and a higher level on hands-on activities in science lessons tend to significantly lessen Colombian students' environmental optimism.

\section{Model 4}

Since families play a fundamental role in shaping students' attitudes, views and opinions about environmental issues, we also control for parent characteristics. The results are reported in Table 5.5. When examining environmental awareness, environmental education remains statistically significant at the 10 percent level.

Similar to the student science ability variables in Model 3, the majority of the parental variables have significant explanatory power. Parents' perception of environmental issues, parents' personal value of science and the level of science activities of parents at age 10 are positively correlated with students' environmental awareness. Parents' environmental optimism, however, is inversely related with students' environmental awareness and two other environmental output measures (responsibility for sustainable development and perception of environmental issues). Looking at awareness for RETs, we only find parents science activities at age 10 and parents personal value of science to be positive and statistically significant predictors. Surprisingly, the parents' view of the importance of science is negatively correlated with awareness for RETs. This results requires further investigation in the future because we do not have an intuitive explanation 
for this finding. The coefficient on environmental education, in turn, remains statistically insignificant.

Table 5.5 Environmental Education and Environmental Output Measures, Controlling for Parents Characteristics at Individual Level (Model 4)

\begin{tabular}{|c|c|c|c|c|c|}
\hline & $\begin{array}{c}\text { (1) } \\
\text { Envaware }\end{array}$ & $\begin{array}{c}(2) \\
\text { Retaware }\end{array}$ & $\begin{array}{c}(3) \\
\text { Respdev }\end{array}$ & $\begin{array}{c}\text { (4) } \\
\text { Envopt }\end{array}$ & $\begin{array}{c}(5) \\
\text { Envperc }\end{array}$ \\
\hline \multicolumn{6}{|l|}{ Fixed Effects } \\
\hline Envlearn & $\begin{array}{l}0.06^{*} \\
(0.03)\end{array}$ & $\begin{array}{c}0.00 \\
(0.05)\end{array}$ & $\begin{array}{l}0.04^{* *} \\
(0.02)\end{array}$ & $\begin{array}{l}-0.03 \\
(0.03)\end{array}$ & $\begin{array}{l}-0.02 \\
(0.02)\end{array}$ \\
\hline PqEnperc & $\begin{array}{l}0.07^{* * *} \\
(0.02)\end{array}$ & $\begin{array}{l}-0.00 \\
(0.05)\end{array}$ & $\begin{array}{l}0.04^{* *} \\
(0.02)\end{array}$ & $\begin{array}{l}-0.01 \\
(0.03)\end{array}$ & $\begin{array}{c}0.28^{* * *} \\
(0.02)\end{array}$ \\
\hline PqEnvopt & $\begin{array}{c}-0.05^{* * *} \\
(0.01)\end{array}$ & $\begin{array}{l}-0.01 \\
(0.03)\end{array}$ & $\begin{array}{c}-0.03^{* * *} \\
(0.01)\end{array}$ & $\begin{array}{c}0.38^{* * *} \\
(0.02)\end{array}$ & $\begin{array}{c}-0.02^{* *} \\
(0.01)\end{array}$ \\
\hline PqScimp & $\begin{array}{l}-0.00 \\
(0.02)\end{array}$ & $\begin{array}{l}-0.09^{*} \\
(0.05)\end{array}$ & $\begin{array}{c}0.02 \\
(0.01)\end{array}$ & $\begin{array}{c}0.01 \\
(0.02)\end{array}$ & $\begin{array}{l}-0.00 \\
(0.02)\end{array}$ \\
\hline PqPersci & $\begin{array}{l}0.05^{* * *} \\
(0.02)\end{array}$ & $\begin{array}{c}0.17^{* * *} \\
(0.05)\end{array}$ & $\begin{array}{c}0.08^{* * *} \\
(0.01)\end{array}$ & $\begin{array}{c}0.07^{* * *} \\
(0.02)\end{array}$ & $\begin{array}{l}-0.01 \\
(0.02)\end{array}$ \\
\hline PqSciact & $\begin{array}{l}0.14^{* * *} \\
(0.01)\end{array}$ & $\begin{array}{l}0.15^{* * *} \\
(0.04)\end{array}$ & $\begin{array}{l}0.05^{* * *} \\
(0.01)\end{array}$ & $\begin{array}{l}-0.03^{*} \\
(0.02)\end{array}$ & $\begin{array}{l}-0.00 \\
(0.01)\end{array}$ \\
\hline Intercept & $\begin{array}{c}-0.55^{* * *} \\
(0.03)\end{array}$ & $\begin{array}{c}0.77^{* * *} \\
(0.06)\end{array}$ & $\begin{array}{l}-0.02 \\
(0.02)\end{array}$ & $\begin{array}{l}0.20^{* * *} \\
(0.04)\end{array}$ & $\begin{array}{l}0.68^{* * *} \\
(0.02)\end{array}$ \\
\hline \multicolumn{6}{|c|}{ Random Effects } \\
\hline sd (Envlearn) & $\begin{array}{c}0.00 \\
(0.00)\end{array}$ & $\begin{array}{c}0.00 \\
(0.00)\end{array}$ & $\begin{array}{c}0.06 \\
(0.03)\end{array}$ & $\begin{array}{c}0.00 \\
(0.00)\end{array}$ & $\begin{array}{c}0.00 \\
(0.00)\end{array}$ \\
\hline sd (Intercept) & $\begin{array}{c}0.29 \\
(0.02)\end{array}$ & $\begin{array}{c}0.29 \\
(0.06)\end{array}$ & $\begin{array}{c}0.08 \\
(0.03)\end{array}$ & $\begin{array}{c}0.27 \\
(0.03)\end{array}$ & $\begin{array}{c}0.11 \\
(0.02)\end{array}$ \\
\hline sd (Residual) & $\begin{array}{c}0.79 \\
(0.01)\end{array}$ & & $\begin{array}{c}0.68 \\
(0.01)\end{array}$ & $\begin{array}{c}1.08 \\
(0.01)\end{array}$ & $\begin{array}{c}0.76 \\
(0.01)\end{array}$ \\
\hline \multicolumn{6}{|c|}{ Model Fit Statistics } \\
\hline Deviance & 8818.52 & 4231.93 & 7569.15 & 10985.34 & 8328.47 \\
\hline AIC & 8838.52 & 4249.93 & 7589.15 & 11005.34 & 8348.47 \\
\hline $\mathrm{BIC}$ & 8900.49 & 4305.59 & 7651.12 & 11067.30 & 8410.43 \\
\hline Observations & 3628 & 3583 & 3628 & 3628 & 3628 \\
\hline
\end{tabular}

Note: Standard errors are shown in parentheses. ${ }^{* * *}$ denotes significance at the $1 \%$ level, ${ }^{* *}$ at the $5 \%$ level, ${ }^{*}$ at the $10 \%$ level.

When examining students' varying levels of environmental optimism and perception of environmental issues, we observe that the strongest predictors (in terms of magnitude) for the respective outcome variables are parents' environmental optimism (coefficient $=0.38$ ) and parents' perception of environmental issues (coefficient $=0.28$ ), respectively. Or put differently, a higher 
level of parents' environmental optimism is associated with a higher level of environmental optimism among students. The same is true for perception of environmental issues. These effects are much greater than the parental impact on students' environmental awareness and awareness for RETs.

Our results confirm the notion that students often share their parents' views towards the environment. Parents that show a stronger environmental literacy and a stronger sense of responsibility towards environmental issues create an environment in which a child or student may feel more susceptible towards environmental issues. Our empirical findings do, however, also suggest that this relationship is much more pronounced with regard to feelings of optimism or general perceptions than with actual awareness or a sense of personal responsibility.

\section{Model 5}

In the previous models we have explored the relationship between environmental literacy and environmental education controlling for student-level characteristics. In Model 5, we will address our fourth research question by accounting for schoollevel characteristics. We investigate to what extent does the school 'infrastructure' (public versus private, school size, teacher-student ratio, teacher shortage, proportion of qualified/certified teachers, quality of educational resources, etc.) promote environmental awareness and awareness for RETs. The results are displayed in Table 5.6.

When controlling for school-level characteristics, environmental education no longer exerts a positive impact on environmental awareness. The negative and statistically significant coefficient on public schools suggests that, holding all other factors constant, students in Colombian public school have a lower level of environmental awareness if compared to students in Colombian private schools. At the same time, the quality of educational resources has a significant effect on environmental awareness. Since teacher shortage is measured on a negative scale, the negative coefficient on teacher shortage suggests that a teacher shortage impacts environmental awareness negatively, ceteris paribus: the higher the level of teacher shortage, the lower the level of students' environmental awareness. Our first tentative explanation for this result is that school classes that suffer from teacher shortage do not have adequate human resources to provide high quality instruction in all fields of education, including science and environment. 
Table 5.6 Environmental Education and Environmental Output Measures, Controlling for School Characteristics at School Level (Model 5)

\begin{tabular}{|c|c|c|c|c|c|}
\hline & $\begin{array}{c}(1) \\
\text { Envaware }\end{array}$ & $\begin{array}{c}(2) \\
\text { Retaware }\end{array}$ & $\begin{array}{c}(3) \\
\text { Respdev }\end{array}$ & $\begin{array}{c}\text { (4) } \\
\text { Envopt }\end{array}$ & $\begin{array}{c}(5) \\
\text { Envperc }\end{array}$ \\
\hline \multicolumn{6}{|l|}{ Fixed Effects } \\
\hline Env. Education & $\begin{array}{c}0.02 \\
(0.03)\end{array}$ & $\begin{array}{l}-0.01 \\
(0.05)\end{array}$ & $\begin{array}{c}0.03 \\
(0.02)\end{array}$ & $\begin{array}{l}-0.02 \\
(0.04)\end{array}$ & $\begin{array}{l}-0.01 \\
(0.02)\end{array}$ \\
\hline Public & $\begin{array}{l}-0.23^{* *} \\
(0.11)\end{array}$ & $\begin{array}{l}-0.20 \\
(0.17)\end{array}$ & $\begin{array}{l}-0.08 \\
(0.05)\end{array}$ & $\begin{array}{l}0.15 \\
(0.14)\end{array}$ & $\begin{array}{c}0.02 \\
(0.07)\end{array}$ \\
\hline Log School Size & $\begin{array}{c}0.05 \\
(0.05)\end{array}$ & $\begin{array}{l}-0.06 \\
(0.08)\end{array}$ & $\begin{array}{l}-0.02 \\
(0.02)\end{array}$ & $\begin{array}{c}0.09 \\
(0.06)\end{array}$ & $\begin{array}{l}-0.04 \\
(0.03)\end{array}$ \\
\hline $\begin{array}{l}\text { Log Student- } \\
\text { Teacher Ratio }\end{array}$ & $\begin{array}{l}-0.06 \\
(0.06)\end{array}$ & $\begin{array}{c}0.02 \\
(0.02)\end{array}$ & $\begin{array}{l}-0.01 \\
(0.03)\end{array}$ & $\begin{array}{l}-0.03 \\
(0.07)\end{array}$ & $\begin{array}{c}0.01 \\
(0.04)\end{array}$ \\
\hline Teacher Shortage & $\begin{array}{l}0.05^{*} \\
(0.03)\end{array}$ & $\begin{array}{l}0.09^{*} \\
(0.04)\end{array}$ & $\begin{array}{l}0.02^{*} \\
(0.01)\end{array}$ & $\begin{array}{l}-0.07^{* *} \\
(0.04)\end{array}$ & $\begin{array}{l}0.04^{* *} \\
(0.02)\end{array}$ \\
\hline Certified Teachers & $\begin{array}{c}0.17 \\
(0.11)\end{array}$ & $\begin{array}{c}0.06 \\
(0.17)\end{array}$ & $\begin{array}{l}0.05 \\
(0.06)\end{array}$ & $\begin{array}{l}-0.19 \\
(0.14)\end{array}$ & $\begin{array}{l}0.20^{* * *} \\
(0.07)\end{array}$ \\
\hline $\begin{array}{l}\text { Quality of Educat. } \\
\text { Resources }\end{array}$ & $\begin{array}{l}0.06^{*} \\
(0.04)\end{array}$ & $\begin{array}{c}0.07 \\
(0.05)\end{array}$ & $\begin{array}{l}0.04^{* *} \\
(0.02)\end{array}$ & $\begin{array}{l}-0.09^{* *} \\
(0.05)\end{array}$ & $\begin{array}{c}0.01 \\
(0.02)\end{array}$ \\
\hline Curriculum & $\begin{array}{c}0.02 \\
(0.04)\end{array}$ & $\begin{array}{l}0.11^{*} \\
(0.06)\end{array}$ & $\begin{array}{l}0.04^{*} \\
(0.02)\end{array}$ & $\begin{array}{l}-0.01 \\
(0.05)\end{array}$ & $\begin{array}{c}0.02 \\
(0.03)\end{array}$ \\
\hline Intercept & $\begin{array}{l}-0.49^{* *} \\
(0.21)\end{array}$ & $\begin{array}{l}1.52^{* * *} \\
(0.36)\end{array}$ & $\begin{array}{l}0.29^{* * *} \\
(0.11)\end{array}$ & $\begin{array}{l}-0.24 \\
(0.28)\end{array}$ & $\begin{array}{c}0.78^{* * *} \\
(0.14)\end{array}$ \\
\hline \multicolumn{6}{|l|}{ Random Effects } \\
\hline sd (Envlearn) & $\begin{array}{c}0.00 \\
(0.00)\end{array}$ & $\begin{array}{c}0.00 \\
(0.00)\end{array}$ & $\begin{array}{c}0.00 \\
(0.00)\end{array}$ & $\begin{array}{c}0.00 \\
(0.00)\end{array}$ & $\begin{array}{c}0.00 \\
(0.00)\end{array}$ \\
\hline sd (Intercept) & $\begin{array}{c}0.27 \\
(0.02)\end{array}$ & $\begin{array}{c}0.19 \\
(0.09)\end{array}$ & $\begin{array}{c}0.07 \\
(0.02)\end{array}$ & $\begin{array}{c}0.33 \\
(0.03)\end{array}$ & $\begin{array}{c}0.12 \\
(0.02)\end{array}$ \\
\hline sd (Residual) & $\begin{array}{c}0.82 \\
(0.01) \\
\end{array}$ & & $\begin{array}{c}0.69 \\
(0.01) \\
\end{array}$ & $\begin{array}{c}1.14 \\
(0.01) \\
\end{array}$ & $\begin{array}{c}0.79 \\
(0.01) \\
\end{array}$ \\
\hline \multicolumn{6}{|l|}{ Model Fit Statistics } \\
\hline Deviance & 7553.95 & 3568.82 & 6427.38 & 9574.49 & 7240.74 \\
\hline AIC & 7577.95 & 3590.82 & 6451.38 & 9598.49 & 7264.74 \\
\hline $\mathrm{BIC}$ & 7650.20 & 3656.90 & 6523.63 & 9670.74 & 7336.99 \\
\hline Observations & 3043 & 3003 & 3043 & 3043 & 3043 \\
\hline
\end{tabular}

Note: Standard errors are shown in parentheses. ${ }^{* * *}$ denotes significance at the $1 \%$ level, ${ }^{* *}$ at the $5 \%$ level, ${ }^{*}$ at the $10 \%$ level.

The relationship between environmental education and awareness for RETs remains statistically insignificant even after controlling for school-level characteristics. The results in column (2) show that most school-level determinants of RET awareness are not statistically significant. The exception is the positive 
coefficient on both teacher shortage and school autonomy ('curriculum'). Schools with lower levels of teacher shortage and schools with a higher autonomy in making decisions about curricula and assessments exert a positive effect on the students' awareness of RETs. Teacher shortage also has a significant negative impact on responsibility for sustainable development and perceptions of environmental issues. When using environmental optimism as output measure, we find the opposite: a higher level of teacher shortage is correlated with a higher level of environmental optimism.

Another variable that has some explanatory power is the quality of educational resources. It is significant in three out of six cases. A better quality of educational resources is not only associated with a higher level of environmental awareness but also with a higher responsibility for sustainable development and a more pessimistic environmental outlook.

\subsection{Discussion and Concluding Remarks}

The overarching objective of this chapter has been to contribute to the knowledge of how to reduce the impact of the rebound effect and generate a potentially postive framework condition for RETs adoption. By focusing on what effect environmental education can have on generating environmental awareness in 15year olds in a developing country, the aim has been to contribute to widening the knowledge pertaining to these broader sustainability challenges.

To summarize, we found weak evidence that environmental education can promote a higher level of environmental awareness. This is not the case for RETs awareness, however. Moreover, the empirical analysis above indicates that the determinants of environmental awareness and awareness for RETs vary significantly. Our results also suggest that there seem to be more reliable predictors for environmental awareness than for awareness of RETs. In general, the socioeconomic status, stronger student science abilities, several parent characteristics and a few school-level characteristics such as quality of education resources and school ownership (public versus private) seem to be decisive factors for varying levels of environmental awareness among students in Colombia.

Our results have shown that, depending on which environmental output measure is chosen, both individual-level variables and school-level variables had similar and different effects on environmental literacy. The most robust explanatory variables in understanding different levels of environmental literacy were the students' socio-economic status (significant in five out of six cases), students' enjoyment of science (significant in five out of six cases), hands-on activities in science lessons (significant in all six cases), parents' science activities at age 10 (significant in five out of six cases) and teacher shortage (significant in five out of six cases). 
Several other parental and science ability characteristics appeared to have an impact on specific environmental output measures. Overall, a stronger environmental knowledge through students' parents and science lessons taught in school tend to promote a higher level of environmental awareness while also contributing to a less optimistic outlook. In contrast, other individual student-level factors such as gender or immigration status or other school-level variables such as school ownership, school size or student-teacher ratio appear to have little influence on environmental literacy in Colombia. All in all, we do not find systematic empirical evidence that school-level characteristics 'trump' studentlevel characteristics in explaining students' environmental awareness, attitudes, optimism or perception. Environmental awareness, beliefs and attitudes do not develop/exist in isolation. Environmental literacy is shaped through the family environment, the socio-economic status, environmental education, the school 'infrastructure' and several other factors. Our study supports Kollmuss and Agyeman (2002) theoretical viewpoint that both internal and external factors encourage enhanced environmental literacy.

The empirical results presented in this chapter suggest that environmental education should not be considered a silver bullet in promoting environmental literacy among young people. This does not mean that schools should reduce their efforts in emphasizing and promoting environmental education at school. Schools can to some extent promote more pro-environmental attitudes in their students in both developed countries (Coertjens et al. 2010; Lin and Shi 2014) and in developing countries (this chapter). We do, however, conclude that strengthening environmental education in school curricula is a necessary but not sufficient condition for improving environmental awareness among the youth. Since a child spends most time with, and learns from, parents in a particular socio-economic environment, parents do play a crucial role in the environmental education of their child. Moreover, since several developing countries may either lack the human resources, or the financial resources (or both) to effectively improve the quality and quantity of environmental education in school curricula, environmental literacy must be supported with both national and global political leadership.

While the study provides a number of insights, there are limitations. First, even though PISA data offers a wide range of student information, PISA assesses only a limited amount of what is actually taught in schools and collects very little data on the role and contribution of teachers (see also Mortimore 2009). Second our study uses cross-sectional data which prevents us from analyzing the impact of environmental education on environmental output measures over time. Third, our multilevel analysis does not allow for causal inferences. Even in those cases where Envaware and Envedu are positively correlated, we do not know the direction of influence and we cannot rule out the possibility that causality could run both ways. Fourth, our model did not account for potential regional differences across Colombian schools. As discussed above, environmental literacy could vary 
significantly depending on whether (i) the school is located in a rural or urban area, and (ii) whether the students live in an urban or rural context.

Our empirical results call for further research. Future research studies should investigate to what extent the impact of environmental education on environmental awareness and RETs varies between different developing countries. Another interesting research question is to what extent environmental education can induce a change in behavior and attitudes towards environmental issues over the long-run. Moreover, research that investigates to what extent environmental education aimed at children can influence environmental literacy of parents is still at its infancy (see Damerell, Howe, and Milner-Gulland 2013). Lastly, in line with Coertjens et al. (2010), more international comparative research is vital to test our and previous results in other educational, cultural, social and economic settings. 


\section{Chapter 6. Framework Conditions of Technological Transition: Re-thinking the Boundary for a Technological Innovation System}

\subsection{Introduction}

The integral activities of a technological transition have been studied to great length in the technological innovation systems' literature, resulting in several lists of processes or 'functions' deemed essential for the generation, development, diffusion and utilization of a new technology (Johnson and Jacobsson 2001; Edquist 2005; S. Jacobsson and Bergek 2006; Hekkert et al. 2007). These lists of functions have been both developed and empirically tested in high-income industrialized countries such as Sweden, the Netherlands and Germany (Negro, Hekkert, and Smits 2007; Negro, Suurs, and Hekkert 2008; Negro and Hekkert 2008; Hillman et al. 2008). By making certain adjustments to the lists of functions (Chapter 3), the TIS function approach, initially developed for high-income industrialized nations, has also been used for empirical analyses of technological adoption in low and middle-income developing countries (e.g., Chapter 4 of this thesis; van Alphen, Hekkert, and van Sark 2008). ${ }^{92}$

While these integral activities of the inner workings of the technological system have received much focus in the analysis of technological innovation and in helping delimit the system, certain aspects of the contextual setting in which a technological sector operates have received less attention. With the exception of institutions, other socio-political contextual factors or framework conditions, have been regarded as external factors, and consequently insufficiently mapped as part of the system. While several authors (e.g., Hekkert and Negro 2009; S. Jacobsson and Bergek 2006) have raised the potential relevance of these external factors, they have not been analyzed in an explicit and systematic manner. Moreover, when mentioned in previous TIS literature external factors have been predominately discussed in the context of high-income countries. There is scattered reporting in the literature on renewable energy diffusion in developing countries of the influence of external factors, but this has not been sufficiently synthesized nor

\footnotetext{
92 This chapter uses the income classification (GNI per capita) by the World Bank. For the fiscal year of 2017 , low-income economies are those of $\$ 1,025$ or less in 2015 ; lower middle-income economies are those between $\$ 1,026$ and $\$ 4,035$; upper middle-income economies are those between $\$ 4,036$ and $\$ 12,475$; high-income economies have a GNI per capita of $\$ 12,476$ or more (The World Bank 2016b).
} 
conceptualized to allow for a systematic analysis of how these factors may influence technological innovation.

In an attempt to develop a comprehensive framework for analyzing technological change in developing countries, Chapter 3 took one step towards explicitly including a number of external factors to complement the TIS function analysis. By taking a step back from the technological innovation systems approach (Ch. 3 and 4), and instead discussing technological innovation from a wider systems perspective, this chapter aims to specifically advance the knowledge about the number and type of possible framework conditions, and whether they should be considered endogenous or exogenous to the system. In order to avoid confusion, framework conditions will predominately be used in this chapter to describe 'external' or contextual factors. More specifically, by placing focus on sociopolitical framework conditions, the aim of the chapter is to: 1) identify relevant framework conditions and how these conditions may vary for countries of different income category; 2) discuss in what ways these framework conditions may influence the system; 3 ) contribute to the debate about the boundaries within the systems of innovation approach, i.e., where the boundary of the system should be drawn; and 4) discuss the implications that framework conditions can have on policy.

Section 6.2 will review some early developments and use of systems. This will be followed by a discussion of the background, key concepts and remaining challenges of the systems of innovation approach (section 6.3). In section 6.4, data from previous empirical studies concerning framework conditions from countries of different income categories will be reviewed. Based on the results from these theoretical and empirical sections, reflections on the implications for the boundaries of systems in developing and high-income countries will be carried out in section 6.5. Section 6.6. will conclude.

\subsection{Using Systems Thinking for Studying Innovation}

A systems approach has been increasingly used in the last decades to analyze the complexity and the nonlinearity in response to policy interventions resulting from feedback loops in the context of innovation (Edquist 1997). As can be derived from its name, the Technological Innovation System Approach focuses on the generation, diffusion and utilization of a technology (Carlsson and Stankiewicz 1991). Other innovation systems such as Sectoral Innovation Systems (SIS) (Breschi and Malerba 1997) and Regional Innovation Systems (RIS) (Cooke, Uranga, and Etxebarria 1997; Saxenian 1994) have been used to analyze innovation activities in a specific sector or region.

The most common of the different innovation systems is the National Innovation Systems (NIS) approach. The concept of national systems of innovation was first 
expressed by Christopher Freeman (1987) in a combined analysis of Japan's economic and technological policy and development. Besides Freeman, the NIS was also discussed as a concept and developed by Nelson (1993) and Lundvall (1992). The definition of what makes up an NIS differs slightly between the authors, but their concepts still share several central elements, also with the Technological Innovation System (TIS) approach, namely the focus on technological innovation and the importance of institutions (Edquist 1997) (Table $6.1)$.

Table 6.1 Definitions of Systems of Innovation

\begin{tabular}{|l|l|l}
\hline \multicolumn{2}{|c|}{ NIS } & \multicolumn{1}{c}{ TIS } \\
\hline \multicolumn{1}{|c|}{ Freeman (1987) } & \multicolumn{1}{|c}{ Lundvall (1992) } & \multicolumn{1}{c}{ Carlsson and Stankiewicz (1991) } \\
\hline $\begin{array}{l}\text { "the network of } \\
\text { institutions in the public } \\
\text { and private sectors } \\
\text { whose activities and } \\
\text { interactions initiate, } \\
\text { import, modify and } \\
\text { diffuse new } \\
\text { technologies" (Freeman } \\
\text { 1987, 1) }\end{array}$ & $\begin{array}{l}\text { Broad Definition: } \\
\text { "all parts and aspects } \\
\text { of the economic } \\
\text { structure and the } \\
\text { institutional set up } \\
\text { affecting learning as } \\
\text { well as searching and } \\
\text { exploring" (Lundvall } \\
\text { 1992, 13) }\end{array}$ & $\begin{array}{l}\text { "a network of agents interacting in } \\
\text { the economic/industrial area under } \\
\text { a particular institutional } \\
\text { infrastructure and involved in the } \\
\text { generation, diffusion and utilization } \\
\text { of technology" (Carlsson and } \\
\text { Stankiewicz 1991, 94) }\end{array}$ \\
\hline
\end{tabular}

Source: Author, based on literature as presented in table.

\subsection{Where to Draw the Line?}

One key aspect that is unclear in the discussion about innovation systems is what specifically defines the system. In other words, what should be included in the system and what should be left out? Lundvall (1992) argued for a flexible approach to deciding what processes to consider in a system. In a context of technological transition, the boundary of the system may be regional, national or even global, thus providing an exact definition of what makes up the system becomes a challenge.

Charles Edquist $(1997,14)$ solves the issue of specifying the system by defining it as being "all important economic, social, political, organizational, institutional, and other factors that influence the development, and use of innovation". Edquist (1997, 14) motivates this broad and comprehensive definition by stating that "important determinants cannot be excluded a priori if we are to be able to understand and explain innovation". Edquist $(1997,15)$ continues to recognize the monumental task of identifying all the determinants that make up the innovation system adding that "we might never be able completely to identify the determinants of innovation". 


\subsubsection{Categories of Determinants for a Systems of Innovation Approach}

Following Edquist's (1997) suggestion of specifying the boundary of a system based on its determinants, i.e., what helps the system achieve its purpose, a systematic analysis of potential candidates is necessary. Categorizing determinants in a structured manner can also serve as an important tool in the process of identifying what makes up the system, and what is irrelevant for the system to realize its objective. A first step to categorizing the determinants of innovation is differentiating integral components and activities from framework conditions of the system.

\section{Integral Components and Activities}

From a Systems of Innovation (SI) perspective, integral components that shape the formal structures of the system are a set of actors collectively denoted organizations. These actors can include firms, universities and private and/or public agencies that are engaged in the innovation activities of the system in question, with a strong focus on learning. ${ }^{93}$

In the TIS literature, activities that are considered to constitute the integral processes or functions ${ }^{94}$ of a technological system have been identified and empirically analyzed. The collection of these integral activities ${ }^{95}$ has been referred to as the focal system of technological innovation. ${ }^{96} \mathrm{~A}$ focus on these integral activities as the principal activities of the system has resulted in a delimitation of the system, where these functions are considered endogenous to the system, while factors outside of the focal system are regarded as exogenous (Bergek et al. 2015). As put by Hekkert and Negro $(2009,592)$ "the [TIS] approach focuses strongly on activities endogenous to the innovation system, rather than exogenous factors". While the relevance of these integral functions has been shown in previous literature, what is less clear is whether the focal system alone should delimit the

${ }^{93}$ Liu and White (2001) based their framework consisting of five activities on earlier research, namely: R\&D, implementation, end-use, education, and linkage.

${ }^{94}$ One example of a list of functions includes: entrepreneurial activities; knowledge development; knowledge diffusion; guidance of the search; market formation; resource mobilization; and legitimacy creation (Hekkert et al. 2007).

${ }^{95}$ Note that 'functions' and 'activities' are variations in terminology from different strand of literature that essentially describe the same aspect, namely integral processes an innovation system. For example, in the statistical measurement literature, such as the third version of the Oslo Manual, key processes for developing and implementing innovations are referred to as innovation activities rather than functions (OECD/Eurostat 2005).

${ }^{96}$ See also Chapter 2 (page 13) for additional discussion concerning definitions of the focal system. 
system. In other words, if there are additional determinants of the system that are not part of the integral functions, should these be considered endogenous to the system?

\section{Framework Conditions}

The other form of system determinants, and the main focus of this chapter are framework conditions. As shown in Table 6.1, since the origin of systems of innovation, institutions have been considered a central framework condition to the approach. While the term institutions has been used differently by various authors ${ }^{97}$, this chapter will draw on Edquist and Johnson's definition of institutions as "sets of common habits, routines, established practices, rules, or laws that regulate the relations and interactions between individuals and groups" (Edquist and Johnson 1997, 46). Edquist (2005) later extended the definition of institutions to also include the regulation of the links between organizations. Depending on the make up, quality and effectiveness of these institutions, they can provide driving or constraining conditions for technological transition.

It can also be useful to separate institutions into formal and informal, where formal institutions are e.g., "constitutions, laws, property rights," and informal refers to norms in society such as "sanctions, taboos, customs, traditions, and codes of conduct" (North 1991, 97). While the SI literature has traditionally conceptually and implicitly considered institutions as an integral framework condition for technological transitions, a systematic integration of the different aspects of institutions, particularly informal institutions, into the SI approach for empirical analyses, represents a research gap.

Beyond institutions, there are other framework conditions, such as sociopolitical and economic factors, that may constrain or drive technological transition, and that thus far have been largely overlooked, or at least "not conceptualized in a formal way" (Hekkert and Negro 2009, 592). The relevance of considering additional sociopolitical and economic framework conditions has been emphasized in another approach, namely the Multiple-Level Perspective (MLP). By including in this heuristic approach, a socio-technical landscape analysis of technological transitions, authors have more consistently raised the potential influence of factors such as "oil prices, economic growth, wars, emigration, broad political coalitions, cultural and normative values, environmental problems" (Geels 2002, 1260) or "growing environmental awareness" (Smith, Voß, and Grin 2010, 441). The MLP

${ }^{97}$ For example Lundvall (1992) mostly follows the definition of Douglas North (1991) by referring to institutions as the 'rules of the game', while Nelson and Rosenberg (1993) refer to institutions more as different types for organizations. 
literature represents one important strand of research that can support the Systems of Innovation approach to identify and systematically incorporate important framework conditions that may constrain or drive technological transitions.

\subsection{Reviewing the Evidence - A Comparative View of Framework Conditions}

Following Edquist's $(1997,14)$ broad definition of what specifies a system, this section will review previous empirical case studies across different income categories, in order to identify framework conditions that can be considered determinants for a system of innovation, and how these may differ between developing and developed countries. Moreover, an analysis of how the identified framework conditions influence and interact with the focal system will be conducted.

\subsubsection{Overview of Framework Conditions}

This section provides a comparative review of eleven studies, involving in total 24 countries of different income categories. All studies have considered various framework conditions in their analyses of technological transitions, specifically addressing the adoption of renewable energy technologies (RETs) (Table 6.2). In total, summarized over the eleven studies, 17 different framework conditions were mentioned (Table 6.3). It should be emphasized that the framework conditions included in the different studies are influenced by the design of the study. Moreover, the studies analyzed do not represent an exhaustive list of studies considering framework conditions. ${ }^{98}$ In that respect, there may be additional framework conditions that influenced the adoption of RETs in any of the countries that are not visible due to the design of the study, or that are considered in omitted studies. The purpose of this comparative literature review is not to produce a conclusive list of framework conditions, but rather to provide an initial indicative overview of relevant framework conditions acting in countries of different income categories.

\footnotetext{
${ }^{98}$ The studies were selected through a Boolean search with several combinations of the following keywords: renewable energy, transitions, (non-technical) barriers, technological innovation, and technological change. Two additional criterions were then applied, i.e., that the papers would address factors of technological change beyond the integral actors and activities, and that the selection of case studies included at least one country from each income category.
} 


\section{Table 6.2 List of Studies Included}

\begin{tabular}{|c|c|c|c|c|c|}
\hline$\#$ & Country & Income Level & Title & Author(s) & Year \\
\hline 1 & $\begin{array}{l}\text { Germany and the } \\
\text { Netherlands }\end{array}$ & $\mathrm{H}$ & $\begin{array}{l}\text { Functions of innovation systems as a framework to understand } \\
\text { sustainable technological change: Empirical evidence for earlier } \\
\text { claims }\end{array}$ & $\begin{array}{l}\text { Marko P. Hekkert, Simona O. } \\
\text { Negro }\end{array}$ & 2009 \\
\hline 2 & USA & $\mathrm{H}$ & $\begin{array}{l}\text { The cultural barriers to renewable energy and energy efficiency } \\
\text { in the United States }\end{array}$ & Sovacool & 2009 \\
\hline 3 & USA & $\mathrm{H}$ & $\begin{array}{l}\text { Nontechnical Barriers to Solar Energy Use: Review of Recent } \\
\text { Literature }\end{array}$ & R. Margolis and J. Zuboy & 2006 \\
\hline 4 & Germany & $\mathrm{H}$ & $\begin{array}{l}\text { Institutional dynamics and technology legitimacy }-\mathrm{A} \\
\text { frameworkand a case study on biogas technology }\end{array}$ & $\begin{array}{c}\text { Jochen Markard, Steffen Wirth and } \\
\text { Bernhard Truffer }\end{array}$ & 2016 \\
\hline 5 & Colombia & UM & $\begin{array}{l}\text { Identifying Barriers to Wind Energy Diffusion in Colombia: A } \\
\text { Function Analysis of the Technological Innovation System and } \\
\text { the Wider Context }\end{array}$ & Edsand, Hans-Erik & 2017 \\
\hline 6 & $\begin{array}{l}\text { Bangladesh, China, } \\
\text { Laos, Mongolia, } \\
\text { Nepal, Sri Lanka, }\end{array}$ & LM and UM & $\begin{array}{l}\text { A qualitative factor analysis of renewable energy and } \\
\text { Sustainable Energy for All (SE4ALL) in the Asia-Pacific }\end{array}$ & Benjamin K. Sovacool & 2013 \\
\hline 7 & $\begin{array}{l}\text { Morocco and the } \\
\text { Philippines }\end{array}$ & LM & $\begin{array}{l}\text { Driving force or forced transition? The role of development } \\
\text { cooperation in promoting energy transitions in the Philippines } \\
\text { and Morocco }\end{array}$ & $\begin{array}{c}\text { Jens Marquardt, Karoline } \\
\text { Steinbacher, Miranda Schreurs }\end{array}$ & 2016 \\
\hline 8 & Nigeria & LM & $\begin{array}{l}\text { Transitions in unlikely places: Exploring the conditions for } \\
\text { renewable energy adoption in Nigeria }\end{array}$ & $\begin{array}{l}\text { Olufolahan Osunmuyiwa and Agni } \\
\text { Kalfagianni }\end{array}$ & 2016 \\
\hline 9 & India & LM & $\begin{array}{l}\text { Determinants of success and failure of community } \\
\text { based micro hydro projects: In: Proceedings of the Energy and } \\
\text { Climate Change in Cold Regions of Asia Seminar }\end{array}$ & Ete, M., Prochaska, F. & 2009 \\
\hline 10 & Pakistan & LM & $\begin{array}{l}\text { Identifying and addressing barriers to renewable energy } \\
\text { development in Pakistan }\end{array}$ & $\begin{array}{l}\text { Umar K. Mirza, Nasir Ahmada, } \\
\text { Khanji Harijan, Tariq Majeed }\end{array}$ & 2009 \\
\hline 11 & $\begin{array}{l}\text { Kenya, Tanzania, } \\
\text { Uganda }\end{array}$ & $\mathrm{L}$ and $\mathrm{LM}$ & $\begin{array}{l}\text { Review of solar PV policies, interventions and diffusion in East } \\
\text { Africa }\end{array}$ & $\begin{array}{l}\text { Hansen, Ulrich Elmer } \\
\text { Pedersen, Mathilde Brix } \\
\text { Nygaard, Ivan }\end{array}$ & 2015 \\
\hline
\end{tabular}

Note 1: H (High-Income); UM (Upper Middle-Income); LM (Lower Middle-Income); L (Low Income)

Note 2: Edsand (2017) is also Chapter 4 of this thesis.

\section{Table 6.3 Authors and List of Framework Conditions}

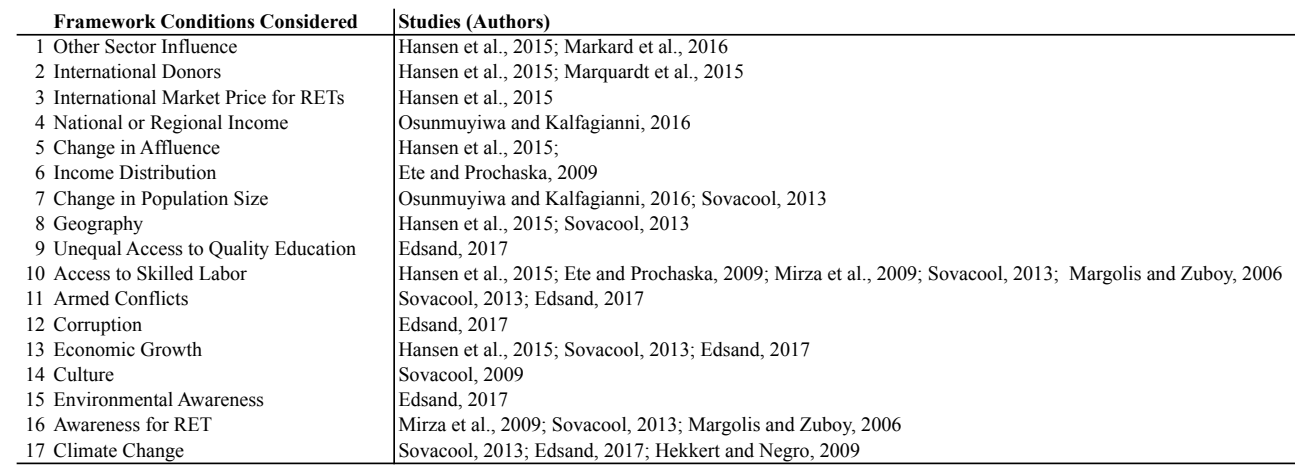

Note: Edsand (2017) is also Chapter 4 of this thesis.

To start, it is important to clarify a few definitional aspects of the framework conditions identified in the case studies (Table 6.3). Other sector influence refers to potential influence by other RETs sectors and/or any other non-technical sectors on RET adoption. Economic issues are addressed differently and at different levels (e.g., household vs. national) in the various case studies. U. E. Hansen, Pedersen and Nygaard (2015), for example, refer specifically to a change in the affluence of households. Osunmuyiwa and Kalfagianni (2016) analyze the influence of regional or national income on RET adoption in Nigeria. The denotation National or 
Regional has been added to differentiate it from changes in household income or affluence. National or Regional income is strictly concerned with monetary influence, i.e., the amount of the money available for investments. Economic Growth is the economic rate of change, which encompasses both positive and negative growth (e.g., financial crisis) ${ }^{99}$ Income distribution (Ete and Prochaska 2009) is related to affluence, as both influence a household's monetary strength. However, it is different from affluence in that it refers to the underlying structural aspect of income distribution and salary composition, and should therefore be considered a separate framework condition. Unequal Access to Quality Education is separated from Access to Skilled Labor, as the former refers to a structural framework condition relating to the national education system.

Finally, while culture is not for measurement purposes explicitly defined, Sovacool $(2009,366)$ divides the analysis of culture and its influence on RET adoption and energy efficiency in three categories, namely: "public apathy and misunderstanding, conceptions of consumption and abundance, and psychological resistance". Culture and informal institutions are interrelated but are not equivalent. Culture can help shape informal institutions (Helmke and Levitsky 2004). Therefore, they are treated as a separate framework conditions.

Specific awareness for RET and the more general environmental awareness are treated as two separate framework conditions, with the latter going beyond awareness about a particular technology. Considering environmental awareness as a framework condition allows for a wider analysis of the potential influence of a change in environmental awareness on a society's position on sustainability issues, such as a country's choice of sources of energy generation.

\subsubsection{Framework Condition Influence on RETs Adoption}

A comparative analysis of the framework conditions considered in the case studies reveals both differences and similarities across the various income-categories (Table 6.4). In total, there are 12 framework conditions that are only considered in studies for developing countries, while one framework condition was exclusively considered in the high-income category. Influence from four framework conditions were considered in both developed and developing country studies, namely, Other Sectors, Access to Skilled Labor, Awareness for RET and Climate Change. For the mixed study by Sovacool (2013), involving a comparative review of one uppermiddle (Malaysia) and nine lower middle-income Asian-Pacific countries, Table

${ }^{99}$ See e.g., Geels (2013) for a discussion on the potential influence of a financial-economic crisis on 'sustainable transitions'. 
6.4 simply indicates if a framework condition was mentioned in one or more of the included countries.

Table 6.4 Framework Conditions Influence on Adoption of RETs

\begin{tabular}{|c|c|c|c|c|c|c|c|c|c|c|c|c|c|c|}
\hline \multirow{2}{*}{ Country } & \multicolumn{10}{|c|}{ Developing Countries } & \multicolumn{4}{|c|}{ Developed Countries } \\
\hline & \begin{tabular}{|l|} 
Tanzania \\
\end{tabular} & \begin{tabular}{|l|l|} 
Uganda \\
\end{tabular} & Kenya & \begin{tabular}{|l|} 
Morocco \\
\end{tabular} & \begin{tabular}{|l} 
Philippines \\
\end{tabular} & Nigeria & India & \begin{tabular}{|l|} 
Pakistan \\
\end{tabular} & Multiple $^{1}$ & Colombia & GER and NED & USA & USA & Germany \\
\hline Income Level & $\mathrm{L}$ & $\mathrm{L}$ & LM & LM & LM & LM & \begin{tabular}{|l|l|} 
LM \\
\end{tabular} & LM & UM & $\overline{\mathrm{UM}}$ & $\mathrm{H}$ & $\mathrm{H}$ & $\mathrm{H}$ & $\mathrm{H}$ \\
\hline \multicolumn{15}{|l|}{ Framework Conditions } \\
\hline Other Sectors & + & + & + & & & & & & & & & & & +- \\
\hline International Donors & + & + & + & + & 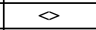 & & & & & & & & & \\
\hline $\begin{array}{l}\text { Reduced International } \\
\text { Market Price for RETs } \\
\end{array}$ & + & + & + & & & & & & & & & & & \\
\hline $\begin{array}{l}\text { National or Regional } \\
\text { Income }\end{array}$ & & & & & & $<$ & & & & & & & & \\
\hline Change in Affluence & & & + & & & & & & & & & & & \\
\hline Income Distribution & & & & & & & - & & & & & & & \\
\hline Change in Population Size & & & & & & 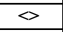 & & & 1 & & & & & \\
\hline Geography & - & & + & & & & & & 1 & & & & & \\
\hline \multicolumn{15}{|l|}{$\begin{array}{l}\text { Unequal Access to Quality } \\
\text { Education }\end{array}$} \\
\hline Access to Skilled Labor & & & * & & & & - & - & 1 & & & & - & \\
\hline Armed Conflicts & & & & & & & & & 1 & +- & & & & \\
\hline Corruption & & & & & & & & & & - & & & & \\
\hline Economic Growth & & & + & & & & & & 1 & + & & & & \\
\hline Culture & & & & & & & & & & & & - & & \\
\hline Environmental Awareness & & & & & & & & & & $\infty$ & & & & \\
\hline Awareness for RET & & & & & & & & - & 1 & & & & - & \\
\hline $\begin{array}{l}\text { Climate Change } \\
\end{array}$ & & & & & & & & & 1 & + & + & & & \\
\hline+ & Postive Ef & ffect on RH & ET Ado & ption & & & & & & & & & & \\
\hline+ & $\begin{array}{l}\text { Negative } \mathrm{I} \\
\text { Dual Effec }\end{array}$ & & RET & & & & & & & & & & & \\
\hline $\begin{array}{l}+- \\
\infty\end{array}$ & Dual Effec & & & & & & & & & & & & & \\
\hline$*$ & $\begin{array}{l}\text { Little or } n \\
\text { Measures }\end{array}$ & o effect & $\mathrm{mil}$ & esative & & & & & & & & & & \\
\hline 1 & $\begin{array}{l}\text { Measures } \\
\text { Effect mer }\end{array}$ & $\begin{array}{l}\text { taken elim } \\
\text { ntioned }(\mathrm{P}\end{array}$ & Positiv & or $\mathrm{Neg}_{2}$ & ve) in one & more c & he 10 & case studie & & & & & & \\
\hline
\end{tabular}

Source: Author tabulation, based on analysis of included list of studies and framework conditions.

Again, since the frameworks or approaches for the studies vary, it is not possible to infer definite conclusions concerning relevant framework conditions in developing and developed countries. However, as Table 6.4 shows, authors designing studies that analyze barriers to RETs adoption in developing countries appear more concerned about a plurality of framework conditions. An explanation regarding the direction of the influence (positive or negative) follows.

\section{Driving or Obstructing Framework Conditions}

As can be deduced from Table 6.4, framework conditions can have a positive effect, i.e., drive technological transition forward or act as a negative effect obstructing the adoption of RETs. For example in Tanzania, Uganda and Kenya, the Information and Communication (ICT) sector, particularly through an expansion in mobile phone usage, positively influenced the adoption of solar Photovoltaic (PV) technology (Hansen, Pedersen, and Nygaard 2015). A decrease in international market price for RETs, along with international donor support also represent framework conditions that have driven the expansion of RETs in Tanzania, Uganda and Kenya. An interesting contrasting effect of international donor support was found between Morocco and the Philippines. While donor support had a limited effect in the Philippines, in Morocco, international donor 
support, through policy advice, helped drive forward new initiatives for solar and wind projects, along with the incorporation of RETs in the Moroccan national energy strategy (Marquardt, Steinbacher, and Schreurs 2016).

Access to skilled labor was unanimously regarded as an obstructing framework condition across all studies that included this condition in the analysis. In the case of Kenya, developing specialized technical training, with the support of international donor assistance, into the analyzed solar PV project mitigated an expected negative influence from the limited access to skilled labor. The structural framework condition of unequal access to quality education was only specifically tested in Colombia (Chapter 4), where low access to quality education in remote rural areas was described as one of the most important reasons for the limited availability of skilled labor in these areas, which consequently negatively affected decisions for initiating new RETs projects. The only other study that relates a framework condition to the access to quality education is the Asia-Pacific comparative study (Sovacool 2013), by referring to the influence of literacy rates amongst rural villagers in Sri Lanka, Indonesia and Papua New Guinea. Low literacy rates in Indonesia and Papua New Guinea were found to be an obstructing factor for project dissemination, while higher literacy rates in Sri Lanka was described as a facilitating factor. In the study and in Table 6.3, low literacy was included under access to skilled labor, however Unequal access to quality education can provide an alternate structural explanation for the low skills in rural Indonesia and Papua New Guinea.

Other findings from Sovacool (2013) include a positive influence of population density in Bangladesh and China, compared to disadvantage of the smaller populations in Papua New Guinea and Malaysia. Geography and natural endowments have strongly influenced the adoption of various RETs, e.g., hydroelectric systems in mountainous Nepal and Sri Lanka, or solar energy in Papua New Guinea and Indonesia. Armed conflicts obstructed planned projects in both Nepal and Sri Lanka, slowing down the adoption of RETs. Awareness for RETs was considered an important ingredient for a successful implementation, and countries that spent time and resources marketing and spreading information about RETs saw a positive effect on adoption. Climate change was generally found to create (positive) pressure on key actors (e.g., governments) to take action and initiate RETs projects, while a negative economic growth as a result of the global financial crisis increased the cost of RETs materials, which had a negative effect on RET adoption.

\section{Dual Influence}

Two of the studies found a dual effect from framework conditions, i.e., they had a driving and obstructing effect on RETs adoption. For example, the study by Markard, Wirth and Truffer (2016) showed how the agriculture sector in Germany 
positively influenced the development of biogas technology at its genesis. The authors explain this positive relationship by a positioning of the biogas technology as beneficial to the agricultural sector, which gave legitimacy to the new technology. In a later and more expansive stage of biogas technology, the relationship with the agriculture sector was re-framed into a competitor role, as a consequence of increasing farming for energy production instead of food production. This conflict with the agriculture sector contributed to a loss in legitimacy for biogas in Germany, negatively affecting the technology. ${ }^{100}$

Another form of dual influence was found with the armed conflict in Colombia, where the framework condition proved obstructive for one type of technological innovation, while driving another one forward. As shown in Chapter 4, armed conflict was found to have an obstructing effect on large wind parks in Colombia. Interestingly, the armed conflict simultaneously drove small-scale innovations of RETs, as the Colombian military required renewable energy solutions to aid soldiers in the field. ${ }^{101}$ As a consequence, by investing military funding in contracts with research institutes in Colombia, small-scale solar and wind innovations have emerged.

While the framework conditions can directly influence the integral components and activities of the system (focal system), e.g., armed conflicts blocking or slowing down RETs projects, framework conditions can also have an indirect impact on the focal system through an interaction with existing institutions. The interactions between FCs and institutions will be explained next.

\section{Framework Conditions Interaction with the Focal System}

When discussing how the various framework conditions influence the focal system, institutions become a central part of the story. In a general sense, since institutions constitute the "sets of common habits, routines, established practices, rules, or laws that regulate the relations and interactions between individuals, groups, and organizations" (Edquist and Johnson 1997, 46), actors relevant to the RET will always, in one way or another be affected by the institutions of the country in question. How framework conditions influence the focal system through interactions with institutions is perhaps less clear. In order to discuss the dynamics between framework conditions (FC) and institutions (North 1991), it is proposed to divide the FC in six different categories, namely, modifying, structural, secondary,

${ }^{100}$ The conflict between food production and the bio-fuel energy sector is not isolated to Germany. The production of grains or maize for fuel consumption for cars in high-income countries has contributed to price increases for food in developing countries.

${ }^{101}$ Based on fieldwork in Colombia (see Chapter 4). 
internal, multilevel, and natural (see Fig. 6.1). Armed conflicts, corruption, other sectors, and climate change are considered modifying FC because they influence the focal system by repositioning or modifying existing institutions. As a result, the institutional set-up can become better or worse aligned with the needs of the focal system, which was the case of Germany (Markard, Wirth, and Truffer 2016), where another sector (agriculture) helped modify the institutional set-up for biogas technology. Another example of the dynamics between FC and institutions is corruption. Corruption negatively influences the quality of national institutions, reducing the efficiency of focal system. The various types of interactions between different FC and institutions (formal and informal) are graphically depicted in Figure 6.1.

The structural category refers to FCs that are a result of the current institutional set-up, e.g., exclusive and elitist institutions will create structural inequality, including income inequality and unequal access to quality education. Access to skilled labor and changes in affluence are regarded as derivatives of structural FCs, hence the label secondary FCs. National and regional income and changes in population size also fall into the secondary FC category. Changes in National or Regional income are a product of economic growth and the institutional set-up, e.g., distribution of wealth through taxes. A change in population size is a product of multiple factors, such as migration (urbanization), economic and social development of a region.

Following North's (1991) definition of institutions, culture, environmental and RET awareness can be considered internal FCs, or as part of the existing informal institutions. Current internal FCs can directly influence the focal system; for instance, environmental awareness can play a role in the willingness of decision makers to invest in RETs. Changes in internal FCs can overtime induce modifications in the formal institutions that have a stake in the focal system. Following the environmental awareness example, increased environmental awareness can result in changes in policy makers' attitudes towards RETs and that in turn result in policy changes. 
Figure 6.1 Framework Condition (FC) Interaction with Institutions

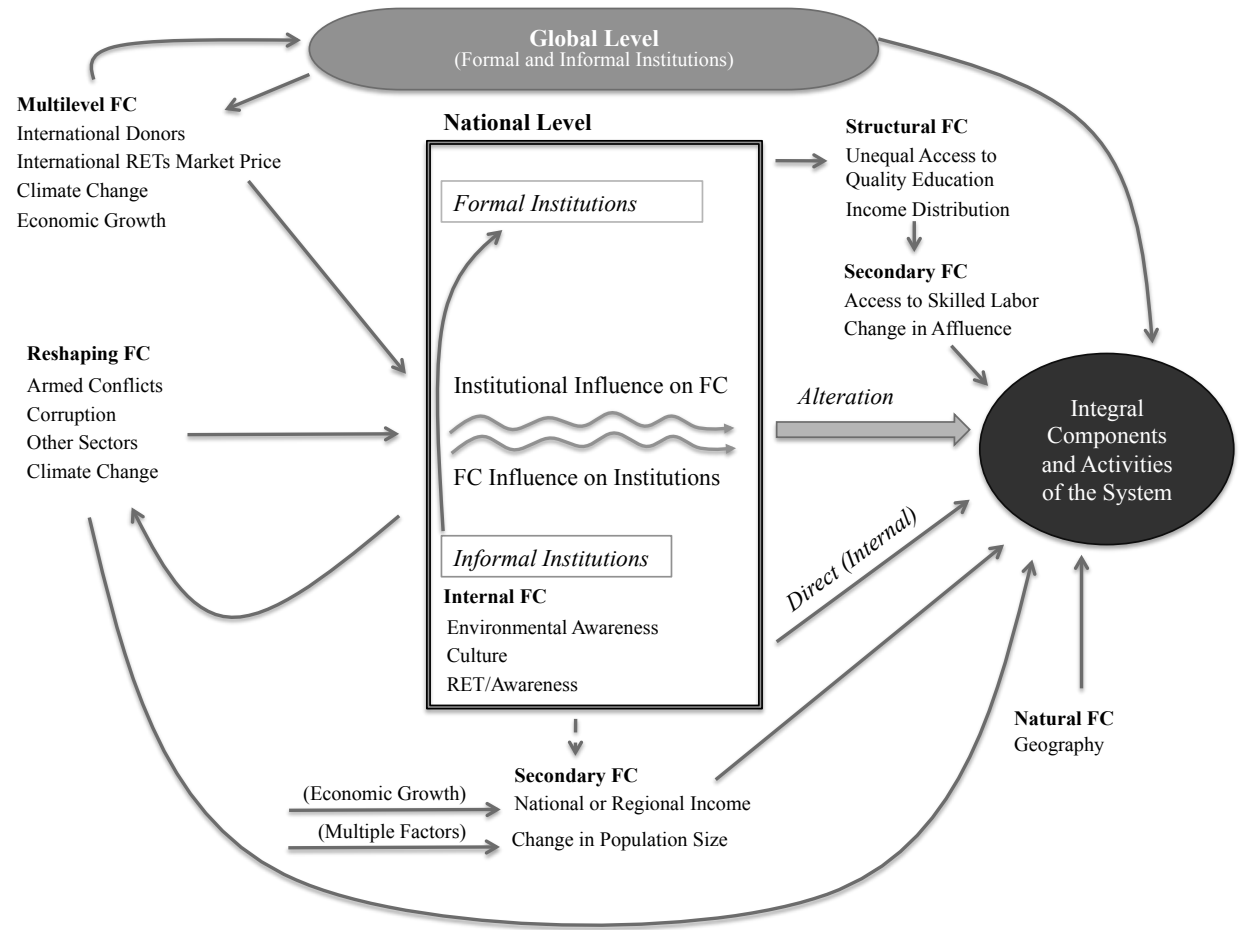

Source: Author.

Note: This graph aims to depict the different way that FC can interact with institutions. Wavy arrows indicate ongoing change within National Institutions due to FC interaction; the bold gray arrow on the right side of the figure indicates final institutional alteration influencing focal TIS, after interaction between FC and existing institutional setup has occurred.

Certain FCs, such as international donor support, changes in international RETs' market price, climate change and economic growth interact with institutions at the global level, and thus transcend the national system and consequently the domestic institutions. Finally, the natural FCs refers to geography, which provides a set of national endowments, obstructing or driving RETs adoption.

It must be noted that the focal system can also influence institutions and certain framework conditions, e.g., German Biogas Technology on the agriculture sector. However, as the aim of Figure 6.1 is to depict how different framework conditions interact with institutions, the focal system influence on institutions and FCs factors is not shown here. The direct influence that the focal system has on institutions and framework conditions contributes to the multiple positive and negative feedback loops within the system and to the non-linearity of response to policy interventions. 


\subsection{Implications for the Boundary of the SI Approach}

Following the strategy proposed by Edquist $(2005 ; 1997)$ to delimit the system based on its determinants, the majority of framework conditions would consequently be considered endogenous to the system. This would in turn have implications for the boundary of the system. This chapter has shown that there are multiple framework conditions that help shape the trajectory of RET adoption in countries across income categories. The analysis of the empirical studies suggests that there are generally more framework conditions influencing (positively and/or negatively) the adoption of RETs in developing countries than in high-income countries (Fig. 6.2).

Figure 6.2 System Boundaries for Developing and Developed Countries
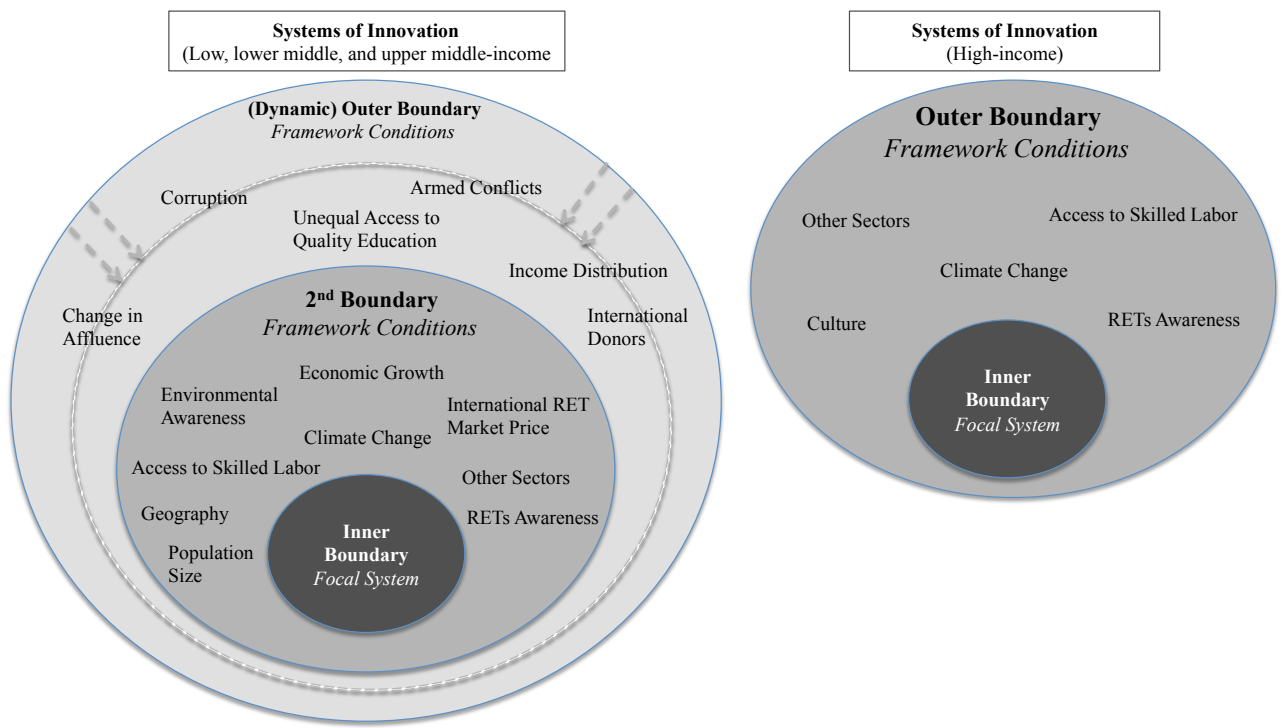

Source: Illustration by author.

Note 1: The dotted circle and arrows indicate a potential reduction in the size of the dynamic outer boundary, as a developing country shifts to a higher level of development.

Note 2: Figure 6.2 is illustrative based on the framework conditions considered in the included studies. It is not an exhaustive depiction of possible framework conditions.

However, in both developed and developing countries it is useful to view the system boundary as made up of several levels. In the case of high-income countries the delimited system includes an inner and outer boundary. The inner boundary includes the integral elements and activities, defined in the TIS literature as the functions of the technological system. The outer boundary fully delimits the system by including the framework conditions that influence the trajectory of the system. 
For developing countries, it is proposed that delimiting the system requires a third level, referred to here as the dynamic outer boundary. The third level is made up by framework conditions that are predominately related to sociopolitical factors and/or the institutional quality of the country in question. An interesting historical parallel to high-income countries concerning the dynamic outer boundary can be found in Geels (2005). As part of his socio-technical landscape analysis of the transition from horse-drawn carriages to automobiles between 1860 and 1930, he refers to corruption as one of the driving and obstructing factors (dual influence) for the transition. As a developing country's sociopolitical status improves, e.g., moving towards increasing equality, the framework conditions that make up the dynamic outer boundary reduce their influence on the focal system, and eventually drop out as determinants for technological transitions. Once the dynamic outer boundary grows obsolete, the $2^{\text {nd }}$ boundary becomes the outer boundary of the system. The framework conditions that make up the outer boundary in highincome countries and the $2^{\text {nd }}$ boundary in developing countries, on the other hand, can be considered as more stable conditions, i.e., they will remain influential determinants of technological transitions to renewable energies for the foreseeable future.

\subsubsection{Framework Conditions and Policy}

While improving the conceptualization of framework conditions will assist a systematic analysis of their influence on technological transitions, the inclusion of framework conditions in the analysis of innovation systems also supports a wider discussion related to policy options.

If integral activities and their linkages delimit the system, policy interventions will be restricted to the actors (e.g., through policies such as tax credits or subsidies), or on the linkages directly involved in the technology (e.g., commercialization of $R \& D$ from universities or government research laboratories, involving actors in the private sector). Adding framework conditions to the analysis (i.e., delimiting the system with the outer boundaries) expands the alternatives for policies that can address both short-term (e.g., trade policy, regulation of business activities, etc.) and long-term (e.g., educated labor force or culture) barriers or drivers of the innovation system.

Even though certain framework conditions, such as unequal access to education, can only be fully addressed in the long-term, recognizing its role as a barrier to the system can open up the possibility for policy interventions that can circumvent the barrier in the short-term. For example, as was shown in the case of Kenya (Hansen, Pedersen, and Nygaard 2015), identifying the poorly educated labor force as an obstacle allowed them to temporarily circumvent the long-term framework condition by including targeted training into the donor supported RETs project. Developing strategies for tackling framework conditions in the short and long-term 
is an important area for future research, which is enabled by the systems approach discussed in this chapter.

\subsection{Concluding Remarks}

Much of the emphasis in the technological innovation system approach literature has focused on the integral innovation activities or functions of the system. However, in order to achieve a full appreciation of the driving and obstructing factors of technological change, it is necessary to look beyond the system that is limited to actors, their activities and linkages. By taking a wider system of innovation approach and expanding the definition of what makes up a system, this chapter has focused on the determinants that are, in many cases, held to be exogenous to the system.

By combining a conceptual discussion with empirical data from previous studies, this chapter has highlighted framework conditions that exist in both developing and high-income countries. While framework conditions in general can be regarded as determinants for technological transition in countries of all income categories, the plurality of framework conditions in most developing countries suggests a particular relevance for their inclusion in technological transition analyses. The occurrence of framework conditions acting on the focal TIS in both developed and developing countries requires a re-thinking of the delimiting of the system. Moreover, this chapter has discussed how various types of framework conditions can influence the focal TIS through an interaction with existing institutions. In addition, this chapter has shown that by systematically incorporating framework conditions to complement the analysis of the functions or innovation activities, additional avenues for policies are made available that could enhance the success of future technological change.

The aim of this chapter has not been to provide a conclusive list of relevant framework conditions, nor is it practically possible given the context specificity of different countries. For example, the influence of incumbent actors was not included in the studies reviewed in this chapter. Instead, the aim has been to provide an initial overview of possible framework conditions and to stimulate future research on the topic. The evidence provided in the comparative literature analysis was not sufficient to infer any tangible evidence of differences of relevant framework conditions between developing countries, e.g., between low income and upper middle-income countries. This provides an avenue for further research, and over time, with additional empirical studies that include a framework analysis, framework conditions will be dropped or added in an organic manner, contributing to a more accurate delimiting of the system and supplemental information that can support policy development. 


\section{Chapter 7: Conclusions}

This thesis has aimed to increase the knowledge of the factors that contribute towards sustainable development paths in developing countries. A particular focus and contribution of this thesis have been on improving the understanding of how developing countries can accelerate their transition towards RETs adoption, essential for enhancing energy security and reducing future emissions from anthropogenic Greenhouse Gases (GHG).

A holistic approach was taken to identify the determinants (positive-that contribute or negative-that hinder) of technological transitions (in particular renewable energy technologies - RETs) in developing countries. The research has also aimed to generate concrete policy suggestions. Through a combination of conceptual (Ch. 3 and 6) and empirical chapters (Ch. 4 and 5), a number of findings and lessons can be drawn. This chapter will revisit and highlight the key findings of this thesis, as well as discuss how they could have an impact on policy. The chapter concludes by reflecting on persisting knowledge gaps, while also providing ideas for how future research could build upon the findings presented in this thesis.

\subsection{Integral Activities and Processes in Developing Countries}

Chapter 3 conceptually addressed two major limitations of the Technological Innovation Systems (TIS) function approach and proposed an extended framework. Chapter 4 applied this extended framework to empirically identify obstructing and driving factors for wind energy adoption in Colombia. This section will review the findings from the empirical Chapter (4) and discuss how they can complement Chapter 3 by providing some initial insights into the validity of the conceptually motivated alterations to the framework. A full depiction of the findings from the function analysis will not be repeated here. The discussion is restricted to the empirical findings related to the proposed changes to the list of functions made in Chapter 3. To revisit the complete list of empirical findings from the function analysis please see Table 4.3 in Chapter 4.

Three out of the four suggestions proposed in Chapter 3 involved alterations to the baseline list of functions developed by Hekkert et al. (2007), in order for the framework to be better suited for developing countries. The proposed suggestions include adding creating adaptive capacity, international resource mobilization, and informal legitimacy creation functions to the baseline list. Moreover, contrary to previous studies (e.g., van Alphen, Hekkert, and van Sark 2008), Chapter 3 chose to keep the knowledge development function, to enable an analysis of changes in learning trends. 
The findings in Chapter 4 showed positive learning trends in Colombia, with increased collaboration between actors engaged in research and small-scale innovation in wind and other RETs. The adaptive capacity of Colombia demonstrated a mixed picture, with high degree of qualified engineers in the urban centers (especially in Bogotá and Medellín), while significant human capacity constraints were revealed in remote rural areas. The organizational and institutional capacity in Colombia was described as a blocking mechanism to wind energy adoption because of e.g., high bureaucracy, slow decision-making and a reactive (informal) institutional culture. In regards to international resource mobilization, this function revealed availability of resources and an interest to invest in wind and other RETs in Colombia from international actors. However, the potential positive influence from this function is reduced by an insufficient guidance of the search (F4), i.e., lack of expectations set by the government, and a resistance to international financing due to fear of debt. Only scattered informal lobbying (legitimacy creation) for wind energy could be observed in Colombia from universities and smaller environmental groups, albeit with limited strength to influence other activities (functions) of the system, such as resources mobilization, guidance of the search or market formation. A more ample analysis in Chapter 3 of informal lobbying through social media was constrained by unavailability of historical social media data.

Based on the combined conceptual discussion in Chapter 3 and the empirical findings in Chapter 4, the following general lessons for the extended list of functions are provided. It is argued here that the creating adaptive capacity function should be included in the list of functions, as it allows mapping the ability of developing countries to receive a technology that was partly or entirely developed by foreign companies. Despite the common reliance on technologies initially developed by foreign companies (often in high-income countries), tracking knowledge development in the case of Colombia yielded interesting information about newly established research and small-scale innovations. It should be noted, however, that Colombia is an upper middle-income country with the ability to conduct high-quality domestic research. In low-income countries with very low capacity for $\mathrm{R} \& \mathrm{D}$ and innovation the relevance of mapping knowledge development trends may be reduced, and in this case, the argument can be made for dropping this function from the list.

Including the international resource mobilization function in Chapter 4, demonstrated that alternative resources for RETs investments are available. The international resource mobilization function can act as a complement that can reduce the blocking effect from a weak domestic resource mobilization function. At the same time, as was shown in the case of Colombia, without the support and interest from the government (guidance of the search), much of this potential positive effect from international resource mobilization could be lost. The conclusion based on Chapters 3 and 4 in this thesis is that the inclusion of the 
international resource mobilization brings valuable information concerning the integral activities of the system and therefore should be included in the list of functions. Finally, while the addition of informal lobbying (legitimacy creation) was conceptually motivated in Chapter 3, Chapter 4 failed to show that it had any significant influence on the trajectory of wind energy adoption in Colombia. As was discussed in Chapter 3, it is fair to assume that with increased access to Internet and activity in social media in developing countries, combined with the pressing urgency of climate change and urban pollution, the influence from informal lobbying may increase in importance in coming years. However, it is also reasonable to concede to the notion that the influence from informal lobbying may remain limited in developing countries, and that this function, at this moment in time, may be of greater relevance in high-income countries.

The suggested additions to the TIS function approach that were conceptually justified in Chapter 3 and empirically tested in Chapter 4 are not meant to be a conclusive list of relevant activities or processes for technological systems in developing countries. However, the lessons and findings from these chapters should be seen as a complement to ongoing ambitions of improving the framework to analyze weaknesses and strengths of the systems under study. In accordance with Lundvall (1992), this process should be kept open and flexible to allow for dropping and adding of integral activities and processes (functions) to incrementally improve the delimitation of the system.

\subsection{A Closer Look at 'Exogenous' Factors}

The fourth suggestion in Chapter 3 and an overarching theme of this thesis is the recognition and proposed systematic inclusion of factors deemed exogenous to the TIS function approach, namely landscape factors or framework conditions. All chapters of this thesis addressed these framework conditions, however in different ways. While Chapters 3 and 4 drew much inspiration from the Multi-Level Perspective (MLP) approach to complement the TIS function analysis, Chapter 6, analyzed the role and influence of framework conditions from a wider Systems of Innovation (SI) approach. Chapter 5, on the other hand, was concerned with how a single framework conditions, environmental awareness, could be strengthened, by analyzing the effect from environmental education on environmental awareness and specific RETs awareness. The following sections will review the findings concerning landscape factors/framework conditions found in the chapters of this thesis.

\subsubsection{Systematic Inclusion of Framework Conditions}

Delimiting a system, or in other words differentiating it from the rest of the world, represents an essential aspect of any systems approach. Improving the accuracy of identifying the boundary of a technological system by its determinants (i.e., the 
factors that allow the system to achieve its purpose) (Edquist 1997) has been addressed in several chapters of this thesis. Chapter 3 conceptually identified six landscape factors to be systematically analyzed as a complement to the TIS function approach, implicitly arguing that the functional analysis was inadequate to delimit the technical innovation system in developing countries. The six landscape factors that were conceptually motivated as determinants of the system were 1) Economic Growth; 2) Environmental Awareness; 3) Climate Change; 4) Armed Conflicts; 5) Corruption; and 6) Unequal Access to Quality Education. Chapter 4 included these landscape factors in the analysis to assess their influence on technological transition, specifically wind energy adoption, in Colombia.

Chapter 4 found both driving and obstructing influence from the landscape factors on the functions (integral actors and activities) of the system, with climate change demonstrating the strongest positive influence (i.e. contributing to adoption), and corruption and unequal access to quality education the strongest negative influence (i.e. obstructing adoption). More specifically, climate change related events, such as increased droughts (from more severe El Niño) and ensuing water shortages were found to positively influence the wind energy sector, as existing energy regimes (the hydropower and thermoelectric sector) faced deficiencies, resulting in increased pressure for the country to diversify its energy mix. Moreover, climate change was found to strongly contribute to the passing of several initiatives to expand wind energy and other RETs, such as the 'Low Carbon Development Strategy' and Renewable Energy (RE) Law.

Corruption, on the other hand, was found to block and/or slow down entrepreneurial activities (F1) and wind energy research projects (F2a), due to requests for informal payments at the local level. Unequal access to quality education largely explained the low access to skilled labor in remote rural areas of Colombia. Low access to skilled labor, in turn, reduced incentives for entrepreneurial activities (F1) in these areas. Paradoxically, many remote rural areas of Colombia have little or no access to electricity while having a high technical potential for wind energy, and could greatly benefit from electrification from Wind Energy and other RETs.

For the other landscape factors, i.e., economic growth, environmental awareness, and armed conflicts a lesser but not insignificant influence could be derived. For example, while the armed conflicts were expressed to negatively influence new investments, e.g., through higher interest rates, energy generating companies regarded it as a limited concern for new wind energy projects. The risks from the armed conflict could also be further reduced by thoroughly legitimizing the projects with the local community. For further details about landscape factors influence in Colombia, see Chapter 4. 
Another step to improve the accuracy of the framework is to better understand the relevant determinants for technological transition in countries of different developmental status. Chapter 6 aimed to reduce the knowledge gap in this area by collating and comparing empirical findings of previous studies that had discussed the role of framework conditions (landscape factors) in developing (low, lowmiddle, upper-middle income) and developed countries (high-income).

In Chapter 6, 17 different framework conditions were identified and compared across 24 countries of different income categories. The plurality of framework conditions that influence technological change speaks to the difficulty of accurately delimiting the system. One of the main findings of Chapter 6 was that while several framework conditions overlapped across developed and developing countries, e.g., access to skilled labor, RET awareness and climate change, it appears that more framework conditions influence technological change in developing countries. This divergence is strongly tied to the developmental status of the country, where more elitists and lower quality institutions contribute to, for example, higher degrees of corruption and less distribution of wealth. Conclusions are made in Chapter 6 that an additional dynamic outer boundary should be included, which is made up by framework conditions such as income inequality, unequal access to quality education, corruption, etc. As the country in question develops (i.e., moves towards a more inclusive institutional set-up), these framework conditions gradually reduce their influence on technological change.

To conclude, the explicit and systematic inclusion on landscape factors/framework conditions in Chapter 3, 4 and 6 can provide an important step towards enhancing the understanding of the 'wider context' - outside the integral actors and activities (focal system) - and improving the comprehensiveness of the approach. As emphasized in Chapter 6, taking a wider systems approach, where all forms of determinants are treated as endogenous to the system, can be beneficial in more accurately delimiting the system and moving the systems approach towards a systems theory for analyzing technological change. While the focus in this thesis has been on the TIS, the findings presented also contribute to responding to critique made about the National Innovation System (NIS) approach when applied in a developing country context. For example, an explicit inclusion of framework conditions can help address the critique of Lundvall et al. (2002) that the NIS approach requires a broadening of its concepts to account for various instabilities (e.g., that of institutions) found in many developing countries.

\subsubsection{Strengthening 'Positive' Framework Conditions}

In Chapters 3, 4 and 6, this thesis has shown that framework conditions can have a positive or negative influence on technological transition. As was established in Chapter 3 environmental awareness represents one of these framework conditions that through a change in behavior in a population can positively influence 
technological transition towards RETs and reduce the impact from the re-bound effect. Moreover, Chapters 3 and 6 demonstrated how a lack of RETs awareness in developing countries can act as a barrier for the new technology. For that reason, Chapter 5 of this thesis was dedicated to improving the understanding of how environmental awareness and specific awareness for RETs can be augmented.

In doing so, Chapter 5 analyzed the effect that environmental education can have on increasing environmental awareness and specific RETs awareness in 15-year olds. The chapter, which used OECD data from the Programme for International Student Assessment (PISA) in Colombia, found weak evidence that environmental education can strengthen environmental awareness, and an even lower effect on RETs awareness. While Chapter 5 did not find environmental education to be the silver bullet, the evidence suggests that strengthening environmental education in school curricula is a necessary but not sufficient condition for improving environmental awareness among the youth. For RETs awareness, other aspects such as socio-economic status, parents' background, and quality of educational resources or ownership (private or public) at the school level proved to be decisive explanatory factors.

Another interesting finding in Chapter 5 was that environmental optimism appeared to decrease with more environmental education. The idea that as students learn more about environmental concerns, they become less optimistic emphasizes the importance for parallel environmental initiatives outside the educational system. Increasing environmental awareness without providing alternatives for practicing 'greener' behavior, e.g., accessibility to recycling stations or affordable 'clean' energy could result in an attitude of indifference towards sustainability challenges. With these alternatives present, efforts in schools to promote individual responsibilities for environmental concerns could potentially reduce the decreasing optimism amongst youths.

\subsection{Policy Implications}

The topics and questions dealt with in thesis relate to sustainability issues of a time-sensitive nature. Mitigating an unsustainable human impact on the environment by expanding the adoption of RETs and by encouraging overall environmentally conscious decisions amongst the general public are issues that cannot be deferred to future generations. The urgency to address the challenges in this field of study stresses the importance for providing concrete policies that can help promote sustainable development. For that reason, this section is dedicated to discussing specific policy suggestions that can be derived from the chapters of this thesis.

The empirical lessons (Ch. 4) that were derived from analyzing the technological innovation system in Colombia revealed weaknesses within its functions and 
provided policy suggestions to address these barriers to facilitate the expansion of wind energy in the country (see Table 4.3 in Chapter 4 for a complete list of barriers within the functions). The following section will discuss the policy implications from the landscape/framework condition analysis provided in this thesis, while also discussing their relations to certain policies for reducing weaknesses in the functions.

\subsubsection{Long, Medium and Short-Term Policies for Innovation Systems}

By expanding the analysis beyond the integral actors and activities of the system (focal system), a wider array of policy options that facilitate technological change becomes available. Firstly, the inclusion of the landscape/framework condition analysis in this thesis instigates a policy discussion from a long-term perspective, in order to take into consideration the slow changing framework conditions. For example, unequal access to quality education (Ch. 3) or culture (Ch. 6), relating the institutional structure of the country in question, requires years of incremental changes to be 'fully' addressed. Even though these structural framework conditions transcend terms of elected politicians, acknowledging and discussing long-term policy changes to tackle obstructing framework conditions deserves attention. Increasing the recognition amongst government organizations concerning the framework conditions discussed in this thesis and their role in creating a more innovation-prone environment is an important first step. The second step would be to devise policies to incrementally reduce obstructing factors and promote driving framework conditions into long-term national strategies, adapted to the unique country conditions.

While the long-term policies to address negative structural framework conditions are of great importance, devising policies for facilitating short or medium-term technological change are also necessary. The knowledge acquired from the framework conditions analysis can provide information about positive and negative conditions that can be temporarily circumvented through short-term policies. As was shown in Colombia, by thoroughly legitimizing new RETs with the local population, the risk of obstruction from armed groups is reduced. Therefore, building in local participation as central element during planning and implementation phase of new RETs projects, can reduce or remove risks from armed conflicts. Moreover, if awareness for RETs is expected to be low, building in information sessions with the community into the planned RETs project constitute a short-term policy that can help reduce potential negative effects from low RETs awareness. In the same fashion, obstruction from unequal access to quality education or low access to skilled labor could be partly circumvented by building specific skills training programs into the project, to train personnel before the implementation of the new technology. If short-term training policies are successful, they can be substituted by medium-term policies, moving towards a more permanent solution for improving RETs awareness and access to skilled 
labor. Combining these types of short and/or medium-term policy fixes with incrementally resolving long-term structural obstructing framework conditions represent avenues for improving innovation policies as a result of the explicit and systematic framework condition analysis conducted in this thesis.

\subsubsection{Remaining Challenges and Suggestions for Future Research}

The findings in Chapter 3,4 and 6 of this thesis suggests that the inclusion of a landscape/framework condition analysis to complement the examination of the integral actors and activities is beneficial for both enhancing comprehensiveness and to expand alternatives for policy. The extended TIS function approach developed in Chapter 3, and empirically tested in Chapter 4, should be seen first step to learning more about the links between the focal system and its wider context.

That said, 'developing countries' is a widely heterogeneous group and it cannot be assumed that all developing countries will benefit equally from the propositions provided in this thesis. The empirical analysis in this thesis has focused on Colombia, an upper-middle income developing country, which will most likely have different barriers, both within functions and framework conditions, to RETs adoption than a low-income developing country. Also, data availability can help determine the usefulness of the framework proposed in this thesis. Poor data availability to depict long-term trends in function and landscape factors or sectors in early formative stages is not uncommon in developing countries, and additional data collection and studies are required to complement existing results. For example, restricted data availability for several factors in Colombia resulted in an empirical analysis (Ch. 4) that was heavily reliant on the expert evaluations. Most likely, several lists, of both functions and framework conditions, will be required for countries of different development status, i.e., low-income, low middle-income, upper middle-income, and high-income countries.

Moreover, while the development of the extended TIS function approach, including the landscape/framework condition analysis, was developed with a developing country context in mind, there are several aspects, as shown in Chapter 6, which hold relevance in a high-income country context as well. Differences between high-income and developing countries also represent an area in need of additional research. For example, in what way does global governance, through international organizations, such as the World Bank, International Monetary Fund (IMF) or World Trade Organization (WTO) influence developing countries as compared to high-income countries in their path towards RETs adoption; this is a question that was not explicitly addressed in this thesis. This represents one interesting avenue for future work, which will require more empirical studies that continue developing the understanding of the drivers and obstacles for 
technological transitions in countries of different development stages and income levels.

The long and short-term policies enabled by treating framework conditions as endogenous to the system (Ch. 6) are an interesting avenue for future research, which was not addressed to a great extent in this thesis. Just as learning about and developing policies for reducing or removing blocking mechanisms for technological transition is an important area for research, better understanding how positive framework conditions can be strengthened (Ch. 5) also deserves further attention. The empirical knowledge about environmental education needs to be complemented with more studies from developing countries to fully access the potential of the education sector to strengthen environmental awareness. Moreover, beyond the role of the education sector, increasing the knowledge of strategies to reinforce awareness building of society in general, and identifying the appropriate incentive structures is required to transform initial awareness into changed behavior.

Finally, continuing with a flexible approach to the list of functions is preferred, in order to incrementally improve the understanding of integral innovation activities that make up the focal TIS. However, focusing future research on technical and economic aspects of energy transition alone is likely to fall short of its goals. Giving more attention to framework conditions such as culture or environmental awareness can help reduce resistance to the technology and improve the environment for innovation. The field of psychology can complement existing transition research by bringing a greater understanding of the behavior of the population in which the technology aims to be diffused. In order for future research to be successful in addressing the many challenges facing socio-technical transitions as well broader sustainability goals, a special prominence should therefore be placed on greater collaboration between different related fields. 


\section{References}

Abadie, A, and J Gardeazabal. 2003. "The Economic Costs of Conflict: A Case Study of the Basque Country." The American Economic Review 93 (1): 113 32.

Acemoglu, Daron, Philippe Aghion, Leonard Bursztyn, and David Hémous. 2012. "The Environment and Directed Technical Change." American Economic Review 102 (1): 131-66. doi:10.1257/aer.102.1.131.

Acemoglu, Daron, Philippe Aghion, and David Hémous. 2014. "The Environment and Directed Technical Change in a North-South Model." Oxford Review of Economic Policy 30 (3): 513-30. doi:10.1093/oxrep/gru031.

Acemoglu, Daron, and James A Robinson. 2012. Why Nations Fail: The Origins of Power, Prosperity, and Poverty. New York: Crown Business.

ACOLGEN. 2015. "Capacidad Instalada." http://www.acolgen.org.co.

ADB. 2009. "Improving Energy Security and Reducing Carbon Intensity in Asia and the Pacific." Mandaluyong City.

Ahern, Lee. 2012. "The Role of Media System Development in the Emergence of Postmaterialist Values and Environmental Concern: A Cross-National Analysis." Social Science Quarterly 93 (2): 538-57. doi:10.1111/j.15406237.2012.00848.x.

Ahuja, Gautam, and Riitta Katila. 2001. "Technological Acquisitions and the Innovation Performance of Acquiring Firms: A Longitudinal Study." Strategic Management Journal 22 (3): 197-220. doi:10.1002/smj.157.

Ajzen, Icek. 1991. "The Theory of Planned Behavior." Organizational Behavior and Human Decision Processes 50 (2): 179-211.

Angrist, Joshua, Eric Bettinger, and Michael Kremer. 2006. "Long-Term Educational Consequences of Secondary School Vouchers: Evidence from Administrative Records in Colombia." The American Economic Review 96 (3): 847-62.

Arcury, T. A., and E. H. Christianson. 1993. "Rural-Urban Differences in Environmental Knowledge and Action." Journal of Environmental Education 25 (1): 19-25.

Armengol, Vicenç Fisas, Josep Maria Royo Aspa, Jordi Urgell García, Pamela Urrutia Arestizábal, Ana Villellas Ariño, and María Villellas Ariño. 2013. Alert 2013! Report on Conflicts, Human Rights and Peacebuilding. Barcelona: Icaria Editorial.

Arocena, Rodrigo, and Judith Sutz. 2000. "Looking At National Systems of Innovation From the South.” Industry \& Innovation 7 (1): 55-75. doi:10.1080/713670247.

_. 2001. "Innovation Systems and Developing Countries." 02-05. DRUID Working Paper. DRUID Working Paper. Copenhagen. doi:10.2307/1515847.

Bamberg, Sebastian, and Guido Möser. 2007. "Twenty Years after Hines, Hungerford, and Tomera: A New Meta-Analysis of Psycho-Social 
Determinants of pro-Environmental Behaviour." Journal of Environmental Psychology 27 (1): 14-25. doi:10.1016/j.jenvp.2006.12.002.

Baumol, W. J., W. E. Oates, and S. A. B Blackman. 1979. Economics,

Environmental Policy, and the Quality of Life. Englewood Cliffs, N.J:

Prentice Hall.

Berenguer, Jaime, José A. Corraliza, and Rocío Martin. 2005. "Rural-Urban

Differences in Environmental Concern, Attitudes, and Actions." European Journal of Psychological Assessment 21 (2): 128-38. doi:10.1027/10155759.21.2.128.

Bergek, Anna, Marko Hekkert, Staffan Jacobsson, Jochen Markard, Björn Sandén, and Bernhard Truffer. 2015. "Technological Innovation Systems in Contexts: Conceptualizing Contextual Structures and Interaction Dynamics."

Environmental Innovation and Societal Transitions 16. Elsevier B.V.: 51-64. doi:10.1016/j.eist.2015.07.003.

Bergek, Anna, and Staffan Jacobsson. 2003. "The Emergence of a Growth Industry: A Comparative Analysis of the German, Dutch and Swedish Wind Turbine Industries." In Change, Transformation and Development, edited by S. Metcalfe and U Cantner, 197-227. Heidelberg: Physica-Verlag HD. Bergek, Anna, Staffan Jacobsson, Bo Carlsson, Sven Lindmark, and Annika Rickne. 2008. "Analyzing the Functional Dynamics of Technological Innovation Systems: A Scheme of Analysis." Research Policy 37 (3): $407-$ 29. doi:10.1016/j.respol.2007.12.003.

Bergek, Anna, Staffan Jacobsson, and Björn A. Sandén. 2008. “'Legitimation” and 'development of Positive Externalities': Two Key Processes in the Formation Phase of Technological Innovation Systems." Technology Analysis \& Strategic Management 20 (5): 575-92. doi:10.1080/09537320802292768.

Bertalanffy, 1. von. 1950a. "An Outline of General System Theory." British Journal of Philosophy of Science 1: 139-64.

. 1950b. "The Theory of Open Systems in Physics and Biology." Science 111: 23-29.

Bhide, Anjali, and Carlos Rodríguez Monroy. 2011. "Energy Poverty: A Special Focus on Energy Poverty in India and Renewable Energy Technologies." Renewable and Sustainable Energy Reviews 15 (2). Elsevier Ltd: 1057-66. doi:10.1016/j.rser.2010.11.044.

Biel, Anders, and Andreas Nilsson. 2005. "Religious Values and Environmental Concern: Harmony and Detachment." Social Science Quarterly 86 (1): 17891. doi:10.1111/j.0038-4941.2005.00297.x.

Bijker, Wiebe E, Thomas P Hughes, and Trevor Pinch, eds. 2012. The Social Construction of Technological Systems: New Directions in the Sociology and History of Technology. Cambridge, MA: MIT press.

Binswanger, Mathias. 2001. "Technological Progress and Sustainable

Development: What about the Rebound Effect?" Ecological Economics 36 (1): 119-32. doi:10.1016/S0921-8009(00)00214-7.

Blocker, T. Jean, and Douglas L Eckberg. 1997. "Gender and Environmentalism: 
Results from the 1993 General Social Survey." Social Science Quarterly 78 (4): 841-58.

Borchers, C., C. Boesch, J. Riedel, H. Guilahoux, D. Ouattara, and C Randler. 2014. "Environmental Education in Côte D'ivoire/West Africa: ExtraCurricular Primary School Teaching Shows Positive Impact on Environmental Knowledge and Attitudes." International Journal of Science Education 4 (3): 240-59.

Borup, Mads, Nik Brown, Kornelia Konrad, and Harro Van Lente. 2006. "The Sociology of Expectations in Science and Technology." Technology Analysis \& Strategic Management 18 (3-4). Taylor \& Francis: 285-98.

Bovenberg, A. Lars, and Sjak Smulders. 1995. "Environmental Quality and Pollution-Augmenting Technological Change in a Two-Sector Endogenous Growth Model." Journal of Public Economics 57: 369-91.

Bradley, Jennifer Campbell, T. M. Waliczek, and J. M. Zajicek. 1999.

"Relationship between Environmental Knowledge and Environmental Attitude of High School Students." Journal of Environmental Education 30 (3): 17-21. doi:10.1080/00958969909601873.

Brechin, Steven R. 1999. "Objective Problems, Subjective Values, and Global Environmentalism: Evaluating the Postmaterialist Argument and Challenging a New Explanation." Social Science Quarterly. doi:10.1017/CBO9781107415324.004.

Brechin, Steven R., and Willett Kempton. 1994. "Global Environmentalism: A Challenge to the Postmaterialism Thesis?" Social Science Quarterly 75 (2): 245-69.

Breschi, S, and F Malerba. 1997. "Sectoral Innovation Systems: Technical Regimes, Schumpeterian Dynamics and Spatial Boundaries." In Systems of Innovation: Technologies, Institutions and Organizations, edited by Charles Edquist. Science, Technology and the International Political Economy. London: Pinter Publishers.

Brück, Tilman, Wim Naudé, and Philip Verwimp. 2013. "Entrepreneurship and Violent Conflict in Developing Countries.” 2013/28. WIDER Working Paper. WIDER Working Paper. Helsinki: UNU-WIDER.

Carlsson, Bo, ed. 1995. Technological Systems and Economic Performance: The Case of Factory Automation. Dordrecht: Kluwer Academic Publishers.

Carlsson, Bo, and R Stankiewicz. 1991. "On the Nature, Function and Composition of Technological Systems." Journal of Evolutionary Economics 1 (2): 93-118.

Coenen, Lars, and Fernando J. Díaz López. 2010. “Comparing Systems Approaches to Innovation and Technological Change for Sustainable and Competitive Economies: An Explorative Study into Conceptual Commonalities, Differences and Complementarities." Journal of Cleaner Production 18 (12). Elsevier Ltd: 1149-60. doi:10.1016/j.jclepro.2010.04.003.

Coertjens, Liesje, Jelle Boeve-de Pauw, Sven De Maeyer, and Peter Van Petegem. 
2010. "Do Schools Make a Difference in Their Students' Environmental Attitudes and Awareness? Evidence From Pisa 2006." International Journal of Science and Mathematics Education 8 (3): 497-522. doi:10.1007/s10763010-9200-0.

Cohen, W. M., and D Levinthal. 1989. "Innovation and Learning: The Two Faces of R \& D.” Economic Journal 99 (397): 569-596.

Cohen, W. M., and Daniel a. Levinthal. 1990. "Absorptive Capacity: A New Perspective on Learning and Innovation." Administrative Science Quarterly 35 (1): 128-52. doi:10.2307/2393553.

Collier, P. 1999. "On the Economic Consequences of Civil War." Oxford Economic Papers 51 (1): 168-83.

Collier, P, and M. Duponchel. 2013. "The Economic Legacy of Civil War: FirmLevel Evidence from Sierra Leone.” Journal of Conflict Resolution 57 (1): 65-88.

Cooke, Philip, Mikel Gomez Uranga, and Goio Etxebarria. 1997. "Regional Innovation Systems: Institutional and Organizational Dimensions." Research Policy 26: 475-91. doi:10.1016/S0048-7333(97)00025-5.

Coviello, Manlio F., Juan Gollán, and Miguel Pérez. 2012. "Public-Private Partnerships in Renewable Energy in Latin America and the Caribbean." Santiago.

Criscuolo, Paola, and Rajneesh Narula. 2008. "A Novel Approach to National Technological Accumulation and Absorptive Capacity: Aggregating Cohen and Levinthal." European Journal of Development Research 20 (1): 56-73. doi:10.1080/09578810701853181.

Cronbach, Lee J. 1951. "Coefficient Alpha and the Internal Structure of Tests." Psychometrika 16 (3): 297-334. doi:10.1007/BF02310555.

Dahlman, Carl J., and Richard Nelson. 1995. "Social Absorption Capability, National Innovation Systems and Economic Development." In Social Capability and Long-Term Economic Growth, edited by Bon Ho Koo and Dwight H Perkins, 1st editio, 82-122. Hampshire, UK: MacMillan Press Ltd. doi:10.1007/978-1-349-13512-7.

Damerell, P, C Howe, and E.J. Milner-Gulland. 2013. "Child-Orientated Environmental Education Influences Adult Knowledge and Household Behaviour." Environmental Research Letters 8: 1-7. doi:10.1088/17489326/8/1/015016.

Damon, W, and D Hart. 1988. Self-Understanding in Childhood and Adolescence. New York: Cambridge University Press.

Das, Kasturi. 2011. "Technology Transfer under the Clean Development Mechanism: An Empirical Study of 1000 CDM Projects." 14. Governance of Clean Development Working Paper. doi:10.2139/ssrn.1887727.

Davison, Robert, Doug Vogel, Roger Harris, and Noel Jones. 2000. "Technology Leapfrogging in Developing Countries - An Inevitable Luxury?" The Electronic Journal on Information Systems in Developing Countries 1 (5): 110. doi:10.1.1.33.7786. 
de Groot, Judith I. M., and Linda Steg. 2007. "Value Orientations and Environmental Beliefs in Five Countries: How to Measure Egoistic, Altruistic, and Biospheric Value Orientations." Journal of Cross-Cultural Psychology 38 (3): 318-32. doi:10.1177/0013916506297831.

De Groot, Judith I. M., Linda Steg, Martijn Keizer, Andrea Farsang, and Alan Watt. 2012. "Environmental Values in Post-Socialist Hungary: Is It Useful to Distinguish Egoistic, Altruistic and Biospheric Values?" Czech Sociological Review 48 (3): 421-40.

DeChano, Lisa M. 2006. "A Multi-Country Examination of the Relationship Between Environmental Knowledge and Attitudes." International Research in Geographical and Environmental Education 15 (1): 15-28. doi:10.2167/irgee/184.0.

Dell, R. M., and D. A J Rand. 2001. "Energy Storage - A Key Technology for Global Energy Sustainability." Journal of Power Sources 100 (1-2): 2-17. doi:10.1016/S0378-7753(01)00894-1.

Delucchi, Mark A. 2010. "Impacts of Biofuels on Climate Change, Water Use, and Land Use." Annals of the New York Academy of Sciences 1195: 28-45. doi:10.1111/j.1749-6632.2010.05457.x.

Diekmann, Andreas, and Axel Franzen. 1999. "The Wealth of Nations and Environmental Concern." Environment and Behavior 31 (4): 540-49. http://www.jstor.org/stable/10.2307/2808082\%5Cnhttp://www.jstor.org/disco ver $/ 10.2307 / 2808082$ ?uid $=3738032 \&$ uid $=2 \& u i d=4 \&$ sid $=21101188914321$.

Dietz, T., Paul C. Stern, and G. A. Guagnano. 1998. "Social Structural and Social Psychological Bases of Environmental Concern." Environment and Behavior 30 (4): 450-71.

Dincer, Ibrahim. 2000. "Renewable Energy and Sustainable Development: A Crucial Review." Renewable and Sustainable Energy Reviews 4 (2): 157-75. doi:10.1016/S1364-0321(99)00011-8.

Dunlap, R.E., and Kent D. Van Liere. 1978. "The 'New Environmental Paradigm." Journal of Environmental Education 9 (4): 10-19. doi:10.3200/JOEE.40.1.19-28.

Dunlap, Riley E., George H. Gallup, and Alec M. Gallup. 1993. "Of Global Concern: Results of the Health of the Planet Survey." Environment: Science and Policy for Sustainable Development 35 (9): 7-39. doi:10.1080/00139157.1993.9929122.

Dunlap, Riley E., and Angela G. Mertig. 1995. "Global Concern for the Environment: Is Affluence a Prerequisite?” Journal of Social Issues 51 (4): 121-37.

. 1997. "Global Environmental Concern: An Anomaly for Postmaterialism." Social Science Quarterly 78 (1): 24-29.

Dyner, I., Y. Olaya, and C.J. Franco. 2011. "An Enabling Framework for Wind Power in Colombia: What Are the Lessons from Latin America?" In Diffusion of Renewable Energy Technologies: Case Studies of Enabling Frameworks in Developing Countries, edited by J. Haselip, I. Nygaard, U. 
Hansen, and E. Ackom. Denmark: Technology Transfer Perspectives Series, UNEP Risø Centre.

Edison, Henry, Nauman bin Ali, and Richard Torkar. 2013. "Towards Innovation Measurement in the Software Industry." The Journal of Systems and Software 86: 1390-1407.

Edquist, Charles. 1997. "Systems of Innovation Approaches-Their Emergence and Characteristics." In Systems of Innovation: Technologies, Institutions and Organizations, edited by Charles Edquist, 1-35. London: Pinter Publishers/Cassell Academic.

. 2001. "The Systems of Innovation Approach and Innovation Policy: An Account of the State of the Art." In DRUID Conference, 1-24. Aalborg. . 2005. "Systems of Innovation: Perspectives and Challenges." In The Oxford Handbook of Innovation, edited by J Fagerberg, D. C Mowery, and R. R Nelson, 181-208. Oxford: Oxford University Press. doi:10.1093/oxfordhb/9780199286805.001.0001.

Edquist, Charles, and Björn Johnson. 1997. "Institutions and Organizations in Systems of Innovation." In Systems of Innovation: Technologies, Institutions and Organizations, edited by Charles Edquist, 41-63. London: Pinter Publishers/Cassell Academic.

Edsand, Hans-Erik. 2016. "Technological Innovation Systems and the Wider Context: A Framework for Developing Countries." \#2016-017. UNU-MERIT Working Paper Series. Working Paper Series. Maastricht. http://www.merit.unu.edu/publications/working-papers/abstract/?id=5999. _. 2017. "Identifying Barriers to Wind Energy Diffusion in Colombia: A Function Analysis of the Technological Innovation System and the Wider Context." Technology in Society 49 (May): 1-15.

Ehrnberg, E., and Staffan Jacobsson. 1997. "Technological Discontinuities and Incumbents' Performance: An Analytical Framework." In Systems of Innovation: Technologies, Institutions and Organizations, edited by Charles Edquist, 318-41. London: Pinter Publishers.

EIA. 2013. "International Energy Outlook 2013: With Projections to 2040." Outlook 2013. Washington. doi:EIA-0484(2013).

EPA. 2016. "Climate Change Indicators: Global Greenhouse Gas Emissions." Climate Change Indicators. https://www.epa.gov/climate-indicators/climatechange-indicators-global-greenhouse-gas-emissions\#ref2.

Ete, Mibi, and Frieda Prochaska. 2009. "Determinants of Success and Failure of Community Based Micro Hydro Project." In Energy and Climate Change in Cold Regions of Asia, 33-35. Ladakh: GERES.

http://scholar.google.com/scholar?hl=en\&btnG=Search\&q=intitle:Determina nts + of + success + and + failure + of + community + based + micro + hydro + project $\# 0$.

European Commission. 2016. "Paris Agreement - Climate Action." Climate Action - European Commission. http://ec.europa.eu/clima/policies/international/negotiations/paris/index_en.ht $\mathrm{m}$. 
Fagerberg, Jan. 2005. “Innovation: A Guide to the Literature.” In The Oxford Handbook of Innovation, edited by J Fagerberg, D. C Mowery, and R. R Nelson, 1-27. Oxford: Oxford University Press.

Faguet, Jean-Paul, and Fabio Sánchez. 2008. "Decentralization's Effects on

Educational Outcomes in Bolivia and Colombia." World Development 36 (7): 1294-1316. doi:10.1016/j.worlddev.2007.06.021.

. 2014. "Decentralization and Access to Social Services in Colombia." Public Choice 160: 227-49. doi:10.1007/s11127-013-0077-7.

Farla, Jacco, Jochen Markard, Rob Raven, and Lars Coenen. 2012. "Sustainability Transitions in the Making: A Closer Look at Actors, Strategies and Resources." Technological Forecasting and Social Change 79 (6). Elsevier Inc.: 991-98. doi:10.1016/j.techfore.2012.02.001.

Field, B. C. 1994. Environmental Economics: An Introduction. New York, NY: McGraw-Hill.

Flatten, Tessa C., Andreas Engelen, Shaker A. Zahra, and Malte Brettel. 2011. "A Measure of Absorptive Capacity: Scale Development and Validation."

European Management Journal 29 (2). Elsevier Ltd: 98-116. doi:10.1016/j.emj.2010.11.002.

Forrester, Jay W. 1961. Industrial Dynamics. Waltham, MA: Pegasus Communications.

- 1968. Principles of Systems. 2nd ed. Waltham, MA: Pegasus Communications.

- 1969. Urban Dynamics. Waltham, MA: Pegasus Communications. - 2009. "Some Basic Concepts in System Dynamics." D-4894.

Massachusetts Institute of Technology. http://www.systemsmodelbook.org/uploadedfile/238_63f73156-02df-4d87b0c6-c286a7beec26_SomeBasicConcepts.pdf.

Fransman, M. 1982. "Learning and the Capital Goods Sector under Free Trade:

The Case of Hong Kong." World Development 10 (11): 991-1014.

Fransson, N., and T. Garling. 1999. "Environmental Concern: Conceptual

Definitions, Measurement Methods, and Research Findings." Journal of

Environmental Psychology 19 (4): 369-82. doi:10.1006/jevp.1999.0141.

Franzen, Axel. 2003. "Environmental Attitudes in International Comparison: An Analysis of the ISSP Surveys 1993 and 2000." Social Science Quarterly 84 (2): 297-308.

Freeman, Christopher. 1987. Technology Policy and Economic Performance: Lessons from Japan. London: Pinter Publishers.

Freeman, Christopher, and Francisco Louçã. 2001. As Time Goes by: From the Industrial Revolutions to the Information Revolution. Oxford University Press.

Frey, B. S., and A Stutzer. 2002. Happiness and Economics: How the Economy and Institutions Affect Human Well-Being. Princeton, NJ: Princeton University Press.

Gallagher, Kelly Sims. 2006. "Limits to Leapfrogging in Energy Technologies? 
Evidence from the Chinese Automobile Industry.” Energy Policy 34 (4): 383-94. doi:10.1016/j.enpol.2004.06.005.

Gallón Gómez, Santiago Alejandro, and Karol Gómez Portilla. 2000. "El

Fenómeno de La Corrupción Y Su Influencia En La Economía Colombiana Entre 1960 Y 1999." Revista de Estudiantes de Economía Oikos 15. Medellín: 3-22.

García, Helena, Alejandra Corredor, Laura Calderón, and Miguel Gómez. 2013. "Análisis Costo Beneficio de Energías Renovables No Convencionales En Colombia.” Bogotá. http://www.fedesarrollo.org.co/wpcontent/uploads/2011/08/WWF_Analisis-costo-beneficio-energiasrenovables-no-convencionales-en-Colombia.pdf.

Gault, Fred. 2010. Innovation Strategies for a Global Economy: Development, Implementation, Measurement and Management. Cheltenham, UK and Northhampton, MA, USA: Edward Elgar and Ottawa: IDRC.

- 2016. "Defining and Measuring Innovation in All Sectors of the Economy: Policy Relevance." In OECD Blue Sky Forum III, 1-22. Ghent, Belgium.

Geels, Frank W. 2002. “Technological Transitions as Evolutionary Reconfiguration Processes: A Multi-Level Perspective and a Case-Study." Research Policy 31: 1257-74. doi:10.1016/S0048-7333(02)00062-8.

Geels, Frank W. 2005. "The Dynamics of Transitions in Socio-Technical Systems: A Multi-Level Analysis of the Transition Pathway from Horse-Drawn Carriages to Automobiles (1860-1930).” Technology Analysis \& Strategic Management 17 (4): 445-76. doi:10.1080/09537320500357319.

. 2011. "The Multi-Level Perspective on Sustainability Transitions: Responses to Seven Criticisms." Environmental Innovation and Societal Transitions 1 (1). Elsevier B.V.: 24-40. doi:10.1016/j.eist.2011.02.002. . 2013. "The Impact of the Financial-Economic Crisis on Sustainability Transitions: Financial Investment, Governance and Public Discourse." Environmental Innovation and Societal Transitions 6. Elsevier B.V.: 67-95. doi:10.1016/j.eist.2012.11.004.

Geels, Frank W., and René Kemp. 2007. "Dynamics in Socio-Technical Systems: Typology of Change Processes and Contrasting Case Studies." Technology in Society 29 (4): 441-55. doi:10.1016/j.techsoc.2007.08.009.

Geels, Frank W., and Johan Schot. 2007. "Typology of Sociotechnical Transition Pathways." Research Policy 36 (3): 399-417. doi:10.1016/j.respol.2007.01.003.

Geels, Frank W, Marko P. Hekkert, and Staffan Jacobsson. 2008. "The Dynamics of Sustainable Innovation Journeys." Technology Analysis \& Strategic Management 20 (5): 521-36. doi:10.1080/09537320802292982.

Gelissen, John. 2007. "Explaining Popular Support for Environmental Protection: A Multilevel Analysis of 50 Nations." Environment and Behavior 39 (3): 392-415. doi:10.1177/0013916506292014.

George, D., and M. Mallery. 2010. Using SPSS for Windows Step by Step: A 
Simple Guide and Reference. Boston, MA: Allyn \& Bacon.

Givens, J. E., and A. K. Jorgenson. 2011. "The Effects of Affluence, Economic

Development, and Environmental Degradation on Environmental Concern: A Multilevel Analysis." Organization \& Environment 24 (1): 74-91. doi:10.1177/1086026611406030.

Global Footprint Network. 2015. "Carbon Footprint." http://www.footprintnetwork.org/en/index.php/GFN/page/glossary/\#overshoo t.

Goetz, SJ, DL Debertin, and Angelos Pagoulatos. 1998. "Human Capital, Income, and Environmental Quality: A State-Level Analysis." Agricultural and Resource Economics Review 27: 200-208.

Goldman, Daphne, Orit Ben Zvi Assaraf, and Dina Shaharabani. 2013. "Influence of a Non-Formal Environmental Education Programme on Junior HighSchool Students' Environmental Literacy." International Journal of Science Education 35 (3): 515-45. doi:10.1080/09500693.2012.749545.

Gosens, Jorrit, and Yonglong Lu. 2013. "From Lagging to Leading? Technological Innovation Systems in Emerging Economies and the Case of Chinese Wind Power." Energy Policy 60. Elsevier: 234-50. doi:10.1016/j.enpol.2013.05.027.

Greening, L. A, and D. L Greene. 1998. "Energy Use, Technical Efficiency, and the Rebound Effect: A Review of the Literature. Report to the US Department of Energy." Denver: Hagler Bailly and Co.

Guha, R. 1999. Environmentalism: A Global History. New York: Addison Wesley. Gutierrez, Herman. 2013. "Colombia : Overview of Corruption and AntiCorruption.” Transparency International. www.transparency.org.

GWEC. 2014. "Global Statistics: Top Ten Cumulative Installed Capacity in 2014." http://www.gwec.net/global-figures/graphs/.

Hand, Carl M., and Kent D. Van Liere. 1984. "Religion, Mastery-Over-Nature, and Environmental Concern." Social Forces 63 (2): 555-70.

Hansen, Ulrich Elmer, Mathilde Brix Pedersen, and Ivan Nygaard. 2015. "Review of Solar PV Policies, Interventions and Diffusion in East Africa." Renewable and Sustainable Energy Reviews 46. Elsevier: 236-48. doi:10.1016/j.rser.2015.02.046.

Haryono, Andy, Soemarno, M. Sasmito Djati, and Amin Setyoleksono. 2014.

"Learning Attitude and Awareness against Students in Cultured

Environmental Success in Probolinggo." Journal of Environment and Earth Science 4 (16): 72-81.

Haughton, Jonathan, and Shahidur R. Khandker. 2009. "Inequality Measures.” In Handbook on Poverty + Inequality. Washington, DC.: The World Bank.

Hekkert, Marko P., and Simona O. Negro. 2009. "Functions of Innovation Systems as a Framework to Understand Sustainable Technological Change: Empirical Evidence for Earlier Claims." Technological Forecasting and Social Change 76 (4). Elsevier Inc.: 584-94. doi:10.1016/j.techfore.2008.04.013.

Hekkert, Marko P., Roald A. A. Suurs, Simona O. Negro, S. Kuhlmann, and Ruud 
E. Smits. 2007. "Functions of Innovation Systems: A New Approach for Analysing Technological Change." Technological Forecasting and Social Change 74 (4): 413-32. doi:10.1016/j.techfore.2006.03.002.

Hellsmark, Hans, and Staffan Jacobsson. 2009. "Opportunities for and Limits to Academics as System Builders-The Case of Realizing the Potential of Gasified Biomass in Austria." Energy Policy 37 (12). Elsevier: 5597-5611. doi:10.1016/j.enpol.2009.08.023.

Helmke, Gretchen, and Steven Levitsky. 2004. "Informal Institutions and Comparative Politics: A Research Agenda." Perspectives on Politics 2 (4): 725-40. doi:10.1017/S1537592704040472.

Hershfield, Hal E, H Min Bang, and Elke U Weber. 2014. "National Differences in Environmental Concern and Performance Are Predicted by Country Age." Psychological Science 25 (1): 152-60. doi:10.1177/0956797613501522.

Hillman, Karl M., Roald A. A. Suurs, Marko P. Hekkert, and Björn A. Sandén. 2008. "Cumulative Causation in Biofuels Development: A Critical Comparison of the Netherlands and Sweden." Technology Analysis \& Strategic Management 20 (5): 593-612. doi:10.1080/09537320802292826.

Howenstine, E. 1993. "Market Segmentation for Recycling." Environment and Behavior 25 (1): 86-102.

Humphreys, Macartan. 2003. "Economics and Violent Conflict." Program on Humanitarian Policy and Conflict Research.

Hungerford, Harold R, and Trudi L Volk. 1990. "Changing Learner Behavior through Environmental Education." Journal of Environmental Education 21 (3): 8-21. doi:10.1080/00958964.1990.10753743.

IDB. 2015a. "IDB - GEF Portfolio." http://www.iadb.org/en/topics/environment/global-environment-facility/idbgef-portfolio, 1708.html.

-. 2015b. "Project Details: Colombia." http://www.iadb.org/en/projects/projectdetails, $1301 . \mathrm{html}$ ?Country $=$ CO\&Sector $=$ EN $\&$ Status $=\&$ ProjectType $=\&$ SubSe ctor $=\&$ YearFrom $=1960 \&$ YearTo $=1980 \&$ FinancingOver $=\&$ FinancingUnder $=$ $\&$ Fund $=\&$ Cofinancing $=\&$ FinancialProd $=\&$ FinCurrency $=\&$ Topic $=\& E S I C=\&$ ProjectNumber $=$.

IEA. 2007. "World Energy Outlook 2007: China and India Insights." IEA Publications. Paris.

http://www.iea.org/publications/freepublications/publication/weo_2007.pdf.

- 2011. Deploying Renewables 2011: Best and Future Policy Practice.

Paris: International Energy Agency. doi:10.1787/9789264124912-en.

. 2015. "World Energy Outlook 2015." Paris. www.iea.org.

. 2016a. "Colombia: Indicators (1990-2014)." International Energy Agency Statistics.

http://www.iea.org/statistics/statisticssearch/report/?country=Colombia\&prod uct $=$ indicators.

- 2016b. "World Energy Outlook: Energy Access Database." World Energy 


\section{Outlook.}

http://www.worldenergyoutlook.org/resources/energydevelopment/energyacc essdatabase/.

Iizuka, Michiko, and Mulu Gebreeyesus. 2012. "A Systemic Perspective in Understanding the Successful Emergence of Non- Traditional Exports: Two Cases from Africa and Latin America." Working Paper Series. Maastricht. doi:10.1111/j.1467-629X.1980.tb00220.x. . 2016. "Using Functions of Innovation Systems to Understand the Successful Emergence of Non-Traditional Agricultural Export Industries in Developing Countries: Cases from Ethiopia and Chile." The European Journal of Development Research. Palgrave Macmillan UK, 1-20. doi:10.1057/s41287-016-0004-0.

Inglehart, Ronald. 1977. The Silent Revolution: Changing Values and Political Styles among Western Publics. Princeton, NJ: Princeton University Press. . 1990. Culture Shift in Advanced Industrial Society. Princeton, NJ: Princeton University Press.

. 1997. Modernization and Postmodernization: Cultural, Economic and Political Change in 43 Societies. Princeton, NJ: Princeton University Press.

Iozzi, L. A. 1989. "What Research Says to the Educator: Environmental Education and Affective Domain." The Journal of Environmental Education 20 (3-4): $3-13$.

IPCC. 2001. "Setting the Stage : Climate Change and Sustainable Development." In Climate Change 2001: Working Group III: Mitigation, 42. Cambridge: Cambridge University Press.

- 2007. "Climate Change 2007: Mitigation of Climate Change: Contribution of Working Group III to the Fourth Assessment Report of the Intergovernmental Panel on Climate Change." Edited by Bert Metz, Ogunlade Davidson, Peter Bosch, Rutu Dave, and Leo Meyer. Intergovernmental Panel on Climate Change. Cambridge, United Kingdom and New York, NY, USA: Cambridge University Press.

. 2012. "Managing the Risks of Extreme Events and Disasters To Advance Climate Change Adaptation." Edited by Christopher. B. Field, Vicente Barros, Thomas. C. Stocker, Qin Dahe, David. Jon. Dokken, Kristie. L. Ebi, Michael. D. Mastrandrea, et al. Cambridge: Cambridge University Press. - 2013. "Summary for Policymakers." In Climate Change 2013: The Physical Science Basis. Contribution of Working Group I to the Fifth Assessment Report of the Intergovernmental Panel on Climate Change, edited by T.F. Stocker, D. Qin, G.-K. Plattner, M. Tignor, S.K. Allen, J. Boschung, A. Nauels, Y. Xia, V. Bex, and P.M. Midgley. Cambridge, United Kingdom and New York, NY, USA: Cambridge University Press. doi:10.1017/CBO9781107415324.004.

. 2014. Climate Change 2014: Impacts, Adaptation, and Vulnerability. Part A: Global and Sectoral Aspects. Contribution of Working Group II to the Fifth Assessment Report of the Intergovernmental Panel on Climate Change 
[Field, C.B., V.R. Barros, D.J. Dokken, K.J. Edited by Christopher B Field, Vincente R Barros, D J Dokken, K J Mach, M D Mastrandrea, T E Bilir, M Chatterjee, K L Ebi, Y O Estrada, and R C Genova. Cambridge, United Kingdom and New York, NY, USA: Cambridge University Press.

IRENA. 2015. "Note of the Director-General. Renewable Energy Deployment: Decreasing Costs - Increasing Benefits." In Sixth Session of the Assembly, 12. Abu Dhabi: International Renewable Energy Agency.

Israel, Debra, and Arik Levinson. 2004. "Willingness to Pay for Environmental Quality: Testable Empirical Implications of the Growth and Environment Literature." Contributions to Economic Analysis \& Policy 3 (1): 1-24. doi:10.2202/1538-0645.1254.

Jacobsson, Staffan, and Anna Bergek. 2004. "Transforming the Energy Sector: The Evolution of Technological Systems in Renewable Energy Technology." Industrial and Corporate Change 13 (5): 815-49. doi:10.1093/icc/dth032. - 2006. "A Framework for Guiding Policy-Makers Intervening in Emerging Innovation Systems in 'Catching-Up' Countries." The European Journal of Development Research 18 (4): 687-707. doi:10.1080/09578810601094902. Jacobsson, Staffan, and Anna Johnson. 2000. "The Diffusion of Renewable Energy Technology: An Analytical Framework and Key Issues for Research." Energy Policy 28 (9): 625-40. doi:10.1016/S0301-4215(00)00041-0.

Jacobsson, Staffan, and Volkmar Lauber. 2006. "The Politics and Policy of Energy System Transformation - Explaining the German Diffusion of Renewable Energy Technology." Energy Policy 34 (3): 256-76. doi:10.1016/j.enpol.2004.08.029.

Jacobsson, Thomas, and Staffan Jacobsson. 2014. "Conceptual Confusion - an Analysis of the Meaning of Concepts in Technological Innovation Systems and Sociological Functionalism." Technology Analysis \& Strategic Management 26 (7): 811-23. doi:10.1080/09537325.2014.900171.

Jerneck, Anne, Lennart Olsson, Barry Ness, Stefan Anderberg, Matthias Baier, Eric Clark, Thomas Hickler, et al. 2011. "Structuring Sustainability Science." Sustainability Science 6 (1): 69-82. doi:10.1007/s11625-010-0117-x. Johnson, Anna. 2001. "Functions in Innovation System Approaches." Göteborg. Johnson, Anna, and Staffan Jacobsson. 2001. "Inducement and Blocking Mechanisms in the Development of a New Industry: The Case of Renewable Energy Technology in Sweden." In Technology and the Market: Demand, Users and Innovation, edited by R Coombs, K Green, A Richards, and V Walsh, 89-111. Cheltenham: Edward Elgar.

Karp, D.G. 1996. "Values and Their Effect on pro-Environmental Behavior." Environment and Behavior 28: 111-133.

Kemp, René, Arie Rip, and Johan Schot. 2001. "Constructing Transition Paths through the Management of Niches." In Path Dependence and Creation, edited by R. Garud and P. Karnoe, 269-99. London: Lawrence Erlbaum. Kemp, René, Johan Schot, and Remco Hoogma. 1998. "Regime Shifts to Sustainability through Processes of Niche Formation: The Approach of 
Strategic Niche Management.” Technology Analysis \& Strategic

Management 10 (2). Taylor \& Francis: 175-98.

Kennedy, Matthew, and Biswajit Basu. 2013. "Overcoming Barriers to Low

Carbon Technology Transfer and Deployment: An Exploration of the Impact of Projects in Developing and Emerging Economies." Renewable and Sustainable Energy Reviews 26. Elsevier: 685-93. doi:10.1016/j.rser.2013.05.071.

Kern, Florian, and Adrian Smith. 2008. "Restructuring Energy Systems for Sustainability? Energy Transition Policy in the Netherlands." Energy Policy 36 (11). Elsevier: 4093-4103.

Kidd, Quentin, and Aie-Rie Lee. 1997. "Postmaterialist Values and the Environment: A Critique and Reappraisal." Social Science Quarterly 78 (1): $1-15$.

Kim, Daniel H. 1999. "Introduction to Systems Thinking." http://www.thinking.net/Systems_Thinking/Intro_to_ST/intro_to_st.html.

King, Elizabeth M, Peter F Orazem, and Darin Wohlgemuth. 1999. "Central Mandates and Local Incentives: The Colombia Education Voucher Program." The World Bank Economic Review 13 (3): 467-91.

King, Elizabeth M, Laura Rawlings, Marybell Gutierrez, Carlos Pardo, and Carlos Torres. 1997. "Colombia's Targeted Education Voucher Program: Features, Coverage, and Participation." 3. Impact Evaluation of Education Reforms. Washington, DC.

Klagge, Britta, Zhigao Liu, and Pedro Campos Silva. 2012. "Constructing China's Wind Energy Innovation System.” Energy Policy 50. Elsevier: 370-82. doi:10.1016/j.enpol.2012.07.033.

Kollmuss, Anja, and Julian Agyeman. 2002. "Mind the Gap: Why Do People Act Environmentally and What Are the Barriers to pro- Environmental Behavior?" Environmental Education Research 8 (3): 37-41. doi:10.1080/1350462022014540.

Kuhlmann, S., P. Shapira, and Ruud E. Smits. 2010. "A Systemic Perspective: The Innovation Policy Dance." In The Theory and Practice of Innovation Policy. An International Research Handbook, edited by R. Smits, S. Kuhlmann, and P. Shapira, 1-22. Cheltenham, UK: Edward Elgar.

Lambrechts, Wim, Ingrid Mulà, Kim Ceulemans, Ingrid Molderez, and Veerle Gaeremynck. 2013. "The Integration of Competences for Sustainable Development in Higher Education: An Analysis of Bachelor Programs in Management." Journal of Cleaner Production 48. Elsevier Ltd: 65-73. doi:10.1016/j.jclepro.2011.12.034.

Lewis, Joanna I. 2007. "Technology Acquisition and Innovation in the Developing World: Wind Turbine Development in China and India." Studies in Comparative International Development 42 (3-4): 208-32. doi:10.1007/s12116-007-9012-6.

Limaye, Dilip R., and Xianli Zhu. 2012. “Accessing International Financing for Climate Change Mitigation: A Guidebook for Developing Countries." UNEP 
Risø Centre on Energy, Climate and Sustainable Development. Roskilde. Lin, Emily, and Qingmin Shi. 2014. "Exploring Individual and School-Related Factors and Environmental Literacy: Comparing U.S. and Canada Using PISA 2006." International Journal of Science and Mathematics Education 12 (1): 73-97. doi:10.1007/s10763-012-9396-2.

Littledyke, Michael. 2008. "Science Education for Environmental Awareness:

Approaches to Integrating Cognitive and Affective Domains." Environmental Education Research 14 (1): 1-17. doi:10.1080/13504620701843301.

Liu, Xielin, and Steven White. 2001. "Comparing Innovation Systems: A Framework and Application to China's Transitional Context." Research Policy 30: 1091-1114.

Loorbach, Derk A. 2010. "Transition Management for Sustainable Development: A Prescriptive, Complexity-Based Governance Framework." Governance, An International Journal of Policy, Administration, and Institutions 23 (1): 16183. doi:10.1111/j.1468-0491.2009.01471.x.

Louv, R. 2008. Last Child in the Woods: Saving Our Children from Nature-Deficit Disorder. 2nded. New York: Woodman Publishing Company, Inc.

Lucas, A. M. 1979. Environment and Environmental Education: Conceptual Issues and Curriculum Implications. Melbourne, Australia: Australian International Press \& Pub.

Lundvall, Bengt-Åke. 1992. National Systems of Innovation: Towards a Theory of Innovation and Interactive Learning. London: Pinter Publishers.

Lundvall, Bengt-Åke, Björn Johnson, Esben Sloth Andersen, and Bent Dalum. 2002. "National Systems of Production, Innovation and Competence Building." Research Policy 31 (2): 213-31. doi:10.1016/S00487333(01)00137-8.

Luthra, Sunil, Sanjay Kumar, Dixit Garg, and Abid Haleem. 2015. "Barriers to Renewable/sustainable Energy Technologies Adoption: Indian Perspective." Renewable and Sustainable Energy Reviews 41. Elsevier: 762-76. doi:10.1016/j.rser.2014.08.077.

Macías Parra, Ana María. 2013. "Estudio de Generación Eléctrica Bajo Escenario de Cambio Climático.” UPME. Bogotá. doi:10.1017/CBO9781107415324.004.

Magnani, Elisabetta. 2000. "The Environmental Kuznets Curve, Environmental Protection Policy and Income Distribution." Ecological Economics 32 (3): 431-43. doi:10.1016/S0921-8009(99)00115-9.

Marcinkowski, Tom. 2003. "Commentary on Rickinson's 'Learners and Learning in Environmental Education: A Critical Review of the Evidence' (EER 7(3))." Environmental Education Research 9 (2): 181-214. doi:10.1080/13504620303474.

Markard, Jochen, Martin Stadelmann, and Bernhard Truffer. 2009. "Prospective Analysis of Technological Innovation Systems: Identifying Technological and Organizational Development Options for Biogas in Switzerland." Research Policy 38 (4): 655-67. doi:10.1016/j.respol.2009.01.013. 
Markard, Jochen, and Bernhard Truffer. 2008. "Technological Innovation Systems and the Multi-Level Perspective: Towards an Integrated Framework." Research Policy 37 (4): 596-615. doi:10.1016/j.respol.2008.01.004.

Markard, Jochen, Steffen Wirth, and Bernhard Truffer. 2016. "Institutional Dynamics and Technology Legitimacy - A Framework and a Case Study on Biogas Technology." Research Policy 45 (1). Elsevier B.V.: 330-44. doi:10.1016/j.respol.2015.10.009.

Marquardt, Jens, Karoline Steinbacher, and Miranda Schreurs. 2016. "Driving Force or Forced Transition? The Role of Development Cooperation in Promoting Energy Transitions in the Philippines and Morocco." Journal of Cleaner Production 128. Elsevier Ltd: 22-33. doi:10.1016/j.jclepro.2015.06.080.

Meadows, Donella, Dennis L. Meadows, Jorgen Randers, and William W. Behrens III. 1972. The Limits to Growth: A Report for the Club of Rome's Project on the Predicament of Mankind. Universe Books. New York: Universe Books. doi:10.1111/j.1752-1688.1972.tb05230.x.

Meelen, Toon, and Jacco Farla. 2013. "Towards an Integrated Framework for Sustainable Innovation." Technology Analysis \& Strategic Management 25 (8): 957-970. doi:10.1080/09537325.2013.823146.

Melo, Ligia. 2005. "Impacto de La Descentralización Fiscal Sobre La Educación Pública Colombiana." No. 350. Borradores de Economía. Borradores de Economía.

Meyers, L. S., G. Gamst, and A. J. Guarino. 2006. Applied Multivariate Research: Design and Interpretation. Thousand Oaks, CA: Sage Publications.

Millennium Ecosystem Assessment. 2005. "Ecosystems and Human Well-Being: Synthesis." Washington, DC.: Island Press.

Mitchell, Melanie. 2009. Complexity: A Guided Tour. Oxford: Oxford University Press.

Moller, Lars Christian. 2012. "Breaking with History: Why Colombia Needs a More Progressive Tax System." Colombia Reports. http://www.worldbank.org/en/news/opinion/2012/12/17/why-colombianeeds-a-more-progressive-tax-system.

Mortimore, Peter. 2009. "Alternative Models for Analysing and Representing Countries' Performance in PISA.” Brussels.

Mowery, D, and J Oxley. 1995. "Inward Technology Transfer and Competitiveness: The Role of National Innovation Systems." Cambridge Journal of Economics 1: 67-93.

MRI, UNC, and NUMARK. 2010. "Sustainable Energy and Biofuel Strategies for Colombia: Preliminary Report I." Bogotá: Minstry of Mines and Energy and Inter-American Development Bank.

Murphy, Kevin, Grant A. Kirkman, Stephen Seres, and Erik Haites. 2015.

"Technology Transfer in the CDM: An Updated Analysis." Climate Policy 15 (1): 127-45. doi:10.1080/14693062.2013.812719.

Myrdal, Gunnar. 1957. Economic Theory and Underdeveloped Regions. Edited by 
Gunnar Myrdal. London: Gerald Duckworth \& Co. Ltd.

Naudé, Wim. 2007. "Peace, Prosperity, and Pro-Growth Entrepreneurship." 2007/02. UNU-WIDER Discussion Paper. Vol. 2. Discussion Paper.

Helsinki: UNU-WIDER.

Negev, Maya, Gonen Sagy, Yaakov Garb, Alan Salzberg, and Alon Tal. 2008.

"Evaluating the Environmental Literacy of Israeli Elementary and High

School Students." The Journal of Environmental Education 39 (2): 3-20. doi:10.3200/JOEE.39.2.3-20.

Negro, Simona O., and Marko P. Hekkert. 2008. "Explaining the Success of

Emerging Technologies by Innovation System Functioning: The Case of Biomass Digestion in Germany." Technology Analysis \& Strategic

Management 20 (4): 465-82. doi:10.1080/09537320802141437.

Negro, Simona O., Marko P. Hekkert, and Ruud E. Smits. 2007. "Explaining the Failure of the Dutch Innovation System for Biomass Digestion-A Functional Analysis.” Energy Policy 35 (2): 925-38. doi:10.1016/j.enpol.2006.01.027. Negro, Simona O., Roald A. A. Suurs, and Marko P. Hekkert. 2008. "The Bumpy Road of Biomass Gasification in the Netherlands: Explaining the Rise and Fall of an Emerging Innovation System." Technological Forecasting and Social Change 75 (1): 57-77. doi:10.1016/j.techfore.2006.08.006.

Nelson, R. R, ed. 1993. National Innovation Systems: A Comparative Analysis. New York: Oxford University Press.

Nelson, R. R, and N Rosenberg. 1993. "Technical Innovation and National Systems.” In National Innovation Systems: A Comparative Analysis, edited by R. R Nelson, 3-21. Oxford: Oxford University Press.

Neumayer, Eric. 2002. "Do Democracies Exhibit Stronger International Environmental Commitment? A Cross-Country Analysis." Journal of Peace Reseach 39 (2): 139-64.

North, Douglass C. 1991. "Institutions.” The Journal of Economic Perspectives 5 (1): 97-112. doi:10.2307/2234910.

Núñez, Jairo, Roberto Steiner, Ximena Cadena, and Renata Pardo. 2002. “¿Cuáles Colegios Ofrecen Mejor Educación En Colombia?” 1657-7191. Documento $C E D E$. Vol. 193. Universidad de los Andes.

OECD. 1992. OECD Proposed Guidelines for Collecting and Interpreting Technological Innovation Data - Oslo Manual. 1st ed. Paris: OECD.

—. 2007. "Pisa 2006: Science Competencies for Tomorrow's World. Volume

1 - Analysis." Paris. doi:10.1787/9789264040014-en.

- 2009. "PISA 2006: Technical Report." Paris.

. 2011. "The Learning Environment and Organisation of Schools." In Education at a Glance, 224-31. Paris: OECD.

- 2013. "Roadmap Fo the Accession of Colombia to the OECD Convention. C(2013)110/Final. Adopted by the Council at Its 1285th Session on 19 September 2013." Paris. . 2014. "Background Brief: The Rationale for Fighting Corruption." CleanGovBiz. Paris. www.cleangovbiz.org. 
OECD/Eurostat. 2005. Oslo Manual: Guidelines for Collecting and Interpreting Innovation Data. OECD. 3rd ed. Paris: OECD. doi:10.1787/9789264013100en.

OECD, and IBRC/The World Bank. 2012. "Reviews of National Policies for Education: Tertiary Education in Colombia 2012." OECD Publishing. doi:http://dx.doi.org/10.1787/9789264180697-en.

Oltra, Maria J, and Marisa Flor. 2003. "The Impact of Technological Opportunities and Innovative Capabilities on Firms' Output Innovation." Creativity and Innovation Management 12 (3): 137-44. doi:doi:10.1111/1467-8691.00277.

Oreg, Shaul, and Tally Katz-Gerro. 2006. "Predicting Proenvironmental Behavior Cross-Nationally: Values, the Theory of Planned Behavior, and Value-BeliefNorm Theory." Environment and Behavior 38 (4): 462-83. doi:10.1177/0013916505286012.

Ostrom, Elinor. 2009. "A General Framework for Analyzing Sustainability of Social-Ecological Systems.” Science 325 (419). doi:10.1126/science.1172133.

Osunmuyiwa, Olufolahan, and Agni Kalfagianni. 2016. "Transitions in Unlikely Places: Exploring the Conditions for Renewable Energy Adoption in Nigeria." Environmental Innovation and Societal Transitions. Elsevier B.V. doi:10.1016/j.eist.2016.07.002.

Panayotou, Theodore. 1993. "Empirical Tests and Policy Analysis of Environmental Degradation at Different Stages of Economic Development." WEP 2-22/WP. 238. World Employment Programme Research. Geneva. http://ideas.repec.org/p/ilo/ilowps/292778.html.

- 1997. "Demystifying the Environmental Kuznets Curve: Turning a Black Box into a Policy Tool." Environment and Development Economics 2 (4): 465-84. doi:10.1017/S1355770X97000259.

Pawar, K.V., and Ravi V. Rothkar. 2015. "Forest Conservation \& Environmental Awareness." Procedia Earth and Planetary Science 11: 212-15. doi:10.1016/j.proeps.2015.06.027.

Perez, C. 2002. Technological Revolutions and Financial Capital: The Bubbles and Dynamics of Golden Ages. Cheltenham, UK: Edward Elgar.

Pérez Bedoya, Edigson, and Jaime Antonio Osorio Osorio. 2002. Energía, Pobreza $Y$ Deterioro Ecológico En Colombia: Introducción a Las Energías Alternativas. Medellín: Estrategias y Desarrollo.

Perkins, Richard. 2003. "Environmental Leapfrogging in Developing Countries: A Critical Assessment and Reconstruction." Natural Resources Forum 27: $177-$ 88. doi:10.1111/1477-8947.00053.

Perrot, Radhika. 2012. "The Dynamics of Renewable Energy Transition in Developing Countries: The Case of South Africa and India.” \#2012-067. UNU-MERIT Working Paper Series. Working Paper Series. Maastricht.

Peuckert, Jan, Miriam Bodenheimer, and Carsten Gandenberger. 2016. "The Role of International Trade for the Global Build-up of Innovation Capabilities in the Wind Industry." Innovation and Development 6 (1). Taylor \& Francis: 
103-21. doi:10.1080/2157930X.2015.1116965.

Popp, David. 2011. "International Technology Transfer, Climate Change, and the Clean Development Mechanism." Review of Environmental Economics and Policy 5 (1): 131-52. doi:10.1093/reep/req018.

Portafolio. 2010a. "Ecopetrol Toma El Reto de Buscar Nuevas Energías." Portafolio, January 20.

. 2010b. "Isagen Entró En La Era de Las Energías Renovables." Portafolio, March 24.

Porter, A.L., W.B. Ashton, G. Clar, J.F. Coates, K. Cuhls, S.W. Cunningham, K. Ducatel, et al. 2004. "Technology Futures Analysis: Toward Integration of the Field and New Methods." Technological Forecasting and Social Change 71 (3). Elsevier: 287-303.

Poveda, Germán, Diana M Álvarez, and Óscar A Rueda. 2011. "Hydro-Climatic Variability over the Andes of Colombia Associated with ENSO: A Review of Climatic Processes and Their Impact on One of the Earth's Most Important Biodiversity Hotspots." Climate Dynamics 36 (11): 2233-49. doi:10.1007/s00382-010-0931-y.

Qualman, Erik. 2009. Socialnomics: How Social Media Transforms the Way We Live and Do Business. Hoboken, NJ: John Wiley \& Sons, Inc.

Radermacher, F. J. 1997. "Building the Information Society." In Information Society and the Regions in Europe, edited by R. Sturm, G Weinmann, and O Will, 14thed. Tübingen: University of Tübingen.

Rakotomamonjy, S. N., J. P G Jones, J. H. Razafimanahaka, B. Ramamonjisoa, and S. J. Williams. 2015. "The Effects of Environmental Education on Children's and Parents' Knowledge and Attitudes towards Lemurs in Rural Madagascar." Animal Conservation 18 (2): 157-66. doi:10.1111/acv.12153.

Rangel, Claudia, and Christy Lleras. 2010. "Educational Inequality in Colombia:

Family Background, School Quality and Student Achievement in Cartagena." International Studies in Sociology of Education 20 (4): 291-317. doi:10.1080/09620214.2010.530855.

Rao, K. Usha, and V. V N Kishore. 2010. "A Review of Technology Diffusion Models with Special Reference to Renewable Energy Technologies."

Renewable and Sustainable Energy Reviews 14 (3): 1070-78. doi:10.1016/j.rser.2009.11.007.

Raven, Rob. 2005. "Strategic Niche Management for Biomass." Eindhoven University.

Raven, Rob, and Frank W. Geels. 2010. "Socio-Cognitive Evolution in Niche Development: Comparative Analysis of Biogas Development in Denmark and the Netherlands (1973-2004)." Technovation 30 (2). Elsevier: 87-99.

Raworth, Kate. 2012. "A Safe and Just Space For Humanity: Can We Live within the Doughnut?" Oxfam Discussion Papers. Oxford. doi:10.5822/978-161091-458-1.

Reddy, Sudhakar, and J. P. Painuly. 2004. "Diffusion of Renewable Energy Technologies-Barriers and Stakeholders' Perspectives." Renewable Energy 
29 (9): 1431-47. doi:10.1016/j.renene.2003.12.003.

REN21. 2011. "Renewables 2011 Global Status Report." REN21 Secretariat.

Paris: REN21 Secretariat. doi:[26/08/2013].

Rip, Arie, and René Kemp. 1998. "Technological Change.” In Human Choice and Climate Change - Resources and Technology, edited by S. Rayner and E.L. Malone, 327-399. Columbus: Battelle Press.

Rip, Arie, Johan Schot, and T J Misa. 1995. "Constructive Technology Assessment: A New Paradigm for Managing Technology in Society.” In Managing Technology in Society. The Approach of Constructive Technology Assessment, 1-12. London: Pinter Publishers.

Rockström, J, Will Steffen, Kevin Noone, Johan Rockstrom, Will Steffen, Kevin Noone, Asa Persson, et al. 2009. "A Safe Operating Space for Humanity." Nature 461 (September). Nature Publishing Group: 472-75. http://dx.doi.org/10.1038/461472a.

Rotmans, Jan, René Kemp, and Marjolein Van Asselt. 2001. "More Evolution than Revolution: Transition Management in Public Policy." Foresight 3 (1). MCB UP Ltd: $15-31$.

Sadorsky, Perry. 2009. "Renewable Energy Consumption and Income in Emerging Economies." Energy Policy 37 (10). Elsevier: 4021-28. doi:10.1016/j.enpol.2009.05.003.

Sánchez, Fabio. 2006. "Decentralización Y Progreso En El Acceso a Los Servicios Sociales de Educación, Salud Y Agua Y Alcantarillado.” 2006-15. Documento CEDE. Bogotá.

Savage, R. D, P. G Britton, N Bolton, and E. H Hall. 1973. Intellectual Functioning in the Aged. London: Methuen.

Saxenian, AnnaLee. 1994. Regional Advantage: Culture and Competition in Silicon Valley and Route 128. Cambridge, MA: Harvard University Press.

Scherrer, Christian P. 2003. "Contemporary Violent Conflict World-Wide: Types, Index, Cases and Trends." Hiroshima.

Schot, Johan, and Frank W Geels. 2008. "Strategic Niche Management and Sustainable Innovation Journeys: Theory, Findings, Research Agenda, and Policy." Technology Analysis \& Strategic Management 20 (5): 537-54. doi:10.1080/09537320802292651.

Schott, Thomas, and Kent Wickstrom Jensen. 2008. "The Coupling between Entrepreneurship and Public Policy: Tight in Developed Countries but Loose in Developing Countries." Estudios de Economía 35 (2): 195-214. http://www.doaj.org/doaj?func=abstract\&amp;id=474212.

Schwartz, Shalom H. 1977. "Normative Influence on Altruism." In Advances in Experimental Social Psychology, edited by L Berkowitz, 10:221-79. New York: Academic Press Inc.

Scruggs, Lyle. 2003. Sustaining Abundance: Environmental Performance in Industrial Democracies. Cambridge, UK: Cambridge University Press.

SIPRI. 2015. "SIPRI Military Expenditure Database." http://www.sipri.org/research/armaments/milex/milex_database. 
Smith, Adrian. 2007. "Translating Sustainabilities between Green Niches and Socio-Technical Regimes." Technology Analysis \& Strategic Management 19 (4). Taylor \& Francis: 427-50.

Smith, Adrian, Andy Stirling, and Frans Berkhout. 2005. "The Governance of Sustainable Socio-Technical Transitions." Research Policy 34 (10): 14911510. doi:10.1016/j.respol.2005.07.005.

Smith, Adrian, Jan-Peter Voß, and John Grin. 2010. "Innovation Studies and Sustainability Transitions: The Allure of the Multi-Level Perspective and Its Challenges." Research Policy 39 (4): 435-48. doi:10.1016/j.respol.2010.01.023.

Soete, Luc, Bart Verspagen, and Bas Ter Weel. 2010. "Systems of Innovation." In Handbook of the Economics of Innovation, edited by Bronwyn H. Hall and Nathan Rosenberg, 1st ed., 2:1159-80. Amsterdam: Elsevier B.V. doi:10.1016/S0169-7218(10)02011-3.

Somekh, Bridget, and Cathy Lewin, eds. 2005. Research Methods in the Social Sciences. London: Sage Publications.

Sovacool, Benjamin K. 2009. "The Cultural Barriers to Renewable Energy and Energy Efficiency in the United States." Technology in Society 31 (4). Elsevier Ltd: 365-73. doi:10.1016/j.techsoc.2009.10.009.

- 2013. "A Qualitative Factor Analysis of Renewable Energy and Sustainable Energy for All (SE4ALL) in the Asia-Pacific." Energy Policy 59 (August): 393-403. doi:10.1016/j.enpol.2013.03.051.

Spalding-Fecher, R., A. N. Achanta, P. Erickson, E. Haites, M. Lazarus, N. Pahuja, N. Pandey, S. Seres, and R. Tewari. 2012. "Assessing the Impact of the Clean Development Mechanism: Report Commissioned by the High Level Panel on the CDM Policy Dialogue.” Bonn.

Steffen, Will, Katherine Richardson, Johan Rockström, S. E. Cornell, I. Fetzer, E. M. Bennett, R. Biggs, et al. 2015. "Planetary Boundaries: Guiding Human Development on a Changing Planet." Science 347 (6223): 1259855-11259855-10. doi:10.1126/science.1259855.

Steg, Linda, Lieke Dreijerink, and Wokje Abrahamse. 2005. "Factors Influencing the Acceptability of Energy Policies: A Test of VBN Theory." Journal of Environmental Psychology 25 (4): 415-25. doi:10.1016/j.jenvp.2005.08.003.

Steinmueller, W. Edward. 2001. "ICTs and the Possibilities for Leapfrogging by Developing Countries." International Labour Review 140 (2): 193-210. doi:10.1111/j.1564-913X.2001.tb00220.x.

Stern, David I. 2004. "Energy Growth and Energy." Encyclopedia of Energy 2: 35-51. doi:10.1016/0140-9883(93)90033-N.

Stern, Nicholas H. 2007. The Economics of Climate Change: The Stern Review. Cambridge, UK: Cambridge University Press.

Stern, Paul C. 2000. "Toward a Coherent Theory of Environmentally Significant Behavior.” Journal of Social Issues 56 (3): 407-24. doi:10.1111/00224537.00175.

Stern, Paul C., Thomas Dietz, Tabel Abel, Gregory A. Guagnano, and Linda Kalof. 
1999. "A Value-Belief-Norm Theory of Support for Social Movements: The Case of Environmentalism." Human Ecology Review 6 (2): 81-97. doi: $10.2307 / 2083693$.

Suurs, Roald A. A., and Marko P. Hekkert. 2009. "Cumulative Causation in the Formation of a Technological Innovation System: The Case of Biofuels in the Netherlands." Technological Forecasting and Social Change 76 (8). Elsevier Inc.: 1003-20. doi:10.1016/j.techfore.2009.03.002.

The World Bank. 2004. "Colombia: Recent Economic Developments in Infrastructure (REDI): Balancing Social and Productive Needs for Infrastructure." Finance, Private Sector and Infrastructure Unit. Vol. 2. Washington, DC.

- 2008. "Colombia - The Quality of Education in Colombia: An Analysis and Options for a Policy Agenda." Washington, DC. https://openknowledge.worldbank.org/handle/10986/7875. . 2012a. "Turn down the Heat, Why a 4 Degree World Must Be Avoided." Turn down the Heat. Washington, DC.

- 2012b. "World Bank Financing for Renewable Energy Hits Record High." http://web.worldbank.org/WBSITE/EXTERNAL/TOPICS/EXTENERGY2/0 ,,contentMDK:23290974 pagePK:210058 piPK:210062 theSitePK:411420 $0,00$. html.

. 2013. "Ending Extreme Poverty Hinges on Progress in Fragile and Conflict-Affected Situations."

http://www.worldbank.org/en/news/feature/2013/04/30/ending-extremepoverty-hinges-on-progress-in-fragile-and-conflict-affected-situations.

- 2015a. "Research and Development Expenditure (\% of GDP) | Data." http://data.worldbank.org/indicator/GB.XPD.RSDV.GD.ZS.

- 2015b. "World Bank Country and Lending Groups - 2015 Fiscal Year." World Bank Data Help Desk. http://data.worldbank.org/about/country-andlending-groups.

_. 2016a. "Education Statistics." World DataBank.

http://databank.worldbank.org/data/reports.aspx?source=education-statistics$\sim$-all-indicators.

- 2016b. "World Bank Country and Lending Groups - 2016 Fiscal Year." World Bank Data Help Desk.

https://datahelpdesk.worldbank.org/knowledgebase/articles/906519.

. 2016c. "World Development Indicators: GDP Growth (Annual \%) 20002014." World DataBank. http://databank.worldbank.org/.

- 2016d. "World Development Indicators: GDP per Capita." World

DataBank. http://databank.worldbank.org/data/reports.aspx?source=worlddevelopment-indicators.

- 2016e. "World Development Indicators: Internet Users in Developing Countries." World DataBank.

http://databank.worldbank.org/data/reports.aspx?source=world-developmentindicators. 
Transparency International. 2014. "Corruption Perceptions Index 2014.” Berlin. https://www.transparency.org/cpi2014/results.

_. 2015. "Transparency International: The Global Anti-Corruption Coalition." http://www.transparency.org.

Truffer, Bernhard, Jan-Peter Voß, and Kornelia Konrad. 2008. "Mapping Expectations for System Transformations: Lessons from Sustainability Foresight in German Utility Sectors." Technological Forecasting and Social Change 75 (9). Elsevier: 1360-72.

UCDP. 2014. "Definitions." Uppsala Conflict Data Program (UCDP). http://www.pcr.uu.se/research/ucdp/definitions/.

UNEP. 2016. "Chapter 4. Public Awareness and Environmental Education: 4.2. Environmental Public Awareness." Newsletter and Technical Publications $<$ Planning and Management of Lakes and Reservoirs: An Integrated Approach to Eutrophication $>$.

http://www.unep.or.jp/ietc/Publications/techpublications/TechPub-11/42.asp.

UNESCO. 1978. "Intergovernmental Conference on Environmental Education: Final Report." Paris.

UNESCO-UIS. 2012. International Standard Classification of Education: ISCED 2011. Montreal: UIS.

UNFCCC. 2014. "Kyoto Protocol to the United Nations Framework Convention on Climate Change."

http://unfccc.int/essential_background/kyoto_protocol/items/1678.php.

United Nations. 2015. "Paris Agreement." Paris. https://ec.europa.eu/clima/policies/international/negotiations/paris_en.

Unruh, Gregory C. 2000. "Understanding Carbon Lock-In.” Energy Policy 28: 817-30. doi:10.1016/S0301-4215(00)00070-7.

van Alphen, Klaas, Marko P. Hekkert, and Wilfried G.J.H.M. van Sark. 2008. "Renewable Energy Technologies in the Maldives-Realizing the Potential." Renewable and Sustainable Energy Reviews 12 (1): 162-80. doi:10.1016/j.rser.2006.07.006.

Van de Ven, Andrew, and R Garud. 1989. "A Framework for Understanding the Emergence of New Industries." In Research on Technological Innovation, Management and Policy: A Research Annual, edited by Richard S. Rosenbloom and Robert A. Burgelman, 4:195-225. Amsterdam: JAI Press Limited.

Van der Werff, Ellen, Linda Steg, and Kees Keizer. 2013. "The Value of Environmental Self-Identity: The Relationship between Biospheric Values, Environmental Self-Identity and Environmental Preferences, Intentions and Behaviour." Journal of Environmental Psychology 34. Elsevier Ltd: 55-63. doi:10.1016/j.jenvp.2012.12.006.

Van Lente, Harro, and Arie Rip. 1998. "The Rise of Membrane Technology: From Rhetorics to Social Reality." Social Studies of Science 28 (2). Sage Publications London: 221-54. 
Vergara, Walter, Alejandro Deeb, Natsubo Toba, Peter Cramton, and Irene Leino. 2010. "Wind Energy in Colombia: A Framework for Market Entry." World Bank Study. Washington, DC.: The World Bank.

Victor, D. G., D. Zhou, E. H. M. Ahmed, P. K. Dadhich, J.G. J. Olivier, H-H. Rogner, K. Sheikho, and M. Yamaguchi. 2014. "Introductory Chapter.” In Climate Change 2014: Mitigation of Climate Change. Contribution of Working Group III to the Fifth Assessment Report of the Intergovernmental Panel on Climate Change, edited by O. Edenhofer, R. Pichs-Madruga, Y. Sokona, E. Farahani, S. Kadner, K. Seyboth, A. Adler, et al. Cambridge, United Kingdom and New York, NY, USA: Cambridge University Press. doi:10.1017/CBO9781107415324.004.

Vlek, Charles, and Linda Steg. 2007. "Human Behavior and Environmental Sustainability: Problems, Driving Forces, and Research Topics." Journal of Social Issues 63 (1): 1-19. doi:10.1111/j.1540-4560.2007.00493.x.

Voss, C. a. 1988. "Implementation: A Key Issue in Manufacturing Technology: The Need for a Field of Study." Research Policy 17 (2): 55-63. doi:10.1016/0048-7333(88)90021-2.

Voß, Jan-Peter, Dierk Bauknecht, and René Kemp. 2006. Reflexive Governance for Sustainable Development. Cheltenham, UK: Edward Elgar Publishing.

Watson, Jim, and Raphael Sauter. 2011. "Sustainable Innovation through Leapfrogging: A Review of the Evidence." International Journal of Technology and Globalisation 5 (3/4): 170-189. doi:10.1504/IJTG.2011.039763.

Weber, K. Matthias, and Harald Rohracher. 2012. "Legitimizing Research, Technology and Innovation Policies for Transformative Change." Research Policy 41 (6). Elsevier B.V.: 1037-47. doi:10.1016/j.respol.2011.10.015.

Weckowicz, Thaddus E. 2000. "Ludwig von Bertalanffy (1901-1972): A Pioneer of General Systems Theory." 89-2. CSR Working Papers. Vol. 89. CSR Working Papers. Edmonton. doi:10.1080/02604027.1972.9971801.

Welsch, Heinz. 2002. "Preferences over Prosperity and Pollution: Environmental Valuation Based on Happiness Surveys." Kyklos 55 (4): 473-94. doi:10.1111/1467-6435.00198.

Wilson, Edward O. 1984. Biophilia: The Human Bond with Other Species. Cambridge, MA: Harvard University Press.

Wirth, Steffen, and Jochen Markard. 2011. "Context Matters: How Existing Sectors and Competing Technologies Affect the Prospects of the Swiss BioSNG Innovation System.” Technological Forecasting and Social Change 78 (4). Elsevier Inc.: 635-49. doi:10.1016/j.techfore.2011.01.001.

World Commission on Environment and Development. 1987. "Our Common Future." Oslo.

Wüstenhagen, Rolf, Maarten Wolsink, and Mary Jean Bürer. 2007. "Social Acceptance of Renewable Energy Innovation: An Introduction to the Concept." Energy Policy 35 (5): 2683-91. doi:10.1016/j.enpol.2006.12.001.

XM. 2005. "Informe de Operación Y Administración Del Mercado 2005.” Bogotá. 
. 2015. "Informe de Operación Del SIN Y Administración Del Mercado." Informes Anuales.

http://informesanuales.xm.com.co/2015/SitePages/operacion/1-1-

Presentacion.aspx.

Yakita, Akira. 2009. "Technology Choice and Environmental Awareness in a Trade and Environment Context." Australian Economic Papers 48 (3): 27079. doi:10.1111/j.1467-8454.2009.00375.x.

Zahran, Sammy, Eunyi Kim, Xi Chen, and Mark Lubell. 2007. "Ecological Development and Global Climate Change: A Cross-National Study of Kyoto Protocol Ratification." Society \& Natural Resources 20 (1): 37-55. doi:10.1080/08941920600981355.

Zelezny, Lynnette C, Poh-Pheng Chua, and Christina Aldrich. 2000. "Elaborating on Gender Differences in Environmentalism." Journal of Social Issues 56 (3): 443-57. doi:10.1111/0022-4537.00177. 


\section{Appendix I: Interview Guide, Forms and List of Key Actors}

Appendix I provides additional information concerning the data from the structured and semi-structured interviews conducted in Bogota, Colombia between April 21-June 18, 2014. The objective with the fieldwork was to conduct structured and semi-structured interviews with key actors and experts in the field of Wind Energy in Colombia in order to determine the fulfillment of each of the TIS functions and perceived importance of Landscape Factors in terms of their influence on the formation of wind energy projects and other RETs. Key stakeholders and experts in the field involve senior representatives from industry, research institutions, government, non-governmental organizations and environmental groups in order to determine to what extent each of the functions has been fulfilled. Appendix I presents a detailed description of the method for the collecting this data, including a full list of key actors involved in the study.

\section{Method for Selecting Key Actors}

Before conducting the fieldwork, a preliminary review of potential key actors was conducted, which provided the baseline for sampling. Based on this preliminary identification of key actors in Colombia, and to guarantee wide representation of key actors (experts) that actively work within the field of wind energy and other RETs in Colombia, a maximum variation sampling was applied before the beginning the fieldwork. During the fieldwork, snowball sampling was used to reach and set up additional interviews with experts in Colombia.

Full List of Key Actors Interviewed

\begin{tabular}{|l|l|l|l}
\hline $\begin{array}{l}\text { Type of } \\
\text { Actor }\end{array}$ & Name of Organization & $\begin{array}{l}\text { Participated } \\
\text { in Structured } \\
\text { Interviews }\end{array}$ & $\begin{array}{l}\text { Participated in } \\
\text { Structured } \\
\text { Interviews }\end{array}$ \\
\hline \multirow{2}{*}{$\begin{array}{l}\text { Energy } \\
\text { Generating } \\
\text { Companies }\end{array}$} & ISAGEN & Yes & Yes \\
\cline { 2 - 4 } & ISAGEN & No & Yes \\
\cline { 2 - 4 } & ISAGEN & No & Yes \\
\cline { 2 - 4 } & ISAGEN & No & Yes \\
\cline { 2 - 4 } & EMGESA & Yes & Yes \\
\cline { 2 - 4 } & ENEL Green Power & No & Yes \\
\hline \multirow{2}{*}{$\begin{array}{l}\text { Research } \\
\text { Institutions }\end{array}$} & Universidad de Los Andes & Yes & Yes \\
\cline { 2 - 4 } & Universidad de la Salle & Yes & Yes \\
\cline { 2 - 4 } & Universidad de la Salle & Yes & Yes \\
\cline { 2 - 4 } & Universidad de la Salle & Yes & Yes \\
\hline \multirow{2}{*}{$\begin{array}{l}\text { Government } \\
\text { Agencies }\end{array}$} & $\begin{array}{l}\text { DNP - Subdivision Medio } \\
\text { Ambiente } \text { (Environment }\end{array}$ & Yes & Yes \\
\hline
\end{tabular}




\begin{tabular}{|l|l|l|l}
\hline \multirow{5}{*}{} & Sub- Division) & & \\
\cline { 2 - 4 } & $\begin{array}{l}\text { DNP - Subdivision Minas } \\
\text { y Energía (Mines and } \\
\text { Energy Division) }\end{array}$ & Yes & Yes \\
\cline { 2 - 4 } & UPME & Yes & Yes \\
\cline { 2 - 4 } & UPME & Yes & Yes \\
\cline { 2 - 3 } & Yes & Yes \\
\hline $\begin{array}{l}\text { International } \\
\text { Actors }\end{array}$ & $\begin{array}{l}\text { Inter-American } \\
\text { Development Bank }\end{array}$ & Yes & Yes \\
\hline \multicolumn{2}{|l|}{ Total Number of Interviews } & $\mathbf{1 6}$ \\
\hline $\begin{array}{l}\text { Percentages Participating in Structured } \\
\text { and Semi-Structured Interviews }\end{array}$ & $\mathbf{7 5 \%}$ & $\mathbf{1 0 0 \%}$ \\
\hline
\end{tabular}

Note 1: For explanations of the acronyms see List of Acronyms at the beginning of the thesis.

Note 2: Interviews with ISAGEN were conducted over Skype. All other interviews were conducted in-situ.

\section{Structured Interview Form (Translated)}

Before the semi-structured interviews, a document in was shared in Spanish (see box 1) by email to each interviewee before the meeting, which included a brief introduction about the study (its purpose, description of the (extended) TIS framework and role of functions and landscape factors developed in Chapter 2).

As part of the document, participants were asked to rate their level of satisfaction with each of the functions (fulfillment) and indicate their view of the importance of the landscape factors for the transition towards wind energy and other RETs in Colombia, based on a 5-point rating scale (Likert scale), including the option of $\mathrm{N} / \mathrm{A}$ in the following manner:

\begin{tabular}{|l|l|}
\hline Rating Functions & Rating - Landscape Factors \\
\hline 1 point $=$ very weak & 1 point $=$ Not important \\
2 points $=$ weak & 2 points $=$ Of little importance \\
3 points $=$ sufficient & 3 points $=$ Important \\
4 points $=$ good & 4 points $=$ Very important \\
5 points $=$ very good & 5 points $=$ Extremely important \\
N/A $=$ Not Applicable & N/A = Not Applicable \\
\hline
\end{tabular}

The result of the expert evaluation was then compounded and an average between 1 and 5 of the result was presented as part of Chapter 3. The manner of how the data would be used and displayed in the study was explained to the participants before the start of the meeting.

Box 1. Actual Structured Interview Form Sent Out Before Interviews (in Spanish) 
Objetivo y Descripción del Estudio

El objetivo del estudio es investigar las barreras para la adopción de la Energía Eólica en Colombia.

Para el estudio planeo usar una combinación de dos marcos analíticos: El Enfoque de Funciones del Sistema de Innovación Tecnológica (Technological Innovation System Function Approach: TIS) (Hekkert et al., 2007) y la Perspectiva Multinivel (Multi-level Perspective (MLP)) .

Estos marcos analíticos usan la terminología de "Funciones" (Functions) y Factor Externo (Landscape Factor). La palabra "Funciones" se refiere a varias partes del sistema de innovación. Para este estudio el sistema de innovación se refiere a la energía eólica. La palabra "Factor Externo" se refiere a los factores considerados externos a los aspectos integrales del sistema de innovación.

La primera parte del estudio consiste en entrevistas estructuradas. Las entrevistas estructuradas sirven como una parte importante para entender las barreras y para desarrollar estrategias para poder acelerar la adopción de Energía Eólica en Colombia u otros países con características similares.

Para la parte estructurada de la entrevista, por favor indique su nivel de satisfacción de cada función y la importancia de cada factor externo de acuerdo a su perspectiva en cuanto al avance y desarrollo de la energía eólica en Colombia, así como las barreras que pueden estar impidiendo una mayor adopción de la misma. Para identificar su nivel de satisfacción con cada función y factor externo favor clasifique del 1 al 5 de la siguiente manera:

\begin{tabular}{|l|l|}
\hline Clasificado - Funciones & Clasificado - Factores Externos \\
\hline 1 punto = muy mal & 1 punto = No es importante \\
2 puntos = mal & 2 puntos = Poco importante \\
3 puntos = aceptable & 3 puntos = Importante \\
4 puntos = bien & 4 puntos = Muy importante \\
5 puntos = muy bien & 5 puntos = Extrema importancia \\
N/A = No es Aplicable & N/A = No es Aplicable \\
\hline
\end{tabular}

\begin{tabular}{|c|c|c|c|}
\hline \multicolumn{2}{|c|}{ Funciones } & \multirow{2}{*}{$\begin{array}{l}\text { Descripción } \\
\text { Actividades de emprendimiento en el sector de } \\
\text { Energía Eólica }\end{array}$} & \multirow[t]{2}{*}{ Puntos } \\
\hline F1 & Actividades de emprendimiento & & \\
\hline F2a & Creación de Conocimiento & Investigación en Energía Eólica & \\
\hline F2b & Capacidad de adaptación & $\begin{array}{l}\text { Capacidad humana (capacidad y conocimiento } \\
\text { técnico), organizacional, e institucional }\end{array}$ & \\
\hline F3 & Diseminación de conocimiento & $\begin{array}{l}\text { Diseminación de conocimiento de Energía } \\
\text { Eólica, por ejemplo en talleres o conferencias. }\end{array}$ & \\
\hline F4 & Dirección de la búsqueda & $\begin{array}{l}\text { Metas por parte del gobierno } 0 \text { actores } \\
\text { privados }\end{array}$ & \\
\hline F5 & Formación de mercado & $\begin{array}{l}\text { Regímenes fiscales (subsidios, incentivos } \\
\text { económicos), marco regulatorio propicio }\end{array}$ & \\
\hline F6a & $\begin{array}{l}\text { Recursos movilizados por el } \\
\text { gobierno }\end{array}$ & $\begin{array}{l}\text { Recursos del gobierno (ej. subsidio, inversiones) } \\
\text { en energía eólica }\end{array}$ & \\
\hline F6b & $\begin{array}{l}\text { Recursos movilizados del } \\
\text { extranjero }\end{array}$ & $\begin{array}{l}\text { Ayuda (donaciones) y préstamos } \\
\text { internacionales hacia energía eólica. }\end{array}$ & \\
\hline F7a & $\begin{array}{l}\text { Creación de legitimidad de } \\
\text { grupos formales }\end{array}$ & $\begin{array}{l}\text { Cabildeo/actividades para ejercer presión } \\
\text { (lobbying) por parte de grupos formales y } \\
\text { establecidos (compañías y organizaciones) }\end{array}$ & \\
\hline F7b & $\begin{array}{l}\text { Creación de legitimidad de } \\
\text { grupos informales }\end{array}$ & $\begin{array}{l}\text { Actividades para ejercer presión (lobbying) de } \\
\text { manera informal, ej. opinión pública y } \\
\text { aceptación en los medios sociales }\end{array}$ & \\
\hline \multicolumn{2}{|c|}{ Factores Externos } & Descripción & Puntos \\
\hline FE1 & Crecimiento Económico & \multirow{6}{*}{$\begin{array}{l}\text { Por favor indique su opinión sobre la } \\
\text { importancia e impacto de cada factor externo } \\
\text { en el desarrollo y difusión de la Energía Eólica } \\
\text { en Colombia. }\end{array}$} & \\
\hline FE2 & $\begin{array}{l}\text { Conciencia medio ambiental por } \\
\text { parte de la sociedad civil }\end{array}$ & & \\
\hline FE3 & Cambio Climático & & \\
\hline FE4 & Conflicto armado & & \\
\hline FE5 & Corrupción & & \\
\hline FE6 & $\begin{array}{l}\text { Desigualdad en el acceso a la } \\
\text { educación }\end{array}$ & & \\
\hline
\end{tabular}

${ }^{1}$ Estos marcos se basan principalmente en el trabajo de Hekkert et al., 2007 y Geels, 2002, respectivamente.

\section{Semi-Structured Interviews}


In addition to the Likert scale, the interviewees were given the opportunity to provide their perspectives on what are the main impeding factors for an enhanced system performance along with suggesting strategies for improvement. For reliability and comparability purposes, a set of interview questions for all the functions and landscape factors was prepared on beforehand and used for all interviews.

\section{Ethics - Disclosing of Personal Details}

The interviews were recorded by audio, after the interviewees gave consent. $100 \%$ of the interviews conducted gave their consent for audio recording. It was agreed at the start of the interviews with all participants that their individual names would not be included in the final depiction of the data, only the name of their organization.

\section{Average Interview Length}

The planned averaged total length of each interview was 1 hour. Most of the interviews followed the planed average length, with some exceptions going slightly over time.

\section{Semi-structured Interview Questions (Guideline)}

\begin{tabular}{|c|c|c|c|c|}
\hline \multirow[b]{2}{*}{$\begin{array}{l}\text { Function 1: } \\
\text { Actividades de } \\
\text { Emprendimiento } \\
\text { (Entrepreneurial } \\
\text { Activity) }\end{array}$} & \multicolumn{2}{|c|}{ Questions (In Spanish): } & \multicolumn{2}{|c|}{ Questions (In English): } \\
\hline & 1.1 & $\begin{array}{l}\text { ¿En su opinión, cuál puede ser } \\
\text { la estrategia más importante } \\
\text { para aumentar los proyectos } \\
\text { eólicos en Colombia? }\end{array}$ & 1.1 & $\begin{array}{l}\text { In your opinion, what } \\
\text { would be the most } \\
\text { important strategy to } \\
\text { increase the number } \\
\text { of new Wind Energy } \\
\text { projects? }\end{array}$ \\
\hline $\begin{array}{l}\text { Function 2a: } \\
\text { Creación de } \\
\text { Conocimiento } \\
\text { (Knowledge } \\
\text { Creation) }\end{array}$ & $2.1 \mathrm{a}$ & $\begin{array}{l}\text { ¿Qué aspecto de creación de } \\
\text { conocimiento (investigación) } \\
\text { sobre energía eólica necesita } \\
\text { la mayo atención? }\end{array}$ & $2.1 \mathrm{a}$ & $\begin{array}{l}\text { What aspect of } \\
\text { knowledge creation } \\
\text { concerning WE is in } \\
\text { most need of } \\
\text { improvement? }\end{array}$ \\
\hline \multirow[t]{2}{*}{$\begin{array}{l}\text { Function 2b: } \\
\text { Capacidad } \\
\text { Adaptativa } \\
\text { (Adaptive } \\
\text { Capacity) }\end{array}$} & $2.1 b$ & $\begin{array}{l}\text { ¿Cómo describiría usted la } \\
\text { capacidad adaptativa de } \\
\text { Colombia para la adopción de } \\
\text { energía eólica? La capacidad } \\
\text { adaptativa se refiere a la } \\
\text { capacidad humana (capacidad } \\
\text { técnica), organizacional, e } \\
\text { institucional. }\end{array}$ & $2.1 \mathrm{~b}$ & $\begin{array}{l}\text { How would you } \\
\text { describe the adaptive } \\
\text { capacity of Colombia, } \\
\text { that is, the human } \\
\text { (technical capacity), } \\
\text { organizational, and } \\
\text { institutional capacity } \\
\text { for adopting WE? }\end{array}$ \\
\hline & $2.2 \mathrm{~b}$ & $\begin{array}{l}\text { ¿Existe alguna discrepancia } \\
\text { entre los conocimientos }\end{array}$ & $2.2 \mathrm{~b}$ & $\begin{array}{l}\text { Is there a mismatch } \\
\text { between the supply of }\end{array}$ \\
\hline
\end{tabular}




\begin{tabular}{|c|c|c|c|c|}
\hline & & $\begin{array}{l}\text { técnicos referentes a la energía } \\
\text { eólica suministrados por las } \\
\text { universidades y la demanda de } \\
\text { la industria? ¿y existe alguna } \\
\text { discrepancia entre la necesidad } \\
\text { de profesionales } \\
\text { especializados y la cantidad de } \\
\text { profesionales capacitados } \\
\text { disponibles? }\end{array}$ & & $\begin{array}{l}\text { technical knowledge } \\
\text { of WE produced by } \\
\text { Universities and the } \\
\text { demand by the energy } \\
\text { generating } \\
\text { companies? (The right } \\
\text { type of skills and the } \\
\text { adequate amount of } \\
\text { skilled labor) }\end{array}$ \\
\hline \multirow[t]{4}{*}{$\begin{array}{l}\text { Function 3: } \\
\text { Difusión de } \\
\text { Conocimiento } \\
\text { (Knowledge } \\
\text { Diffusion) }\end{array}$} & 3.1. & $\begin{array}{l}\text { ¿En su opinión, cuál es la } \\
\text { manera más importante para } \\
\text { difundir el conocimiento sobre } \\
\text { la energía eólica que } \\
\text { promueva su adopción? }\end{array}$ & 3.1. & $\begin{array}{l}\text { In your opinion, what } \\
\text { is the most important } \\
\text { manner in which } \\
\text { knowledge } \\
\text { concerning WE can } \\
\text { be diffused to } \\
\text { promote adoption? }\end{array}$ \\
\hline & 3.2. & $\begin{array}{l}\text { ¿Qué tipo y cantidad de } \\
\text { colaboración existe entre } \\
\text { actores nacionales e } \\
\text { internacionales sobre la } \\
\text { energía eólica? }\end{array}$ & 3.2. & $\begin{array}{l}\text { What amount and } \\
\text { type of national and } \\
\text { international } \\
\text { collaborating exist } \\
\text { between actors within } \\
\text { the WE Innovation } \\
\text { System? }\end{array}$ \\
\hline & 3.3. & $\begin{array}{l}\text { ¿Qué tipo de conocimiento es } \\
\text { compartido entre estos actores } \\
\text { o bajo estas alianzas? }\end{array}$ & 3.3. & $\begin{array}{l}\text { The kind of } \\
\text { knowledge that is } \\
\text { shared within these } \\
\text { existing partnerships? }\end{array}$ \\
\hline & 3.4 & $\begin{array}{l}\text { ¿Qué tan a menudo son } \\
\text { organizados eventos oficiales } \\
\text { donde se comparte } \\
\text { información? }\end{array}$ & 3.4 & $\begin{array}{l}\text { What type and how } \\
\text { often are official } \\
\text { gatherings organized, } \\
\text { where information is } \\
\text { exchanged? }\end{array}$ \\
\hline \multirow{3}{*}{$\begin{array}{l}\text { Function 4: } \\
\text { Orientación de la } \\
\text { Búsqueda } \\
\text { (Guidance of the } \\
\text { Search) }\end{array}$} & 4.1. & $\begin{array}{l}\text { ¿En su opinión, qué le gustaría } \\
\text { ver en cuanto a orientación por } \\
\text { parte del gobierno? Metas o } \\
\text { regulaciones. }\end{array}$ & 4.1. & $\begin{array}{l}\text { In your opinion, what } \\
\text { would you like to see } \\
\text { in terms of guidance } \\
\text { from the government? }\end{array}$ \\
\hline & 4.2. & $\begin{array}{l}\text { ¿Qué metas o regulaciones } \\
\text { están siendo impuestas por el } \\
\text { gobierno? }\end{array}$ & 4.2. & $\begin{array}{l}\text { What specific targets } \\
\text { or regulations are } \\
\text { being set by the } \\
\text { government? }\end{array}$ \\
\hline & 4.3. & $\begin{array}{l}\text { ¿Qué tipo de visiones y } \\
\text { expectativas existen frente a la } \\
\text { energía eólica? }\end{array}$ & 4.3. & $\begin{array}{l}\text { What type of visions } \\
\text { and expectations exist } \\
\text { about Wind Energy? }\end{array}$ \\
\hline \multirow[t]{2}{*}{$\begin{array}{l}\text { Function 5: } \\
\text { Creación del } \\
\text { Mercado } \\
\text { (Market Creation) }\end{array}$} & 5.1. & $\begin{array}{l}\text { ¿Cuáles son los principales } \\
\text { obstáculos para la creación y/o } \\
\text { fortalecimiento del mercado } \\
\text { de energías eólicas? } \\
\text { ¿Impuestos, estándares? }\end{array}$ & 5.1. & $\begin{array}{l}\text { What obstacles to } \\
\text { market creation } \\
\text { and/or strengthening } \\
\text { are most pressing? }\end{array}$ \\
\hline & 5.2. & $\begin{array}{l}\text { ¿Cuál es el estado del mercado } \\
\text { de energías eólicas y su }\end{array}$ & 5.2 & $\begin{array}{l}\text { What phase is the } \\
\text { market in and what is } \\
\text { its (domestic \& }\end{array}$ \\
\hline
\end{tabular}




\begin{tabular}{|c|c|c|c|c|}
\hline & & $\begin{array}{l}\text { potencial doméstico y } \\
\text { externo? }\end{array}$ & & export) potential? \\
\hline & 5.3. & $\begin{array}{l}\text { ¿Qué tipo de incertidumbres } \\
\text { enfrentan los potenciales } \\
\text { desarrolladores de proyectos? }\end{array}$ & 5.3. & $\begin{array}{l}\text { What are some } \\
\text { uncertainties faced by } \\
\text { potential project } \\
\text { developers? }\end{array}$ \\
\hline \multirow{2}{*}{$\begin{array}{l}\text { Function 6a: } \\
\text { Recursos } \\
\text { movilizados por } \\
\text { el gobierno } \\
\text { (Resource } \\
\text { Mobilization } \\
\text { (government)) }\end{array}$} & $6.1 \mathrm{a}$ & $\begin{array}{l}\text { ¿Cuál es el recurso económico } \\
\text { con mayor escasez necesario } \\
\text { para la energía eólica? }\end{array}$ & $6.1 \mathrm{a}$ & $\begin{array}{l}\text { What is the most } \\
\text { pressing resource } \\
\text { scarcity for WE? }\end{array}$ \\
\hline & $6.2 \mathrm{a}$ & $\begin{array}{l}\text { ¿Cuál es la disponibilidad de } \\
\text { capital financiero (capital } \\
\text { semilla, capital de riesgo, } \\
\text { fondos del gobierno para } \\
\text { ID\&D)? }\end{array}$ & $6.2 \mathrm{a}$ & $\begin{array}{l}\text { How is the } \\
\text { availability of } \\
\text { financial capital (seed } \\
\text { and venture capital, } \\
\text { government funds for } \\
\text { RD\&D)? }\end{array}$ \\
\hline $\begin{array}{l}\text { Function 6b: } \\
\text { Movilización de } \\
\text { recursos } \\
\text { internacionales } \\
\text { (Resource } \\
\text { mobilization - } \\
\text { international } \\
\text { funding) } \\
\end{array}$ & $6.1 \mathrm{~b}$ & $\begin{array}{l}\text { ¿Qué importancia juega la } \\
\text { financiación internacional en } \\
\text { la adopción de EE en } \\
\text { Colombia? ¿Es suficiente? }\end{array}$ & $6.1 b$ & $\begin{array}{l}\text { What role does } \\
\text { international funding } \\
\text { play in adoption of } \\
\text { WE in Colombia? Is it } \\
\text { sufficient? }\end{array}$ \\
\hline \multirow{3}{*}{$\begin{array}{l}\text { Function 7a. } \\
\text { Creación de } \\
\text { legitimidad/ } \\
\text { Lobby formal } \\
\text { (Creation of } \\
\text { Legitimacy/ } \\
\text { Advocacy } \\
\text { coalition -formal } \\
\text { lobbying) }\end{array}$} & $7.1 \mathrm{a}$ & $\begin{array}{l}\text { ¿Qué tan activos son los } \\
\text { grupos de lobby a favor de la } \\
\text { energía eólica (tamaño y } \\
\text { fuerza)? ¿Han crecido en la } \\
\text { última década? }\end{array}$ & $7.1 \mathrm{a}$ & $\begin{array}{l}\text { How active are lobby } \\
\text { groups for WE. Their } \\
\text { size and strength? } \\
\text { Have they been } \\
\text { growing in the past } \\
\text { decade? }\end{array}$ \\
\hline & $7.2 \mathrm{a}$ & $\begin{array}{l}\text { ¿Cómo ha sido el cambio en la } \\
\text { legitimidad para invertir en la } \\
\text { tecnología? }\end{array}$ & $7.2 \mathrm{a}$ & $\begin{array}{l}\text { How has the } \\
\text { legitimacy to make } \\
\text { investments in the } \\
\text { technology changed? }\end{array}$ \\
\hline & $7.3 a$ & $\begin{array}{l}\text { ¿Cuáles son los principales } \\
\text { actores, a favor y en contra, } \\
\text { del desarrollo y adopción de } \\
\text { la energía? }\end{array}$ & $7.3 \mathrm{a}$ & $\begin{array}{l}\text { What are the main } \\
\text { arguments of actors } \\
\text { pro or against the } \\
\text { deployment the } \\
\text { technology? }\end{array}$ \\
\hline \multirow[t]{2}{*}{$\begin{array}{l}\text { Function 7b: } \\
\text { Creación de } \\
\text { legitimidad/Lobb } \\
\text { y informal } \\
\text { (Creation of } \\
\text { Legitimacy/ } \\
\text { Advocacy } \\
\text { coalition - } \\
\text { informal } \\
\text { lobbying) }\end{array}$} & $7.1 \mathrm{~b}$ & $\begin{array}{l}\text { ¿Ha experimentado cambios } \\
\text { en las actividades en medios } \\
\text { sociales, donde temas como } \\
\text { sostenibilidad, energía } \\
\text { renovable, y energía eólica se } \\
\text { hayan discutido? }\end{array}$ & $7.1 \mathrm{~b}$ & $\begin{array}{l}\text { Have you experienced } \\
\text { a change in the } \\
\text { activities in social } \\
\text { media, where } \\
\text { sustainability, RET } \\
\text { and wind energy has } \\
\text { been discussed, and in } \\
\text { what manner, positive } \\
\text { or negative? }\end{array}$ \\
\hline & $7.2 \mathrm{~b}$ & $\begin{array}{l}\text { ¿En su opinión, cuál es la } \\
\text { actitud del público frente a la } \\
\text { tecnología y como es } \\
\text { presentada la tecnología en los }\end{array}$ & $7.2 b$ & $\begin{array}{l}\text { In your opinion, how } \\
\text { is the Public opinion } \\
\text { towards the } \\
\text { technology and how is } \\
\text { the technology }\end{array}$ \\
\hline
\end{tabular}




\begin{tabular}{|c|c|c|c|c|}
\hline & & medios? & & depicted in the media? \\
\hline \multirow[t]{3}{*}{$\begin{array}{l}\text { Factor Externo } 1 . \\
\text { Crecimiento } \\
\text { Económico } \\
\text { (Landscape } \\
\text { Factor 1: } \\
\text { Economic } \\
\text { Growth) }\end{array}$} & 1.1. & $\begin{array}{l}\text { ¿En su opinión, la situación } \\
\text { económica en Colombia está } \\
\text { contribuyendo o impidiendo la } \\
\text { difusión de energía eólica? }\end{array}$ & 1.1 . & $\begin{array}{l}\text { In your opinion, is } \\
\text { the economic } \\
\text { situation in } \\
\text { Colombia } \\
\text { benefitting or } \\
\text { impeding WE } \\
\text { diffusion in } \\
\text { Colombia? }\end{array}$ \\
\hline & 1.2. & $\begin{array}{l}\text { ¿Ha visto un cambio de } \\
\text { recursos hacia la EE que esté } \\
\text { siguiendo el nivel de } \\
\text { crecimiento económico? }\end{array}$ & 1.2 . & $\begin{array}{l}\text { Have you seen a } \\
\text { change in resources } \\
\text { towards WE that } \\
\text { followed the level } \\
\text { of economic } \\
\text { growth? }\end{array}$ \\
\hline & 1.3 & $\begin{array}{l}\text { ¿Cómo ha afectado la crisis } \\
\text { económica los recursos y } \\
\text { legitimidad de EE en } \\
\text { Colombia? }\end{array}$ & 1.3 . & $\begin{array}{l}\text { How has the } \\
\text { economic crisis } \\
\text { influenced } \\
\text { resources and } \\
\text { legitimacy towards } \\
\text { increased WE in } \\
\text { Colombia? }\end{array}$ \\
\hline \multirow[t]{2}{*}{$\begin{array}{l}\text { Landscape } \\
\text { Factor 2: } \\
\text { Consciencia } \\
\text { ambiental } \\
\text { (Environmental } \\
\text { Awareness) }\end{array}$} & 2.1 . & $\begin{array}{l}\text { ¿Qué influencia tiene la } \\
\text { concientización medio } \\
\text { ambiental en la difusión de la } \\
\text { EE y Energía Renovable } \\
\text { (ER)? }\end{array}$ & 2.1 . & $\begin{array}{l}\text { What role does } \\
\text { environmental } \\
\text { awareness play for } \\
\text { WE and RET } \\
\text { diffusion? }\end{array}$ \\
\hline & 2.2 & $\begin{array}{l}\text { ¿Ha notado cambios en la } \\
\text { concientización/conocimiento } \\
\text { de la EE y las ER en } \\
\text { Colombia? }\end{array}$ & 2.2 . & $\begin{array}{l}\text { Do you see a } \\
\text { change in } \\
\text { awareness for WE } \\
\text { and RET in general } \\
\text { in Colombia? }\end{array}$ \\
\hline \multirow[t]{2}{*}{$\begin{array}{l}\text { Landscape } \\
\text { Factor 3: } \\
\text { Cambio Climático } \\
\text { (Climate Change) }\end{array}$} & 3.1. & $\begin{array}{l}\text { ¿Cuáles han sido los impactos } \\
\text { del cambio climático en } \\
\text { Colombia? o ¿de qué manera } \\
\text { ha influido el cambio } \\
\text { climático al país? ¿Cuáles son } \\
\text { los impactos más urgentes? }\end{array}$ & 3.1 . & $\begin{array}{l}\text { Has Colombia been } \\
\text { influenced by } \\
\text { Climate Change } \\
\text { (CC)? In what way? } \\
\text { What is the most } \\
\text { pressing aspect? }\end{array}$ \\
\hline & 3.2 . & $\begin{array}{l}\text { ¿Cómo ha afectado el cambio } \\
\text { climático la movilización de } \\
\text { recursos para la EE y las ER? } \\
\text { ¿De qué manera han influido } \\
\text { los impactos relacionados al } \\
\text { cambio climático influido la } \\
\text { concientización sobre los } \\
\text { riesgos de la inacción? y ¿de }\end{array}$ & 3.2 . & $\begin{array}{l}\text { Has Climate } \\
\text { Change related } \\
\text { events influenced } \\
\text { awareness } \\
\text { concerning the risks } \\
\text { of inaction and has } \\
\text { it helped legitimize } \\
\text { WE? Has the }\end{array}$ \\
\hline
\end{tabular}




\begin{tabular}{|c|c|c|c|c|}
\hline & & $\begin{array}{l}\text { qué manera ha contribuido la } \\
\text { concientización sobre el } \\
\text { cambio climático en la } \\
\text { legitimización de la EE? }\end{array}$ & & $\begin{array}{l}\text { mobilization of } \\
\text { resources towards } \\
\text { WE and other RET } \\
\text { been influenced by } \\
\text { CC? }\end{array}$ \\
\hline \multirow[t]{3}{*}{$\begin{array}{l}\text { Landscape } \\
\text { Factor 4: } \\
\text { Conflicto Armado } \\
\text { (Armed Conflict) }\end{array}$} & 4.1. & $\begin{array}{l}\text { ¿En su opinión, de qué manera } \\
\text { está afectando el conflicto } \\
\text { armado en Colombia las } \\
\text { inversiones en EE? }\end{array}$ & 4.1. & $\begin{array}{l}\text { In your opinion, } \\
\text { does the armed } \\
\text { conflict in } \\
\text { Colombia affect } \\
\text { investments } \\
\text { towards WE? }\end{array}$ \\
\hline & 4.2. & $\begin{array}{l}\text { ¿Influye el costo del conflicto } \\
\text { en la movilización de recursos } \\
\text { hacia la EE? }\end{array}$ & 4.2. & $\begin{array}{l}\text { Does the cost of the } \\
\text { conflict influence } \\
\text { resource } \\
\text { mobilization } \\
\text { towards WE? }\end{array}$ \\
\hline & 4.3. & $\begin{array}{l}\text { ¿Contribuye el conflicto a } \\
\text { niveles de inseguridad que } \\
\text { puedan obstaculizar nuevos } \\
\text { desarrollos de EE y otras } \\
\text { formas de ER? }\end{array}$ & 4.3. & $\begin{array}{l}\text { Does the conflict } \\
\text { contribute to levels } \\
\text { of insecurity that } \\
\text { have obstructed } \\
\text { potential new } \\
\text { developments of } \\
\text { WE and other } \\
\text { forms of renewable } \\
\text { energy? }\end{array}$ \\
\hline \multirow[t]{2}{*}{$\begin{array}{l}\text { Landscape } \\
\text { Factor 5: } \\
\text { Corrupción } \\
\text { (Corruption) }\end{array}$} & 5.1 & $\begin{array}{l}\text { ¿Influye la corrupción la } \\
\text { movilización de recursos para } \\
\text { la EE? }\end{array}$ & 5.1. & $\begin{array}{l}\text { Does corruption } \\
\text { influence resource } \\
\text { mobilization } \\
\text { towards WE? }\end{array}$ \\
\hline & 5.2. & $\begin{array}{l}\text { ¿Ha influido la corrupción en } \\
\text { la interrupción de } \\
\text { emprendimientos eólicos? }\end{array}$ & 5.2. & $\begin{array}{l}\text { Has corruption } \\
\text { contributed to } \\
\text { entrepreneurial } \\
\text { activity being } \\
\text { canceled? }\end{array}$ \\
\hline \multirow{2}{*}{$\begin{array}{l}\text { Landscape } \\
\text { Factor 6: } \\
\text { Desigualdad en el } \\
\text { acceso a } \\
\text { educación } \\
\text { (Inequality: } \\
\text { Unequal Access } \\
\text { to Quality } \\
\text { Education) }\end{array}$} & 6.1. & $\begin{array}{l}\text { ¿Es el acceso a la educación } \\
\text { superior un tema problemático } \\
\text { en Colombia? }\end{array}$ & 6.1. & $\begin{array}{l}\text { Is access to higher } \\
\text { education an issue } \\
\text { in Colombia? }\end{array}$ \\
\hline & 6.2 . & $\begin{array}{l}\text { ¿Hace falta mano de obra } \\
\text { calificada en Colombia hasta } \\
\text { el punto que pueda } \\
\text { obstaculizar el desarrollo de la } \\
\text { EE? Y ¿hasta qué punto está el } \\
\text { acceso desigual a la educación } \\
\text { superior contribuyendo a la } \\
\text { discrepancia entre } \\
\text { disponibilidad y demanda de } \\
\text { personal calificado? }\end{array}$ & 6.2. & $\begin{array}{l}\text { Is there a lack of } \\
\text { skilled labor in } \\
\text { Colombia that } \\
\text { might hamper the } \\
\text { development of } \\
\text { WE? And to what } \\
\text { extent is unequal } \\
\text { access to higher } \\
\text { education } \\
\text { contributing to this } \\
\text { discrepancy? }\end{array}$ \\
\hline
\end{tabular}




\section{Transcribing}

The interviews were manually transcribed using Express Scribe, as the automatic dictation did not exist for Spanish.

\section{Analysis of Data}

The transcribed text was organized and analyzed manually using Microsoft Excel. Trends in the answers from different actors were identified and displayed in Chapter 4 in the text. Direct quotes were translated to English and also displayed in the analysis section of Chapter 4 . 


\section{Appendix II: Scales Constructed by PISA (OECD 2009)}

\author{
Name of Scale Label \\ Environmental Envaware \\ Awareness
}

\author{
Main Question \\ How informed are you about \\ the following environmental \\ issues?
}

\section{Items}

a) The increase in greenhouse gases in the atmosphere

b) Use of genetically modified organisms (GMO)

c) Acid rain

d) Nuclear waste

e) The consequences of clearing forests for other land use

Responsibility

for Sustainable

Development
Respdev

How the statements below?

\section{Items}

a) It is important to carry out regular checks on the emissions from cars as a condition of their use

b) It disturbs me when energy is wasted through the unnecessary use of electrical appliances

c) I am in favour of having laws that regulate factory emissions even if this would increase the price of products d) To reduce waste, the use of plastic packaging should be kept to a minimum

e) Industries should be required to prove that they safely dispose of dangerous waste materials

f) I am in favour of having laws that protect the habitats of endangered species g) Electricity should be produced from renewable
Response Alternatives

1 I have never heard of this

2 I have heard about this but I would not be able to explain what it is really about

3 I know something about this and could explain the general issue

4 I am familiar with this and I would be able to explain this well

1 Strongly agree

2 Agree

3 Disagree

4 Strongly disagree 
sources as much as possible, even if this increases the cost

\begin{tabular}{|c|c|c|c|c|}
\hline $\begin{array}{l}\text { Environmental } \\
\text { Optimism }\end{array}$ & Envopt & $\begin{array}{l}\text { Do you think problems } \\
\text { associated with the } \\
\text { environmental issues below } \\
\text { will improve or get worse over } \\
\text { the next } 20 \text { years? } \\
\text { Items } \\
\text { a) Air pollution } \\
\text { b) Energy shortages } \\
\text { c) Extinction of plants and } \\
\text { animals } \\
\text { d) Clearing of forests for other } \\
\text { land use } \\
\text { e) Water shortages } \\
\text { f) Nuclear waste }\end{array}$ & $\begin{array}{l}1 \\
2 \\
3\end{array}$ & $\begin{array}{l}\text { Improve } \\
\text { Stay about the same } \\
\text { Get worse }\end{array}$ \\
\hline $\begin{array}{l}\text { Perception of } \\
\text { Environmental } \\
\text { Issues }\end{array}$ & Envperc & $\begin{array}{l}\text { Do you see the environmental } \\
\text { issues below as a serious } \\
\text { concern for yourself and/or } \\
\text { others? } \\
\text { Items } \\
\text { a) Air pollution } \\
\text { b) Energy shortages } \\
\text { c) Extinction of plants and } \\
\text { animals } \\
\text { d) Clearing of forests for other } \\
\text { land use } \\
\text { e) Water shortages } \\
\text { f) Nuclear waste }\end{array}$ & 1 & $\begin{array}{l}\text { This is a serious } \\
\text { concern for me } \\
\text { personally as well } \\
\text { as others } \\
\text { This is a serious } \\
\text { concern for other } \\
\text { people in my } \\
\text { country but not me } \\
\text { personally } \\
\text { This is a serious } \\
\text { concern only for } \\
\text { people in other } \\
\text { countries } \\
\text { This is not a serious } \\
\text { concern to anyone }\end{array}$ \\
\hline $\begin{array}{l}\text { Environmental } \\
\text { Education }\end{array}$ & Envedu & $\begin{array}{l}\text { Does your school organize } \\
\text { any of the following activities } \\
\text { to provide opportunities to } \\
\text { students in }<\text { national modal } \\
\text { grade for } 15 \text {-year-olds }>\text { to } \\
\text { learn about environmental } \\
\text { topics? }\end{array}$ & 2 & $\begin{array}{l}\text { Yes } \\
\text { No }\end{array}$ \\
\hline
\end{tabular}

\section{Items}

a) Outdoor education

b) Trips to museums

c) Trips to science and/or technology centres 
d) Extracurricular environmental projects

(including research)

e) Lectures and/or seminars

(e.g. guest speakers)

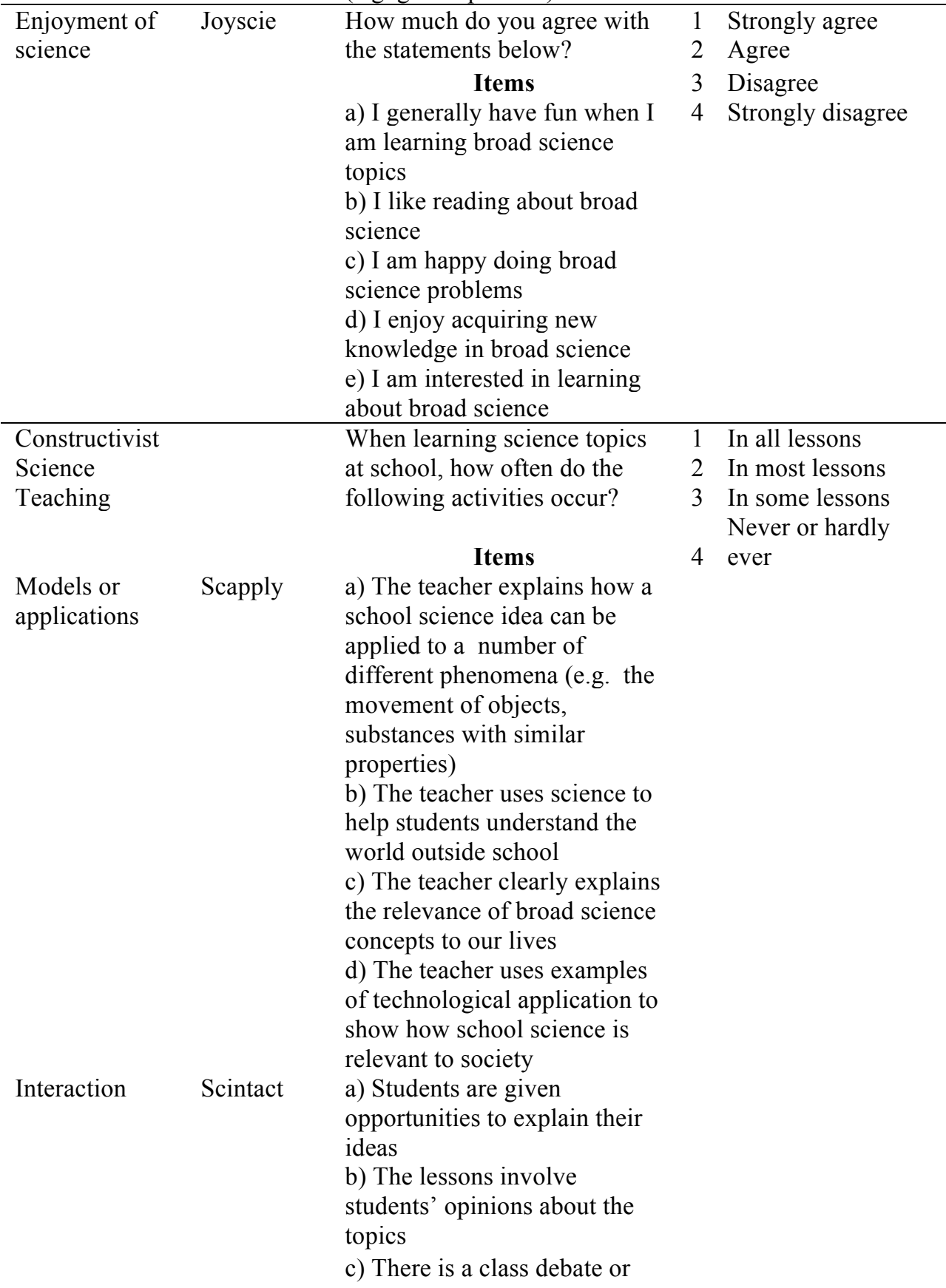




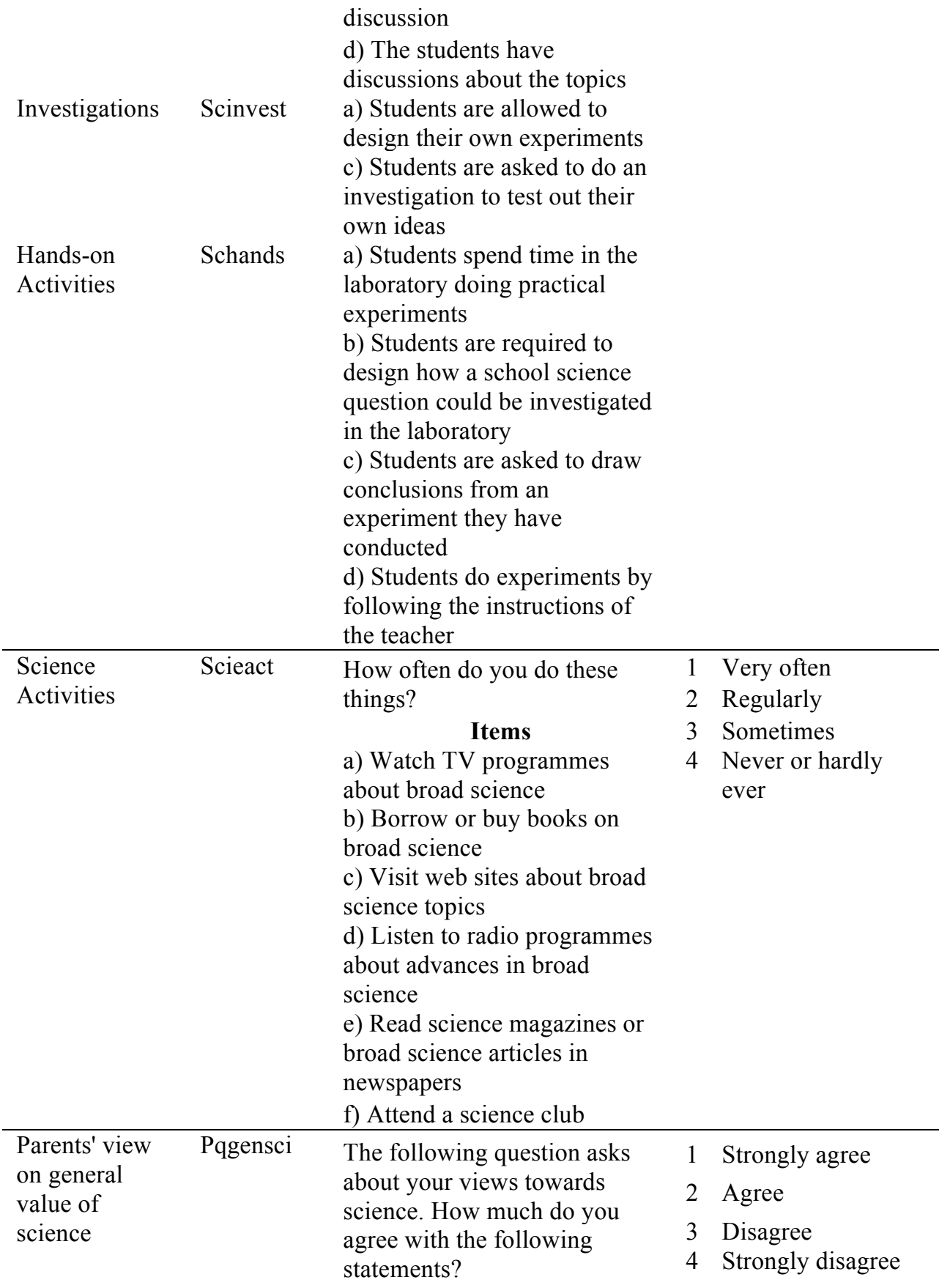




\begin{tabular}{|c|c|c|c|}
\hline Name of Scale & Label & Main Question & Response Alternatives \\
\hline & & $\begin{array}{l}\text { Items } \\
\text { a) Advances in broad science } \\
\text { and technology usually } \\
\text { improve people's living } \\
\text { conditions }\end{array}$ & \\
\hline & & $\begin{array}{l}\text { b) Broad science is important } \\
\text { for helping us to understand } \\
\text { the natural world }\end{array}$ & \\
\hline & & $\begin{array}{l}\text { c) Advances in broad science } \\
\text { and technology usually help } \\
\text { improve the economy } \\
\text { d) Broad science is valuable to } \\
\text { society } \\
\text { e) Advances in broad science } \\
\text { and technology usually bring } \\
\text { social benefit }\end{array}$ & \\
\hline $\begin{array}{l}\text { Parent's view } \\
\text { on personal } \\
\text { value of science }\end{array}$ & Pqpersci & $\begin{array}{l}\text { The following question asks } \\
\text { about your views towards } \\
\text { science. How much do you } \\
\text { agree with the following } \\
\text { statements? }\end{array}$ & $\begin{array}{ll}1 & \text { Strongly agree } \\
2 & \text { Agree } \\
3 & \text { Disagree } \\
4 & \text { Strongly disagree }\end{array}$ \\
\hline & & Items & \\
\hline & & $\begin{array}{l}\text { a) Some concepts in broad } \\
\text { science help me to see how I } \\
\text { relate to other people } \\
\text { b) There are many } \\
\text { opportunities for me to use } \\
\text { broad science in my everyday } \\
\text { life } \\
\text { c) Broad science is very } \\
\text { relevant to me } \\
\text { d) I find that broad science } \\
\text { helps me to understand the } \\
\text { things around me }\end{array}$ & \\
\hline $\begin{array}{l}\text { Parents' science } \\
\text { activties } \\
\text { at age } 10\end{array}$ & Pqsciact & $\begin{array}{l}\text { Thinking back to when your } \\
\text { child was about } 10 \text { years old, } \\
\text { how often would your child } \\
\text { have done these things? }\end{array}$ & $\begin{array}{ll}1 & \text { Very often } \\
2 & \text { Regularly } \\
3 & \text { Sometimes } \\
4 & \text { Never or hardly } \\
& \text { ever }\end{array}$ \\
\hline & & $\begin{array}{l}\text { Items } \\
\text { a) Watched TV programmes } \\
\text { about science } \\
\text { b) Read books on scientific } \\
\text { discoveries } \\
\text { c) Watched, read or listened to } \\
\text { science fiction }\end{array}$ & \\
\hline
\end{tabular}


d) Visited web sites about science topics

e) Attended a science club

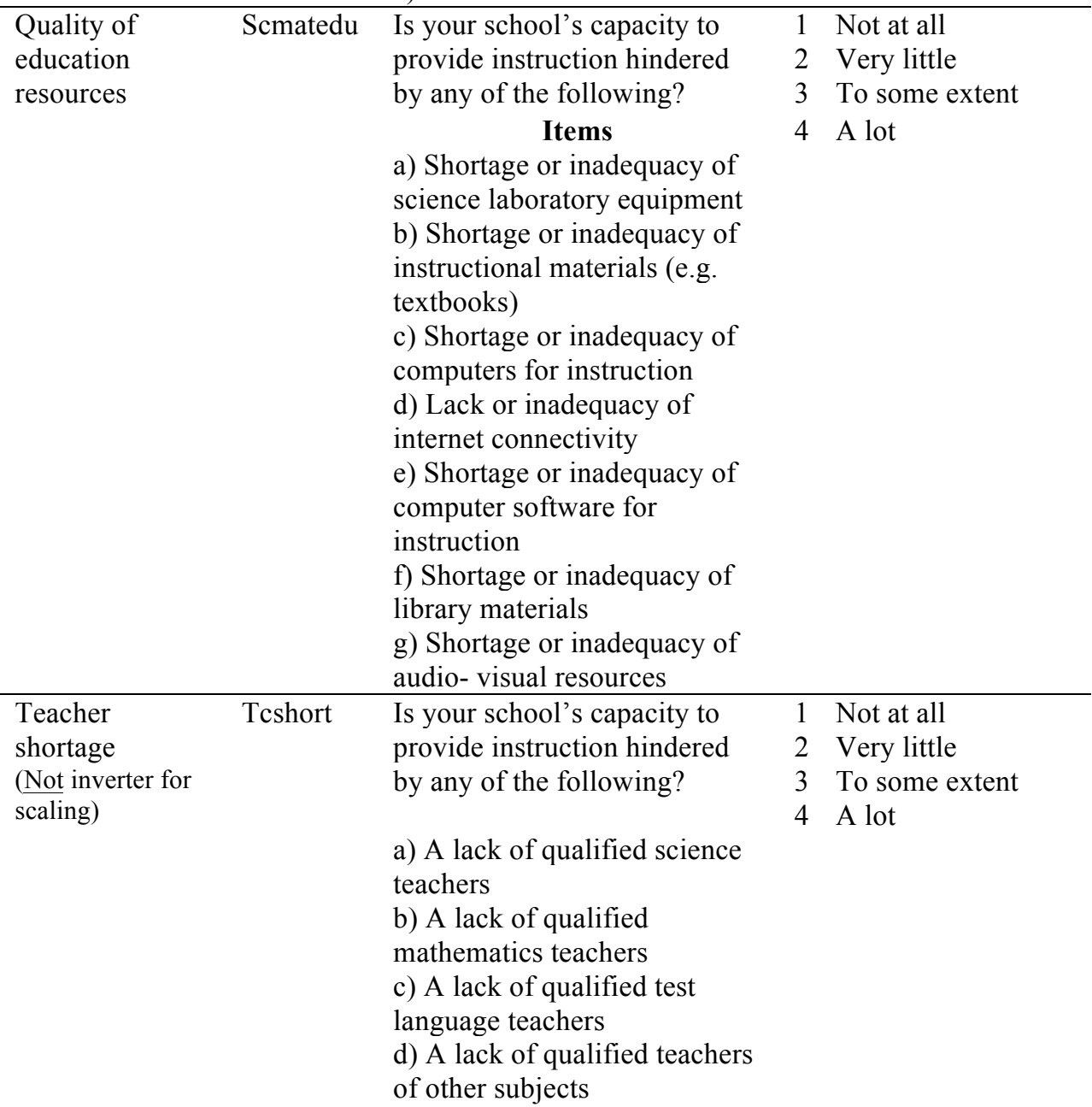




\section{Valorisation Addendum}

In accordance with article 23.5 of the "Regulation governing the attainment of doctoral degrees at Maastricht University" decreed by resolution of the Board of Deans, dated 3 July 2013, an addendum must be added about valorization.

\section{Relevance}

An increasing world population combined with a rapidly rising material and per capita energy consumption is creating an ecological deficit, where roughly 1.5 planets are required to provide the necessary resources (Global Footprint Network 2015). The overarching motivation behind conducting the research in this thesis comes from the urgent need to reduce natural resource consumption to levels that can support human life and development in the future.

Reducing fossil fuel-based energy consumption that is contributing to climate change represents one important strategy to reduce its impacts and the ecological deficit. The importance of this strategy has been emphasized in goal 7 of the United Nation's Sustainable Development Goals (SDGs), which aims to: Ensure access to affordable, reliable, sustainable and modern energy for all. In addition, the Climate Change Paris Agreement, signed in 2015 and ratified by 169 out of 197 parties, has as an ambition to combat climate change. Expanding access to and the use of renewable energy technologies is considered one significant component in achieving that goal.

Meeting the goals of reduced emissions requires a rapid and successful expansion of a wide range of mitigation alternatives. This thesis has focused on increasing the knowledge regarding the driving and obstructing mechanisms for expanding renewable energy technologies (RETs), with a special focus on developing countries. The thesis does this through a combination of conceptual and empirical chapters, including a study on wind energy adoption in Colombia. The focus on developing countries is particularly relevant as projections to 2040 show that energy use is expected to grow substantially, predominately in non-OECD countries $(>85 \%$ of the increase), as a result of population increase, economic growth and higher standards of living (EIA 2013). Global projections estimate that global emissions in developing or emerging countries will exceed that of the developed world in the next decades (EIA 2013). At the same time, approximately 1.2 billion people are without access to any form of electricity and without successful policy interventions, 1 billion people are still expected to be without electricity in 2030 (IEA 2015). Worst off is Sub-Saharan Africa, with data from 2014 demonstrating that only $35 \%$ of the population has access to electricity, with as little as $19 \%$ in rural areas (IEA 2016b). Beyond the positive environmental 
implications, given the low operation and maintenance costs, RETs could also be considered a principal instrument in alleviating energy poverty in developing countries (Bhide and Monroy 2011).

Due to the importance that an increased access to clean and affordable energy (SDG 7) can have on positively affecting other developmental issues, the relevance of the research in this thesis can also be found through a direct or indirect support of several other SDGs. For example, a supply of reliable and clean energy would contribute to the infrastructure that enables innovation and industry development (SDG 9) to occur. Consequentially, by facilitating the formation of new firms, work opportunities and reduced poverty (SDG 1) will followed.

Another example for how the research conducted in this thesis connects to other SDGs is its potential to reduce energy poverty in rural remote areas where the incentive to extend the national electricity grid is limited. As both schools and health clinics are dependent on a reliable source of electricity to provide quality education (SDG 4) and good health care (SDG 3), expanding RETs in these areas can play an important role in reaching these SDGs. Moreover, as has been discussed in this thesis, the expansion of RETs adoption represents one of the essential mitigation strategies for reducing green house gas (GHG) emissions (Climate Action-SDG 13).

In reducing the risk from conflict generated by climate change migration and energy insecurity, the relevance of the research conducted in this thesis can also be found in SDG 16 (peace, justice and strong institutions). In addition, in order to achieve sustainable cities and communities (SDG 11), an increased supply of electricity from RETs is pivotal to transition from a fossil fuel based transport sector to electricity-based vehicles, without increasing $\mathrm{CO} 2$ equivalent emissions and exacerbating climate change (SDG 13).

\section{Innovation}

This thesis proposes an extended technological innovation system function approach that can be considered innovative when compared with the earlier approach. Through the extended approach, this research has provided additional pathways to observe and understand the processes behind transitioning to renewable energy technologies. The thesis proposes a systematic and explicit inclusion of framework conditions, which would benefit future transition studies, both for high-income and developing countries.

Moreover, the evidence presented in this thesis suggests that the prominence and prevalence of relevant framework conditions is higher in developing countries, thus bringing attention to the importance of delimiting the system boundaries to include not only the technological innovation under study but also wider 
framework conditions. In other words, the thesis suggests that a number of conditions that may exercise positive (contributing) or negative (hindering) effects on technological transitions, in this case RETs, should be regarded as endogenous rather than exogenous to the system. For example, in the extended TIS function analysis conducted in Colombia, which complemented the TIS function approach by systematically and explicitly analyzing the influence of framework conditions (landscape factors), revealed several interesting findings were revealed.

The thesis found both driving and obstructing influences from the landscape factors on the functions (integral actors and activities) of the system, with climate change demonstrating the strongest positive influence (i.e. contributing to adoption), and corruption and unequal access to quality education the strongest negative influence (i.e. obstructing adoption). More specifically, climate change related events, such as increased droughts (from a more severe El Niño) and ensuing water shortages were found to positively influence the wind energy sector, as existing energy regimes (the hydropower and thermoelectric sectors) faced deficiencies, resulting in increased pressure for the country to diversify its energy mix. Moreover, climate change was found to strongly contribute to the passing of several initiatives to expand wind energy and other RETs, such as the 'Low Carbon Development Strategy' and Renewable Energy (RE) Law.

Corruption, on the other hand, was found to block and/or slow down entrepreneurial activities and wind energy research projects, due to requests for informal payments at the local level. Unequal access to quality education largely explained the low access to skilled labor in remote rural areas of Colombia. Low access to skilled labor, in turn, reduced incentives for entrepreneurial activities in these areas. Paradoxically, many remote rural areas of Colombia have little or no access to electricity while having a high technical potential for wind energy, and could greatly benefit from electrification from Wind Energy and other RETs.

For the other landscape factors, i.e., economic growth, environmental awareness, and armed conflicts, a lesser but not insignificant influence could be identified. For example, while the armed conflicts led to a negative influence on new investments, e.g., through higher interest rates, energy generating companies regarded armed conflicts as a limited concern for new wind energy projects. Seeking approval and support for planned projects from the local community could also further reduce the risks from the armed conflict. For further details about the influence of landscape factors influence in Colombia, see Chapter 4.

Finally, the extended approach presented in this thesis expands the options of policies that are necessary to circumvent the barriers that are hampering the introduction and/or acceleration of clean energy alternatives, which can be considered an innovation compared with previous approaches used to analyze technological transitions. 
By also discussing the innovation system approach from a broader perspective, the thesis has highlighted links between the TIS function approach and other approaches to measure innovation activities. One such link can be made between the innovation activities raised as part of the Oslo Manual (third edition) and the TIS functions, which could stimulate further research in the academic community to develop a more coherent approach to measure innovation in systems where RETs are present.

\section{Target Groups}

The research conducted in this thesis is relevant for both the academic community and policy makers and analysts in national governments or international organizations. For the national governments or international organizations working on projects to expand the use of renewable energy in developing countries, the result of the conceptual and empirical chapters in this thesis could inform decisionmaking and enhance policy design. For the academic community, the material presented could contribute to both the existing knowledge base for transition studies in developing and high-income countries, while adding to the ongoing effort to enhance the theoretical understanding of a technological system, its determinants and boundaries.

\section{Dissemination}

The results of this thesis (Chapters 3-6) will be disseminated to both academics and policy makers in Colombia and elsewhere that are engaged with energy policies and renewable energy adoption. Prior to the completion of this thesis, the key findings of Chapter 3 and 4 have been disseminated in international conferences, namely at the $14^{\text {th }}$ Globelics International Conference in Bandung (Indonesia) and the 6th International Sustainability Transitions (IST-6) Conference in Brighton (UK), respectively.

In addition to being presented at international conferences, findings from Ch. 3 and 4 have been published as working papers and in peer-reviewed journals. Chapter 3, titled: Technological Innovation System and the Wider Context: A framework for developing countries has been published as a working paper at the UNU-MERIT working paper series in 2016 (Edsand 2016). Chapter 4, titled: Identifying Barriers to Wind Energy Diffusion in Colombia: A Function Analysis of the Technological Innovation System and the Wider Context, was published in 2017 in the journal Technology in Society (Edsand 2017). Chapter 5 (The Impact of Environmental Education on Environmental and Renewable Energy Technology Awareness: Empirical Evidence from Colombia) has been submitted to a peer-reviewed journal and is currently under review. In the time following the $\mathrm{PhD}$, Chapter 3 and Chapter 6 (Framework Conditions of Technological Transition: Re-thinking the 
Boundary for a Technological Innovation System) of this thesis will be submitted for dissemination through suitable peer-reviewed journals. 


\section{About the Author}

Hans-Erik (Hasse) Edsand joined the PhD program at UNU-MERIT/Maastricht Graduate School of Governance in 2012. He holds an MSc in Development Studies from the School of Oriental and African Studies (SOAS), University of London.

Prior to joining the $\mathrm{PhD}$ program at UNU-MERIT, Hasse worked with policy research and implementation of education, health and social protection projects in developing countries at the World Bank and the Inter-American Development Bank.

Other activities at UNU-MERIT during the PhD include the co-development and coordination of a short educational program (Evidence-Based Research Policy Research Methods (EPRM)), along with in-class teaching and online tutoring of qualitative methods. 


\section{UNU-MERIT/MGSoG Dissertation Series}

2017

Ana Patricia Silva Vara

Redressing the Gender Gap

UNU-MERIT/MGSoG Dissertation

Series № 196

Andrés Iván Mideros Mora

Essays on the Economic Effects of Noncontributory Social Protection

UNU-MERIT/MGSoG Dissertation

Series № 195

Tobias Brioch

New Actors in the Global Economy

UNU-MERIT/MGSoG Dissertation

Series № 194

Bernard Nikaj

From No-government to E-government UNU-MERIT/MGSoG Dissertation

Series № 193

Ali Safarnejad

Prioritizing the HIV Response

UNU-MERIT/MGSoG Dissertation

Series № 192

Clovis Freire

Diversification and Structural Economic

Dynamics

UNU-MERIT/MGSoG Dissertation

Series № 191
Michael Verba

Innovation and Knowledge Dynamics:

Essays on the Knowledge Economy

UNU-MERIT/MGSoG Dissertation

Series № 190

Pui Hang Wong

The Hearts and Minds in Conflict and

Peace:The Economics of

Counterinsurgency and the Psychology of Reconstruction

UNU-MERIT/MGSoG Dissertation

Series № 189

Brenda Yamba

Schooling Despite All Odds: Evidence from Lesotho on Female Child Carers who Stayed in School

UNU-MERIT/MGSoG Dissertation

Series № 188

Sheng Zhong

Moving towards An Energy Efficient

Future; Essays on Energy Efficiency,

Technology and Development

UNU-MERIT/MGSoG Dissertation

Series № 187 
Julieta Marotta

Access to Justice and Legal

Empowerment of Victims of Domestic

Violence through Legal Organizations in

the City of Buenos Aires; A Qualitative

Empirical Legal Study

UNU-MERIT/MGSoG Dissertation

Series, № 186

\section{6}

Yesuf Awel

Insurance for Growth; Empirical Essays

on Insurance Demand and Impacts in

Africa

UNU-MERIT Dissertation Series, №

108

Tigist Mekonnen Melesse

Grow More Food using Fewer

Resources;

Agricultural Technology Adoption and

Innovation Practices for Inclusive and

Sustainable Development

UNU-MERIT Dissertation Series, № 107

Eleni Yitbarek

Getting Ahead or left Behind?; Essays on

Poverty Dynamics and Social Mobility

in Africa

UNU-MERIT Dissertation Series, № 106

Thuy Dieu Nguyen

Firm-Level Theory and Evidence of

Corruption

UNU-MERIT Dissertation Series, № 105
Andrea Franco-Correa

On the Measurement of

Multidimensional Poverty as a Policy

Tool; Empirical Applications to Chile,

Colombia, Ecuador and Peru

UNU-MERIT/MGSoG Dissertation

Series, № 185

Raquel Tsukada Lehman

Essays on Household Production with

Labor-Saving Technology

UNU-MERIT Dissertation Series, №

104

Eva Barteková

Multi-Problem Challenges for a

Renewable Future; Empirical Studies on

Competitive Disadvantages from

Electricity Price Differentials and

Mineral Supply Risk in an Open

Economy

UNU-MERIT Dissertation Series, № 103

Jocelyn Olivari

Entrepreneurial Traits and Innovation;

Evidence from Chile

UNU-MERIT Dissertation Series, № 102

Muhammad Shafique

Essays on the role of knowledge, RED, and Technology-based Firms in the

Evolution of Socio-techno-economic

System

UNU-MERIT Dissertation Series, № 101 
Serdar Türkeli

Governance of Innovation Policy;

Empirical Studies on Applied Political

Economy by Multi-Methods Analysis

UNU-MERIT Dissertation Series, № 100

Ayokunu Adedokun

Pathways to Sustainable Peacebuilding

in Divided Societies; Lessons and

Experiences from Mozambique

MGSoG Dissertation Series, № 75

Luiz Rothier Bautzer

Organizing Concurrent Engineering

through ICT Platforms

Blueprinting Product Lifecycle

Management Platforms across

Disciplinary Agencies

MGSoG Dissertation Series, № 74

Natalia Popova

Migration in the Periphery of the

European Union;

Determinants of Successful and

Sustainable Labour Market Integration

of Return Migrants in Albania, Egypt,

Moldova and Tunisia

MGSoG Dissertations Series, № 73

Richard A. Martina

Uncertainty and Resource Constraint in

the Small Island Developing States;

Essays in Entrepreneurial Cognition

MGSoG Dissertations Series, № 72
Cécile Cherrier

The Expansion of Basic Social Protection in Low-income Countries;

An Analysis of Foreign Aid Actors' Role in the Emergence of Social Transfers in Sub-Saharan Africa

MGSoG Dissertations series, № 71

Paul Caldron

The Tacit Bargain in Short-Term

Medical Missions; Why U.S. physicians

go and what it costs

MGSoG Dissertation Series, № 70

\section{Mahmut Kobal}

Customs \& Excellence: A Comparative Approach on Administrative and

Regulatory Compliance Perspectives of the EU-Turkey Customs Union

MGSoG Dissertation Series, № 69

Craig Loschmann

Essays on Conflict-related Migration

and Development in the Case of

Afghanistan

MGSoG Dissertations Series, № 68

Andrea Milan

Rural Livelihoods, Location and

Vulnerable Environments; Approaches

to Migration in Mountain areas of Latin

America

MGSoG Dissertation Series, № 67

Farida Lada

On Guarding the Welfare of Clinical

Trial Subjects While Promoting Novel

Drug Innovation

A Game Theoretical Approach

MGSoG Dissertation Series, № 66 
Hibret Belete Maemir

Dissecting Aggregate Productivity;

International Integration and Growth

with Heterogeneous Firms

UNU-MERIT Dissertation Series, № 96

Giorgio Triulzi

Looking for the Right Path; Technology

Dynamics, Inventive Strategies and

Catching-up in the Semiconductor

Industry

UNU-MERIT Dissertation Series, № 95

Abdul Baseer Qazi

Knowledge flows and networks in the

ICT sector; The case of Pakistan

UNU-MERIT Dissertation Series, № 94

Ajay Thutupalli

Technology Paradigm Shifts in

Agriculture; Drivers of Sustainability

and Catch up

UNU-MERIT Dissertation Series, № 93

Eduardo Urias

Improving access to HIVIAIDS

treatment in Brazil; When are

Compulsory Licenses effective in Price

Negotiations?

UNU-MERIT Dissertation Series, № 92
Francesca Guadagno

Why have so few Countries

Industrialised?

UNU-MERIT Dissertation Series, № 91

Daniel Opolot

The Evolution of Beliefs and Strategic

Behaviour

UNU-MERIT Dissertation Series, № 90

Alejandro Lavopa

Structural Transformation and

Economic Development; Can

Development Traps be Avoided

UNU-MERIT Dissertation Series, №

89

Jinjin Zhao

Urban water management reform; The

Case of China

UNU-MERIT Dissertation Series, № 88

Simona Vezzoli

Borders, Independence and Post-colonial Ties; the Role of the State in Caribbean Migration

MGSoG Dissertation Series, № 65

Silvia Consuelo Gómez Soler

Civil Conflict and Education; How Does

Exposure to Civil Conflict Affect Human

Capital Accumulation? Evidence from

Standardized Exit Exams in Colombia

MGSoG Dissertation Series, № 64 
Paula Nagler

Occupational Choice in the Developing World

MGSoG Dissertation Series, № 63

Jasmin Kientzel

Determinants of Professional

Commitment to Environmental

Sustainability

MGSoG Dissertation Series, № 62

Mehmet Güney Celbiş

Regional Policies; Convergence, Trade, and the Allocation of Public Capital

MGSoG Dissertation Series, № 61

Florian Henning

Living Up to Standard; Interoperability Governance and Standards Adoption in

Government Information Networks

MGSoG Dissertation Series, № 60

Niels P. Groen

The Never-Ending Project

Understanding E-Government Project

Escalation

MGSoG Dissertation Series, № 59

Derek Copp

Teacher-Based Reactivity to Provincial

Large-scale Assessment in Canada

MGSoG Dissertation Series, № 58

\section{4}

\section{Dirk Crass}

The Impact of Brands on Innovation and Firm Performance; Empirical Evidence from Germany

UNU-MERIT Dissertation Series, № 87
Michaella Vanore

Family-Member Migration and the

Psychosocial Health Outcomes of

Children in Moldova and Georgia

MGSoG Dissertation Series, № 57

\section{Sonja Fransen}

The Economic and Social Effects of Remittances and Return Migration in Conflict-Affected Areas; The Case of Burundi

MGSoG Dissertation Series, № 56

Ibrahim Khalil Conteh

The Impact of Floods on Primary School

Education in Zambia

MGSoG Dissertation Series, № 55

Richard Bluhm

Growth Dynamics and Development

Essays in Applied Econometrics and

Political Economy

MGSoG Dissertation Series, № 54

Nevena P. Zhelyazkova

Work-Family Reconciliation and Use of

Parental Leave in Luxembourg;

Empirical Analysis of Administrative

Records

MGSoG Dissertation Series, № 53
Samyukta Bhupatiraju

The Geographic Dimensions of Growth and Development

UNU-MERIT Dissertation Series, № 86 
François Lafond

The Evolution of Knowledge Systems

UNU-MERIT Dissertation Series, № 85

Annalisa Primi

Promoting Innovation in Latin America;

What Countries Have Learned (and

What They Have Not) in Designing and

Implementing Innovation and

Intellectual Property Policies

UNU-MERIT Dissertation Series, № 84

Fatoumata Lamarana Diallo

Evaluation of Meal and Deworming

Programs for Primary Schools in Rural

Senegal

UNU-MERIT Dissertation Series, № 83

Sachin Kumar Badkas

Metachoice and Metadata; Innovating with Environmental Policy Analysis in Europe

MGSoG Dissertation Series, № 52

Irina S. Burlacu

An Evaluation of Tax-Benefit Systems

Impact on the Welfare of Frontier

Worker;

The Case of Luxembourg and Belgium

MGSoG Dissertation Series, № 51

Özge Bilgili

Simultaneity in Transnational

Migration Research; Links Between

Migrants' Host and Home Country

Orientation

MGSoG Dissertation Series, № 50
Yulia Privalova Krieger

Reshaping the Big Agenda;

Transnational Politics and Domestic

Resistance Financial crisis and social

protection reform in Bosnia and

Herzegovina

MGSoG Dissertation Series, № 49

Marieke van Houte

Moving Back or Moving Forward?

Return migration after Conflict

MGSoG Dissertation Series, № 48

Oxana Slobozhan

Global Governance in the Management of Natural Resources; The Case of the

Extractive Industries Transparency

Initiative (EITI)

MGSoG Dissertation Series, № 47

Luis Bernardo Mejia Guinand

The Changing Role of the Central

Planning Offices in Latin America; A

Comparative Historical Analysis

Perspective (1950-2013)

MGSoG Dissertation Series, № 46

Cheng Boon Ong

Ethnic Segregation in Housing, Schools and Neighbourhoods in the Netherlands MGSoG Dissertation Series, № 45

Luciana V. Cingolani

Bureaucracies for Development;

Oxymoron or Reality? Studies on State

Capacity in Challenging Governance

Contexts

MGSoG Dissertation Series, № 44 
Carlos Cadena Gaitán

Green Politics in Latin American Cities -

Sustainable Transport Agendas

MGSoG Dissertation Series, № 43

Katie Kuschminder

Female Return Migration and

Reintegration Strategies in Ethiopia

MGSoG Dissertation Series, № 42

Metka Hercog

Highly-Skilled Migration and New

Destination Countries

MGSoG Dissertation Series, № 41
Margaret Agaba Rugadya

Can Remittances Influence the Tenure

and Quality of Housing in Uganda?

MGSoG Dissertation Series, № 40

Ilire Agimi

New Governance Under Limited

Statehood; The Case of Local

Government Reform in Kosovo

MGSoG Dissertation Series, № 39

2013

Anant Kamath

Information Sharing through Informal

Interaction in Low-Tech Clusters

UNU-MERIT Dissertation Series, № 82

Rufin Baghana

Impacts of Government Incentives to $R \mathcal{E} D$, Innovation and Productivity;

A Micro econometric Analysis of the Québec Case

UNU-MERIT Dissertation Series, №

Flavia Pereira de Carvalho 79

What we talk about when we talk about Brazilian Multinationals; An Investigation on Brazilian FDI,

Economic Structure, Innovation and the Relationship between them

UNU-MERIT Dissertation Series, № 81

Jun Hou

Complementarity in Innovation and

Development; A Cross-country

Comparison

Lilia I. Stubrin

High-Tech Activities in Emerging

Countries; A Network perspective on the Argentinean Biotech Activity

UNU-MERIT/MGSoG Dissertation

Series, № 78

Kristine Farla

Empirical Studies on Institutions,

Policies and Economic Development

MGSoG Dissertation Series, № 38

UNU-MERIT Dissertation Series, № 80 
Marina Petrovic

Social Assistance and Activation in the

Pursuit of Happiness; Shedding New

Light on Old Policy Solutions to Social

Exclusion

MGSoG Dissertation Series, № 37

Laura Torvinen

Assessing Governance Assessments; The

Case of Mozambique; Governance

Assessments in the Context of Aid

Effectiveness Discourse

MGSoG Dissertation Series, № 36

Biniam Egu Bedasso

Institutional Change in the Long

Shadow of Elite; Essays on Institutions,

Human Capital and Ethnicity in

Developing Countries

MGSoG Dissertation Series, № 35
Sepideh Yousefzadeh Faal Deghati

Childhoods Embargoed; Constructing

and Reconstructing Multidimensional

Child Poverty in Iran 1984-2009

MGSoG Dissertation Series, № 34

Robert Bauchmüller

Investing in Early Childhood Care and

Education; The Impact of Quality on

Inequality

MGSoG Dissertation Series, № 33

Martin Rehm

Unified Yet Separated; Empirical Study on the Impact of Hierarchical Positions within Communities of Learning

MGSoG Dissertation Series, № 32

2012

Abdul Waheed

Innovation Determinants and

Innovation as a Determinant; Evidence

from Developing Countries

UNU-MERIT Dissertation Series, №

77

Bilal Mirza

Energy Poverty and Rural Energy

Markets in Pakistan

UNU-MERIT Dissertation Series, № 76
Benjamin Engelstätter

Enterprise Software and Video Games;

An Empirical Analysis

UNU-MERIT Dissertation Series, № 75

Fulvia Farinelli

Natural Resources, Innovation and

Export Growth; The Wine Industry in

Chili and Argentina

UNU-MERIT Dissertation Series 
Rodolfo Lauterbach

Innovation in Manufacturing; From

Product Variety and Labor Productivity

Growth to Economic Development in

Chile

UNU-MERIT Dissertation Series

Kirsten Wiebe

Quantitative Assessment of Sustainable

Development and Growth in Sub-

Saharan Africa

UNU-MERIT/MGSoG Dissertation

Series, № 74

Julio Miguel Rosa

Organizational Strategies, Firms'

Performance and Spatial Spillovers; The

Canadian Case in Research and

Development.

UNU-MERIT Dissertation Series, № 73

Johannes Wilhelmus Marie Boels Joseph Schumpeter, Honderd Jaar

Economische Ontwikkeling; Een

Historisch-theoretische Beschouwing.

UNU-MERIT Dissertation Series
Dorcas Mbuvi

Utility Reforms and Performance of the

Urban Water Sector in Africa

MGSoG Dissertation Series, № 31

Lina Salanauskaite

Distributional Impacts of Public

Policies; Essays in Ex-Ante and Ex-Post

Evaluation

MGSoG Dissertation Series, № 30

Esther Schüring

To Condition or not - is that the

Question?

An Analysis of the Effectiveness of Ex-

Ante and Ex-Post Conditionality in

Social Cash Transfer Programs

MGSoG Dissertation Series, № 29

Joe Abah

Strong Organisations in Weak States;

Atypical Public Sector Performance in

Dysfunctional Environments

MGSoG Dissertation Series, № 28

Zina Samih Nimeh

Social Citizenship Rights; Inequality and Exclusion

MGSoG Dissertation Series, № 27

\section{1}

Daniel Vertesy

Interrupted Innovation; Emerging

Economies in the Structure of the Global Aerospace Industry

UNU-MERIT Dissertation Series, №

72

Tina Saebi

Successfully Managing Alliance

Portfolios; An Alliance Capability View

UNU-MERIT Dissertation Series, №

71 
Nora Engel

Tuberculosis in India; A Case of

Innovation and Control

UNU-MERIT/MGSoG Dissertation

Series, № 70

Evans Mupela

Connectivity and growth in Sub-

Saharan Africa; The Role of

Communication Satellites

UNU-MERIT Dissertation Series, № 69

Nantawan Kwanjai

Cross Cultural Intelligence amid

Intricate Cultural Webs; A Tale of the

UnDutchables in the Land of 1002

Smiles

UNU-MERIT Dissertation Series, № 68

Lina Sonne

Innovation in Finance to Finance

Innovation; Supporting Pro-poor

Entrepreneur-based Innovation

UNU-MERIT Dissertation Series, № 67

Lenka Eisenhamerová

Legitimacy of 'Humanitarian Military

Intervention'

MGSoG Dissertation Series, № 26

Sonila Tomini

Informal Payments for Health Care

Services in Albania

MGSoG Dissertation Series, № 25

Jinjing Li

Dynamic Microsimulation in Public

Policy Evaluation

MGSoG Dissertation Series, № 24
Aziz Atamanov

Rural Nonfarm Employment and

International Migration as Alternatives

to Agricultural Employment; The Case

of Kyrgyzstan

MGSoG Dissertation Series, № 23

Frieda Vandeninden

Poverty Alleviation; Aid and Social

Pensions

MGSoG Dissertation Series, № 22

Juliana Nyasha Tirivayi

The Welfare Effects of Integrating AIDS

Treatment with Food Transfers;

Evidence from Zambia

MGSoG Dissertation Series, № 21

Agnieska Ewa Sowa

Who's Left Behind? Social Dimensions

of Health Transition and Utilization of

Medical Care in Poland

MGSoG Dissertation Series, № 20

Emmanaouil Sfakianakis

The Role of Private Actors in the

Provision of Public Goods with

Applications to Infrastructure and

Financial Stability

MGSoG Dissertation Series, № 19

Siu Hing Lo

White Collars Green Sleeves; An Inter-

organizational Comparison of

Determinants of Energy-Related

Behaviors among Office Workers

MGSoG Dissertation Series, № 18 
Treena $\mathrm{Wu}$

Constraints to Human Capital

Investment in Developing Countries;

Using the Asian Financial Crisis in

Indonesia as a Natural Experiment

MGSoG Dissertation Series, № 17

2010

Fernando Santiago

Human Resources Management

Practices and Learning for Innovation in

Developing Countries; Pharmaceutical

Firms in Mexico

UNU-MERIT Dissertation Series, № 66

Zakaria Babutsidze

Essays on Economies with

Heterogeneous Interacting Consumers

UNU-MERIT Dissertation Series, № 65

Bertha Vallejo

Learning and Innovation Under

Changing Market Conditions; The Auto

Parts Industry in Mexico

UNU-MERIT Dissertation Series, № 64

Donatus Ayitey

Technical Change, Competitiveness and Poverty Reduction; A Study of the

Ghanaian Apparel Industry

UNU-MERIT Dissertation Series, № 63
Henry Espinoza Peña

Impact Evaluation of a Job-Training

Programme for Disadvantaged Youths;

The Case of Projoven

MGSoG Dissertation Series, № 16

\section{Sergey Filippov \\ Multinational Subsidiary Evolution; \\ Corporate Change in New EU Member States \\ UNU-MERIT Dissertation Series, № 62}

\section{Asel Doranova}

Technology Transfer and Learning under the Kyoto Regime; Exploring the Technological Impact of CDM Projects in Developing Countries

UNU-MERIT Dissertation Series, № 61

Florian Tomini

Between Family and Friend;

Understanding the Interdependency of Private Transfers

MGSoG Dissertation Series, № 15

Michał Polalowski

The Institutional Transformation of Social Policy in East Central Europe; Poland and Hungary in Comparative and Historical Perspective MGSoG Dissertation Series, № 14

Maha Ahmed

Defining, Measuring and Addressing

Vulnerability; The Case of Post Conflict

Environments

MGSoG Dissertation Series, № 13 
Pascal Beckers

Local Space and Economic Success; The Role of Spatial Segregation of Migrants in the Netherlands

MGSoG Dissertation Series, № 12

Victor Cebotari

Conflicting Demands in Ethnically

Diverse Societies; Ethno political

Contention and Identity Values in

Europe

MGSoG Dissertation Series, № 11

Dennis Gyllensporre

Competing and Complementary

Perspectives on the EU as a Crisis

Management Actor;

An Examination of the Common

Security and Defence Policy through the Lenses of Idealism and Realism

MGSoG Dissertation Series, № 10
Judit Vall Castello

Business Cycle and Policy Effects on

Labour Market Transitions of Older and

Disabled Workers in Spain

MGSoG Dissertation Series, № 9

Keetie Roelen

False Positives or Hidden Dimensions;

The Definition and Measurement of

Child Poverty

MGSoG Dissertation Series, № 8

Denisa Maria Sologon

Earning Dynamics in Europe

MGSoG Dissertation Series, № 7

Melissa Siegel

Money and Mobility; Migration and

Remittances

MGSoG Dissertation Series, № 6

Jessica S. Hagen-Zanker

Modest Expectations; Causes and Effects of Migration on Migrant Households in Source Countries

MGSoG Dissertation Series, №
Alexis Habiyaremye

From Primary Commodity Dependence to Diversification and Growth;

Absorptive Capacity and Technological Catch Up in Botswana and Mauritius. UNU-MERIT Dissertation Series, № 60
Yoseph Getachew

The Role of Public Capital in Economic

Development

UNU-MERIT Dissertation Series, № 59 
Sandra Leitner

Embodied Technological Change and

Patterns of Investment in Austrian

Manufacturing

UNU-MERIT Dissertation Series, № 58

Semih Akçomak

The Impact of Social Capital on

Economic and Social Outcomes

UNU-MERIT Dissertation Series, № 57

Abraham Garcia

The Role of Demand in Technical

Change

UNU-MERIT Dissertation Series, № 56

\section{8}

Rutger Daems

Medicines for the Developing World

UNU-MERIT Dissertation Series, № 54

Johannes Hanel

Assessing Induced Technology;

Sombart's Understanding of Technical

Change in the History of Economics

UNU-MERIT Dissertation Series, № 53
Saurabh Arora

Coherence in Socio-technical Systems; A

Network Perspective on the Innovation

Process

UNU-MERIT Dissertation Series, № 55

Mirtha R. Muniz Castillo

Human Development and Autonomy in

Project Aid; Experiences from four

bilateral projects in Nicaragua and El

Salvador

MGSoG Dissertation Series, № 4

Christiane Arndt

Governance Indicators

MGSoG Dissertation Series, № 3

Britta Augsburg

Microfinance; Greater Good or Lesser

Evil?

MGSoG Dissertation Series, № 2

Rifka Weehuizen

Mental Capital; the Economic

Significance of Mental Health

UNU-MERIT Dissertation Series, №

52

Danielle Cloodt

The Relationship between RED

Partnership Formation, Social

Embeddedness and Innovative

Performance

UNU-MERIT Dissertation Series, № 51 
Sabine Fuss

Sustainable Energy Development under Uncertainty

UNU-MERIT Dissertation Series, № 50

2007

Tobias Kronenberg

Reconciling Environmental

Conservation with Economic Prosperity; The Feasibility of Double Dividends in the Short and Long Run

UNU-MERIT Dissertation Series, № 49
Geranda Notten

Measuring and Managing Poverty Risks MGSoG Dissertation Series, № 1
Viktoria Kravtsova

Assessing the Impact of Foreign Direct Investment in Transition Economies UNU-MERIT Dissertation Series, № 48

Suhail Sultan

The Competitive Advantage of Small and Medium Sized Enterprises; The Case of Jordan's Natural Stone Industry UNU-MERIT Dissertation Series, № 47

\section{Rose Kiggundu}

Innovation systems and Development;

The Journey of a Beleaguered Nile Perch Fishery in Uganda

UNU-MERIT Dissertation Series, № 43

Thomas Pogue

The Evolution of Research Collaboration in South African Gold Mining; 1886-

1933

UNU-MERIT Dissertation Series, № 42

Andreas Reinstaller

Social Structures and the Innovation

Process; Their Role in the Demand of

Firms and Consumers

UNU-MERIT Dissertation Series, № 44 
Geoffrey Gachino

Foreign Direct Investment, Spillovers

and Innovation; The Case of Kenyan

Manufacturing Industry

UNU-MERIT Dissertation Series, № 41

2005

Samia Satti Osman Mohamed-Nour

Change and Skill Development in the

Arab Gulf Countries

UNU-MERIT Dissertation Series, № 39

Elad Harison

Intellectual Property Rights; Economics and Policy Analysis

UNU-MERIT Dissertation Series, № 38

Daniel Dalohoun

The Relationship between RED

Partnership Formation, Social

Embeddedness and Innovative

Performance; a Multi-level Approach of Social Embeddedness

UNU-MERIT Dissertation Series, № 37

Müge Ozman

Networks, Organizations and

Knowledge

UNU-MERIT Dissertation Series, № 36
Önder Nomaler

Technological Change, International

Trade and Growth; An Evolutionary,

Multi-Agents-Based Modeling Approach

UNU-MERIT Dissertation Series, №

40

\section{Bas Straathof}

Product Variety and Economic Growth;

The Counteracting Effects of Scale and Idiosyncrasy

UNU-MERIT Dissertation Series, № 35

Wilfred Schoenmakers

Knowledge Flows between Multinational Companies; A Patent Data Analysis

UNU-MERIT Dissertation Series, №

34

Myriam Cloodt

Mergers and Acquisitions ( $M$ and $A s$ ) in High-Tech Industries; Measuring the Post-M and A Innovative Performance of Companies

UNU-MERIT Dissertation Series, № 33 
Paola Criscuolo

$R \mathcal{E D}$ Internationalisation and

Knowledge Transfer; Impact on MNEs

and their Home Countries

UNU-MERIT Dissertation Series, № 32

Maarten Verkerk

Trust and Power on the Shop Floor

UNU-MERIT Dissertation Series, № 31

2003

Nadine Roijakkers

Inter-firm Cooperation in High-tech

Industries; a Study of RED

Partnerships in Pharmaceutical

Biotechnology

UNU-MERIT Dissertation Series, №

28

Viki Sonntag

Speed, Scale and Sustainability

UNU-MERIT Dissertation Series, № 27

2002

Annelies Hogenbirk

Determinants of Inward Foreign Direct Investment; the Case of the Netherlands UNU-MERIT Dissertation Series, № 24
Gottfried Leibbrandt

Adoption, Harmonization and

Succession of Network Technologies

across Countries

UNU-MERIT Dissertation Series, № 30

Mark Sanders

Skill Biased Technical change; Its

Origins, the Interaction with the Labour

Market and Policy Implications

UNU-MERIT Dissertation Series, № 29

Masaru Yarime

From End-of-Pipe Technology to Clean

Technology

UNU-MERIT Dissertation Series, №

26

Stéphane Malo

The Combinatorial Chemistry

Revolution; Sustaining a Superior

Performance Position through

Technological Learning

UNU-MERIT Dissertation Series, №

25

Bastiaan Johan ter Weel

The Computerization of the Labour

Market

UNU-MERIT Dissertation Series 
John Adeoti

Technology Investment in Pollution

Control in Sub-Saharan Africa; The Case

of the Nigerian Manufacturing Industry

UNU-MERIT Dissertation Series, №

23
Edward Huizenga

Innovation Management; How

Frontrunners Stay Ahead; An Empirical

Study on Key Success Factors in the ICT sector

UNU-MERIT Dissertation Series, №

22

2000

Machiel van Dijk

Technological Change and the Dynamics of Industries; Theoretical Issues and Empirical evidence from Dutch Manufacturing

UNU-MERIT Dissertation Series, № 21

1999

Jan Cobbenhagen

Managing Innovation at the Company

Level; A Study on Non-Sector-Specific

Success Factors

UNU-MERIT Dissertation Series, №

20
Marjolein Caniëls

Regional Growth Differentials; The

Impact of Locally Bounded Knowledge

Spillovers

UNU-MERIT Dissertation Series, №

19

1998

Aldo Geuna

Resource Allocation and Knowledge production; Studies in the Economics of University Research

UNU-MERIT Dissertation Series, № 18

1996

Reinoud Joosten

Dynamics, Equilibria, and Values

UNU-MERIT Dissertation Series, № 17
Hugo Kruiniger

Investment, $R \mathcal{E D}$, and the Financing

Decisions of the Firm

UNU-MERIT Dissertation Series, №

16 
Hans van Meijl

Endogenous Technological Change; The

Case of Information Technology,

Theoretical Considerations and

Empirical Results

UNU-MERIT Dissertation Series, №

15

René Kemp

Environmental Policy and Technical

Change; A Comparison of the

Technological Impact of Policy

Instruments

UNU-MERIT Dissertation Series, № 14
Rohini Acharya

The Impact of New Technologies on

Economic Growth and Trade; A Case

Study of Biotechnology

UNU-MERIT Dissertation Series, № 13

Geert Duysters

The Evolution of Complex Industrial Systems; The Dynamics of Major IT Sectors

UNU-MERIT Dissertation Series, № 12

Marjan Groen

Technology, Work and Organisation; A Study of the Nursing Process in

Intensive Care Units

UNU-MERIT Dissertation Series, № 11

Hans Voordijk

Naar Integrale Logistiek in

Bedrijfsketens; Ontwikkelingen in de

Bouw

UNU-MERIT Dissertation Series, № 8

Theon van Dijk

The Limits of Patent Protection; Essays on the Economics of Intellectual

Property Rights

UNU-MERIT Dissertation Series, № 9 
Paul Diederen

Technological Progress in Enterprises and Diffusion of Innovation;. Theoretical Reflections and Empirical Evidence UNU-MERIT Dissertation Series, № 7

Ben Dankbaar

Economic Crisis and Institutional

Change; The Crisis of Fordism from the Perspective of the Automobile Industry UNU-MERIT Dissertation Series, № 6

1992

Bart Verspagen

Uneven Growth Between Interdependent Economies; An Evolutionary View on Technology Gaps, Trade and Growth UNU-MERIT Dissertation Series, № 4

1989

John Spangenberg

Economies of Scale, and Atmosphere in Research Organisations

UNU-MERIT Dissertation Series, № 2

1988

John Hagedoorn

Evolutionary and Heterodox Innovation Analysis; A Study of Industrial and Technological Development in Process Control and Information Technology

UNU-MERIT Dissertation Series, № 1
Hanno Roberts

Accountability and Responsibility; The Influence of Organisation Design on Management Accounting UNU-MERIT Dissertation Series, № 5

Sjoerd Romme

A Self-organization Perspective on

Strategy Formation 3
UNU-MERIT Dissertation Series, № 